Printed

RFP-3739

Septêmber 23, 1985

RFP- -3739

UC-70 NUCLEAR WASTE

MANAGEMENT

DE86 001869

DOE/TIC-4500 (Rev. 73)

\title{
GAS GENERATION RESULTS AND VENTING STUDY FOR TRANSURANIC WASTE DRUMS
}

A. R. Kazanjian

P. M. Arnold

W. C. Simmons

E. L. D'Amico

C. A. Deitesfeld, Editor

I. C. Delaney, Compositor

\section{DISCLAIMER}

\begin{abstract}
This report was prepared as an account of work sponsored by an agency of the United States Government. Neither the United States Government nor any agency thereof, nor any of their employees, makes any warranty, express or implied, or assumes any legal liability or responsibility for the accuracy, completeness, or usefulness of any information, apparatus, product, or process disclosed, or represents that its use would not infringe privately owned rights. Reference herein to any specific commercial product, process, or service by trade name, trademark, manufacturer, or otherwise does not necessarily constitute or imply its endorsement, recommendation, or favoring by the United States Government or any agency thereof. The views and opinions of authors expressed herein do not necessarily state or reflect those of the United States Government or any agency thereof.
\end{abstract}

ROCKWELL INTERNATIONAL

NORTH AMERICAN SPACE OPERATIONS

ROCKY FLATS PLANT

P.O. BOX 464

GOLDEN, COLORADO 80402-0464

Prepared under Contract DE-AC04-76DPO3533

for the

Albuquerque Operations Office

U.S. Department of Energy

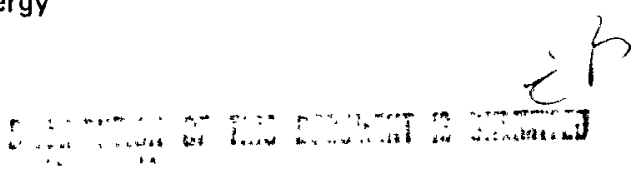




\section{DISCLAIMER}

This report was prepared as an account of work sponsored by an agency of the United States Government. Neither the United States Government nor any agency Thereof, nor any of their employees, makes any warranty, express or implied, or assumes any legal liability or responsibility for the accuracy, completeness, or usefulness of any information, apparatus, product, or process disclosed, or represents that its use would not infringe privately owned rights. Reference herein to any specific commercial product, process, or service by trade name, trademark, manufacturer, or otherwise does not necessarily constitute or imply its endorsement, recommendation, or favoring by the United States Government or any agency thereof. The views and opinions of authors expressed herein do not necessarily state or reflect those of the United States Government or any agency thereof. 


\section{DISCLAIMER}

Portions of this document may be illegible in electronic image products. Images are produced from the best available original document. 
RFP-3739

$$
\text { do no pare }
$$




\section{CONTENTS}

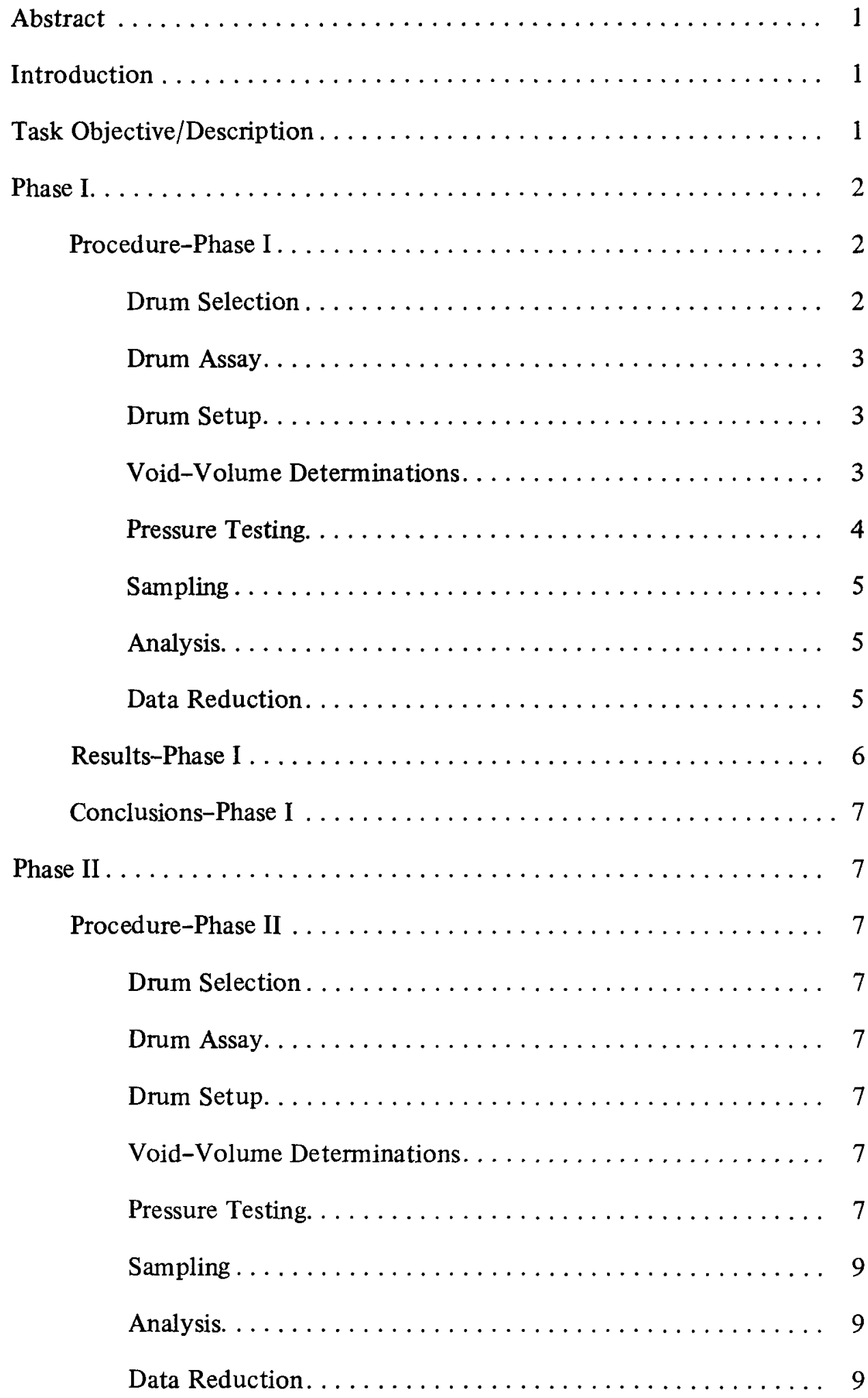


RFP-3739

Results-Phase II ..................... 9

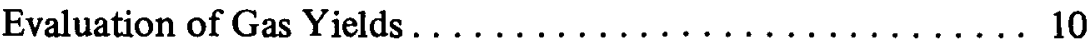

Gas Yield Comparison by Waste Form Type......... 11

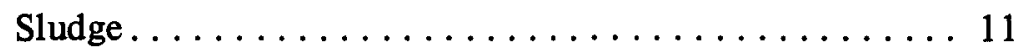

Grease $\ldots \ldots \ldots \ldots \ldots \ldots \ldots \ldots \ldots \ldots \ldots$

Dry Combustibles.................. 12

Wet Combustibles................. 12

Plastics and Rubber................. 12

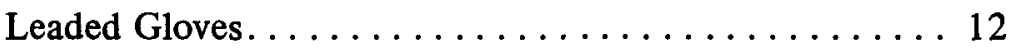

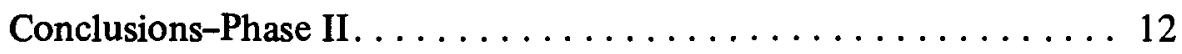

References. ..................... 12

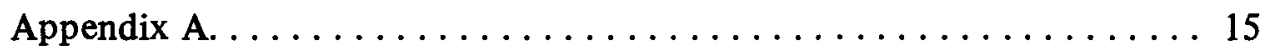

Appendix B. ...................... 73 


\section{APPENDIXES}

\section{LIST OF FIGURES}

\section{Appendix A}

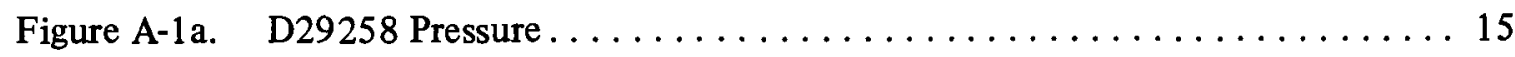

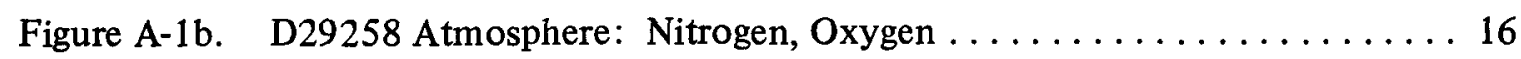

Figure A-1c. D29258 Atmosphere: Argon, Carbon Dioxide, Hydrogen, Other Hydrocarbons, Isopropanol . . . . . . . . . . 17

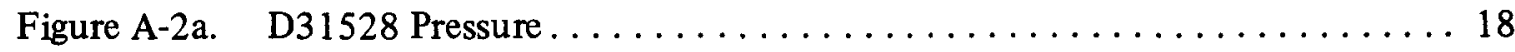

Figure A-2b. D31528 Atmosphere: Nitrogen, Oxygen ............... 19

Figure A-2c. D31528 Atmosphere: Argon,

Carbon Dioxide, Hydrogen, Other Hydrocarbons. . . . . . . . 20

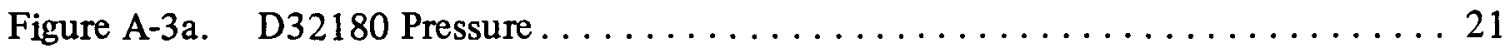

Figure A-3b. D32180 Atmosphere: Nitrogen, Oxygen ............. 22

Figure A-3c. D32180 Atmosphere: Argon,

Carbon Dioxide, Hydrogen, Other Hydrocarbons. . . . . . . . 23

Figure A-4a. $\quad$ D32186 Pressure . . . . . . . . . . . . . . . . . . 24

Figure A-4b. D32186 Atmosphere: Nitrogen, Oxygen .............. 25

Figure A-4c. D32186 Atmosphere: Aryon,

Carbon Dioxide, Hydrogen, Other Hydrocarbons, Isopropanol . . . . 26

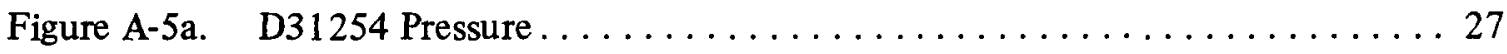

Figure A-5b. D31254 Atmosphere: Nitrogen .................. 28

Figure A-5c. D31254 Atmosphere: Argon,

Carbon Dioxide, Hydrogen, Oxygen, Other Hydrocarbons. . . . . . . 29

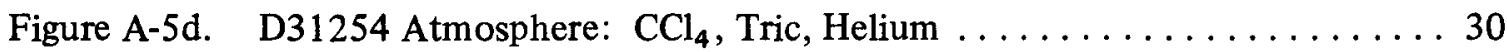

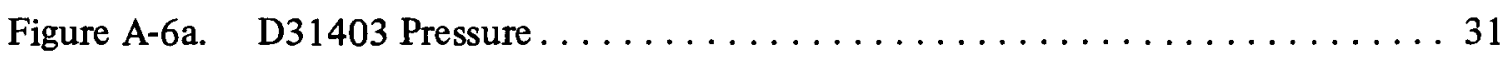

Figure A-6b. D31403 Atmosphere: Nitrogen ................. 32

Figure A-6c. D31403 Atmosphere: Argon,

Carbon Dioxide, Hydrogen, Other Hydrocarbons, Helium . . . . . . 33

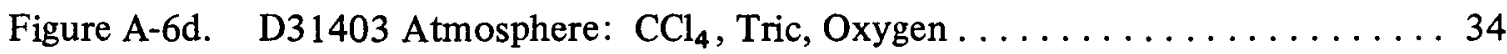

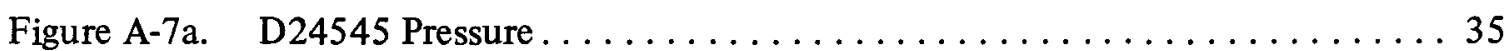

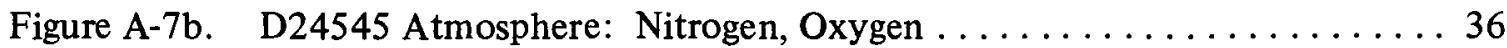

Figure A-7c. D24545 Atmosphere: Argon,

Carbon Dioxide, Hydrogen, Other Hydrocarbons, Isopropanol . . . . 37

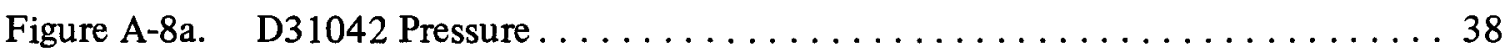

Figure A-8b. D31042 Atmosphere: Nitrogen, Oxygen . . . . . . . . . . . . . . . 39

Figure A-8c. D31042 Atmosphere: Argon, Carbon Dioxide, Hydrogen . . . . . . . 40

Figure A-8d. D31042 Atmosphere: Tric,

Other Hydrocarbons, $\mathrm{CH}_{2} \mathrm{Cl}_{2}$, Isopropanol . . . . . . . . 41 


\section{LIST OF FIGURES (Continued)}

\section{Appendix A}

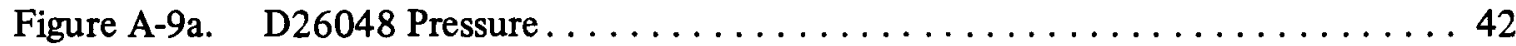

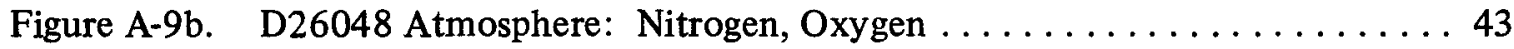

Figure A-9c. D26048 Atmosphere: Argon,

Carbon Dioxide, Hydrogen, Other Hydrocarbons. . . . . . . . . . 44

Figure A-9d. D26048 Atmosphere: Freon TF. . . . . . . . . . . . . . . 45

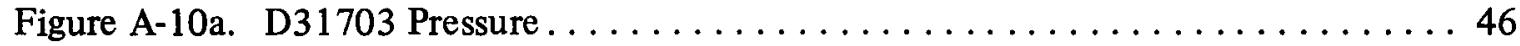

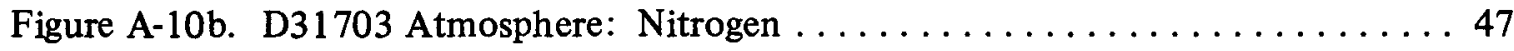

Figure A-10c. D31703 Atmosphere: Argon, Hydrogen, Unidentified Organic . . . . . 48

Figure A-10d. D31703 Atmosphere: Oxygen, Carbon Dioxide............. 49

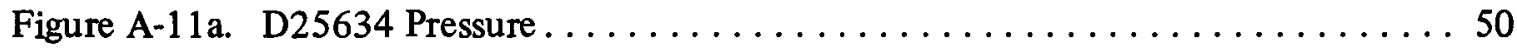

Figure A-1 1b. D25634 Atmosphere: Nitrogen, Oxygen ............. 51

Figure A-11c. D25634 Atmosphere: Argon,

Carbon Dioxide, Hydrogen, Other Hydrocarbons, Isopropano1 . . . . 52

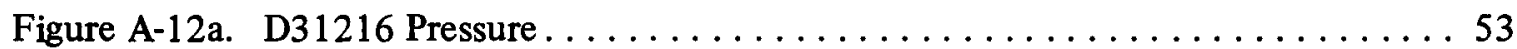

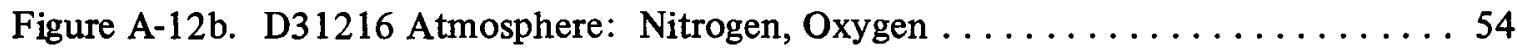

Figure A-12c. D31216 Atmosphere: Argon,

Carbon Dixoide, Hydrogen, Other Hydrocarbons, Isopropanol . . . . 55

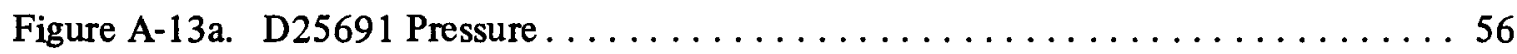

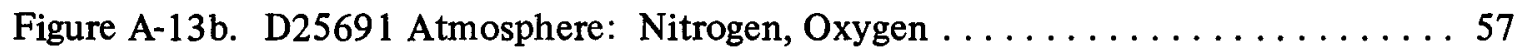

Figure A-13c. D25691 Atmosphere: Argon,

Carbon Dioxide, Hydrogen, Other Hydrocarbons, Isopropanol . . . . 58

Figure A-13d. D25691 Atmosphere: Helium .................... 59

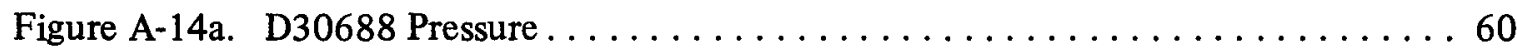

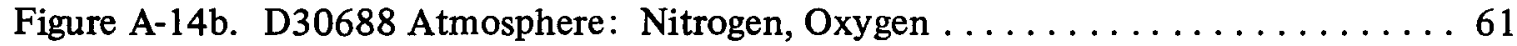

Figure A-14c. D30688 Atmosphere: Argon,

Carbon Dioxide, Hydrogen, Other Hydrocarbons, Isopropanol . . . . 62

Figure A-15a. D29758 Pressure ......................... 63

Figure A-15b. D29758 Atmosphere: Nitrogen, Oxygen . . . . . . . . . . . . . 64

Figure A-15c. D29758 Atmosphere: Argon,

Carbon Dioxide, Hydrogen, Other Hydrocarbons, Isopropanol . . . . 65

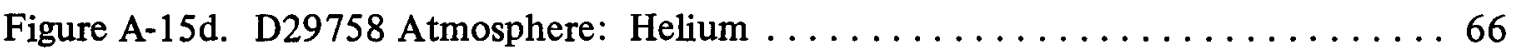

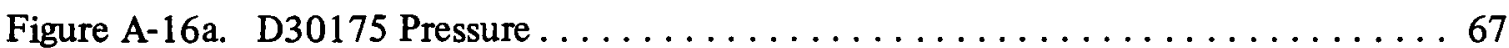

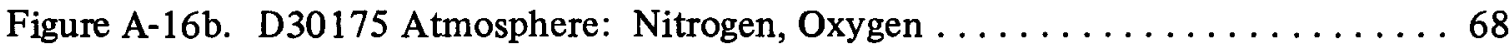

Figure A-16c. D30175 Atmosphere: Argon,

Carbon Dioxide, Hydrogen, Other Hydrocarbons, Isopropanol . . . . 69 


\section{LIST OF FIGURES (Continued)}

\section{Appendix A}

Figure A-17a. D32538 Pressure ....................... 70

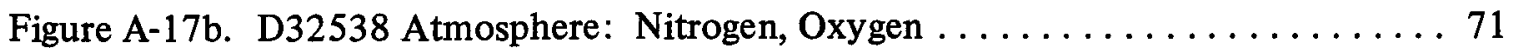

Figure A-17c. D32538 Atmosphere: Argon,

Carbon Dioxide, Hydrogen, Isopropanol 72

\section{Appendix B}

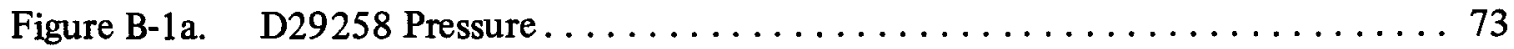

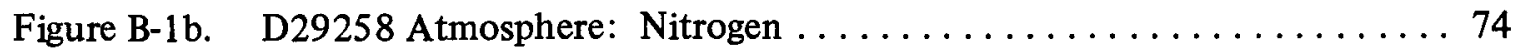

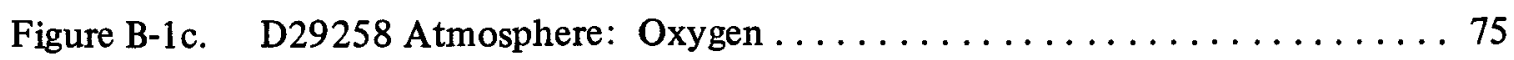

Figure B-1d. D29258 Atmosphere: Argon,

Carbon Dioxide, Hydrogen, Other Hydrocarbons, Isopropanol . . . . 76

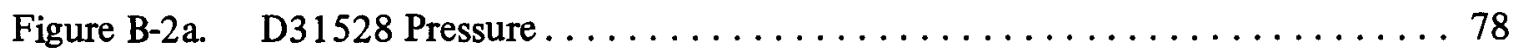

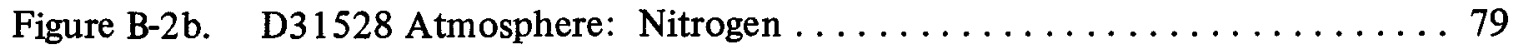

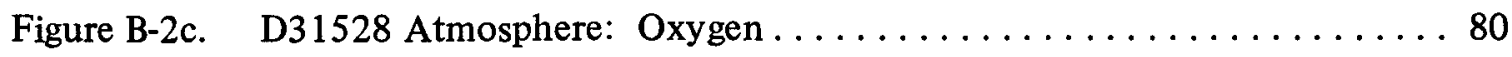

Figure B-2d. D31528 Atmosphere: Argon,

Carbon Dioxide, Hydrogen, Other Hydrocarbons, Isopropanol . . . 81

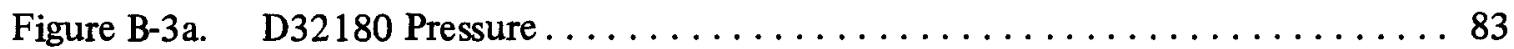

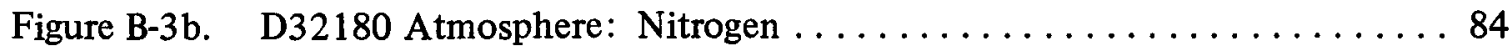

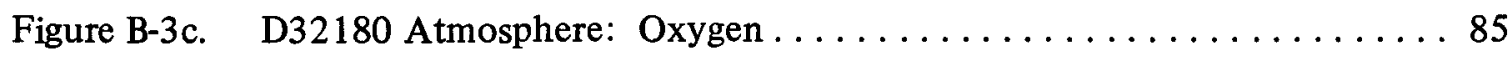

Figure B-3d. D32180 Atmosphere: Argon,

Carbon Dioxide, Hydrogen, Other Hydrocarbons, Isopropanol . . . . 86

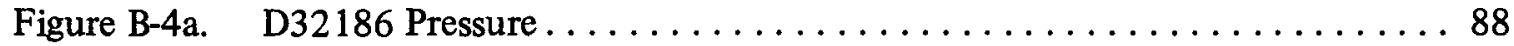

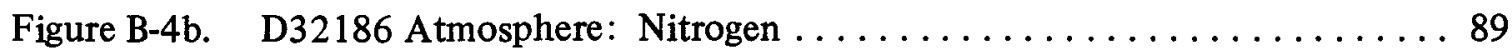

Figure B-4c. D32186 Atmosphere: Oxygen ................. 90

Figure B-4d. D32186 Atmosphere: Argon,

Carbon Dioxide, Hydrogen, Other Hydrocarbons, Isopropanol . . . . 91

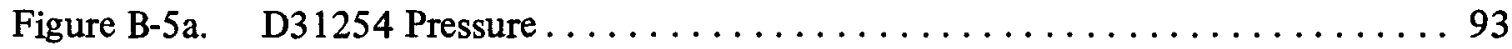

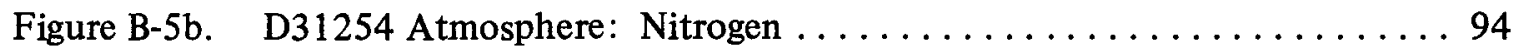

Figure B-5c. D31254 Atmosphere: Oxygen .................. 95

Figure B-5d. D31254 Atmosphere: Argon,

Carbon Dioxide, Other Hydrocarbons, Isopropanol . . . . . . . . . 96

Figure B-5e. D31254 Atmosphere: Tric, $\mathrm{CCl}_{4}$, Hydrogen, $\mathrm{CH}_{2} \mathrm{Cl}_{2}$, Freon TF. . . . 97

Figure B-6a. D31403 Pressure . . . . . . . . . . . . . . . . . 99

Figure B-6b. D31403 Atmosphere: Nitrogen ................. 100 


\section{LIST OF FIGURES (Continued)}

\section{Appendix B}

Figure B-6c. D31403 Atmosphere: Oxygen .................. 101

Figure B-6d. D31403 Atmosphere: Argon,

Carbon Dioxide, Other Hydrocarbons, Isopropanol . . . . . . . 102

Figure B-6e. D31403 Atmosphere: Tric, $\mathrm{CCl}_{4}$, Hydrogen, $\mathrm{CH}_{2} \mathrm{Cl}_{2}$, Freon TF . . . . 103

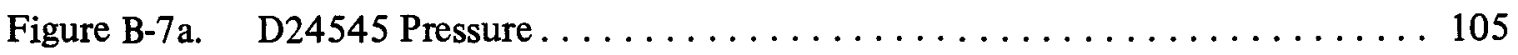

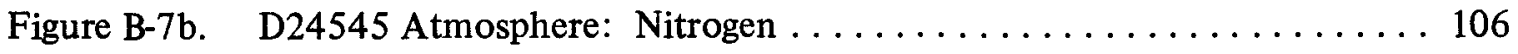

Figure B-7c. D24545 Atmosphere: Oxygen ................. 107

Figure B-7d. D24545 Atmosphere: Argon,

Carbon Dioxide, Hydrogen, Other Hydrocarbons, Isopropanol . . . 108

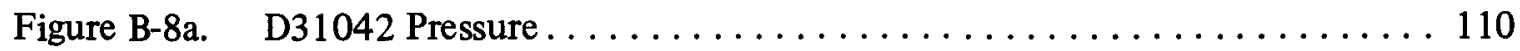

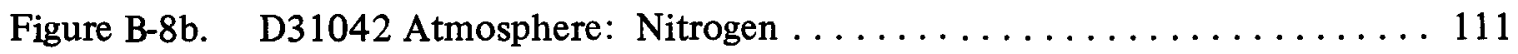

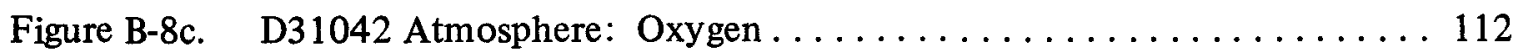

Figure B-8d. D31042 Atmosphere: Argon,

Carbon Dioxide, Hydrogen, Other Hydrocarbons, Isopropanol . . . 113

Figure B-8e. D31042 Atmosphere: $\mathrm{CH}_{2} \mathrm{Cl}_{2}, \mathrm{CCl}_{4}$, Tric, Freon TF $\ldots \ldots \ldots \ldots 114$

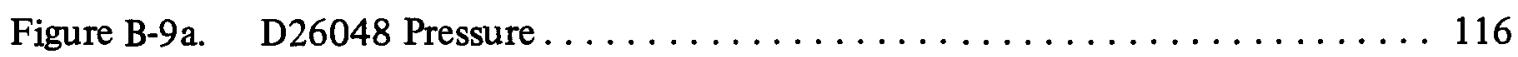

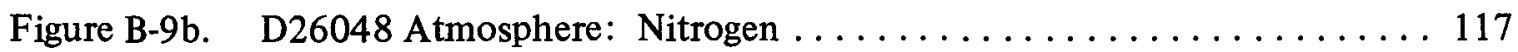

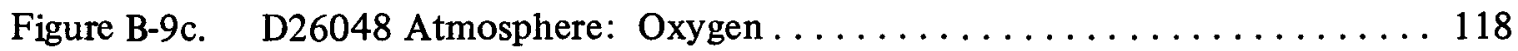

Figure B-9d. D26048 Atmosphere: Argon, Freon TF, Isopropanol . . . . . . . . 119

Figure B-9e. D26048 Atmosphere: $\mathrm{CH}_{2} \mathrm{Cl}_{2}$,

Carbon Dioxide, Hydrogen, Other Hydrocarbons, $\mathrm{CCl}_{4} \ldots \ldots \ldots 120$

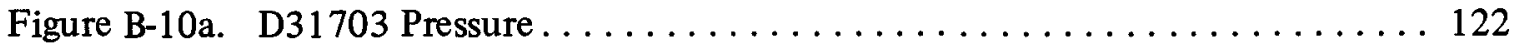

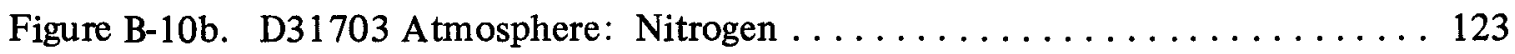

Figure B-10c. D31703 Atmosphere: Oxygen .................. 124

Figure B-10d. D31703 Atmosphere: Carbon Dioxide................ 125

Figure B-10e. D31703 Atmosphere: Argon,

Unidentified Organic, Hydrogen, Isopropanol . . . . . . . . 126

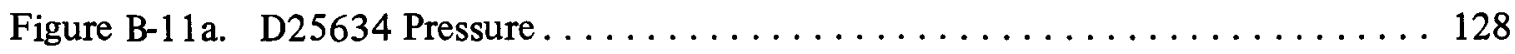

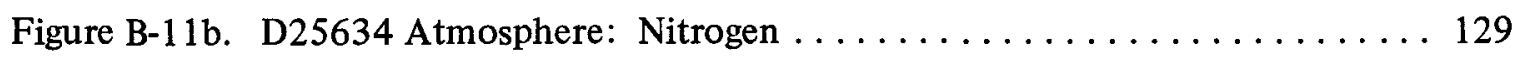

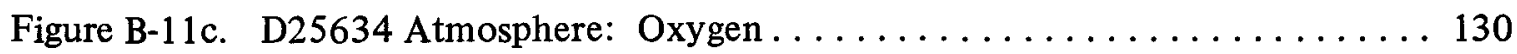

Figure B-11d. D25634 Atmosphere: Argon,

Carbon Dioxide, Hydrogen, Other Hydrocarbons, Isopropanol . . . 131

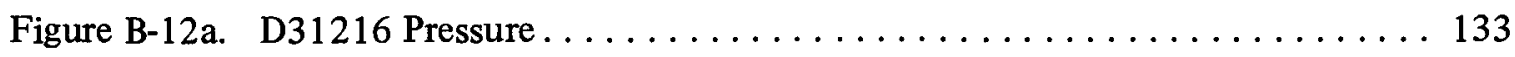

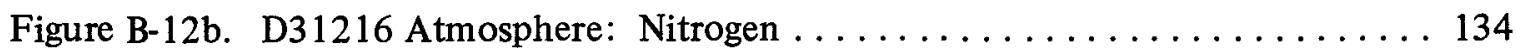

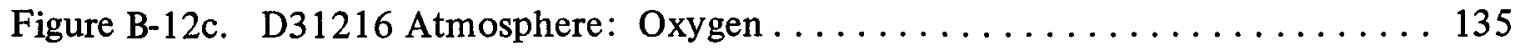

Figure B-12d. D31216 Atmosphere: Argon,

Carbon Dioxide, Hydrogen, Other Hydrocarbons, Isopropanol. . . . 136 


\section{LIST OF FIGURES (Concluded)}

\section{Appendix B}

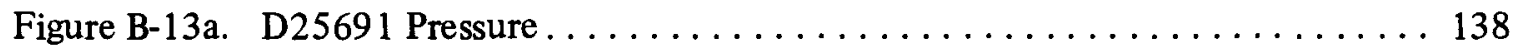

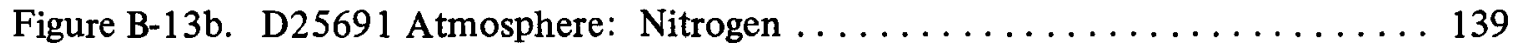

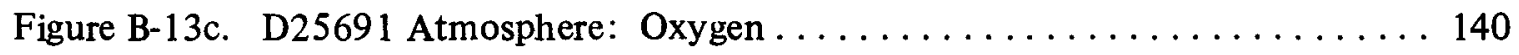

Figure B-13d. D25691 Atmosphere: Argon,

Carbon Dioxide, Hydrogen, Other Hydrocarbons, Isopropanol . . . 141

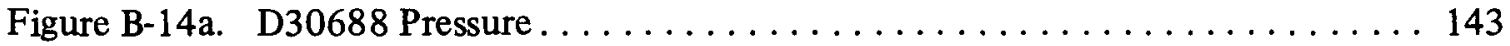

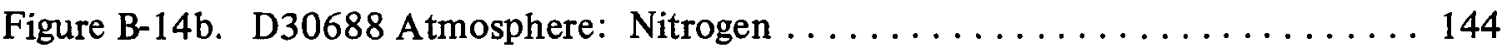

Figure B-14c. D30688 Atmosphere: Oxygen .................. 145

Figure B-14d. D30688 Atmosphere: Argon,

Carbon Dioxide, Hydrogen, Other Hydrocarbons, Isopropanol . . . 146

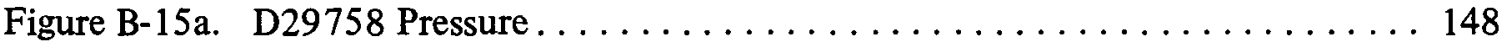

Figure B-15b. D29758 Atmosphere: Nitrogen . . . . . . . . . . . . . . . . 149

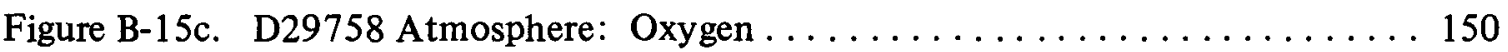

Figure B-15d. D29758 Atmosphere: Argon,

Carbon Dioxide, Hydrogen, Other Hydrocarbons, Isopropanol . . . 151

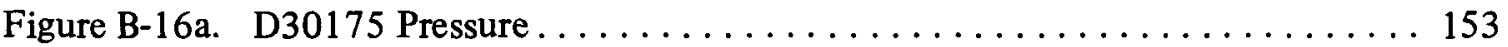

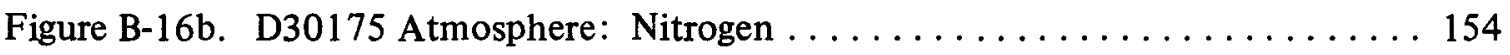

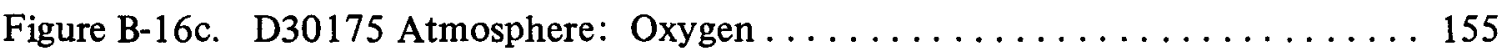

Figure B-16d. D30175 Atmosphere: Argon,

Carbon Dioxide, Hydrogen, Other Hydrocarbons, Isopropanol . . . 156

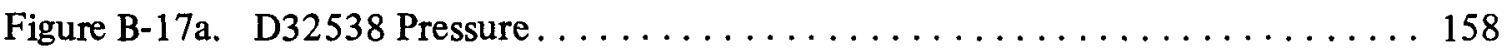

Figure B-17b. D32538 Atmosphere: Nitrogen . . . . . . . . . . . . . . . 159

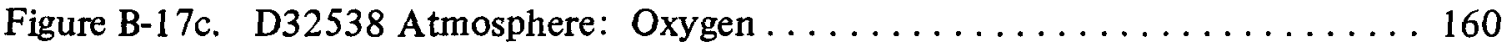

Figure B-17d. D32538 Atmosphere: Argon,

Carbon Dioxide, Hydrogen, Isopropanol . . . . . . . . . 161 


\section{APPENDIXES \\ LIST OF TABLES}

\section{Appendix B}

Table B-1. D29258 TRU Gas Generation Volume Percent. . . . . . . . . . . . 77

Table B-2. D31528 TRU Gas Generation Volume Percent. . . . . . . . . . . . 82

Table B-3. D32180 TRU Gas Generation Volume Percent . . . . . . . . . . . . . 87

Table B-4. D32186 TRU Gas Generation Volume Percent. . . . . . . . . . . . . 92

Table B-5. D31254 TRU Gas Generation Volume Percent. . . . . . . . . . . . 98

Table B-6. D31403 TRU Gas Generation Volume Percent. . . . . . . . . . . . . . . . . 104

Table B-7. D24545 TRU Gas Generation Volume Percent . . . . . . . . . . . . . . 109

Table B-8. D31042 TRU Gas Generation Volume Percent . . . . . . . . . . . . . . 115

Table B-9. D26048 TRU Gas Generation Volume Percent . . . . . . . . . . . . . . 121

Table B-10. D31703 TRU Gas Generation Volume Percent. . . . . . . . . . . . 127

Table B-11. D25634 TRU Gas Generation Volume Percent . . . . . . . . . . . . 132

Table B-12. D31216 TRU Gas Generation Volume Percent . . . . . . . . . . . . 137

Table B-13. D25691 TRU Gas Generation Volume Percent . . . . . . . . . . . . 142

Table B-14. D30688 TRU Gas Generation Volume Percent. . . . . . . . . . . . . 147

Table B-15. D29758 TRU Gas Generation Volume Percent . . . . . . . . . . . . . . 152

Table B-16. D30175 TRU Gas Generation Volume Percent. . . . . . . . . . . . 157 


\section{A C K N O W LE D G M ENTS}

Thomas L. Clements, Jr. of EG\&G, Idaho must be acknowledged for his contributions in establishing, administering and reviewing the Transuranic (TRU) Waste Sampling Program including the efforts of this task. The contribution of Martin A. Molecke of Sandia National Laboratory in conducting an independent, third party review of this document is also appreciated. 
RFP-3739

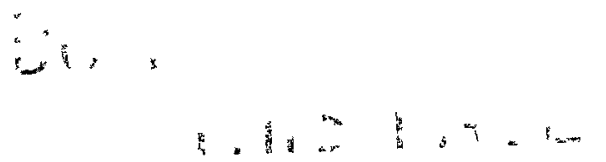




\title{
GAS GENERATION RESULTS AND VENTING STUDY FOR TRANSURANIC WASTE DRUMS
}

\author{
A. R. Kazanjian, P. M. Arnold, W. C. Simmons, \\ and E. L. D'Amico
}

\begin{abstract}
Sixteen waste drums, containing six categories of plutonium contaminated waste, were monitored for venting and gas generation for six months. The venting devices tested appeared adequate to relieve pressure and prevent hydrogen accumulation. Most of the gas generation, primarily $\mathrm{H}_{2}$ and $\mathrm{CO}_{2}$, was due to radiolytic decomposition of the hydrogenous wastes. Comparison of the gas yields with those obtained previously in laboratory tests showed very reasonable agreement with few exceptions.
\end{abstract}

\section{INTRODUCTION}

The Transuranic Waste Sampling Program is a multi-contractor program to evaluate various stored and newly generated TRU wastes. EG\&G, Idaho is the lead contractor with overall responsibility for planning and reporting on the program. Rocky Flats Plant (RFP) is responsible for conducting this gas study on newly generated RFP waste, for gas sampling retrieved waste and for conducting visual examination on the retrieved waste. The primary objective of the program is to develop data to allow certification of stored Idaho National Engineering Laboratory (INEL) TRU wastes to the Waste Isolation Pilot Plant (WIPP)- -Waste Acceptance Criteria (WAC).

This report summarizes gas generation data on 16 drums of newly generated wastes studied in two phases over six months. The studies represent tasks 5 and 7 in the "Implementation Plan for the TRU Waste Sampling Program." In phase I, the drums were vented for three months with one of three venting devices to determine if venting was adequate to maintain hydrogen concentrations within safe limits and to maintain drum pressure at or near atmospheric pressure. In phase II, the drums were sealed for a second three-month period for determination of gas generation rates for comparison with the rates previously determined and reported in laboratory experiments. ${ }^{2-6}$

This study was requested by the Transuranic Waste Systems Office (TWSO) to obtain data on actual drums of waste. Actual waste drums may vary from the previous studies because the drums cannot be as well characterized for matrix composition, radionuclide assay, radioactive deposition, storage time, etc. The results of this study may be useful to TRU waste generating sites or waste transporters in strategy development for dealing with gas generating TRU wastes.

\section{TASK OBJECTIVE/DESCRIPTION}

Following are task objectives and descriptions quoted directly from the Implementation Plan: ${ }^{1}$

Task 5: ${ }^{239}$ Pu Gas-Generation Rate and Carbon Composite Filter Study: Twelve drums of waste representing six content codes will be evaluated to (a) determine gas-generation rates of the worst gas-generating content codes for comparison with experimentally obtained laboratory yields, and (b) ensure the carbon composite filter used for venting will maintain hydrogen within the drums at a safe level. We suggest the following codes be evaluated: content code 1 (combined sludge); content code 3 (organic setups); content code 330 (dry combustibles); content code 336 (wet combustibles); content code 337 (plastics); and content code 339 (leaded rubber gloves).

The following are requirements for this task:

1. Only newly generated waste will be studied 
2. High-activity waste (contaminated with americium), if available, will be used to increase the probability of significant gas generation

3. Waste will be assayed carefully as individual packages or by radiochemical analysis to determine total alpha activity

4. The level of packaging will be recorded

5. Drums will be full (to reduce the void volume)

6. Waste will be contained in drums retrofitted with a carbon composite filter and a separate sampling port that extends inside the drum lid

7. A $100 \%$ seal of the drum lid will be ensured

8. Drums will be conditioned at least 24 hours for temperature stabilization before they are tested for void volume

9. Sludges will be analyzed for water and nitrate content.

Experiments conducted at RFP show there is not a $100 \%$ seal on the rigid liner lid. Also, it is assumed that the vent/purge technique being developed at INEL will provide a pathway for release of gases inside the liner. Therefore, the 90-mil rigid liner insert plug will not be used on the rigid liner lid, so gas will flow from the liner through the filter.

Gas samples will be collected from the sampling port and analyzed periodically. Drum pressures will also be measured. The samples will be analyzed to determine the volume and mole percent of the following gases: hydrogen, oxygen, nitrogen, oxides of nitrogen, carbon dioxide, carbon monoxide and hydrocarbons.

The experiment will be conducted in two threemonth phases. During the first phase, the drum will be allowed to vent, and gas samples will be taken weekly for three months. During the second phase, the filter will be sealed to stop the venting. Gas samples will be taken every two weeks for three months for determination of the gas-generation rate.

Task 7: Vent Clip/Gasket Study: This task involves evaluation of (a) two drums fitted with the styrene butadiene flowed-in-place gasket used at RFP, and (b) two drums fitted with the vent clip used at Hanford. Two content codes known to generate gas, such as dry combustibles and sludge, will be evaluated-two drums/code, one drum fitted with the vent clip, and the other with the gasket.

The experiment will be set up and conducted as described for Task 5. Appropriate RFP and RHO procedures will be used for installing the venting materials. After completion of the first phase, the gaskets and clips will be replaced with nonpermeable gaskets for the gasgeneration rate study.

\section{PHASE I}

In phase I of tasks 5 and 7, drums of newly generated RFP waste were vented with one of three venting devices to monitor any hydrogen accumulations and to monitor drum pressures versus atmospheric pressures. Twelve task 5 drums representing six content codes were vented with a carbon-composite filter. Two task 7 drums were vented with a Hanford vent clip and two others were vented through a styrene-butadiene permeable gasket.

\section{Procedure-Phase I}

Drum Selection

Nondestructive assay personnel in Building 771 selected the highest activity waste drums of the required content codes that passed through the drum counter in approximately two weeks. Sludge drums, codes 1 and 3, were selected at Building 774 where they were generated. Two drums containing unwashed leaded gloves were found in storage; one of these was above the discard limit, but had to be used to avoid further delays in the brief setup period. Since the waste used for this study represents full drum quantities of actual waste, the waste cannot be as carefully controlled for matrix composition, radionuclide assay, radioactive particle size and deposition, etc., as was done in the previous laboratory studies where carefully doped discrete matrices were used. Also, the exact amount of time that the waste has been contaminated is difficult to determine since contaminated waste is continually 
placed in drums and the drums may collect waste for several months before they are sealed. The drums selected for this study were significantly higher in activity than an average waste drum at Rocky Flats Plant and therefore should produce proportionately more gas.

\section{$\underline{\text { Drum Assay }}$}

All of the drums for both tasks 5 and 7 except sludge drums were assayed by segmented drum count. The segmented drum counter uses a 20minute count with high purity germanium detectors for 413,662 , and $185 \mathrm{keV}$ gamma energy to assign plutonium, americium, and uranium gram values respectively. Eight segments, approximately 4 inches high, are counted separately and matrix attenuation corrections are measured for each segment so that the drum need not be completely filled for consistent assay. The sludge and grease drums were assayed by radiochemical analysis of a sample taken during the retrofitting of the drum with the sampling lid. The sludge weight was determined by subtracting the packaging weights (as determined in stored waste examinations of the TRU Waste Sampling Program) from the gross drum weight to arrive at the net sludge weight.

\section{Drum Setup}

After selection and assay, the drums were retrofitted with sampling lids in the size reduction airlock. The original lids were removed along with the rigid polyethylene drum liner (type II) lid. At this point, a visual determination of the number of polyethylene or PVC drum bags used in packaging was made and the capacity utilized was determined. The sludge drums, codes 1 and 3, from both tasks, were sampled with a coring-type sample and representative sample taken from the core for radiochemical assay, water and nitrate determinations. The rigid liner lid was not reinstalled to assure an escape path for the gases.

The 12 task 5 drums were then fitted with lids having a welded carbon steel half-coupling for insertion of the filter housing or pipe plug and also having an O-ring sealed tubing connector, filter, and valve for sample port connection. The task 5 drums were sealed by doping the drum lid gasket with Permatex.®

The four drums from task 7 were fitted with lids having sampling ports only. Two of the drums were fitted with styrene-butadiene permeable gaskets and the other two were fitted with Hanford vent clips and non-permeable gaskets. The task 7 drums in this vented state could not be pressure checked or have void-volume determinations made until phase II.

\section{Void-Volume Determinations}

Void-volume determinations were made on the task 5 drums before phase I sampling commenced on the drums. Task 7 drums were checked for void volumes at the conclusion of phase II. The voidvolume procedure and error analysis is discussed by E. L. D'Amico in analytical report AL583.993 which is reproduced in the following sections.

\section{Certified Error Analysis:}

The void-volume determination was accomplished by expanding the gas inside each drum into a calibrated expansion volume. By knowing the pressure before and after the expansion, the free volume inside the drum was calculated using the equation:

$$
V_{v}=\frac{P_{2} V_{c}}{P_{1}-P_{2}}
$$

(Equation 1)

where

$$
\begin{aligned}
& V_{v}=\text { void volume of drum, } \\
& \mathrm{V}_{\mathrm{c}}=\text { volume of calibrated expansion } \\
& \text { volume, } \\
& P_{1}=\text { pressure inside drum before } \\
& \text { expansion, and } \\
& \mathrm{P}_{2}=\text { pressure inside drum after } \\
& \text { expansion. }
\end{aligned}
$$

The pressure gage used for this determination was certified to be accurate to $\pm 2 \mathrm{~mm} \mathrm{Hg}$. The expansion volume used was certified to be 13.67 liters \pm .1 liter.

As an experiment to test the accuracy and precision of this void volume determination, 
a sealed, empty drum was sent to the Standards Laboratory for certified volume determination. The certification on this drum was 220.3 liters \pm 1 liter.

By using Equation 1, certified error limits can be determined for this 220 -liter drum (i.e., the range of values the void-volume determination of a 220-liter volume could assume with equipment as accurate as was used here). Specifically, if a value of $615 \mathrm{~mm} \mathrm{Hg}$ (an average atmospheric pressure at Rocky Flats) was used for $P_{1}$ in Equation 1 the $P_{2}$ must equal 579 $\mathrm{mm} \mathrm{Hg}$.

$$
220=\frac{P_{2}(13.67)}{615-P_{2}} \quad P_{2}=579 \mathrm{~mm} \mathrm{Hg}
$$

Now since the pressure gage used for this determination was certified to $\pm 2 \mathrm{~mm} \mathrm{Hg}$, then, $P_{2}$ could actually range from 577 to $581 \mathrm{~mm}$ $\mathrm{Hg}$ in the above example. Likewise $\mathrm{P}_{1}$ could range anywhere from 613 to $617 \mathrm{~mm} \mathrm{Hg}$. Also the expansion volume's volume could range between 13.57 to 13.77 liters.

By using the lowest possible value for $\mathrm{P}_{2}$ (i.e., 577) and $V_{c}$ (i.e., 13.57) and the highest possible value for $P_{1}$ (i.e., 617) in Equation 1, a lower certified error limit can be obtained for this 220-liter drum.

$$
V_{v}=\frac{577(13.57)}{617-577} \quad=196 \text { liters }
$$

Similarly, an upper certified error limit can be obtained by using the highest possible value for $P_{2}$ (i.e., 581) and $V_{c}$ (i.e., 13.77) and the lowest possible value for $P_{1}$ (i.e., 613) in Equation 1 .

$$
V_{v}=\frac{581(13.77)}{613-581} \quad=250 \text { liters }
$$

Thus, the certified error in determining the void volume of a 220 -liter calibrated drum by use of the above described equipment (i.e., pressure gage and expansion volume) could range from 196 liters to 250 liters if $P_{1}$ was $615 \mathrm{~mm} \mathrm{Hg}$. In other words, a 220-liter drum could have a void-volume determination ranging anywhere between 196 to 250 liters by use of a pressure gage accurate to $\pm 2 \mathrm{~mm} \mathrm{Hg}$ and a 13.67-liter expansion volume accurate to \pm .1 liter.
Experimental Error Analysis:

A void-volume determination was performed on the 220-liter certified drum six times. The mean and standard deviation for this series of six trials was 233 liters and 1.3 liters, respectively. These experimental results fall well within the certified error limits and indicate that the actual error limits are much less than the certified error limits. Indeed, the rather good reproducibility of the results makes it possible to obtain a correction factor by which void-volume determinations of drums of unknown volume could be multiplied by to give corrected and much more accurate void volume values. Thus the correction factor used was obtained by dividing the actual volume by the experimental value (i.e., $220 / 233=0.944$ ).

Assuming this correction factor is accurate over a wide range of void volumes the experimental error reduces to a combination of the certified error in the 220 liter drum volume determination (which was \pm 1 liter) and the reproducibility of the analysis (which is given by the standard deviation of 1.3 liters). Assuming a normal distribution and using the standard deviation of 1.3 liters and a t-statistic of 2.02 , a one trial $90 \%$ confidence interval of \pm 2.6 liters can be calculated. This value plus the uncertainty in the 220-liter certified drum gives a total uncertainty or error of \pm 3.6 liters. Thus the experimental percentage error reduces to $\pm(3.6 / 220) \times 100= \pm 1.64 \%$.

\section{Pressure Testing}

All of the drums were pressured tested twice during the course of the study. The drums were considered sealed if they held a pressure of 155 torr ( 3 psi) above atmospheric for 3 hours with a pressure loss of no more than 5 torr. Task 5 drums were tested before the start of phase $I$ and the conclusion of phase II. Task 7 drums were tested both before and after phase II. All drums remained sealed to the above criteria during the study, with the exception of two drums. Drums D31254 (Fig. B5a) and D31528 (Fig. B2d) developed leaks of 41 torr and 28 torr respectively in the six-month study. Even though these drums leaked when pressurized to 155 torr, the leak rate would be significantly less with the 
small (less than 15 torr) pressure differential encountered. In fact, the leaks may have developed at the drum gasket or pipe couplings as a direct result of applying 155-torr pressure differential. The leaks were not considered in determining the gas generation rates.

\section{Sampling}

Drums for both tasks were sampled weekly for both pressure and composition for 13 weeks. The gassampling manifold and gas-sampling bottle were evacuated to less than 0.02 torr before a gas sample was drawn. After this pressure was obtained, the valve to the vacuum pump was closed to ensure that there were no leaks in the sampling manifold as demonstrated by a pressure rise of less than 0.01 torr in one minute.

Analysis

Gas determination was done on a DuPont Model CEC 21-104 mass spectrometer. Several rigid parameters were set up to assure better accuracy of the analysis. All samples were analyzed on the same instrument and by the same operator. All samples for a given week were analyzed on the same shift to minimize the effect of instrument drift and the need for recalibration. Calibration consisted of analyzing pure gases for $\mathrm{H}_{2}, \mathrm{Ar}, \mathrm{CO}_{2}, \mathrm{He}, \mathrm{CO}$, $\mathrm{CH}_{4}, \mathrm{~N}_{2} \mathrm{O}$, NO (to cover $\mathrm{NO}_{\mathrm{X}}$ ), and air (to cover $\mathrm{N}_{2}$ and $\mathrm{O}_{2}$ ). All other calibration gases and organics were determined at other times as necessary. A gas standard containing an unknown mixture was also analyzed weekly each time the drums were sampled. The results of the standard analysis are presented in Table 1.

\section{Data Reduction}

Mass spectrometer data were reviewed and processed through a computer program designed to identify and determine the quantity of gases present and the calibration fit. Measures of the degree of "closure" values are in Table 2 .

TABLE 1. Results of Analysis of Gas Standard From Phase I

\begin{tabular}{|c|c|c|c|c|}
\hline \multirow[b]{2}{*}{ Week Number } & \multicolumn{4}{|c|}{$\begin{array}{c}\text { Gas Analysis } \\
\text { (vol \%) }\end{array}$} \\
\hline & $\mathrm{N}_{2}$ & $\mathrm{O}_{2}$ & $\mathrm{H}_{2}$ & $\mathrm{CO}_{2}$ \\
\hline 1 & 65.70 & 19.30 & 2.65 & 12.29 \\
\hline 2 & 65.44 & 19.57 & 2.54 & 12.45 \\
\hline 3 & 66.03 & 19.06 & 2.43 & 12.48 \\
\hline 4 & 66.41 & 18.79 & 2.54 & 12.26 \\
\hline 5 & 65.30 & 19.33 & 2.49 & 12.88 \\
\hline 6 & 65.10 & 19.71 & 2.52 & 12.67 \\
\hline 7 & 65.15 & 19.86 & 2.43 & 12.56 \\
\hline 8 & 65.74 & 19.39 & 2.54 & 12.33 \\
\hline 9 & 65.83 & 19.30 & 2.61 & 12.26 \\
\hline 10 & 66.48 & 18.79 & 2.53 & 12.20 \\
\hline 11 & 66.02 & 19.06 & 2.50 & 12.43 \\
\hline 12 & 65.87 & 19.18 & 2.51 & 12.44 \\
\hline 13 & 65.94 & 19.10 & 2.41 & 12.55 \\
\hline Mean $(\overline{\mathbf{x}})$ & 65.77 & 19.27 & 2.52 & 12.45 \\
\hline $\begin{array}{l}\text { Standard } \\
\quad \text { Deviation(s) }\end{array}$ & 0.43 & 0.32 & 0.07 & 0.19 \\
\hline $\begin{array}{l}\text { Coefficient of } \\
\text { variation }\end{array}$ & 0.65 & 1.66 & 2.78 & 1.53 \\
\hline
\end{tabular}


TABLE 2. Closure Values for Phase I

\begin{tabular}{lcc}
$\begin{array}{c}\text { Drum } \\
\text { Number }\end{array}$ & $\begin{array}{c}\text { Mean } \\
\text { Closure* } \\
(\%)\end{array}$ & $\begin{array}{c}\text { Standard } \\
\text { Deviation } \\
(\%)\end{array}$ \\
\cline { 1 - 2 } D24545 & -0.63 & 2.5 \\
D25634 & -0.22 & 1.9 \\
D25691 & +0.32 & 2.0 \\
D26048 & -0.24 & 2.5 \\
D29758 & +0.38 & 3.1 \\
D30175 & +0.88 & 2.7 \\
D30688 & -0.32 & 2.3 \\
D31042 & -0.16 & 2.7 \\
D31216 & -0.52 & 2.4 \\
D31254 & +0.38 & 2.3 \\
D31403 & +1.31 & 2.5 \\
D31528 & -0.29 & 2.3 \\
D31703 & +1.04 & 2.4 \\
D32180 & -0.70 & 2.6 \\
D32186 & -0.19 & \\
D32538 & -0.96 & 2.0 \\
STD No. 2 & -0.64 & 2.2 \\
\hline *“Closure" is defined as the difference of the \\
sum of the calculated partial pressures of \\
all the gases present in the drum and the \\
analyzer pressure (measured by a Baratron \\
pressure gage) divided by the analyzer \\
pressure and converted to a percentage. \\
The mean closure values and standard \\
deviations represent statistics of 13 \\
analyses made over a 13-week period. & \\
& \\
\hline
\end{tabular}

\section{Results-Phase I}

The results of the vented portion of the study, phase I, are discussed here and also are shown graphically in Figures 1 through 17 in Appendix A. Table 3 lists the figure number, corresponding drum number, content code, and content code description. The internal drum pressure and the atmospheric pressure at the time of sampling are graphically presented in the " $a$ " figures. An excellent correlation between the two exists with one notable exception. The exception, D31703 (Figures A-10a, b, c, d), was fitted with a styrene-butadiene gasket and resulted in a pressure differential of up to 6 torr during the study.

A "control" drum, D32538 (Figures A-17a, b, c), was sealed after volume calibration and contains a subambient atmosphere, the pressure of which was expected to remain constant despite variations in atmospheric pressure. This is indeed the case as slight variations of D32538 (Figure A-17a) pressure are within the calibrated gage tolerance of \pm 2 torr.

The compositions of the sampled atmospheres in each drum are shown in the "b", "c", and "d" figures. Variations in the compositions of each of the drum atmospheres were minimal over the 13-week sampling period with a few notable exceptions. Hydrogen concentrations indicate that for the test period, hydrogen was within safe limits.

Helium was present in four drums: D31254 (Figure A-5d), D31403 (Figure A-6c), D25691 (Figure A-13d), D29758 (Figure A-15d), from

TABLE 3. Drum List

Figure $\quad \begin{gathered}\text { Drum } \\ \text { Number }\end{gathered} \quad$ Content Code/Description

Task 5-Drums Fitted With Carbon-Composite Filter

\begin{tabular}{|c|c|c|}
\hline$A-1 a, b, c$ & D29258 & $001-1$ st stage sludge \\
\hline$A-2 a, b, c$ & D31528 & $001-1$ st stage sludge \\
\hline$A-5 a, b, c, d$ & D31254 & 003-grease \\
\hline$A-6 a, b, c, d$ & D31403 & 003 -grease \\
\hline$A-7 a, b, c$ & D24545 & 330 -dry combustible \\
\hline$A-8 a, b, c, d$ & D31042 & 330-dry combustible \\
\hline$A-11 a, b, c$ & D25634 & 336-wet combustible \\
\hline$A-12 a, b, c$ & D31216 & 336-wet combustible \\
\hline$A-13 a, b, c, d$ & D25691 & $337-$ plastic and rubber \\
\hline$A-14 a, b, c$ & D30688 & 337 -plastic and rubber \\
\hline$A-15 a, b, c, d$ & D29758 & 339-leaded rubber \\
\hline$A-16 a, b, c$ & D30175 & 339-leaded rubber \\
\hline
\end{tabular}

Task 7-Drums Fitted With Hanford Vent Clip $\begin{array}{lll}\text { A-3a, b, c } & \text { D32180 } & \text { 001-1st stage sludge } \\ \text { A-9a, b, c, d } & \text { D26048 } & \text { 330-dry combustible }\end{array}$

Task 7-Drums Fitted With Styrene-Butadiene

$\begin{array}{lll}\text { A-4a, b , c } & \text { D32186 } & 001-1 \text { st stage sludge } \\ \text { A-10a, b c c d } & \text { D31703 } & 330-\text { dry combustible }\end{array}$


leak checks. As expected, in all four cases, helium concentration decreased during the course of the study. The twelve task 5 drums had various amounts of isopropanol (a solvent constituent in the Permatex® Form-A-Gasket used to seal the drums). Other organic solvents were detected and identified in four drums D31254 (Figure A-5c), D31403 (Figure A-6c), D31042 (Figure A-8d), D26048 (Figure A-9c). Drum 31703 (Figure A-10c) contained an organic compound that was unidentifiable using these techniques; it was calculated and included with the $\mathrm{C}_{1}-\mathrm{C}_{4}$ hydrocarbons.

\section{Conclusions-Phase I}

This study represents one of the first radioactive experiments conducted with the carbon-composite filter. The filter has been well characterized as a nuclear grade filter, with high flow rate, etc., but radioactive information was limited. Based on these tests, the carbon-composite filter appears to equilibrate pressure very well. The drums selected for this study had higher activity than normally found in RFP drums and for three months did not significantly accumulate hydrogen.

The Hanford vent clip appears to equilibrate pressure as well as the carbon-composite filter. In all cases, the drums fitted with styrene-butadiene permeable gaskets did not maintain drum pressures as close to atmospheric pressure as the carbon-composite filter or the Hanford vent clip. All venting devices performed well in maintaining hydrogen levels within safe limits.

\section{PHASE II}

In phase II of tasks 5 and 7, the 16 drums of newly generated RFP waste were sealed completely to monitor internal drum pressure and atmosphere.

\section{Procedure-Phase II}

\section{$\underline{\text { Drum Selection }}$}

The drums were carried over from the phase I study.

\section{Drum Assay}

The drums were assayed at the start of the phase $I$ study. Two drums, D31254 (Figures A-5a, b, c, d) and D31403 (Figures A-6a, b, c, d), were resampled at the conclusion of phase II to attempt to obtain a more representative sample. Instead of coring the grease, which removes approximately 2 inches of the surface, the drums were sectioned in a contamination control vault and a composite sample was taken from various areas of the grease.

\section{Drum Setup}

The drums were sealed at the beginning of phase II for determination of gas generation rates. The 12 drums from task 5 , which had carbon-composite filters for the phase I venting tests, had the filters removed and a pipe plug installed into the coupling in the lid. The task 7 drums had the permeable gaskets or vent clips removed and had non-permeable gaskets doped with Permatex $®$ installed.

Since the drum atmospheres in several of the drums at the conclusion of phase I did not represent normal atmosphere, all drums were "flushed" prior to commencing phase II testing. A flushing cycle consisting of evacuating the drums from atmospheric pressure to 300 torr then pressurizing them to 900 torr with bottled air was repeated three times to give the drums a normal atmosphere. This procedure of evacuating and pressurizing three times before the drum was returned to atmospheric pressure should have removed approximately $96.3 \%$ of the original atmosphere and replaced it with ambient air. The drums were then immediately resampled to obtain a time zero baseline.

\section{$\underline{\text { Void-Volume Determinations }}$}

The drum void volumes were determined as outlined in the phase I discussion; the results are shown in Table 4.

\section{Pressure Testing}

The drums were pressure checked as discussed in the phase I section. Two drums, D31254 (Figures B-5a, 
RFP-3739

TABLE 4. Gas Generation Data

\begin{tabular}{|c|c|c|c|c|c|c|c|c|c|c|c|c|c|}
\hline \multirow{2}{*}{$\begin{array}{c}\text { Figure } \\
\text { Number }\end{array}$} & \multirow{2}{*}{$\begin{array}{l}\text { Drum } \\
\text { Number } \\
\end{array}$} & \multirow[b]{2}{*}{ Content and Code } & \multirow{2}{*}{$\begin{array}{l}\mathrm{Pu} \\
(\mathrm{g}) \\
\end{array}$} & \multirow{2}{*}{$\begin{array}{l}\text { Am } \\
(\mathrm{g})\end{array}$} & \multirow{2}{*}{$\begin{array}{l}\mathrm{eV}^{*} \\
\times 10^{24} \\
\end{array}$} & \multirow{2}{*}{$\begin{array}{l}\text { Void } \\
\text { Vol. } \\
(\ell) \\
\end{array}$} & \multicolumn{3}{|c|}{$\begin{array}{l}\text { Partial } \\
\text { Pressure } \\
\text { (torr)** }\end{array}$} & \multicolumn{2}{|c|}{$\begin{array}{c}\text { Moles } \\
\text { Generated }\end{array}$} & \multicolumn{2}{|c|}{$\begin{array}{c}\text { Weight } \\
(\%)\end{array}$} \\
\hline & & & & & & & $\mathrm{H}_{2}$ & $\mathrm{CO}_{2}$ & $\mathrm{O}_{2}$ & $\mathrm{H}_{2}$ & $\mathrm{CO}_{2}$ & $\mathrm{H}_{2} \mathrm{O}$ & $\mathrm{NO}_{3}$ \\
\hline 1 & D29258 & 1st stage sludge-001 & 17.2 & 1.12 & 8.09 & 93 & 8.0 & 0.5 & -16 & 0.0403 & 0.0025 & 48.9 & 8.4 \\
\hline 2 & D31528 & 1st stage sludge-001 & 9.64 & 0.90 & 6.08 & 103 & 5.0 & 0 & -20 & 0.0279 & 0 & 36.1 & 7.8 \\
\hline 3 & D32180 & 1st stage sludge-001 & 68.9 & 3.03 & 24.2 & 102 & 14 & 0.2 & +53 & 0.0773 & 0.0011 & 51.3 & 8.2 \\
\hline 4 & D32186 & 1st stage sludge- 001 & 19.5 & 1.65 & 11.3 & 110 & 4.9 & 0.2 & -18 & 0.0292 & 0.0012 & 55.9 & 7.6 \\
\hline 5 & D31254 & Grease- -003 & 3.19 & 0.033 & 0.517 & 60 & 40 & 0 & $90 \rightarrow 0$ (1 wk) & 0.130 & 0 & & \\
\hline 6 & D31403 & Grease-003 & 1.45 & 0.026 & 0.299 & 86 & 24 & 0 & $90 \rightarrow 0(1 \mathrm{wk})$ & 0.112 & 0 & & \\
\hline 7 & D24545 & Dry combustibles- 330 & 16.4 & 0 & 1.69 & 204 & 5.3 & 4.2 & -24 & 0.0585 & 0.0464 & & \\
\hline 8 & D31042 & Dry combustibles-330 & 28.9 & 0 & 2.99 & 215 & 6.0 & 5.7 & -47 & 0.0698 & 0.0663 & & \\
\hline 9 & D26048 & Dry combustibles-330 & 28.3 & 0 & 2.93 & 182 & 3.9 & 2.3 & -21 & 0.0384 & 0.0227 & & \\
\hline 10 & D31703 & Dry combustibles-330 & 32.4 & 0 & 3.35 & 175 & 2.3 & 30 & -80 & 0.0218 & 0.284 & & \\
\hline 11 & D25634 & Wet combustibles-336 & 15.5 & 0 & 1.60 & 203 & 1.8 & 0.4 & -19 & 0.0198 & 0.0044 & & \\
\hline 12 & D31216 & Wet combustibles-336 & 26.1 & 0 & 2.70 & 213 & 2.0 & 1.1 & -24 & 0.0231 & 0.0127 & & \\
\hline 13 & D25692 & Plastics and rubber-337 & 28.8 & 0 & 2.98 & 182 & 5.4 & 11 & -73 & 0.0532 & 0.108 & & \\
\hline 14 & D30688 & Plastics and rubber-337 & 34.4 & 0 & 3.56 & 186 & 3.8 & 4.5 & -27 & 0.0383 & 0.0453 & & \\
\hline 15 & D29758 & Leaded gloves-339 & 2 & --- & 0.207 & 202 & 0.1 & 2.0 & -17 & 0.0011 & 0.0219 & & \\
\hline 16 & D30175 & Leaded gloves-339 & 163.5 & 0.3 & 18.7 & 201 & 27 & 14 & -75 & 0.294 & 0.152 & & \\
\hline
\end{tabular}

* Energy released in 13 weeks.

** Partial pressure change in 13 weeks (temperature $23^{\circ} \mathrm{C}$ ). 
b, c, d, e) and D31528 (Figures B-2a, b, c, d) developed leaks sometime during the phase $I$ and phase II studies. Refer to the phase I section for additional information.

$\underline{\text { Sampling }}$

All drums were sampled immediately after the flushing operation to establish a baseline for pressure and internal composition. The sampling then proceeded as described in the phase I discussion.

\section{Analysis}

The analysis was conducted as described in the phase I discussion. A gas standard containing an unknown mixture was analyzed weekly each time the drums were sampled. The results of the standard analysis are presented in Table 5.

TABLE 5. Results of Analysis of Gas Standard From Phase II

\begin{tabular}{|c|c|c|c|c|}
\hline \multirow[b]{2}{*}{ Week Number } & \multicolumn{4}{|c|}{$\begin{array}{l}\text { Gas Analysis } \\
\text { (vol \%) }\end{array}$} \\
\hline & $\mathrm{N}_{2}$ & $\mathrm{O}_{2}$ & $\mathrm{H}_{2}$ & $\mathrm{CO}_{2}$ \\
\hline 0 & 66.36 & 18.36 & 2.56 & 12.72 \\
\hline 1 & 65.35 & 19.20 & 2.64 & 12.81 \\
\hline 2 & 65.21 & 19.55 & 2.54 & 12.70 \\
\hline 3 & 65.50 & 18.86 & 2.53 & 13.11 \\
\hline 4 & 66.63 & 18.25 & 2.52 & 12.61 \\
\hline 5 & 65.49 & 18.86 & 2.58 & 13.07 \\
\hline 6 & 66.00 & 18.71 & 2.55 & 12.71 \\
\hline 7 & 65.87 & 18.50 & 2.61 & 13.02 \\
\hline 8 & 65.75 & 18.63 & 2.58 & 13.04 \\
\hline 9 & 66.08 & 18.80 & 2.57 & 12.55 \\
\hline 10 & 66.59 & 19.00 & 2.50 & 11.91 \\
\hline 11 & 65.69 & 19.13 & 2.56 & 12.62 \\
\hline 12 & 66.10 & 18.80 & 2.51 & 12.59 \\
\hline 13 & 65.19 & 18.50 & 2.50 & 13.81 \\
\hline Mean $(\bar{x})$ & 65.84 & 18.80 & 2.55 & 12.81 \\
\hline $\begin{array}{l}\text { Standard } \\
\text { Deviation(s) }\end{array}$ & 0.475 & 0.350 & 0.041 & 0.419 \\
\hline $\begin{array}{l}\text { Coefficient of } \\
\text { Variation } \\
(s / \bar{x} \times 100)\end{array}$ & 0.721 & 1.86 & 1.61 & 3.27 \\
\hline
\end{tabular}

\section{$\underline{\text { Data Reduction }}$}

Mass spectrometer data were reviewed and processed through a computer program designed to identify and determine the quantity of gases present and the calibration fit. Measures of the degree of "closure" values for the phase II study are in Table 6 .

\section{Results-Phase II}

The internal pressure of the drums and atmospheric pressure at the time of sampling are graphically presented in the "a" figures (Figures B-1a through B-17a) in Appendix B. The compositions of the sampled atmospheres in each drum are shown in

TABLE 6. Closure Values for Phase II

\begin{tabular}{lcc}
$\begin{array}{c}\text { Drum } \\
\text { Number }\end{array}$ & $\begin{array}{c}\text { Mean } \\
\text { Closure* } \\
(\%)\end{array}$ & $\begin{array}{c}\text { Standard } \\
\text { Deviation } \\
(\%)\end{array}$ \\
\cline { 2 - 2 } D24545 & -0.19 & 1.25 \\
D25634 & -0.62 & 1.31 \\
D25691 & -0.08 & 0.82 \\
D26048 & -0.24 & 2.52 \\
D29258 & -0.63 & 1.35 \\
D29758 & -0.69 & 0.94 \\
D30175 & -0.43 & 0.98 \\
D30688 & -0.44 & 1.54 \\
D31042 & +1.17 & 1.17 \\
D31216 & -0.76 & 1.51 \\
D31254 & +0.51 & 1.93 \\
D31403 & +0.64 & 1.25 \\
D31528 & -0.48 & 1.71 \\
D31703 & -0.23 & 1.41 \\
D32180 & -1.54 & 1.15 \\
D32186 & -0.47 & 1.61 \\
D32538 & +0.09 & 1.78 \\
STD No. 2 & +0.01 & 0.76 \\
& &
\end{tabular}

*"Closure" is defined as the difference of the sum of the calculated partial pressures of all the gases present in the drum and the analyzer pressure (measured by a Baratron pressure gage) divided by the analyzer pressure and converted to a percentage. The mean closure values and standard deviations represent statistics of 13 analyses made over a 13-week period. 
the " $b$ ", " c", " $d$ ", and "e" (if necessary) figures. The amounts of each gas are graphed as partial pressure (volume percent times the total drum pressure) and are also presented in tabular form as volume percent. Partial pressure graphs are commonly used to present this data because, for example, as the drum pressure increases, the inert gases such as nitrogen and argon should maintain relatively constant partial pressures while the volume percents of nitrogen and argon decrease. The partial pressures are subject to pressure measurement errors associated with the mass spectral analysis and the calibrated gage tolerance of \pm 2 torr.

All drums had various amounts of isopropanol (a solvent constituent in the Permatex® Form-AGasket used to seal the drums). Drum D31703
(Figure B-10e) contained an organic compound that was not identified; it was calculated and included with the $\mathrm{C}_{1}-\mathrm{C}_{4}$ hydrocarbons.

\section{Evaluation of Gas Yields}

The radiolytic gas yields from the six waste categories were calculated from the sampling results and assay values. Table 4 shows the pertinent data used to determine the gas yields. The partial pressures shown were obtained from the slopes of the "a" graphs in Appendix B, Figures 1-16. The moles of gas generated were calculated using the ideal gas law, sampling data and the drum void volume. The gas yields are given in Table 7 as $G$ values. G (gas) is defined as the number of gas molecules formed for each $100 \mathrm{eV}$ of absorbed energy. The $\mathrm{G}$ values were calculated using:

$$
\begin{aligned}
\mathrm{G}= & \frac{\text { moles gas } \times\left(6.02 \times 10^{23} \text { molecules } / \text { mole }\right) \times 100 \mathrm{eV}}{[(\mathrm{g} \mathrm{Pu} \times 0.00211 \mathrm{watt} / \mathrm{g})+(\mathrm{g} \mathrm{Am} \times 0.115 \mathrm{watt} / \mathrm{g})]} \\
& \times\left(6.24 \times 10^{18} \mathrm{eV} / \mathrm{sec} \cdot \mathrm{watt}\right) \times\left(7.86 \times 10^{6} \mathrm{sec} / 13 \mathrm{week}\right)
\end{aligned}
$$

\begin{tabular}{|c|c|c|c|c|c|c|}
\hline $\begin{array}{c}\text { Figure } \\
\text { Number } \\
\end{array}$ & $\begin{array}{c}\text { Drum } \\
\text { Number }\end{array}$ & Content/Code Description & $\mathrm{G}\left(\mathrm{H}_{2}\right)$ & $\mathrm{G}\left(\mathrm{CO}_{2}\right)$ & $\mathrm{G}(\mathrm{HC})$ & $\begin{array}{c}\mathrm{G} \\
\text { (total) }\end{array}$ \\
\hline$B-1 a, b, c, d$ & D29258 & 001-1st stage sludge & 0.30 & $<0.01$ & ---- & 0.31 \\
\hline$B-2 a, b, c, d$ & D31528 & 001-1st stage sludge & 0.28 & $<0.01$ & --- & 0.29 \\
\hline B-3a, b, c, d & D32180 & 001-1st stage sludge & 0.19 & $<0.01$ & --- & 0.20 \\
\hline$B-4 a, b, c, d$ & D32186 & 001-1st stage sludge & 0.16 & $<0.01$ & 0.02 & 0.19 \\
\hline $\mathrm{B}-5 \mathrm{a}, \mathrm{b}, \mathrm{c}, \mathrm{d}, \mathrm{e}$ & D31254 & 003-Grease & 15.1 & 0 & --- & 15.1 \\
\hline B-6a, b, c, d, e & D31403 & 003-Grease & 22.5 & 0 & --- & 22.5 \\
\hline B-7a, b, c, d & D24545 & 330-Dry combustible & 2.1 & 1.6 & --- & 3.7 \\
\hline $\mathrm{B}-8 \mathrm{a}, \mathrm{b}, \mathrm{c}, \mathrm{d}, \mathrm{e}$ & D31042 & 330-Dry combustible & 1.4 & 1.3 & 0.9 & 3.6 \\
\hline B-9a, b, c, d, e & D26048 & 330-Dry combustible & 0.79 & 0.47 & --- & 1.26 \\
\hline $\mathrm{B}-10 \mathrm{a}, \mathrm{b}, \mathrm{c}, \mathrm{d}, \mathrm{e}$ & D31703 & 330-Dry combustible & 0.39 & 5.1 & --- & 5.49 \\
\hline B-11a, b, c & D25634 & 336-Wet combustible & 0.74 & 0.17 & --- & 0.91 \\
\hline B-12a, b, c, d & D31216 & 336-Wet combustible & 0.52 & 0.28 & 0.25 & 1.05 \\
\hline B-13a, b, c, d & D25691 & 337-Plastic and rubber & 1.1 & 2.2 & --- & 3.3 \\
\hline$B-14 a, b, c, d$ & D30688 & 337-Plastic and rubber & 0.65 & 0.77 & --- & 1.42 \\
\hline B-15a, b, c, d & D29758 & 339-Leaded rubber & 0.32 & 6.4 & --- & 6.72 \\
\hline B-16a, b, c, d & D30175 & 339-Leaded rubber & 0.95 & 0.49 & 0.07 & 1.51 \\
\hline
\end{tabular}

TABLE 7. Gas Yields 
In general, the gas yields show satisfactory consistency within each waste category and are reasonable when compared to previously obtained laboratory values. A few of the gas yields ( $G$ values) appear to be greater than expected and these are mentioned in the discussions of each category. Gas yields less than laboratory values can be explained by assuming that the actinides were not thoroughly mixed with the waste.

Oxygen was depleted at a relatively rapid rate as shown in Table 7. Some of these rates are too high to be attributed to radiolysis, and must be the result of another mechanism such as corrosion, bacterial action (to form $\mathrm{CO}_{2}$ ), thermal decomposition or other chemical reactions. The $\mathrm{G}$ values associated with oxygen depletion have not been included in Table 7. The $G$ (total) shown is the sum of $\mathrm{G}\left(\mathrm{H}_{2}\right)$, $\mathrm{G}\left(\mathrm{CO}_{2}\right)$ and $\mathrm{G}$ (hydrocarbons), where applicable. No increase in $\mathrm{NO}_{\mathrm{X}}$ was noted in any of the drums during the study.

Some of the radiolytic yields obtained in previous studies are shown in Table $8 .^{6}$ Table 8 is a partial listing of previous values; the scope of this report did not include resolution of discrepancies which may exist. Table 8 shows that almost all the yields for organics and hydrogenous materials are within an order of magnitude. A two-fold difference in yields obtained in different laboratories is not extraordinary because of differences in materials, radiation sources (in alpha and gamma), and experimental techniques.

\section{Gas Yield Comparison by Waste Form Type}

\section{Sludge}

The $\mathrm{H}_{2}$ yields for the four sludge drums appear reasonable for RFP sludge, ${ }^{2}$ although they correspond to yields that would be obtained from sludge that contained $75 \%$ water. The water and nitrate contents of these sludges have been included in Table 4 because of their influence on the radiolytic yields; presence of nitrate significantly reduces the hydrogen yield. The primary radiolysis product from nitrate sludge is oxygen but only one drum D32180 (Figure B-3c) showed a net increase in oxygen content. The $\mathrm{G}\left(\mathrm{O}_{2}\right)$ value of 0.7 is in
TABLE 8. Radiolytic Degradation Data Summary TRU Waste Contaminated Matrices

\begin{tabular}{llll}
\multicolumn{1}{c}{ Matrix } & & G(Gas, Total) \\
LASL: & cellulosics & & $1.3-2.9$ \\
& PVC & $8-11$ \\
& asphalt & $0.2-1.0$ \\
& cellulosics (dry) & & 1.6 \\
& cellulosics (soaked) & 1.5 \\
& composite & 1.4 \\
& polyethylene & 1.9 \\
& pump oil & $1.3-1.8$ \\
SRL: & cellulosics & \\
& pump oil & 1.9 \\
& octane & 2.0 \\
& concrete TRU ash & 4.5 \\
RFP: & cellulosics (dry) & $0.0003-0.6$ \\
& cellulosics (wet) & 0.63 \\
polyethylene & 0.31 \\
PVC & 0.73 \\
plexiglas & $0.43-0.96$ \\
rubbers & 1.9 \\
oil & 0.37 \\
& & 3.1 \\
& &
\end{tabular}

First stage process sludges

1.0

Source: M. A. Molecke, Gas Generation for Transuranic Waste Degradation: Data Summary \& Interpretation, SAND 79-1245, Sandia National Laboratory, Albuquerque, New Mexico, December 1979.

agreement with previous values. Oxygen depletion in the other three drums must be due to another reaction.

Grease

The $\mathrm{H}_{2}$ yields for the two grease drums are much higher than the expected $G$ values of two to three. ${ }^{2}$ The reason for the discrepancy may be either an incorrect plutonium or americium assay or another type of reaction as indicated by the complete depletion of oxygen in one week. The grease is also bagged into a 55-gallon PVC bag and PVC can exhibit high gas yields. 
Assay for each of the drums was completed twice. The assay was determined by radiochemical analysis of a sample of grease. The original assay was determined from an approximate 2 -inch core taken from the top of the drum. In an attempt to obtain a more representative sample, the drum was sectioned in a contamination control vault and a composite sample was obtained from three locations in the grease matrix. The apparent $\mathrm{G}\left(\mathrm{H}_{2}\right)$ for $\mathrm{D} 31254$ (Figure B-5e) was reduced from 36 to 15.1 , while D31403 (Figure B-6e) increased from 13 to 22.5. The assay results indicate that while the grease may not be homogeneous, the hydrogen rates appear representative for these drums.

Another type of reaction may be responsible for the high $\mathrm{G}$ values from these drums. The rate of oxygen depletion is too rapid to be attributed to radiolysis. Corrosion of the mild steel drum can produce hydrogen gas in an anoxic and wet atmosphere. ${ }^{6}$ The oxygen depletion after one week produced an anoxic atmosphere. These grease drums were analyzed by infrared and thermogravimetric analysis and were found to contain parafin oils, silicates, sulfates and approximately $20 \%$ water. Therefore, the drum atmosphere is expected to be water saturated. A total hydrogen gas generation rate from corrosion of more than twice the rate from radiolysis is possible under certain conditions. ${ }^{6}$

\section{Dry Combustibles}

The gas yields for the four dry combustible drums are in the range of values previously obtained, ${ }^{2-6}$ with one exception. The only anomalous value is the high $\mathrm{CO}_{2}$ yield $(\mathrm{G}=5.1)$ for D31703 (Figure B-10d). A possible explanation for the high $\mathrm{CO}_{2}$ yield is bacterial action. The total gas rate from bacterial action is highly variable but can be 2 to 3 orders of magnitude higher than the rate from radiolysis. Carbon dioxide is the primary component expected. ${ }^{6}$

\section{Wet Combustibles}

Very reasonable values have been obtained for both drums in this category. ${ }^{2}$ The $\mathrm{CO}_{2}$ yields are generally lower than the $\mathrm{H}_{2}$ yields for cellulosics and plastics as is demonstrated in these drums.
Plastics and Rubber

The gas yields obtained for this category are also well within the range of laboratory values. The $G$ values for plastics can vary widely, depending on composition (PVC or polyethylene). Complete characterization of the waste matrix, location and distribution of radionuclides on the matrix was beyond the scope of this study. The $\mathrm{CO}_{2}$ value for D25691 (Figure B-13d) appears to be somewhat higher than those previously obtained.

\section{Leaded Gloves}

The $G$ values for leaded rubber appear to be reasonable but there are no laboratory tests available for direct comparison. The $\mathrm{G}\left(\mathrm{CO}_{2}\right)$ for $\mathrm{D} 29758$ (Figure B-15d) is much higher than can be attributed to radiolysis. This high $\mathrm{CO}_{2}$ value may be due to bacterial action as discussed in the section on dry combustibles.

\section{Conclusions - Phase II}

The gas yields determined in this study are in reasonable agreement, with few exceptions, to gas yields previously determined. The gas yields should therefore be useful in determining gas production from actual drums of stored waste. Care must be used, however, because the gas generation parameters on actual containers at storage sites are probably not controlled in the same manner as the drums used in this study.

\section{REFERENCES}

1. Thomas L. Clements, Jr., Implementation Plan for the TRU Waste-Sampling Program, EGG-WM-6324, July 1983.

2. A. R. Kazanjian, Radiolytic Gas Generation in Plutonium Contaminated Waste Materials, RFP-2469, Rockwell International, Rocky Flats Plant, Golden, CO, October 29, 1976. 
3. A. Zerwekh, Gas Generation From Radiolytic Attack of TRU-Contaminated Hydrogenous Waste, LA-7674-MS, Los Alamos Scientific Laboratory, Los Alamos, NM, June 1979.

4. J. P. Ryan, Radiogenic Gas Accumulation in TRU Waste Storage Drums, DP-1604, Savannah River Laboratory, Aiken, SC, January 1982.

5. N. E. Bibler, Radiolytic Gas Production From Tritiated Waste Forms, DP-1459, Savannah River Laboratory, Aiken, SC, July 1977.

6. M. A. Molecke, Gas Generation for Transuranic Waste Degradation: Data Summary \& Interpretation, SAND 79-1245, Sandia National Laboratory, Albuquerque, NM, December 1979. 
RFP-3739

\section{DO NOT MCROFILM THS PAGE}


APPENDIX A

Results of Phase I, Vented, Tests of Tasks 5 and 7

for the TRU Waste Sampling Program

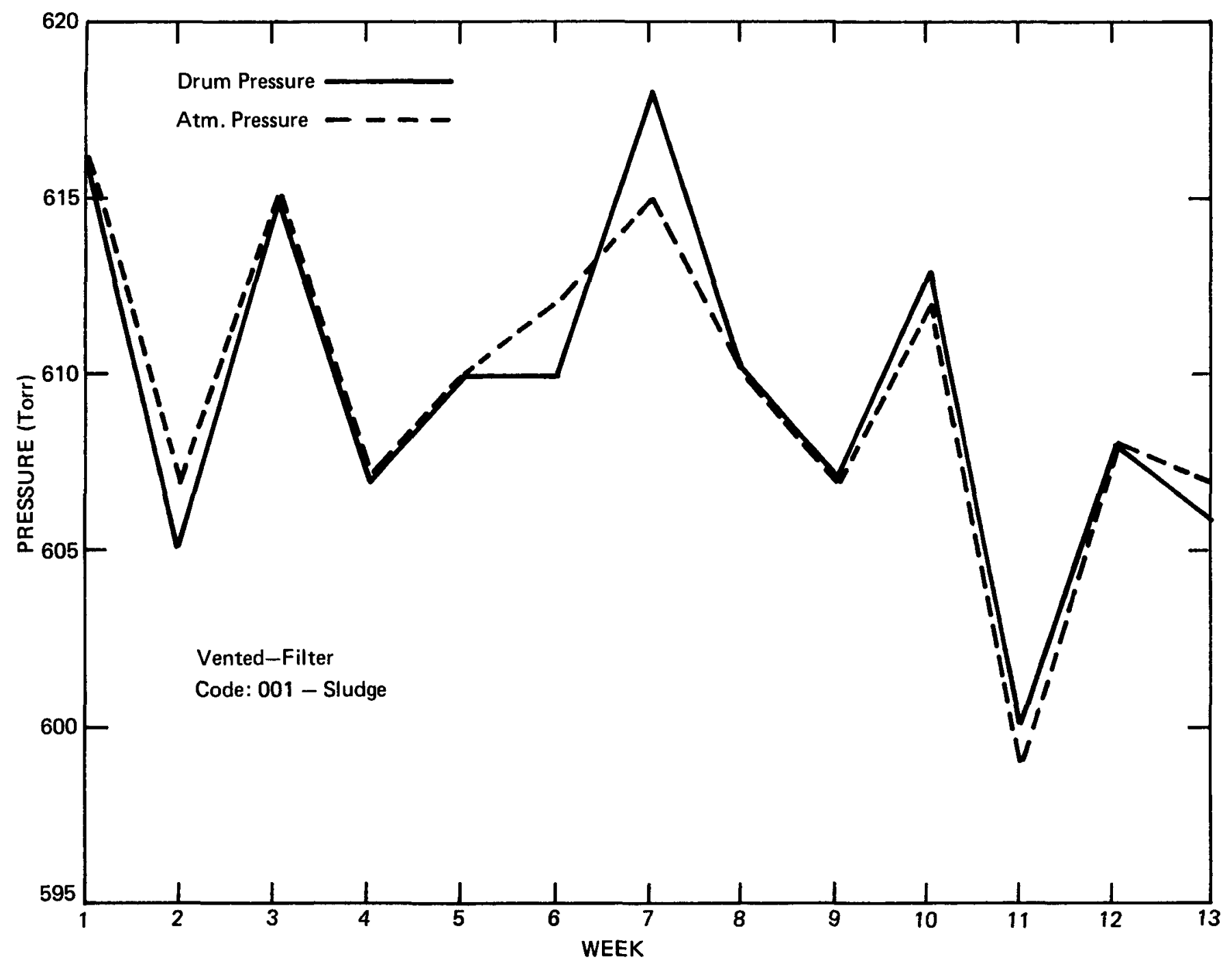

FIGURE A-1a. D29258 Pressure 


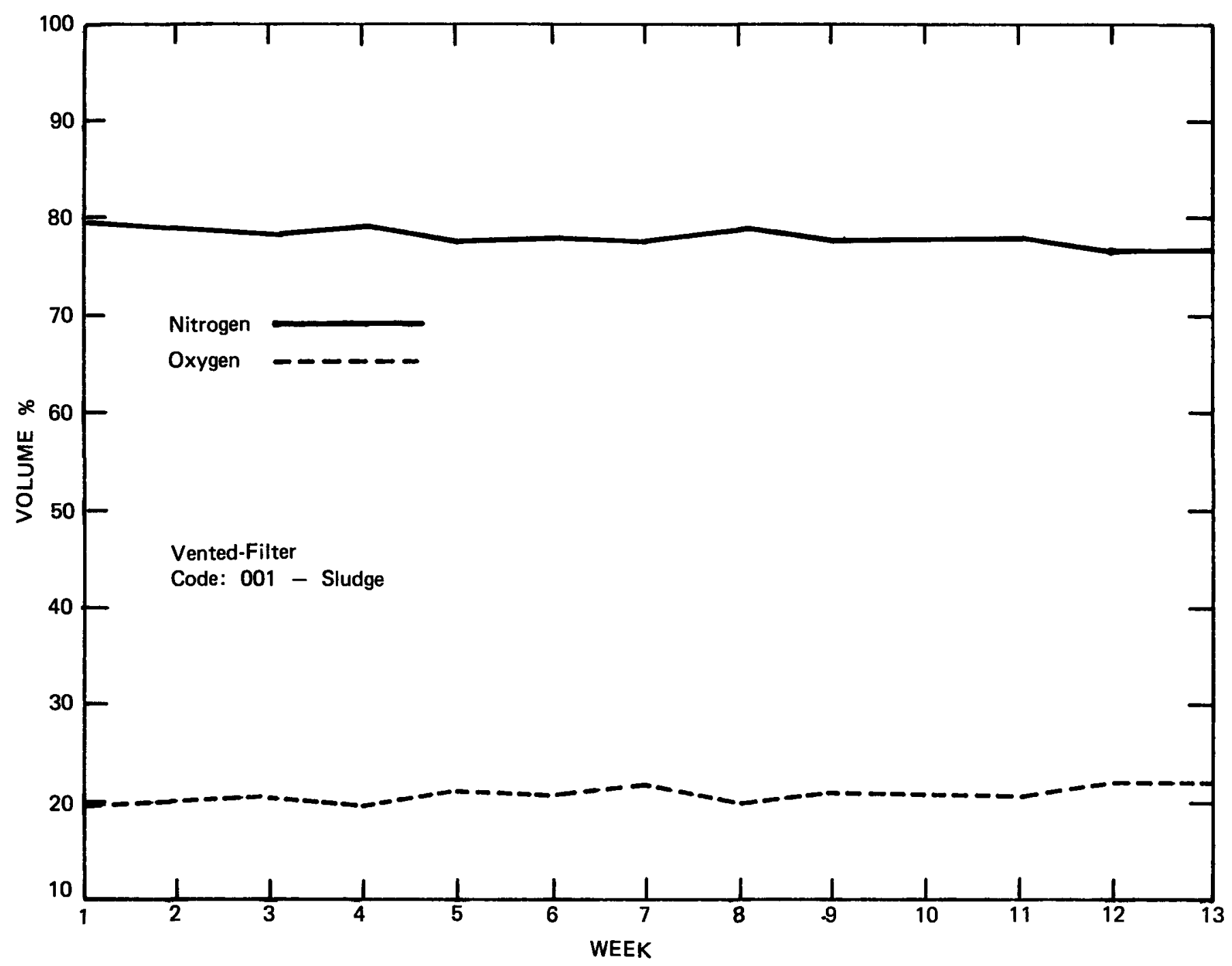

FIGURE A-1b. D29258 Atmosphere: Nitrogen, Oxygen 


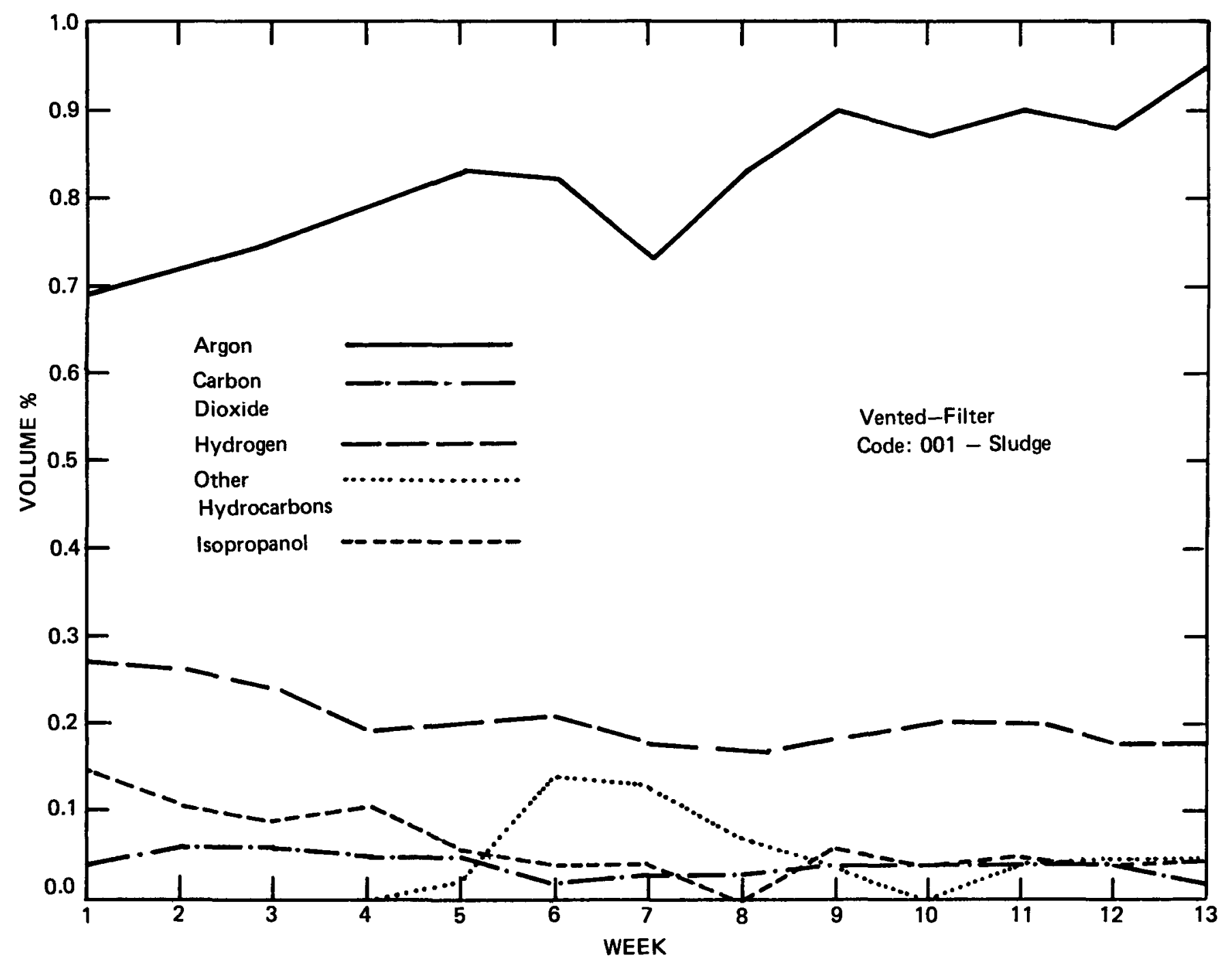

FIGURE A-1c. D29258 Atmosphere: Argon, Carbon Dioxide, Hydrogen, Other Hydrocarbons, Isopropanol 


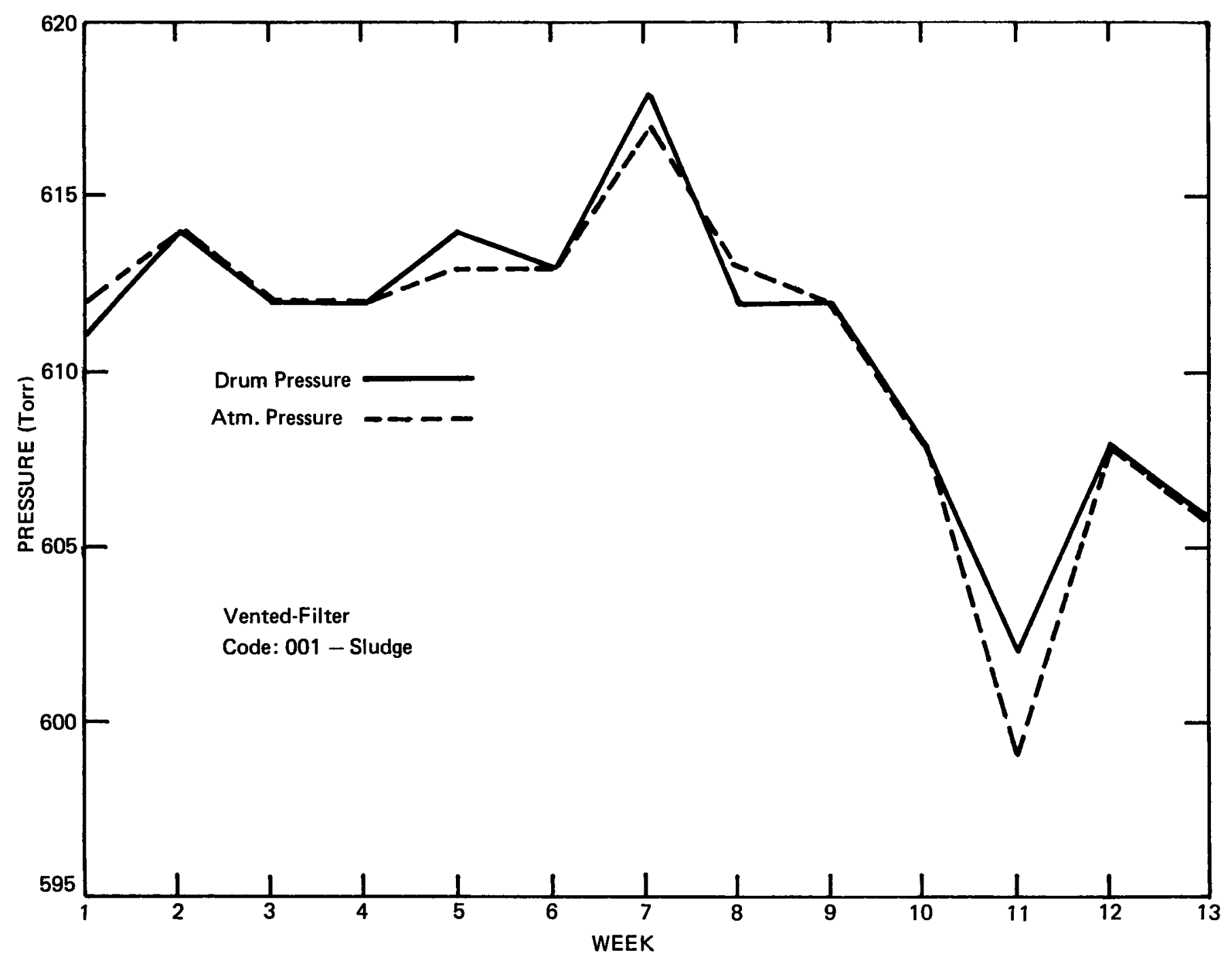

FIGURE A-2a. D31 528 Pressure 


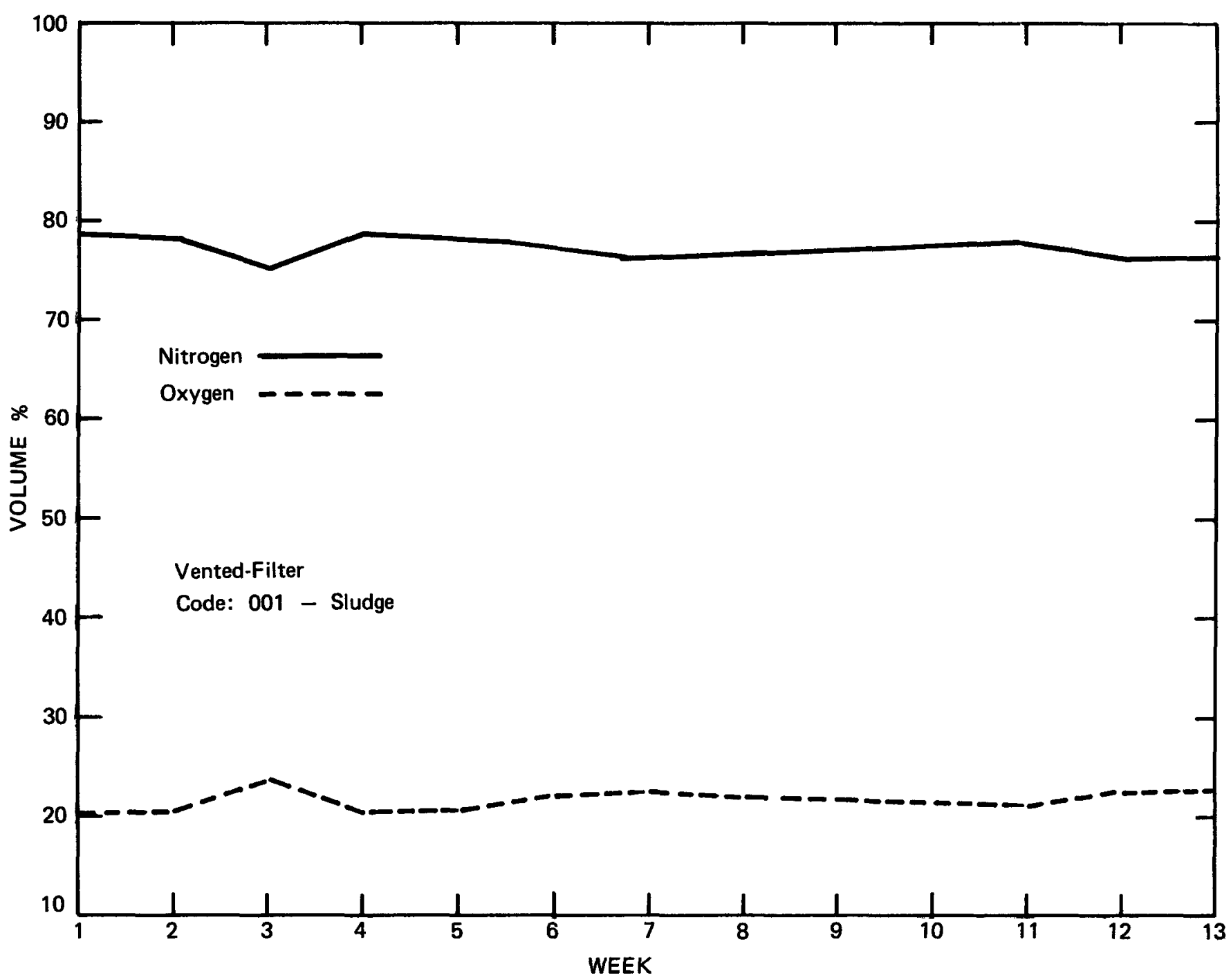

FIGURE A-2b. D31528 Atmosphere: Nitrogen, Oxygen 
RFP-3739

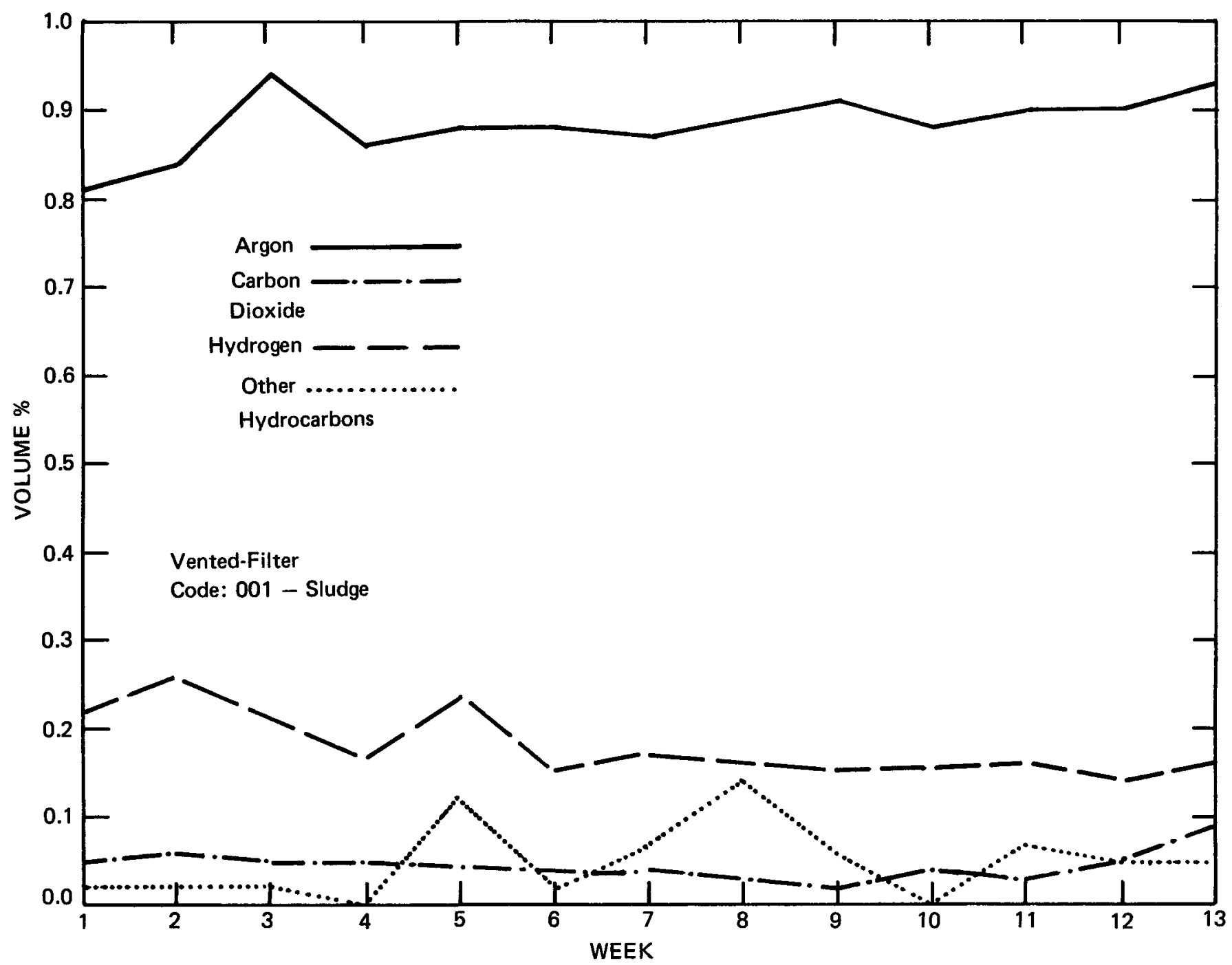

FIGURE A-2c. D31528 Atmosphere: Argon, Carbon Dioxide, Hydrogen, Other Hydrocarbons 


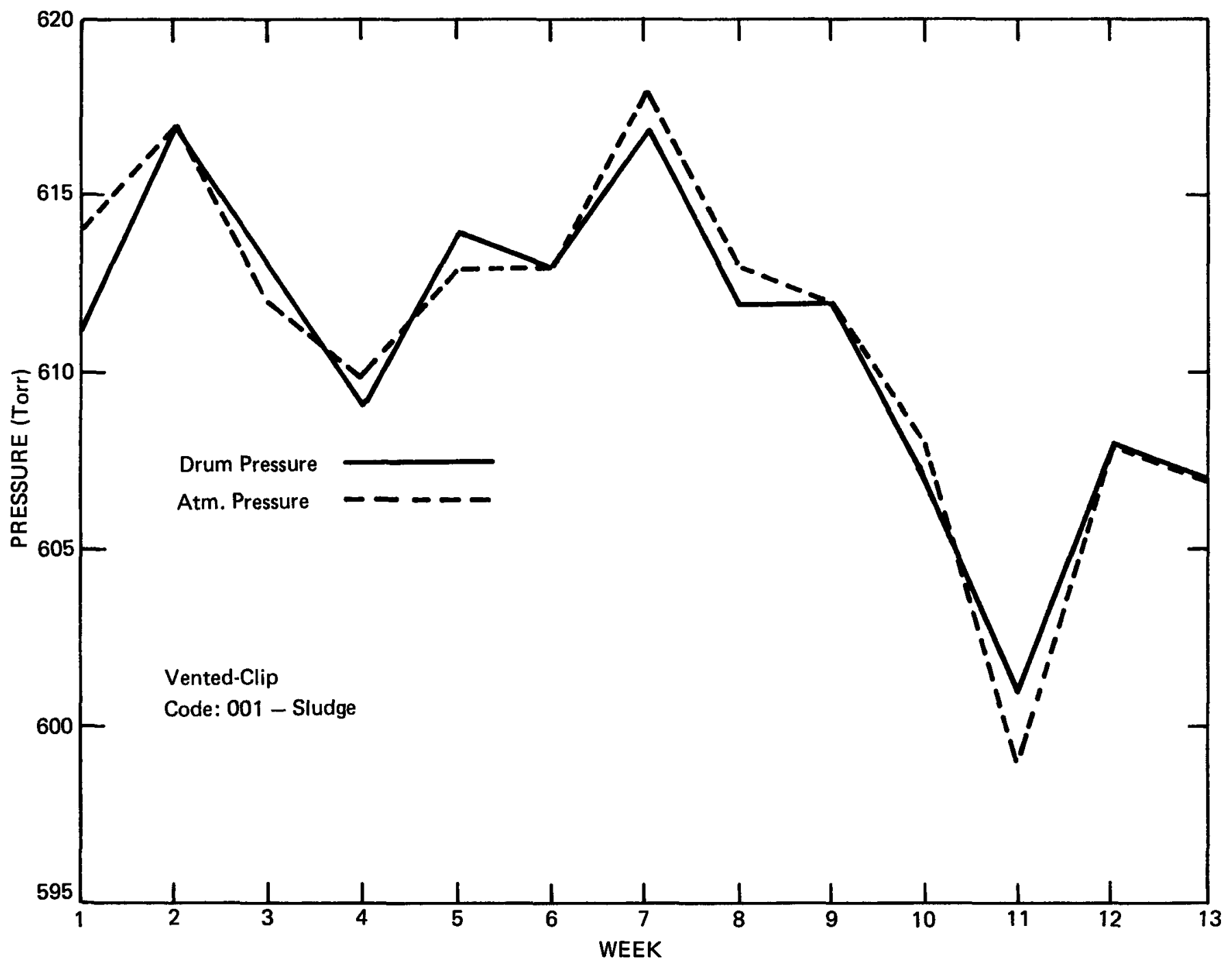

FIGURE A-3a. D32180 Pressure 
RFP-3739

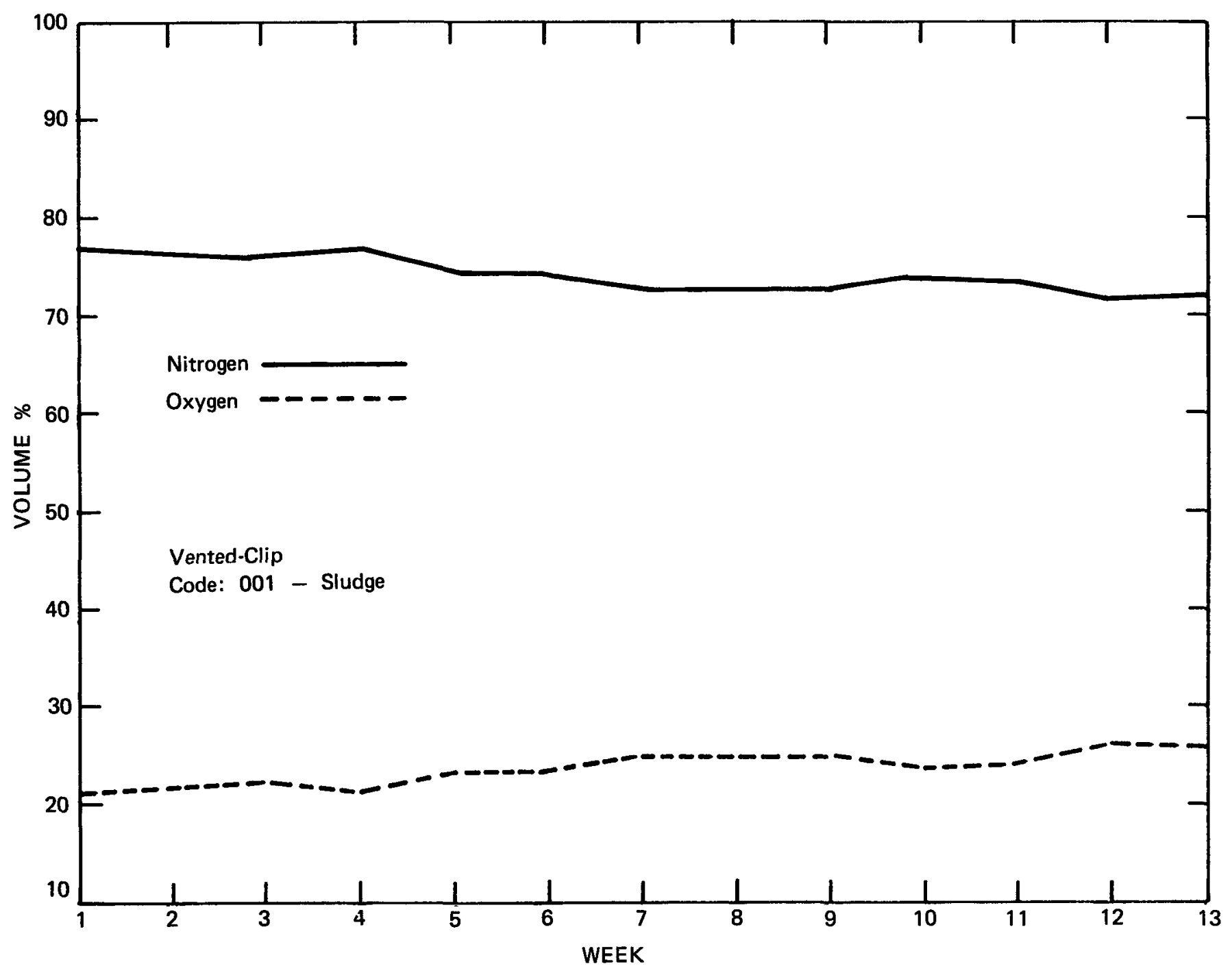

FIGURE A-3b. D32180 Atmosphere: Nitrogen, Oxygen 


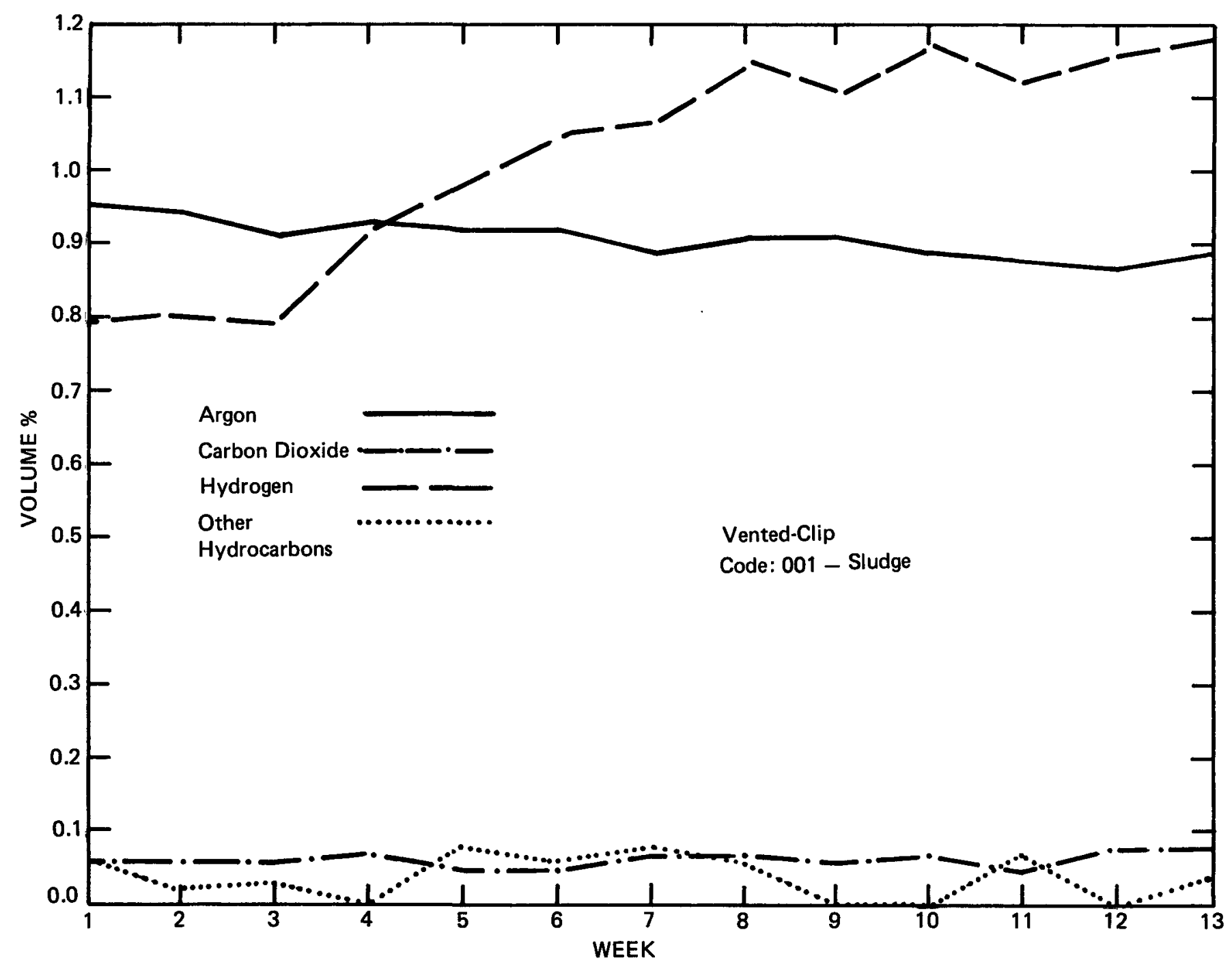

FIGURE A-3c. D32180 Atmosphere: Argon, Carbon Dioxide, Hydrogen, Other Hydrocarbons 
RFP-3739

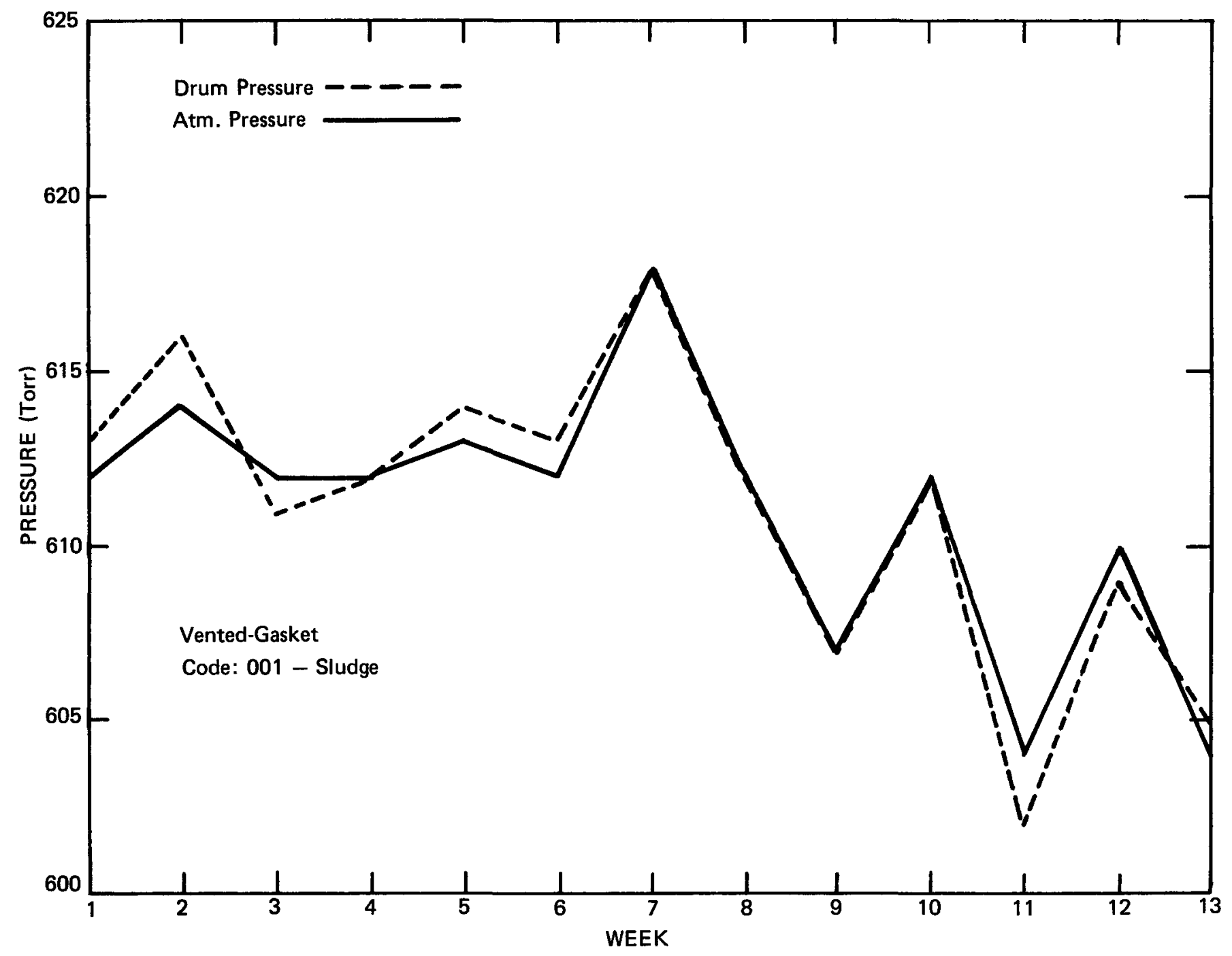

FIGURE A-4a. D32186 Pressure 


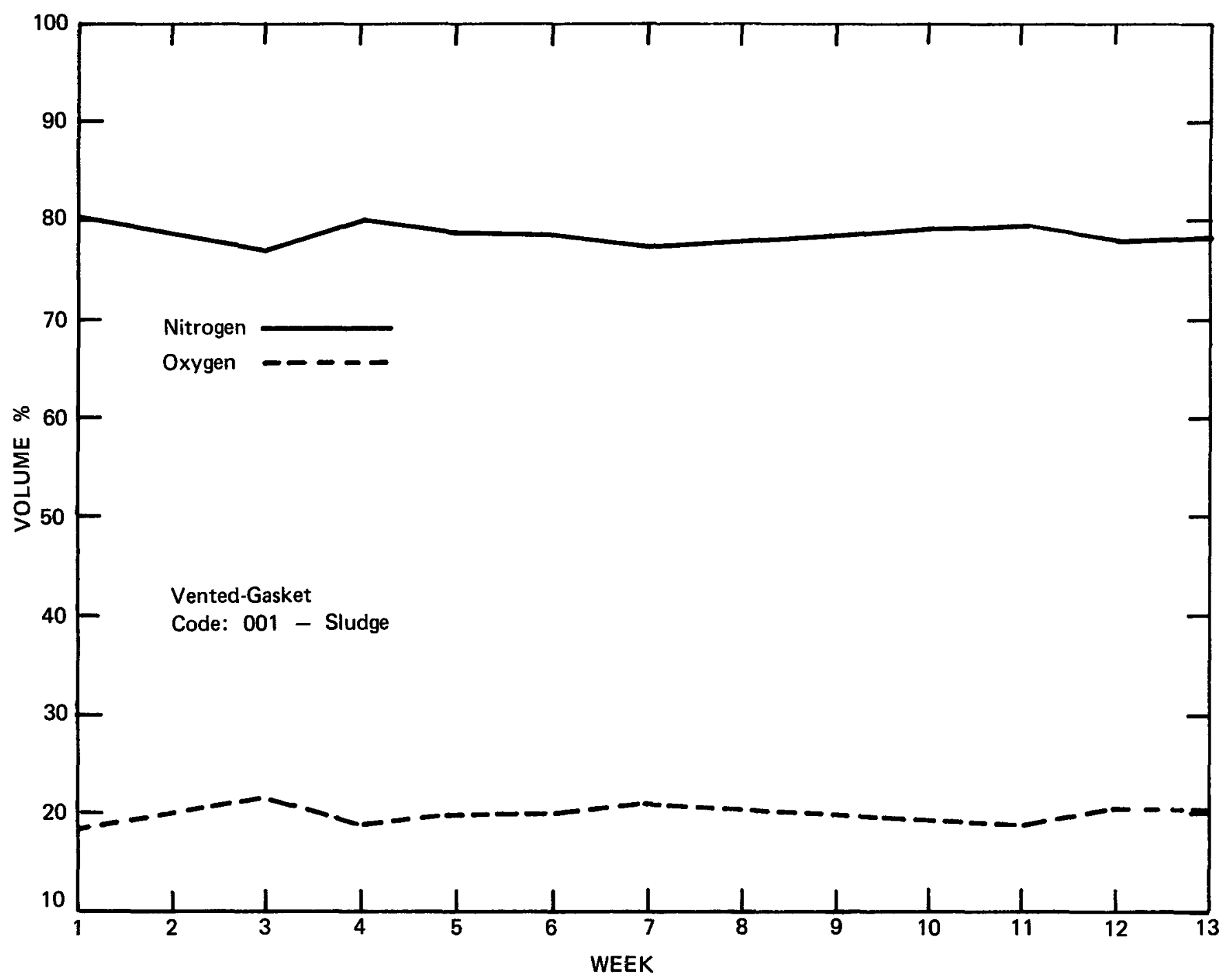

FIGURE A-4b. D32186 Atmosphere: Nitrogen, Oxygen 


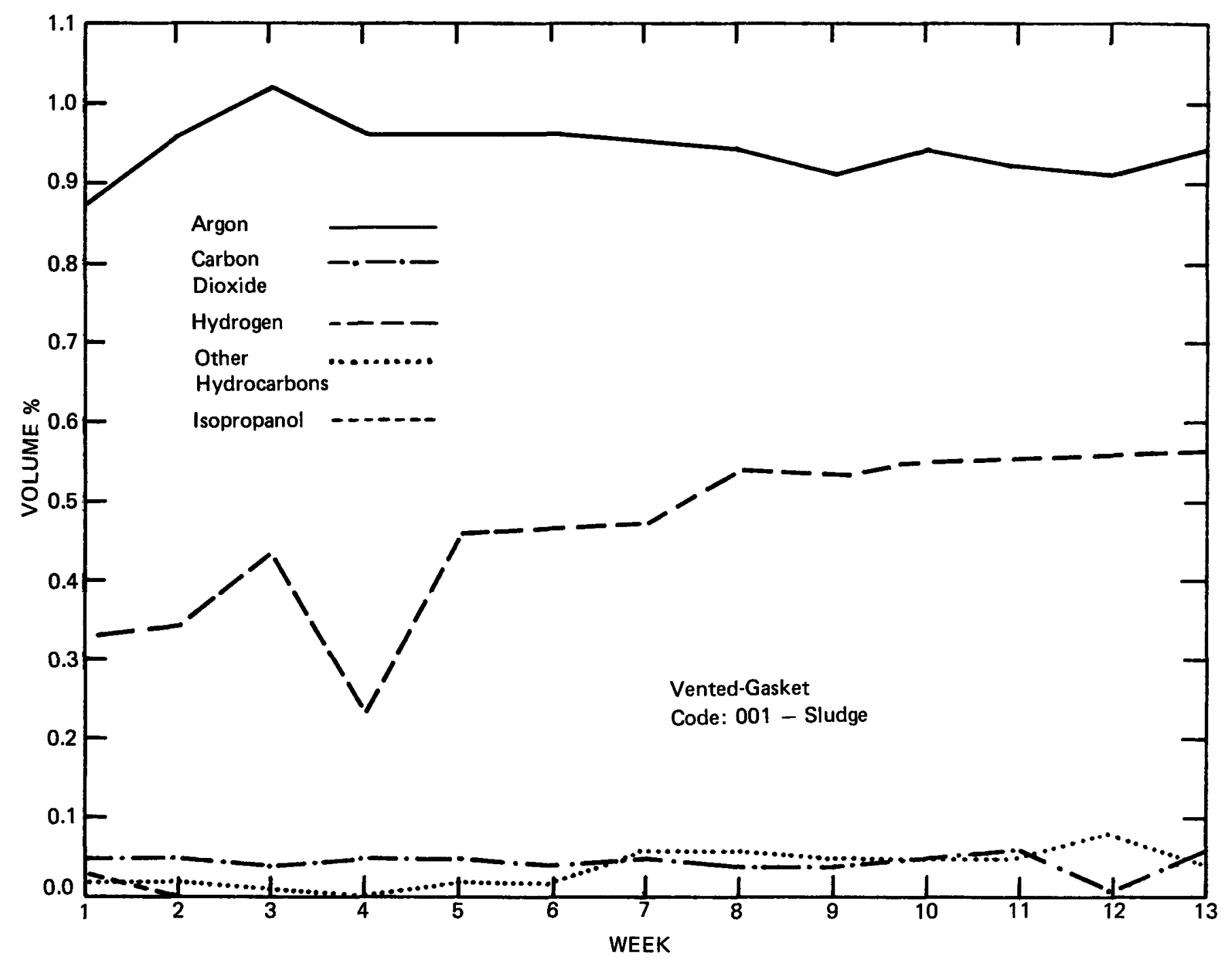

FIGURE A-4c. D32186 Atmosphere: Argon, Carbon Dioxide, Hydrogen, Other Hydrocarbons, Isopropanol 


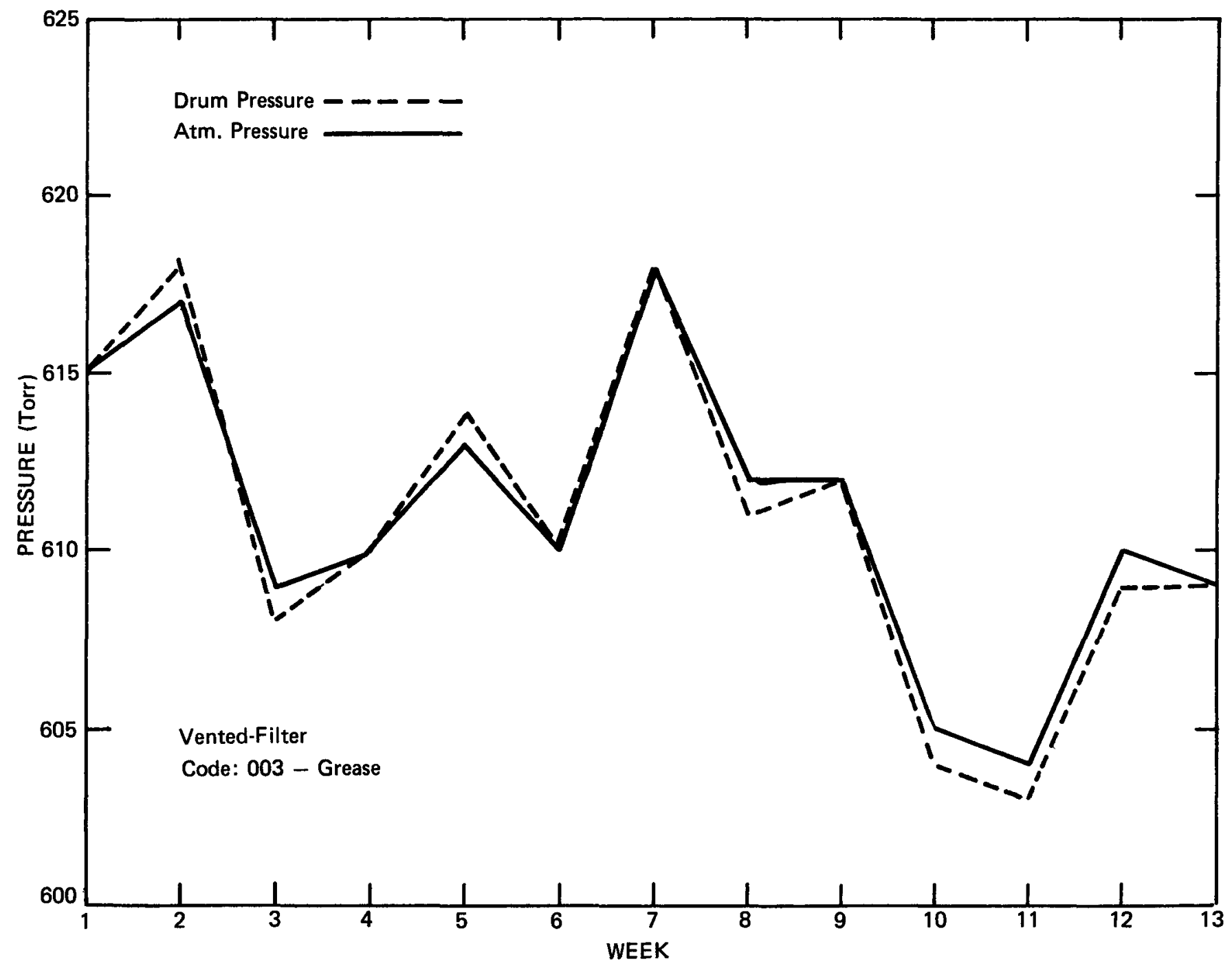

FIGURE A-5a. D31254 Pressure 


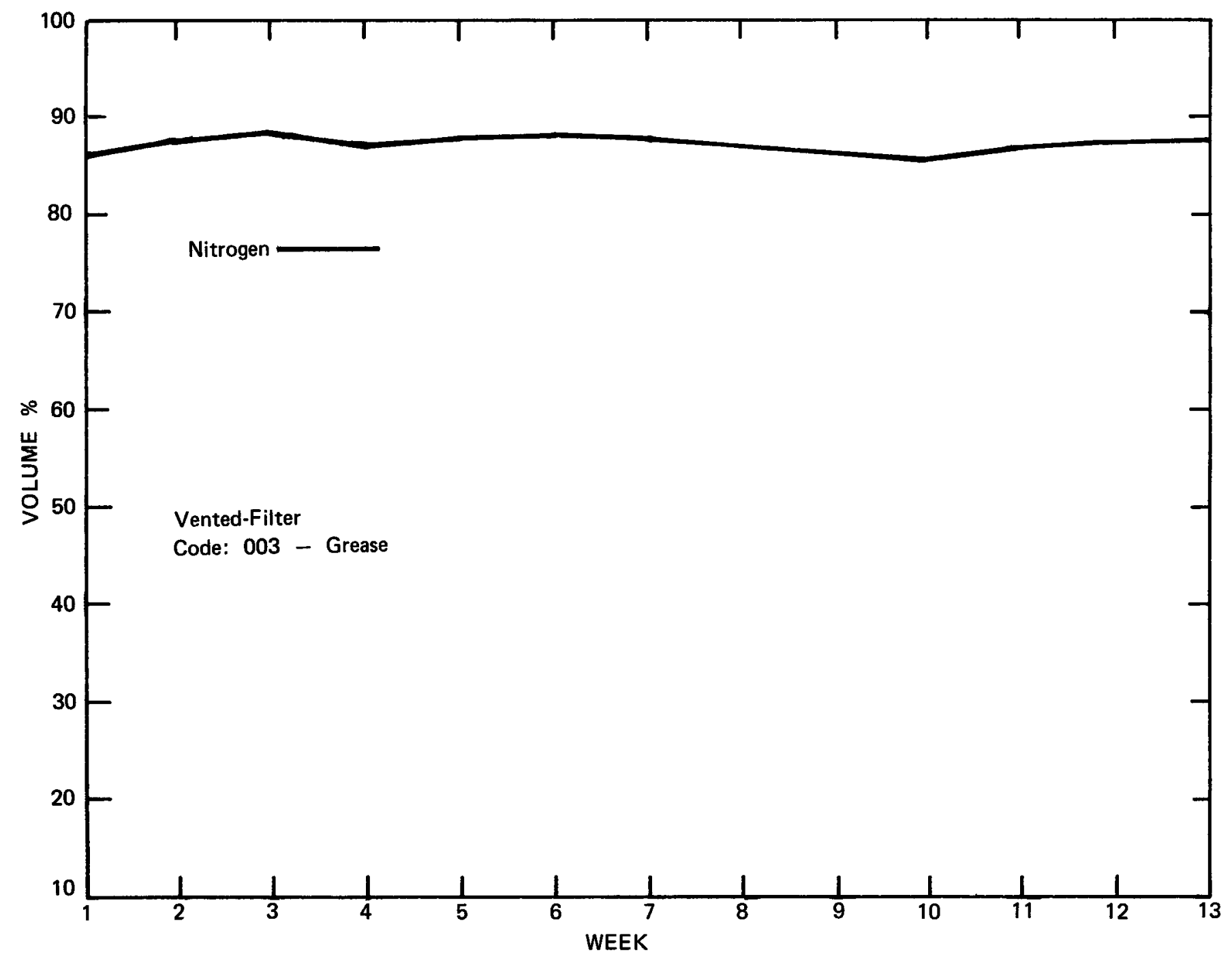

FIGURE A-5b. D31254 Atmosphere: Nitrogen 


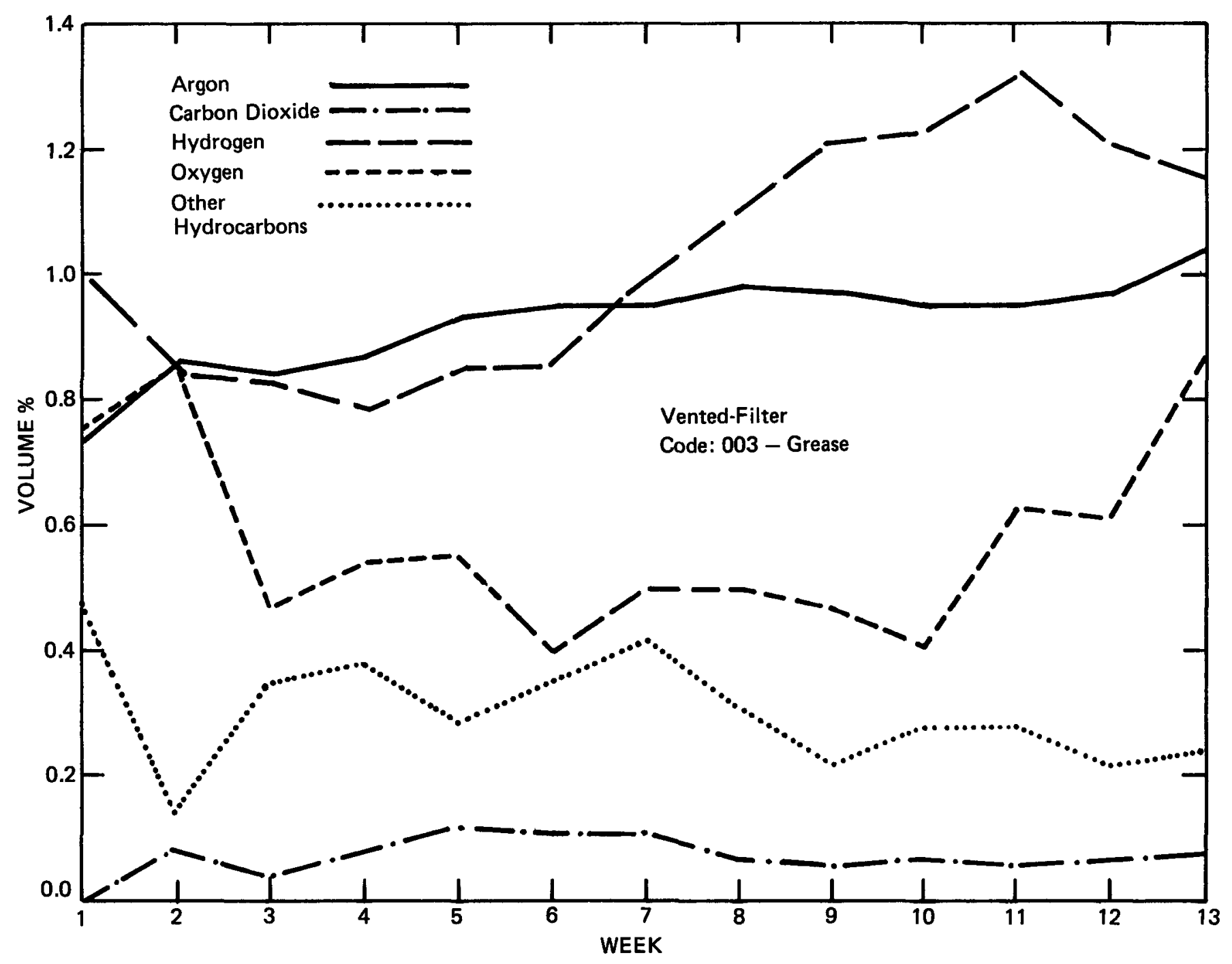

FIGURE A-5c. D31254 Atmosphere: Argon, Carbon Dioxide, Hydrogen, Oxygen, Other Hydrocarbons 


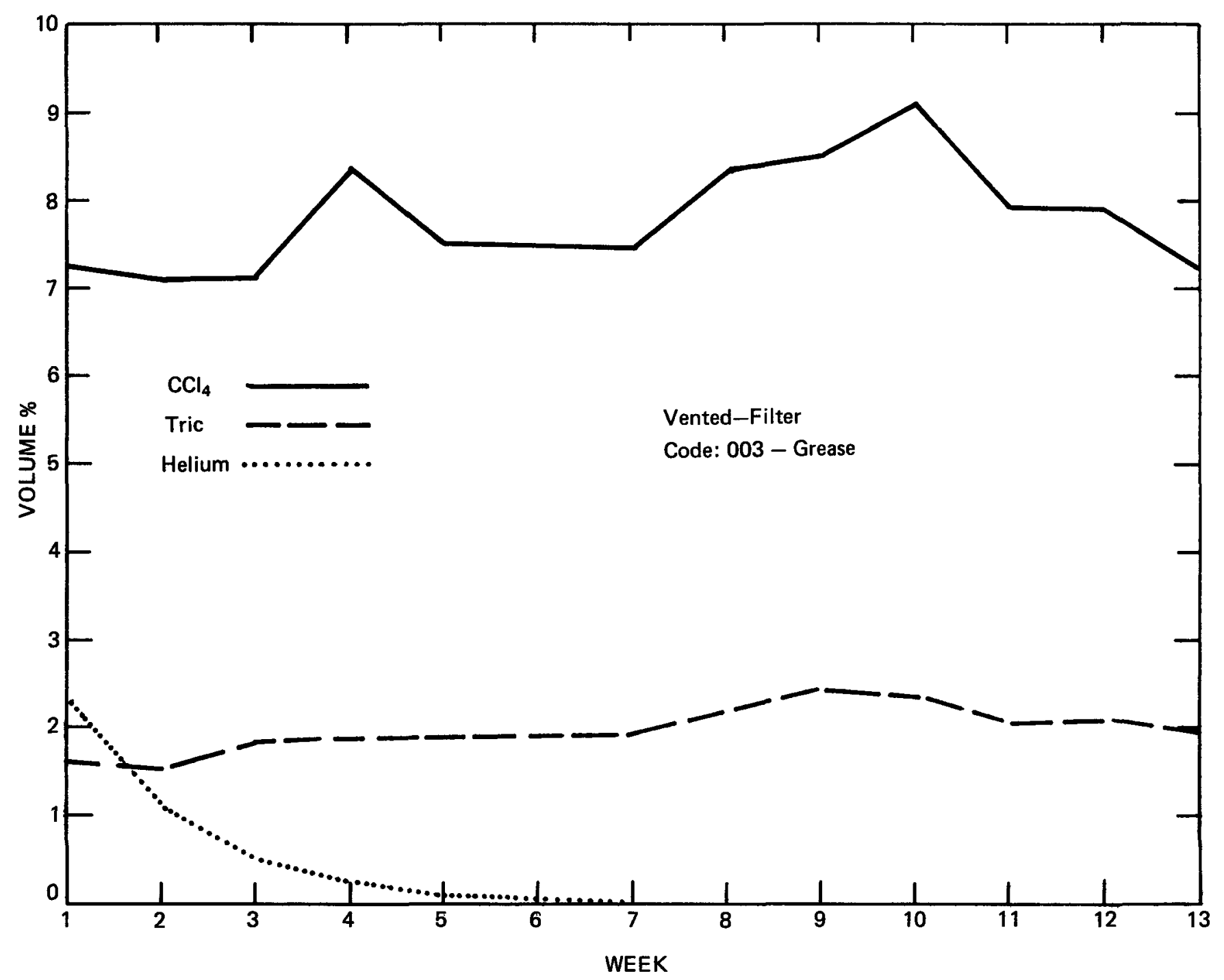

FIGURE A-5d. D31254 Atmosphere: $\mathrm{CCl}_{4}$, Tric, Helium 


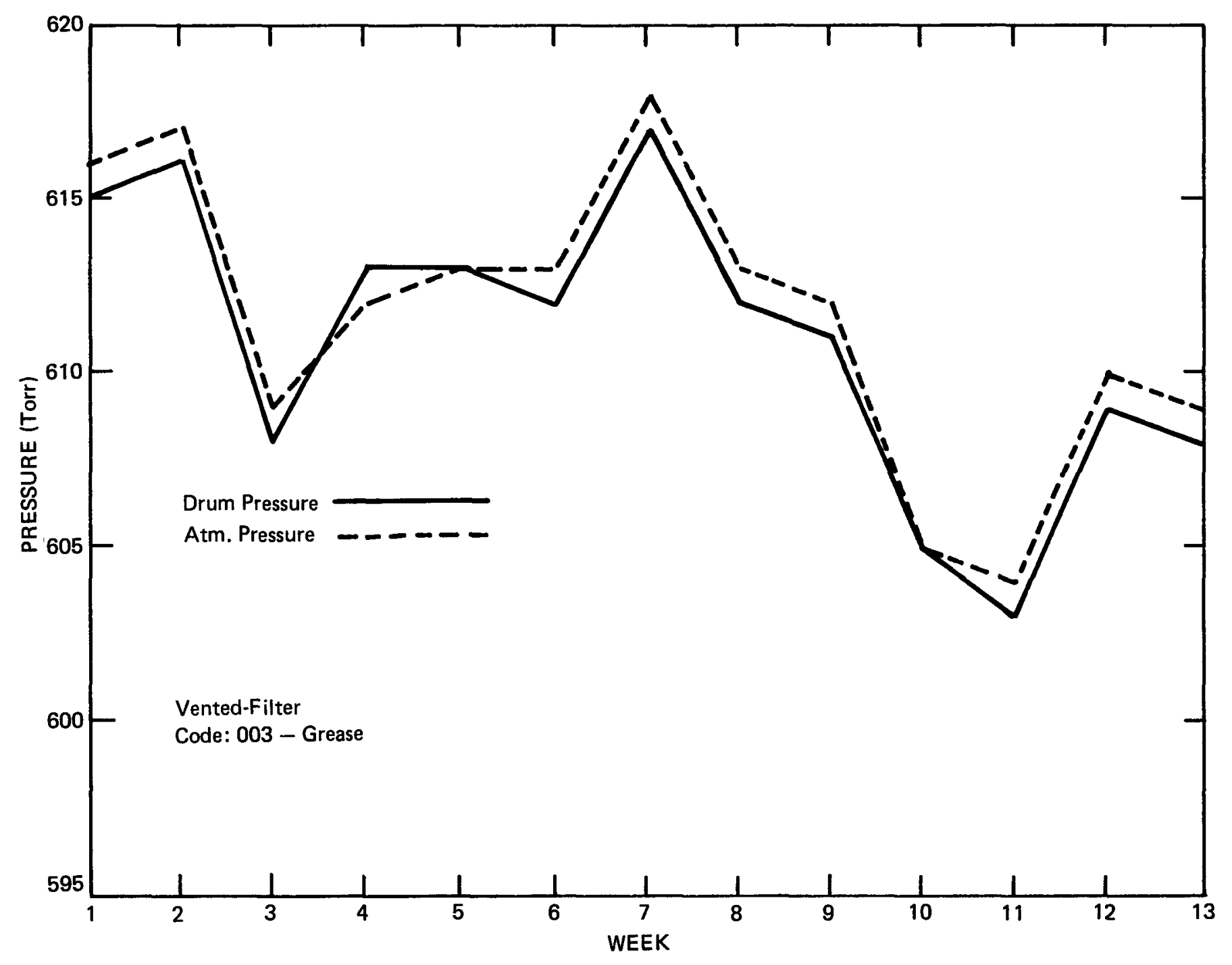

FIGURE A-6a. D31403 Pressure 
RFP-3739

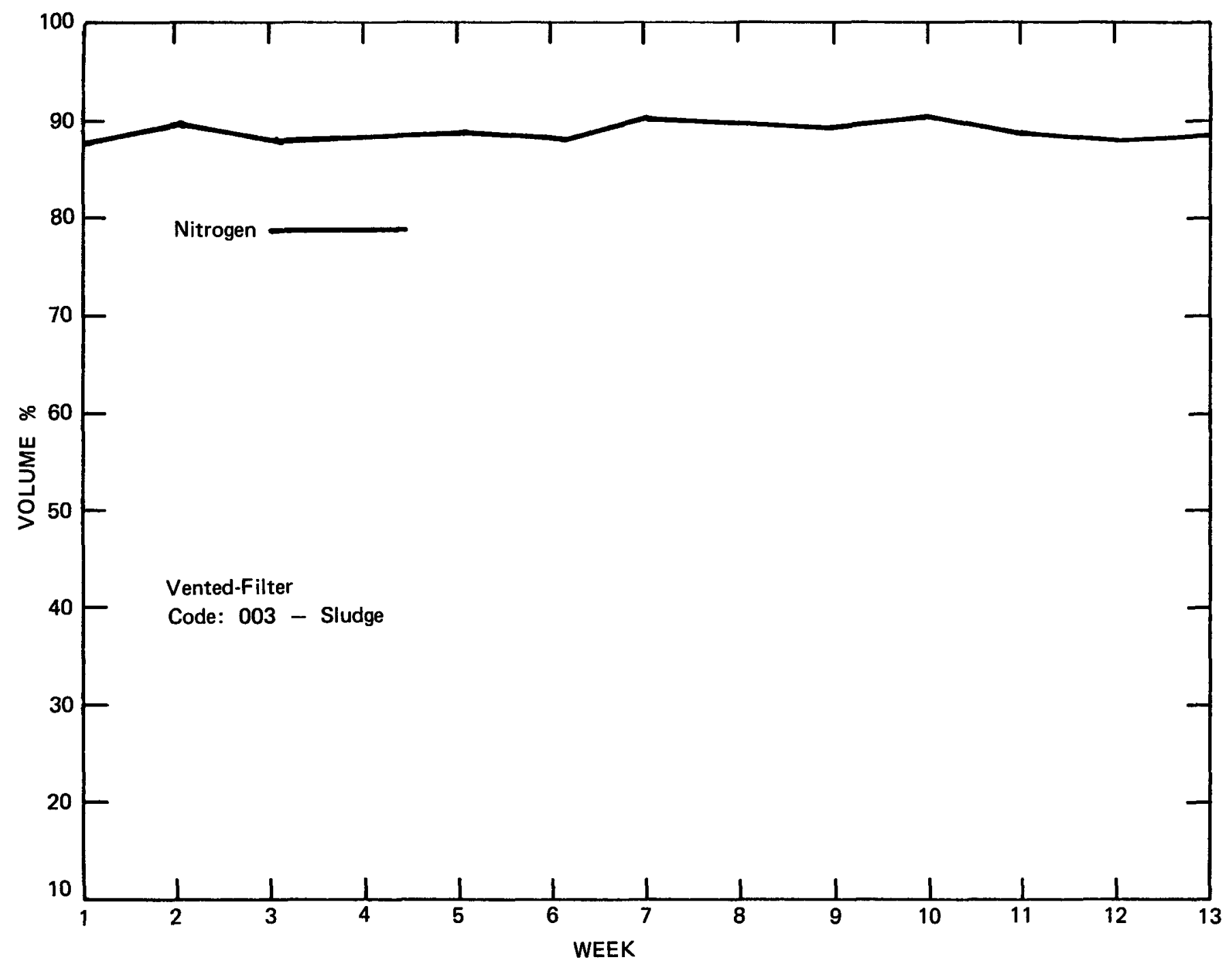

FIGURE A-6b. D31403 Atmosphere: Nitrogen 


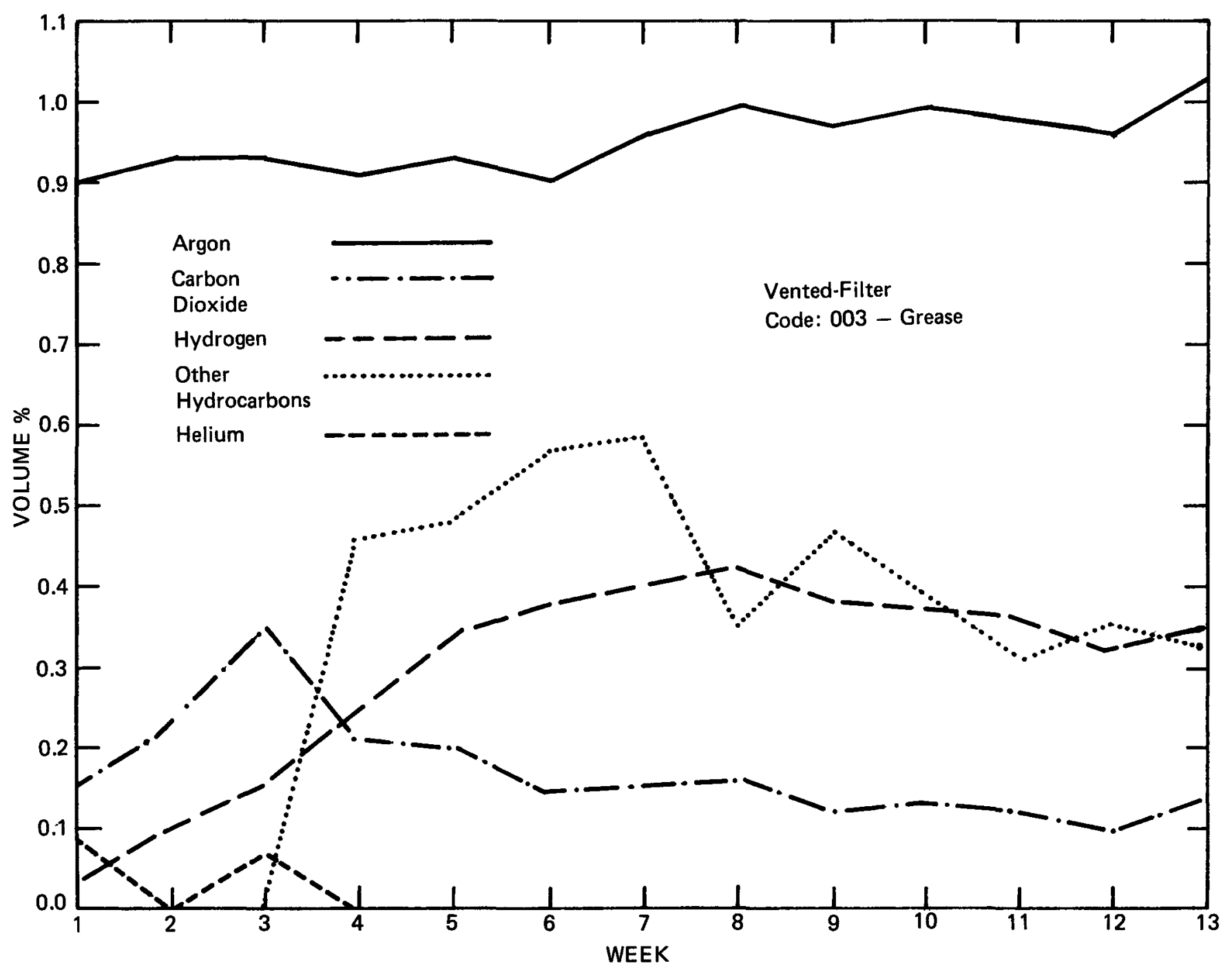

FIGURE A-6c. D31403 Atmosphere: Argon, Carbon Dioxide, Hydrogen, Other Hydrocarbons, Helium 


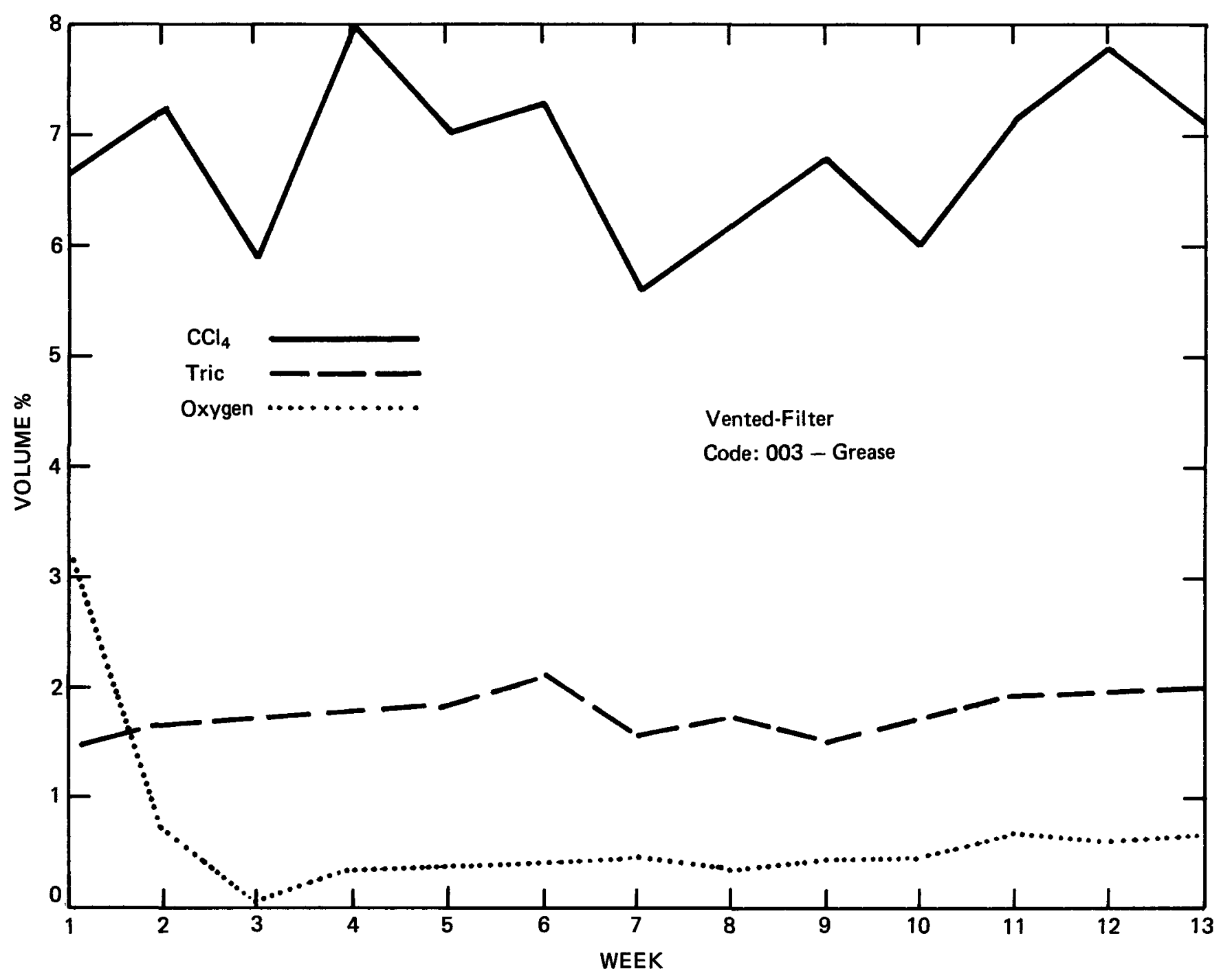

FIGURE A-6d. D31403 Atmosphere: $\mathrm{CCl}_{4}$, Tric, Oxygen 


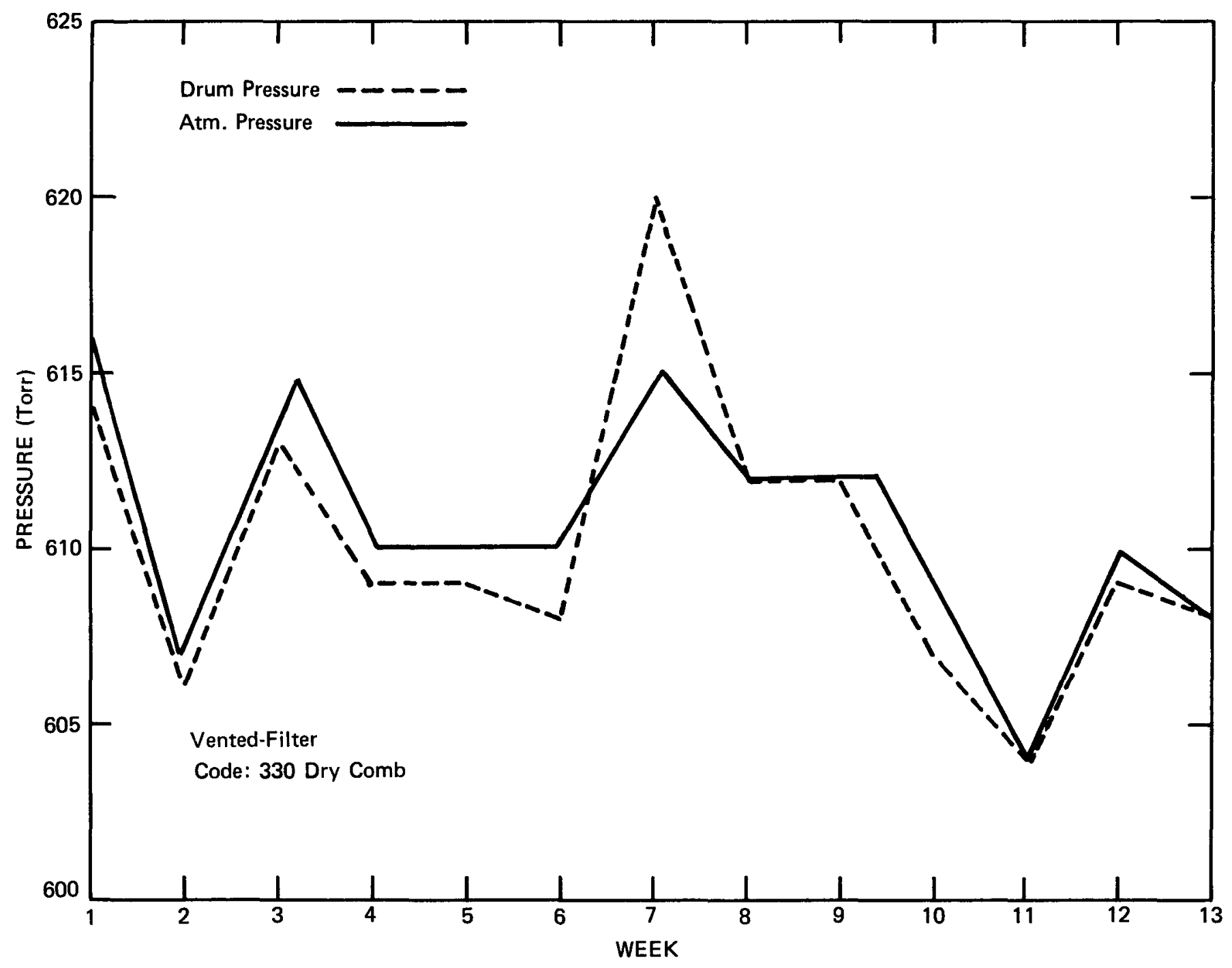

FIGURE A-7a. D24545 Pressure 


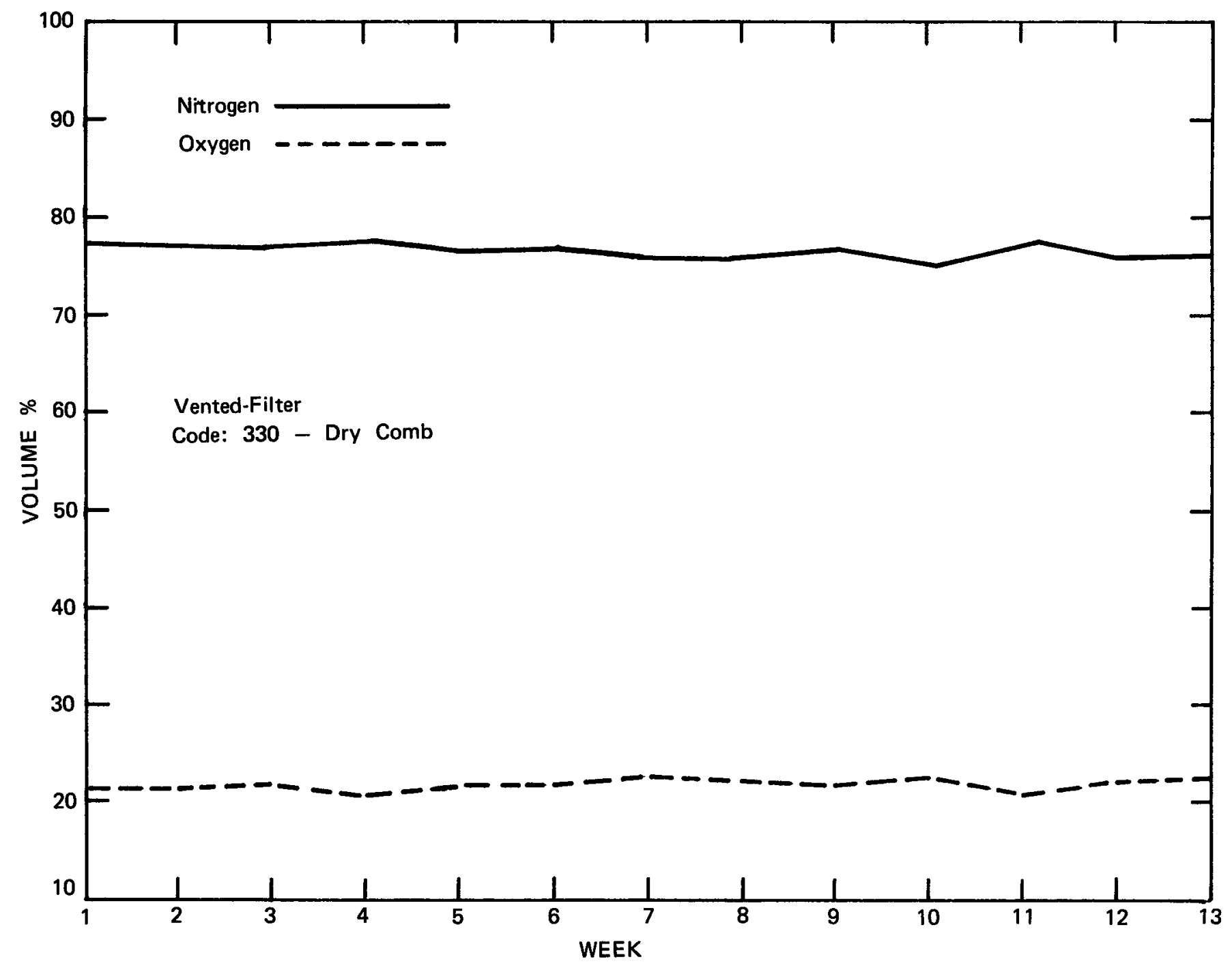

FIGURE A-7b. D24545 Atmosphere: Nitrogen, Oxygen 


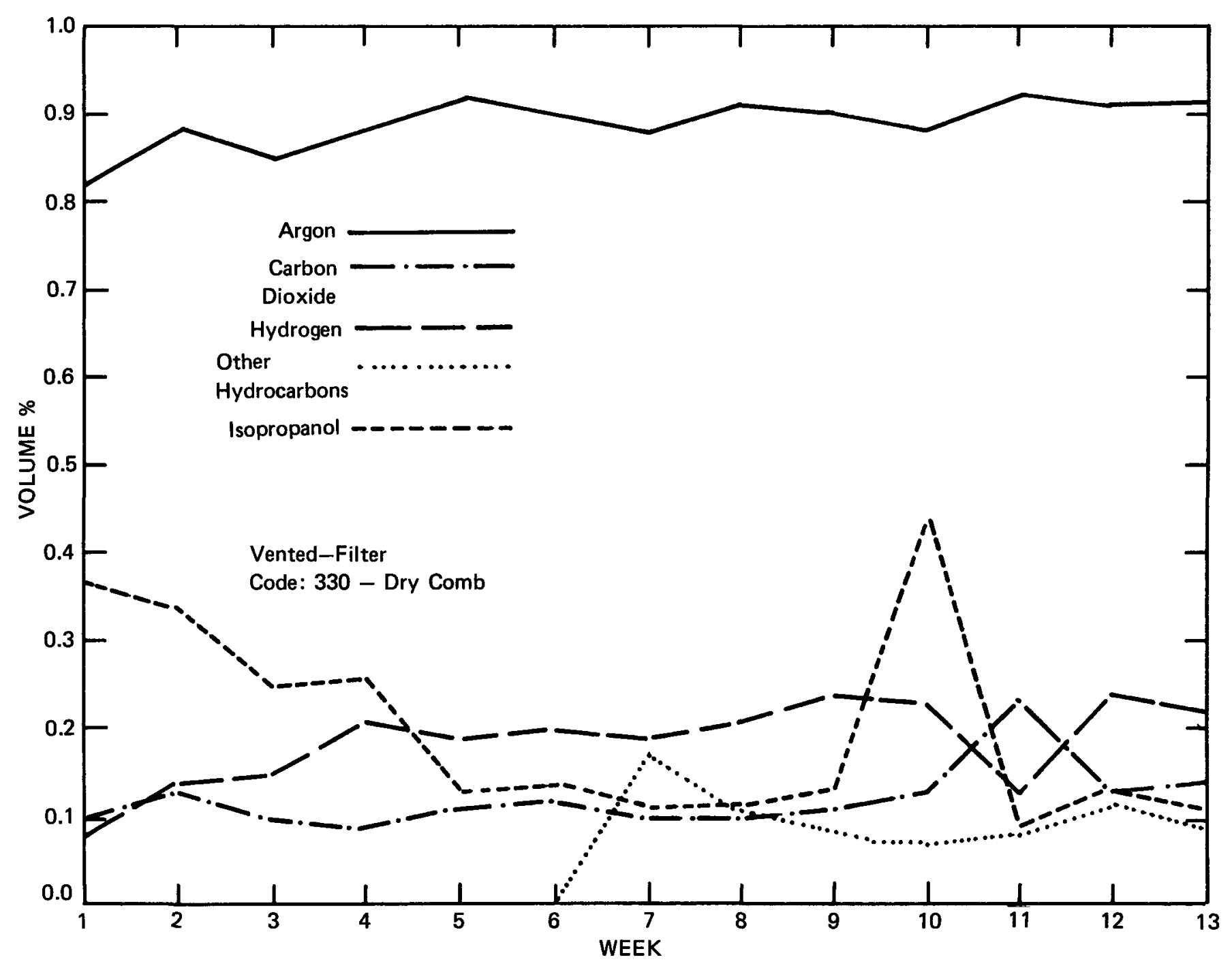

FIGURE A-7c. D24545 Atmosphere: Argon, Carbon Dioxide, Hydrogen, Other Hydrocarbons, Isopropanol 


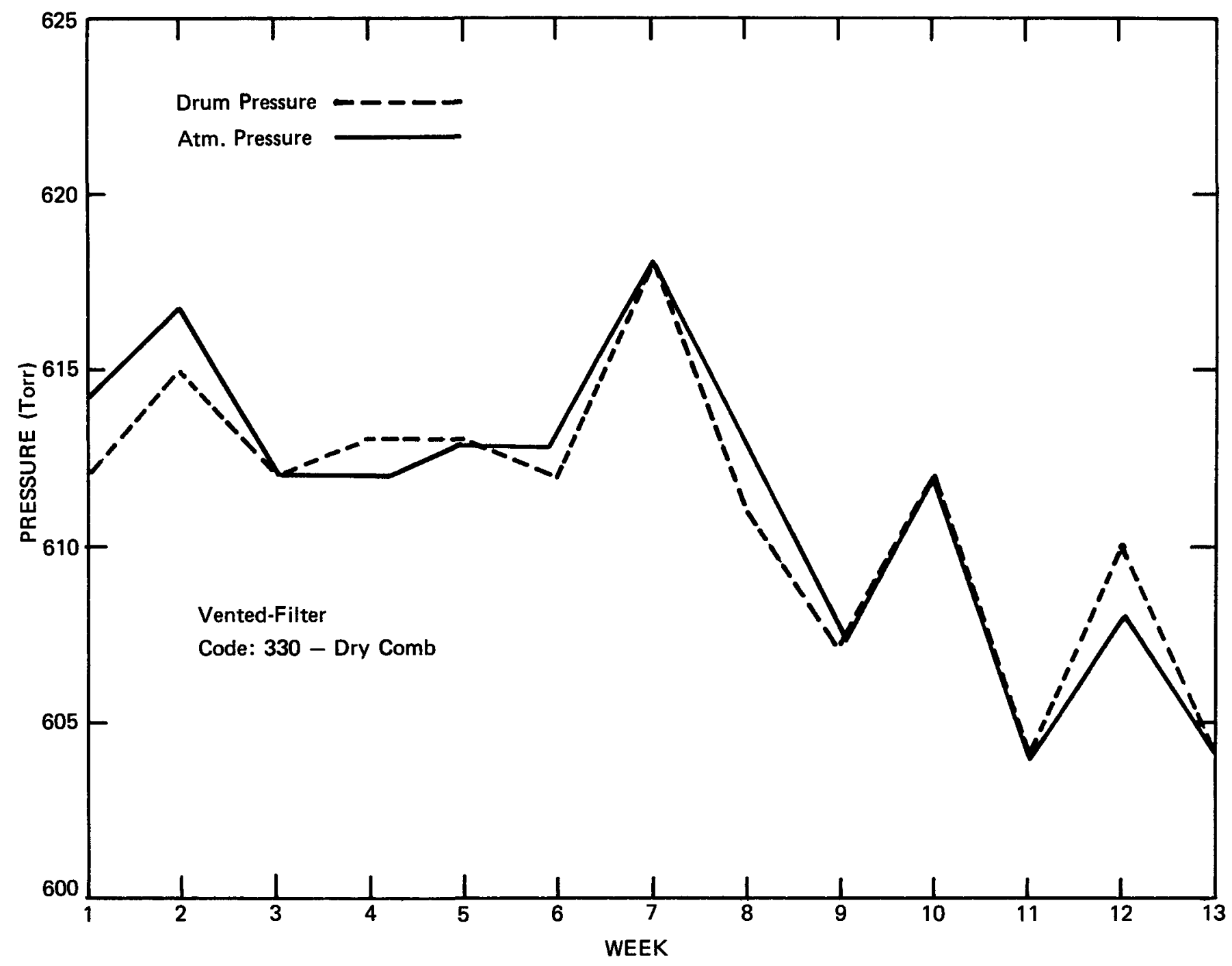

FIGURE A-8a. D31042 Pressure 


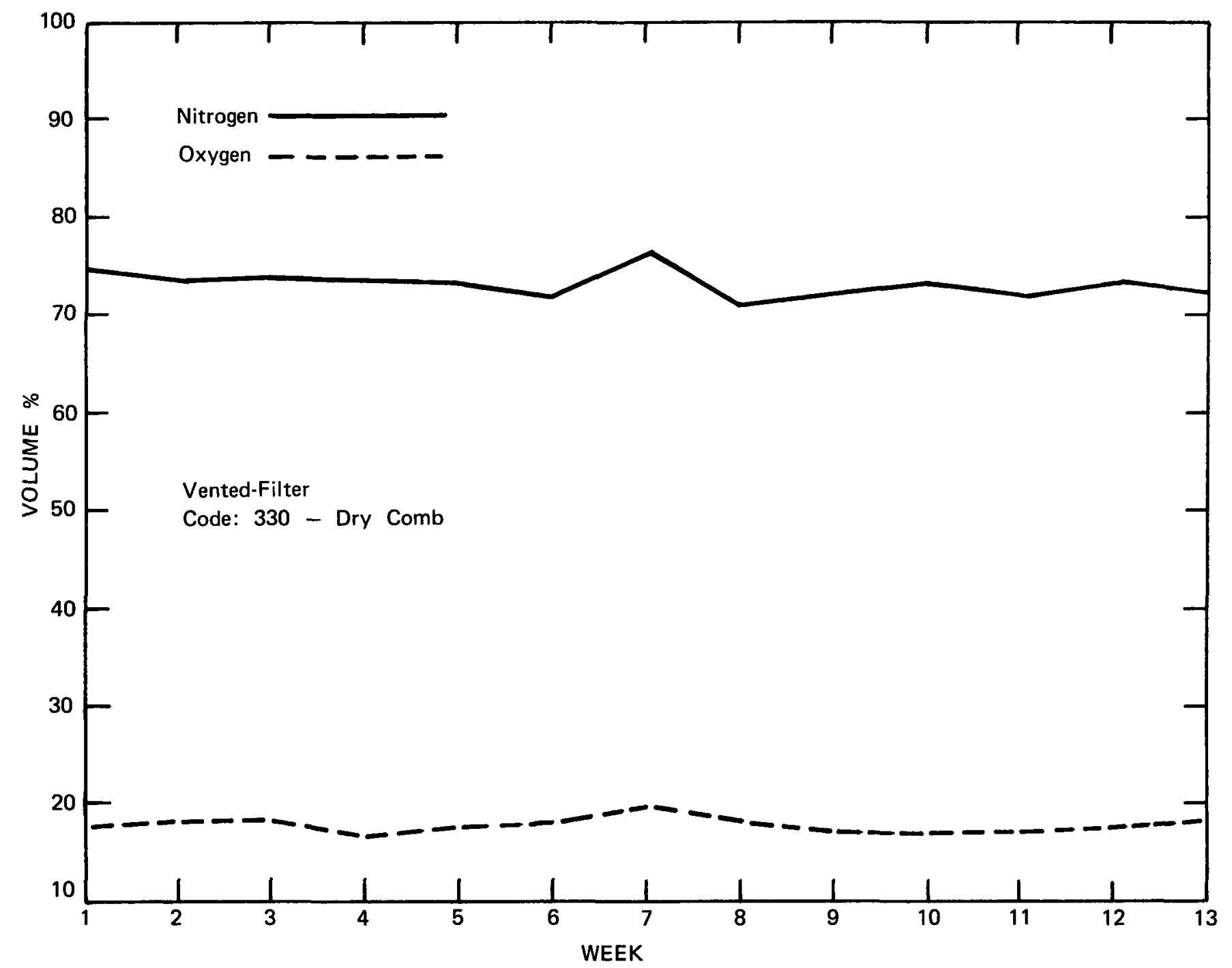

FIGURE A-8b. D31042 Atmosphere: Nitrogen, Oxygen 


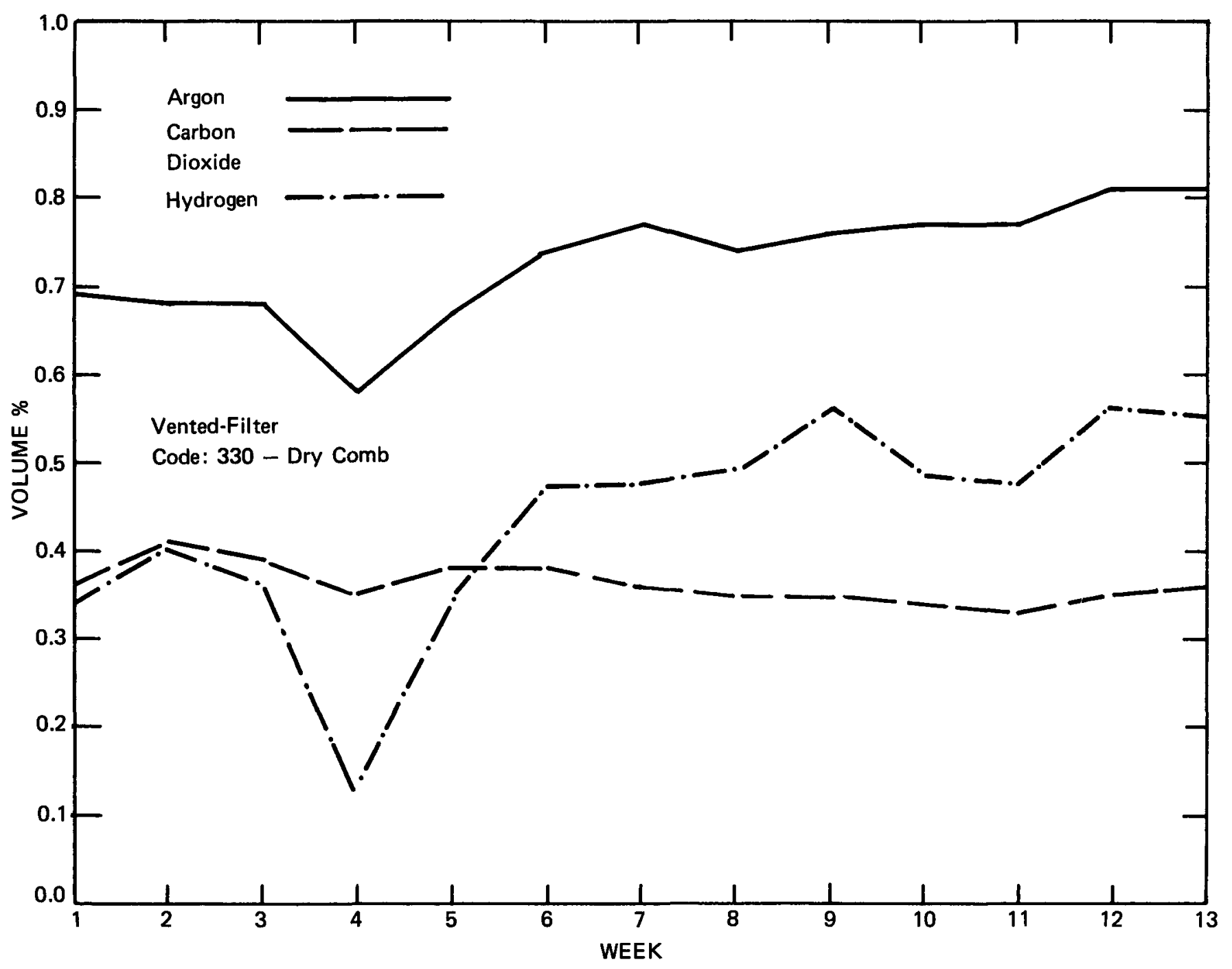

FIGURE A-8c. D31042 Atmosphere: Argon, Carbon Dioxide, Hydrogen 


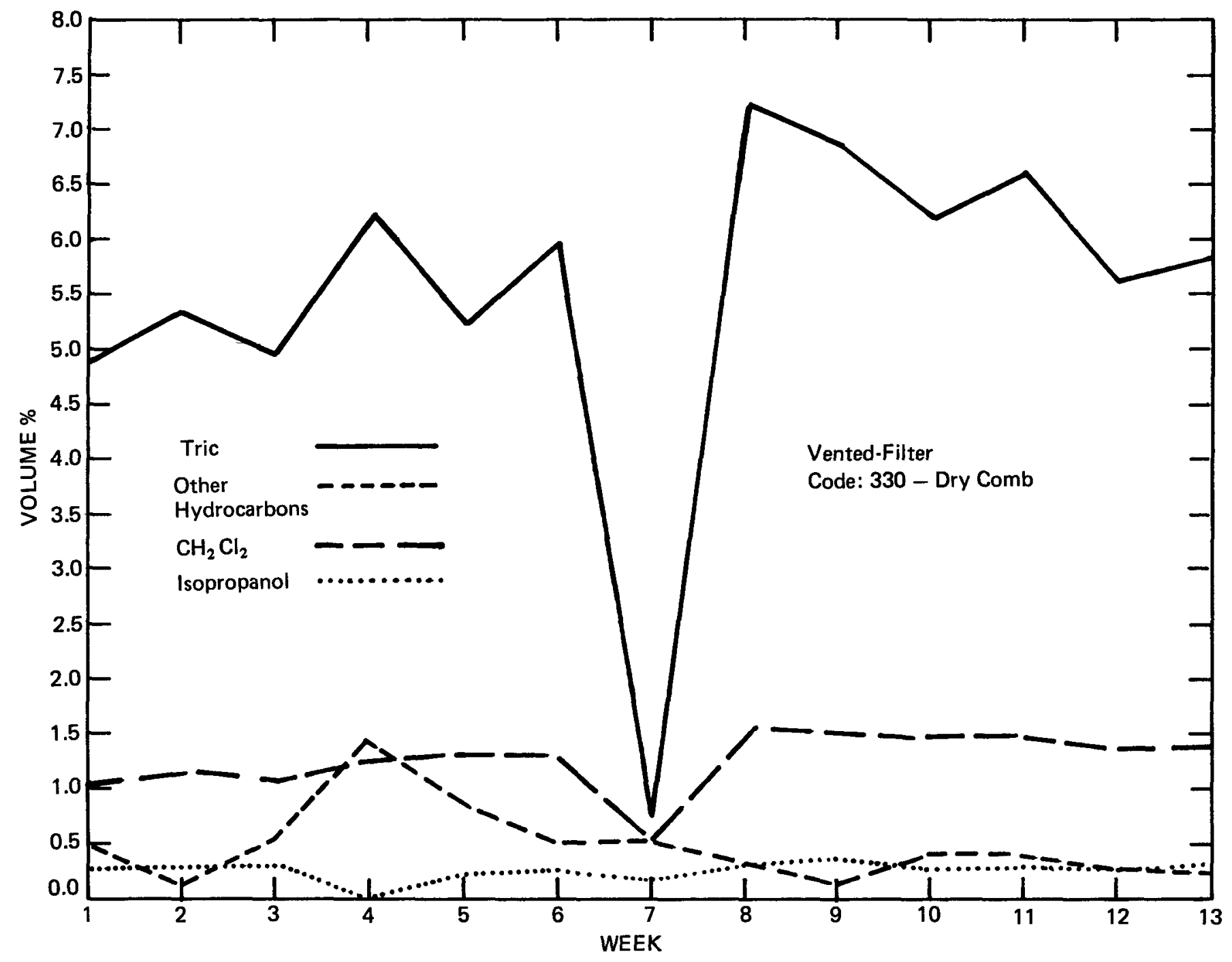

FIGURE A-8d. D31042 Atmosphere: Tric, Other Hydrocarbons, $\mathrm{CH}_{2} \mathrm{Cl}_{2}$, Isopropanol 


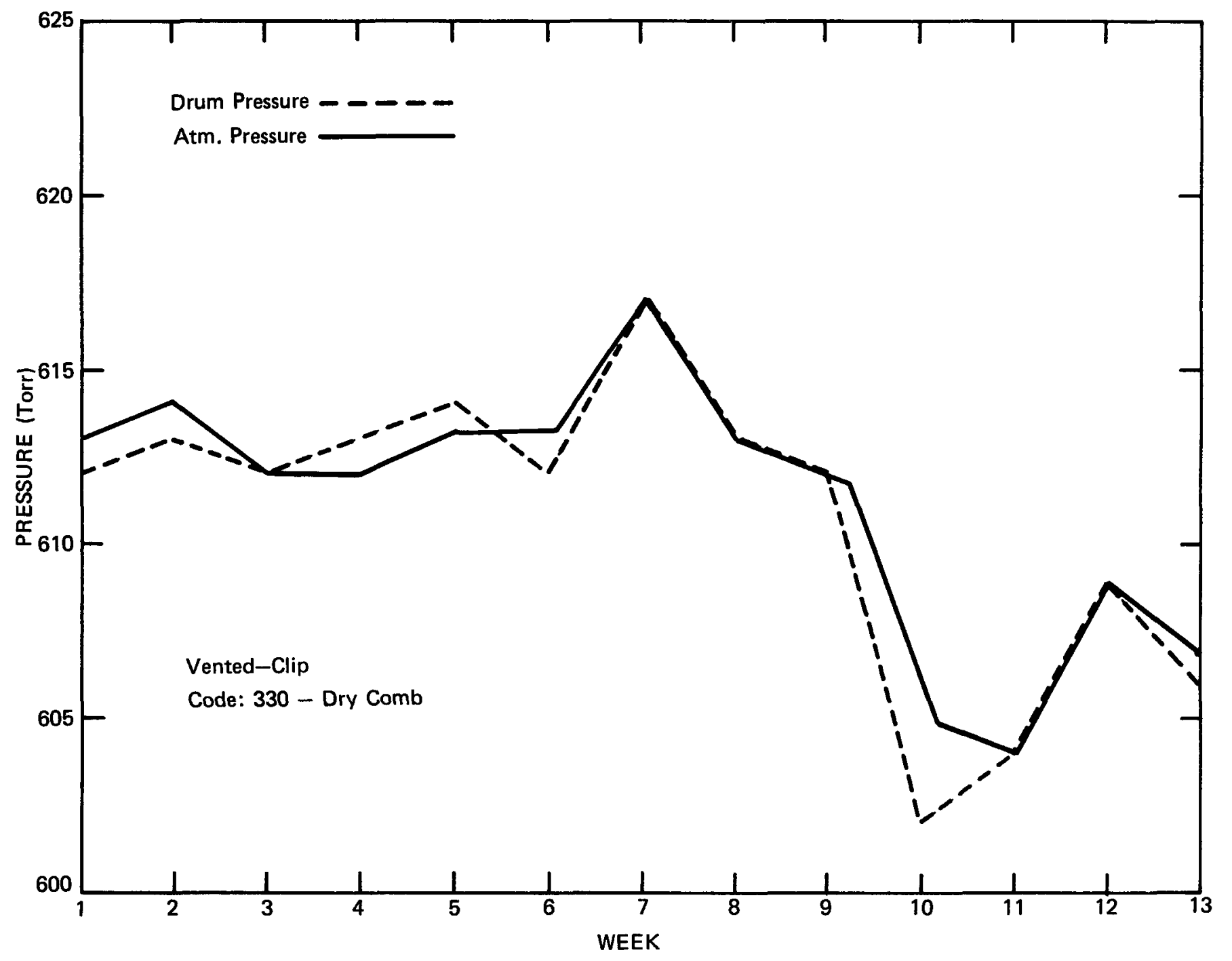

FIGURE A-9a. D26048 Pressure 


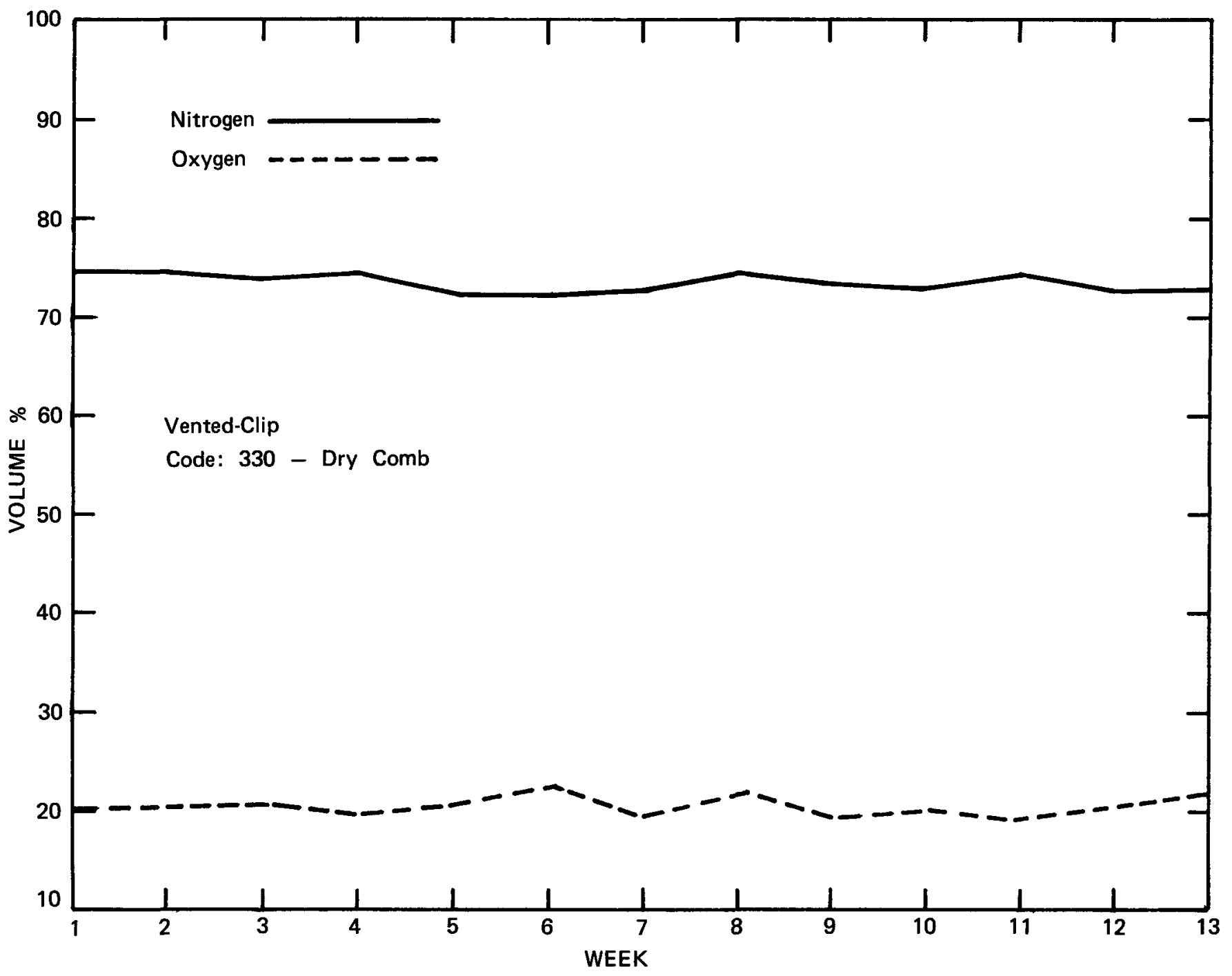

FIGURE A-9b. D26048 Atmosphere: Nitrogen, Oxygen 
RFP-3739

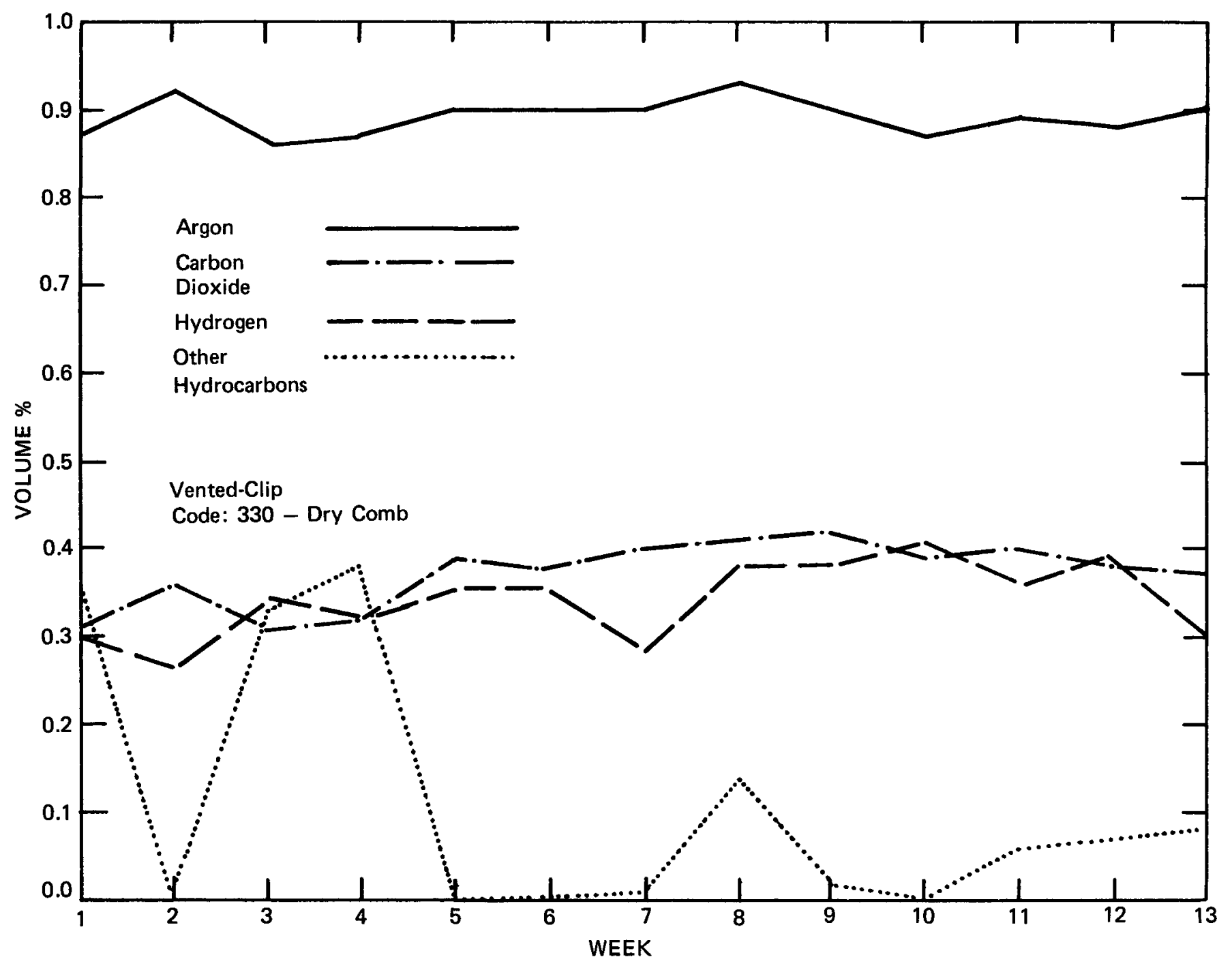

FIGURE A-9c. D26048 Atmosphere: Argon, Carbon Dioxide, Hydrogen, Other Hydrocarbons 


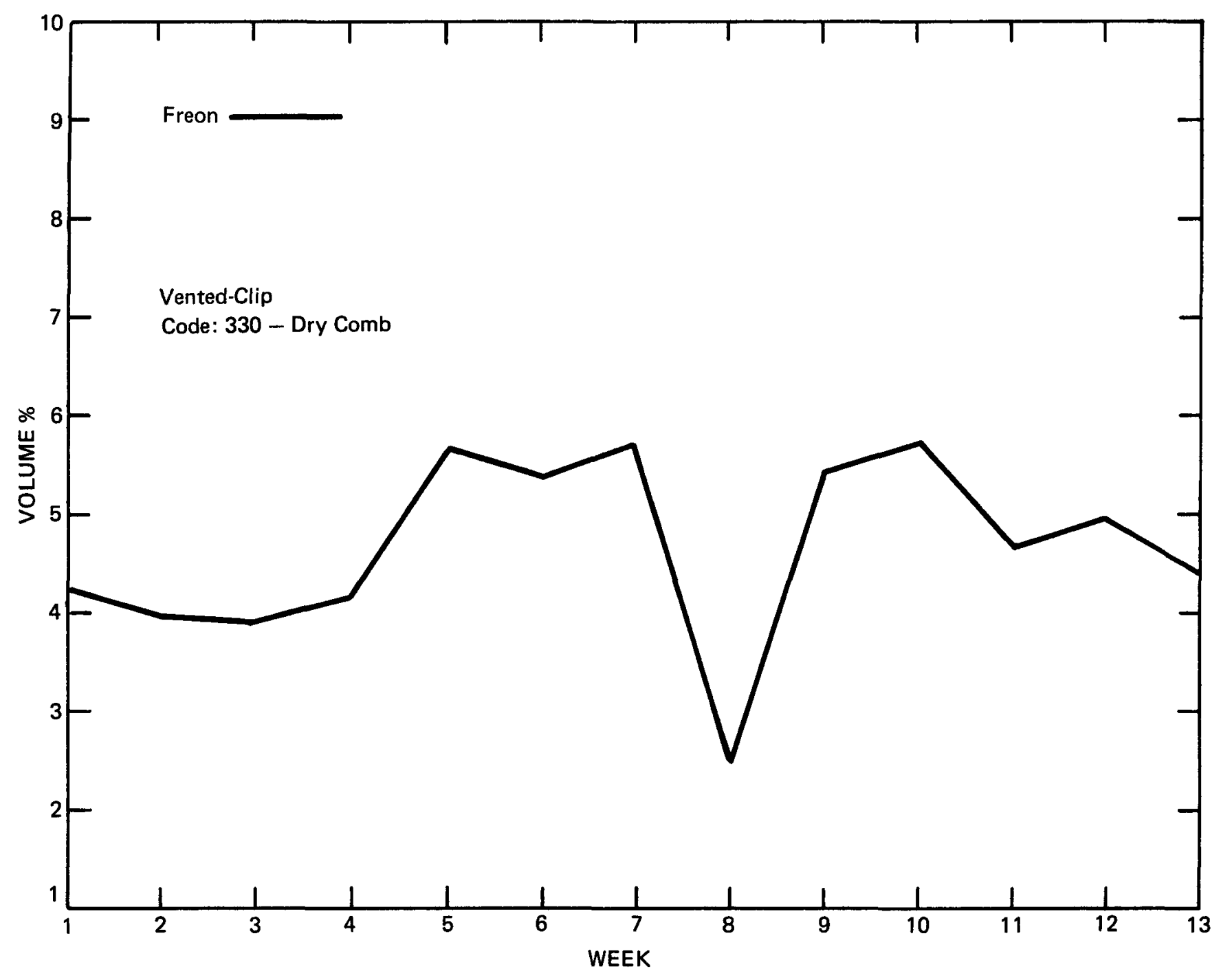

FIGURE A-9d. D26048 Atmosphere: Freon 


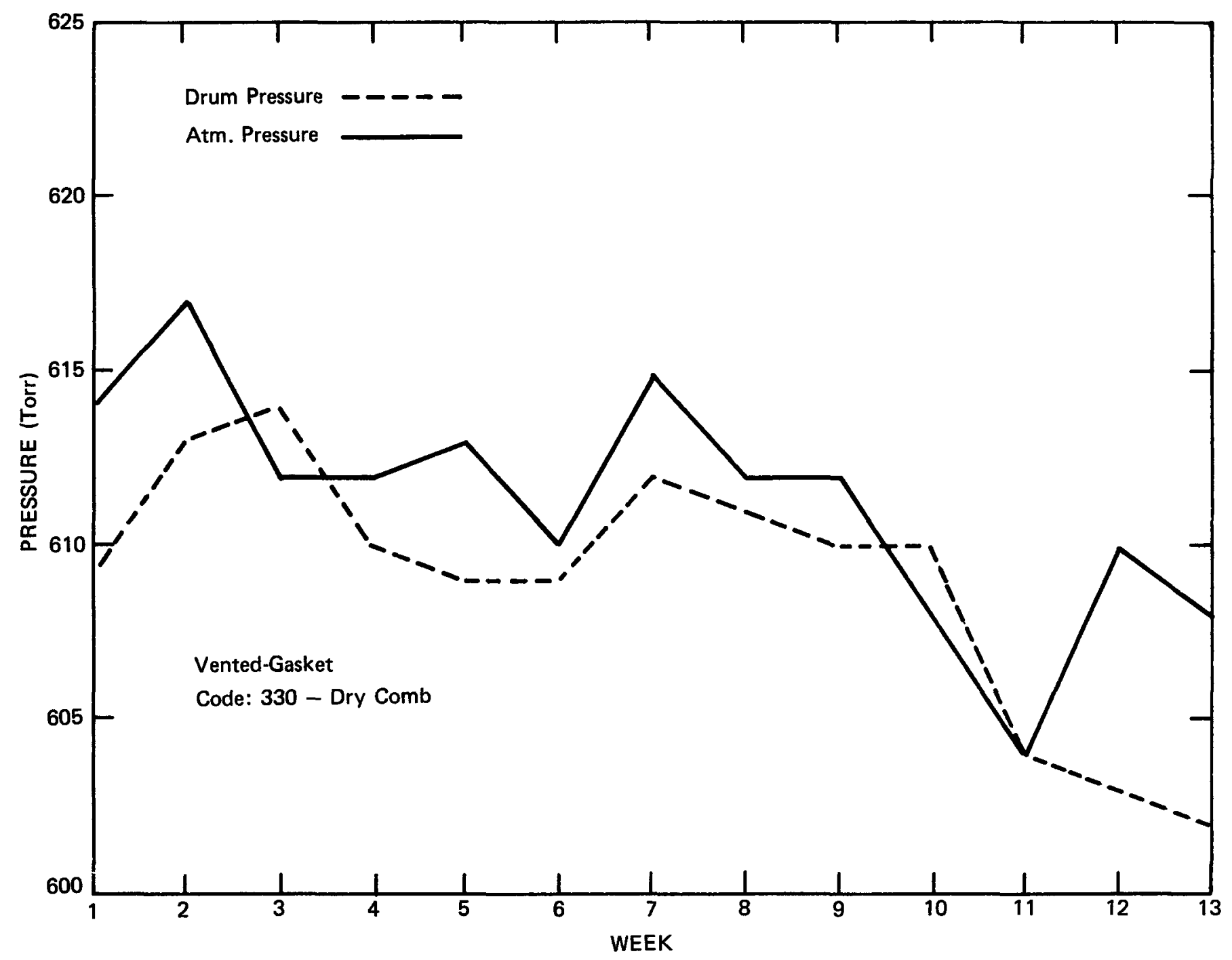

FIGURE A-10a. D31703 Pressure 


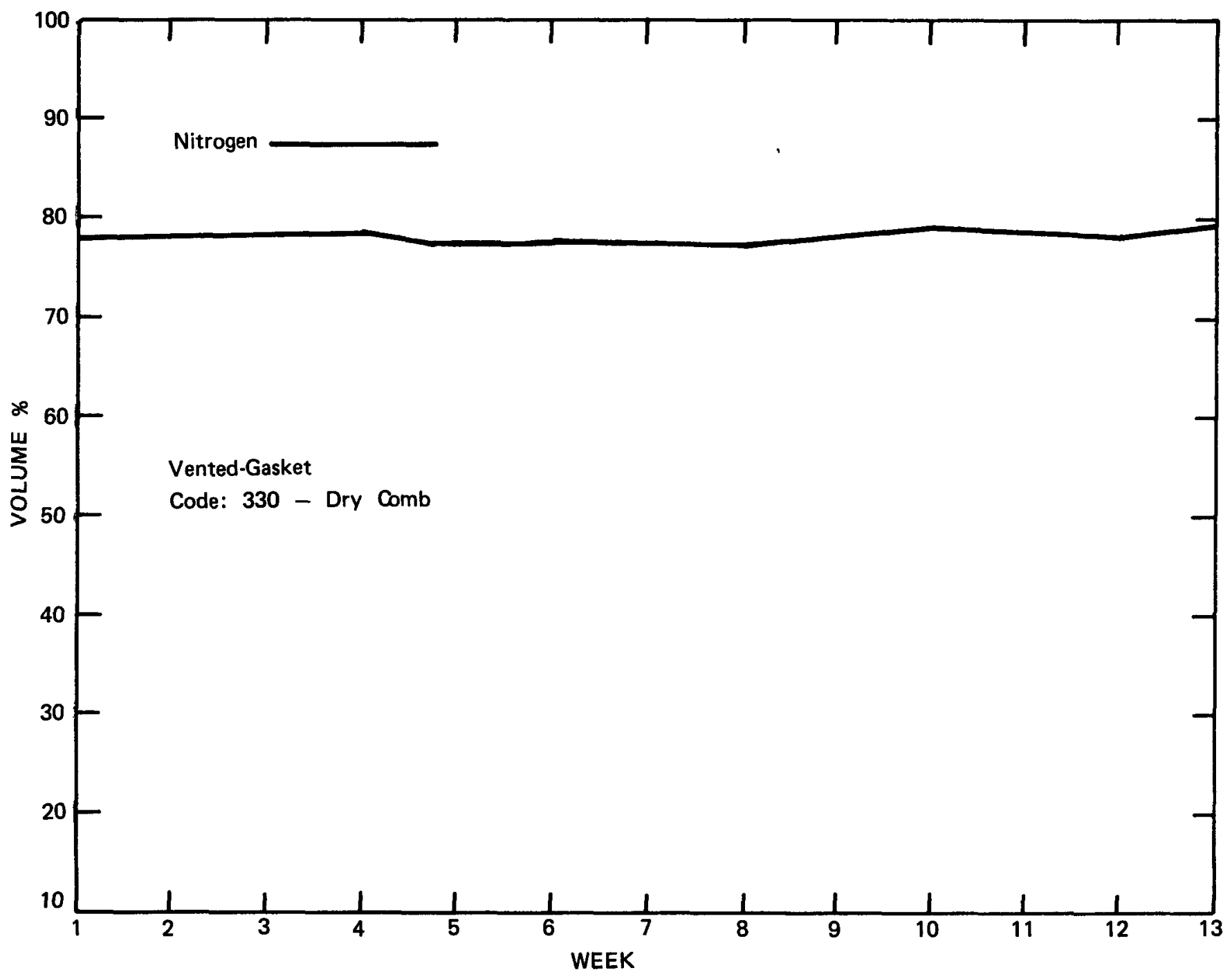

FIGURE A-10b. D31703 Atmosphere: Nitrogen 


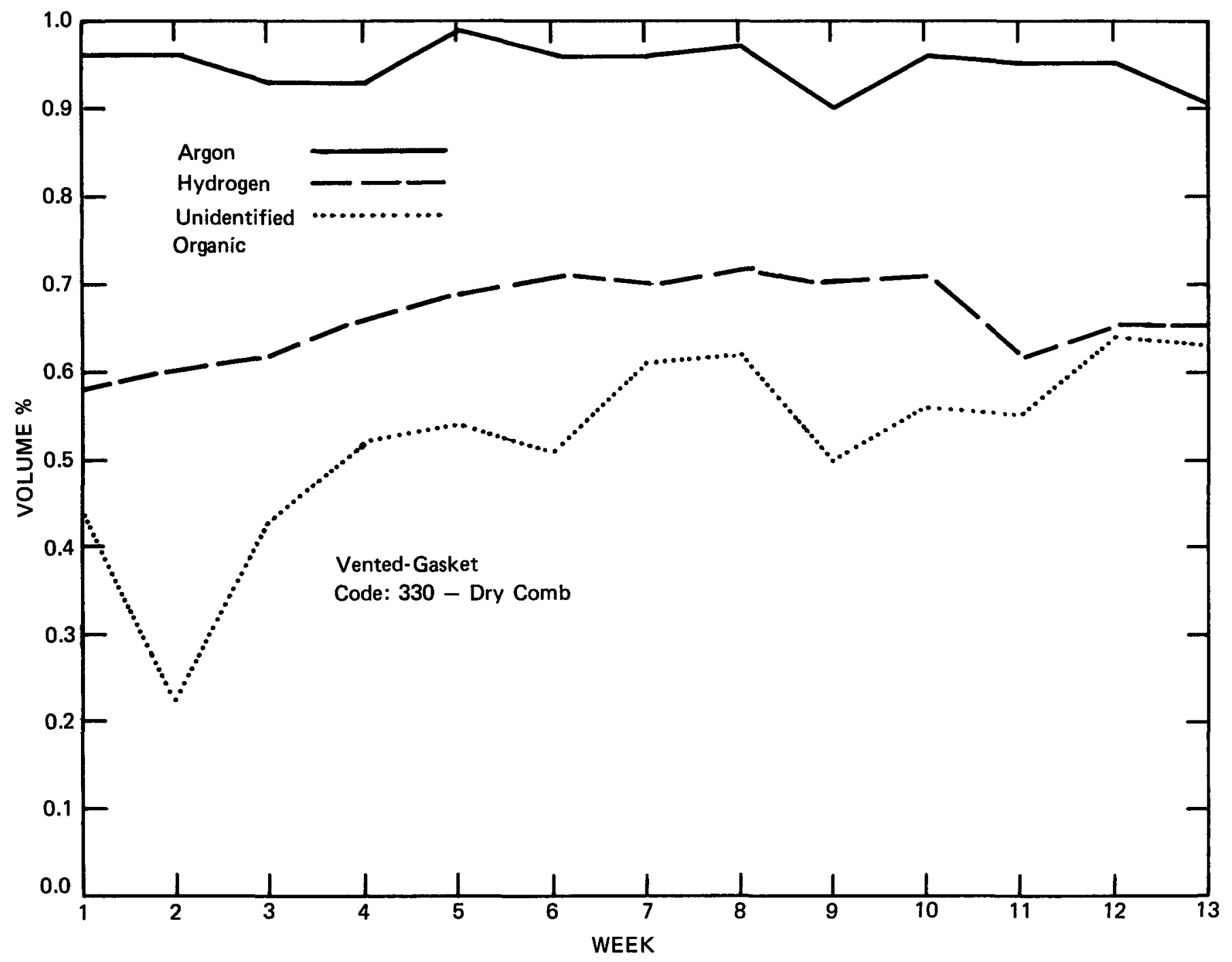

FIGURE A-10c. D31703 Atmosphere: Argon, Hydrogen, Unidentified Organic 


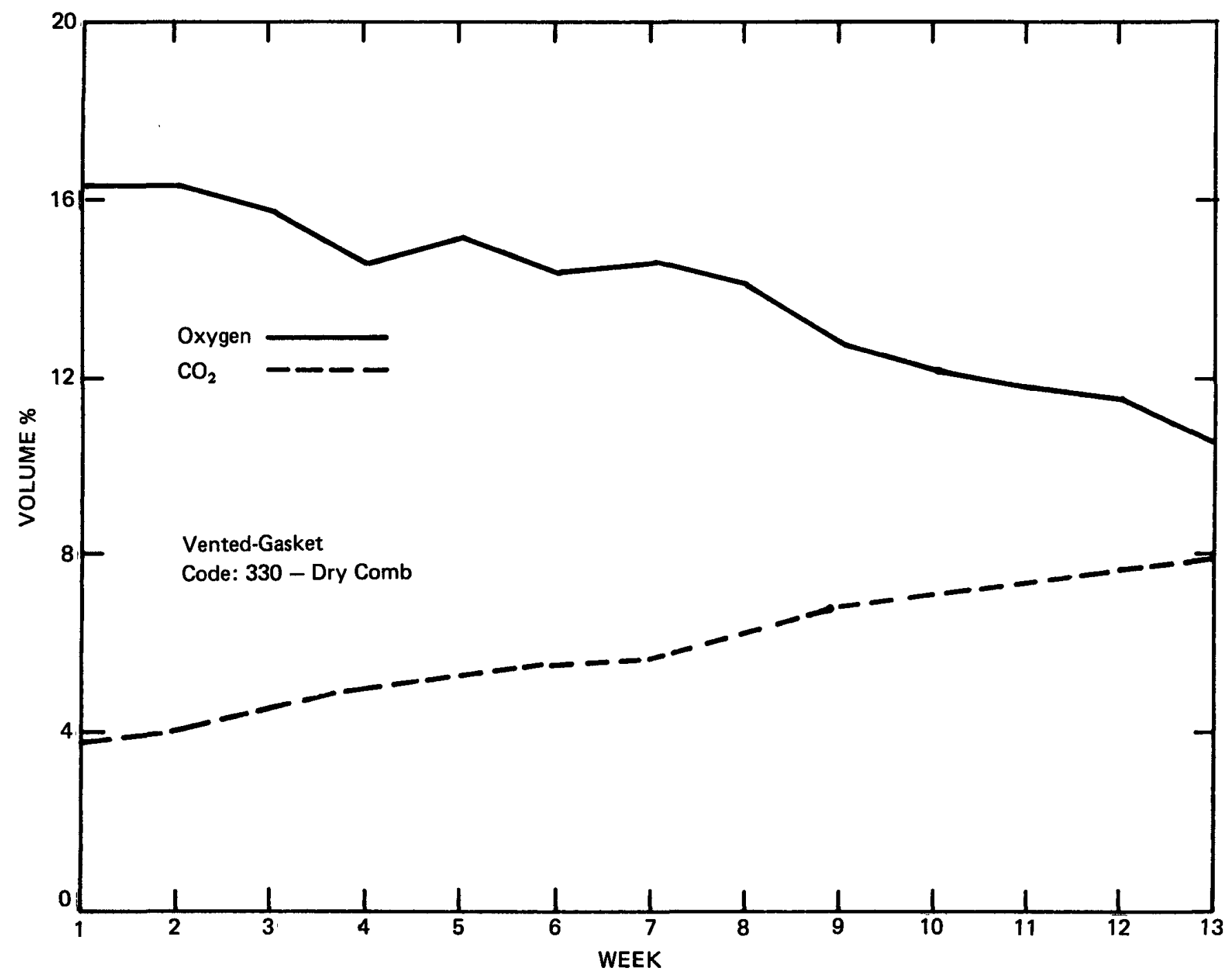

FIGURE A-10d. D31703 Atmosphere: Oxygen, Carbon Dioxide 
RFP-3739

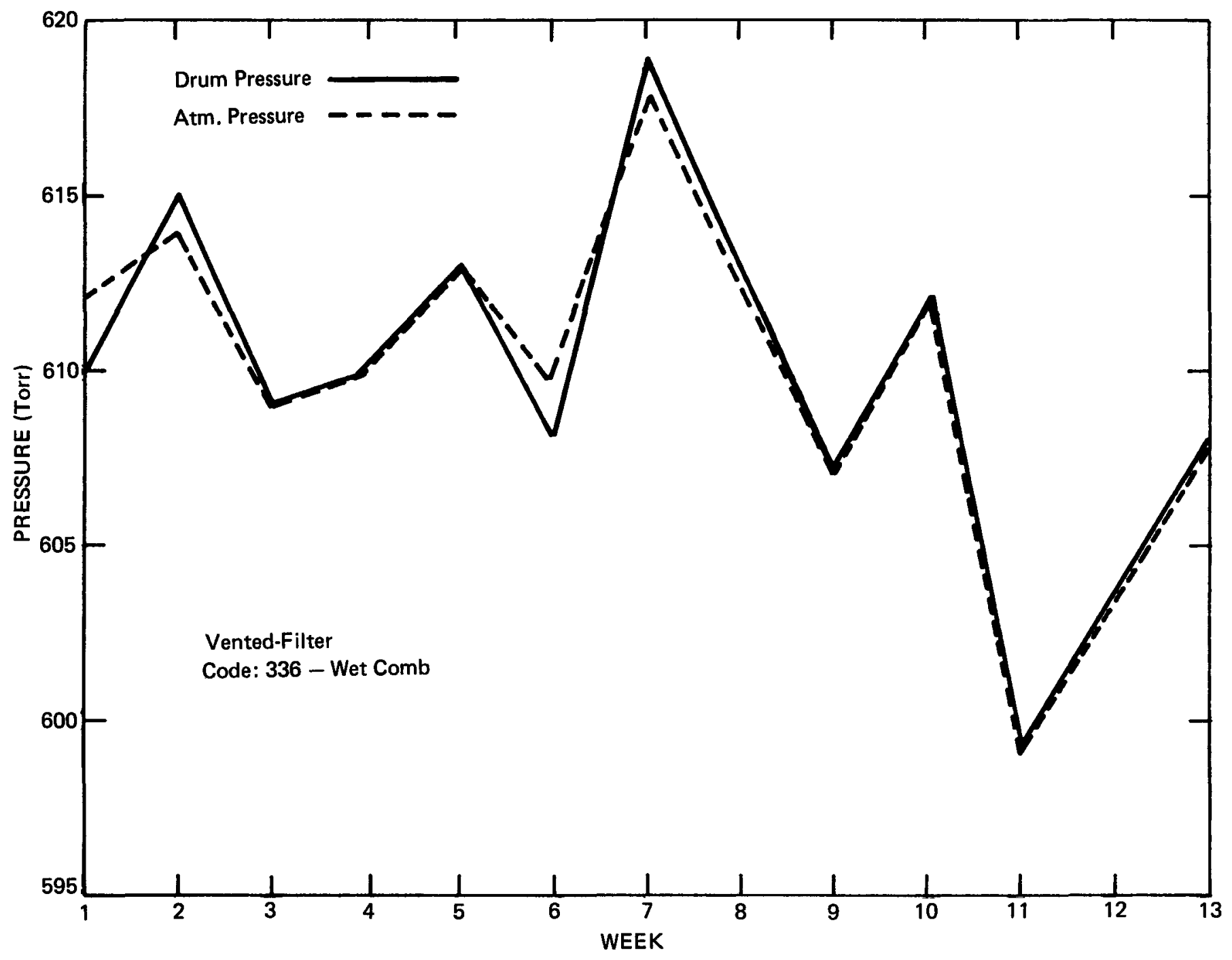

FIGURE A-11a. D25634 Pressure 


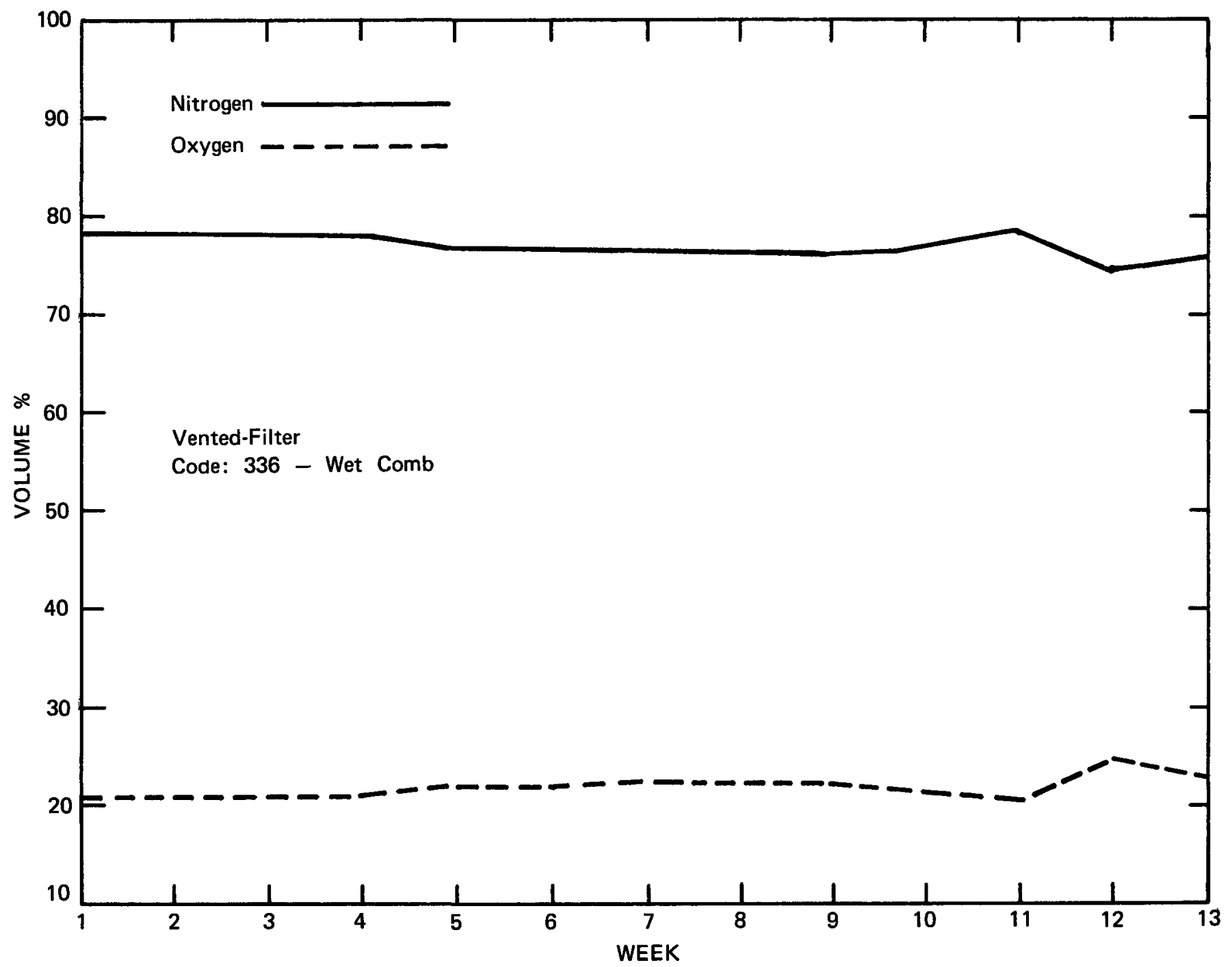

FIGURE A-11b. D25634 Atmosphere: Nitrogen, Oxygen 


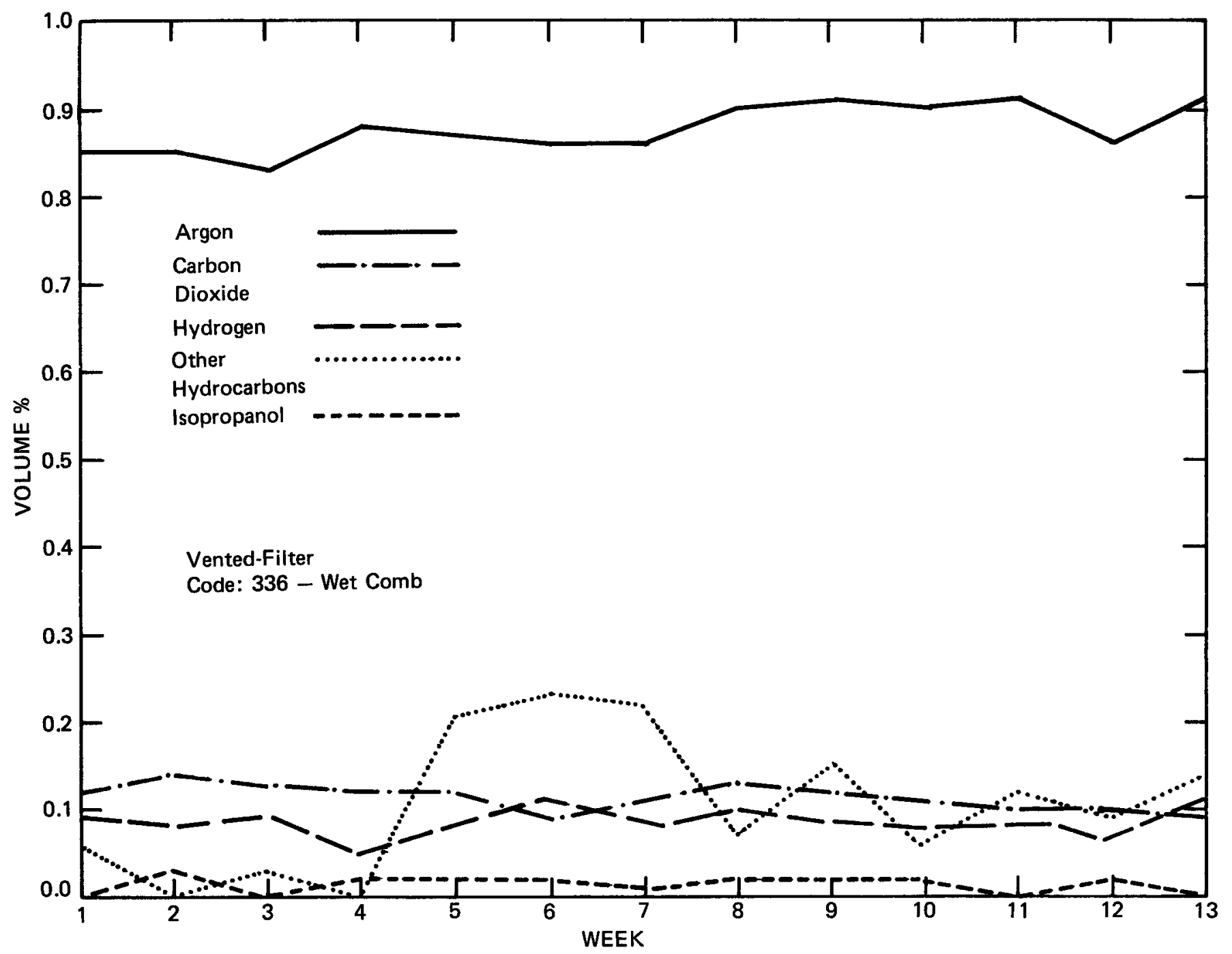

FIGURE A-11c. D25634 Atmosphere: Argon, Carbon Dioxide, Hydrogen, Other Hydrocarbons, Isopropanol 


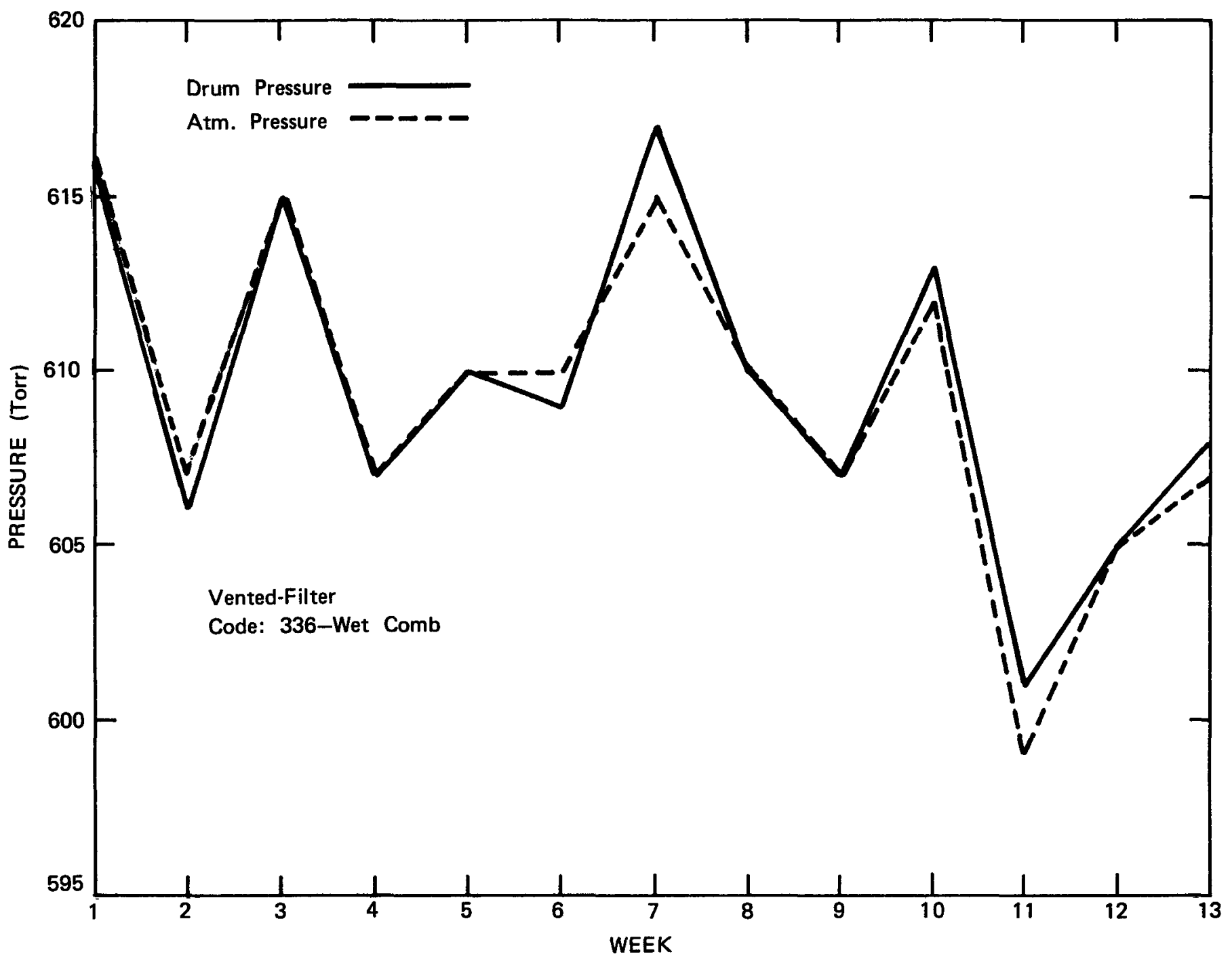

FIGURE A-12a. D31216 Pressure 


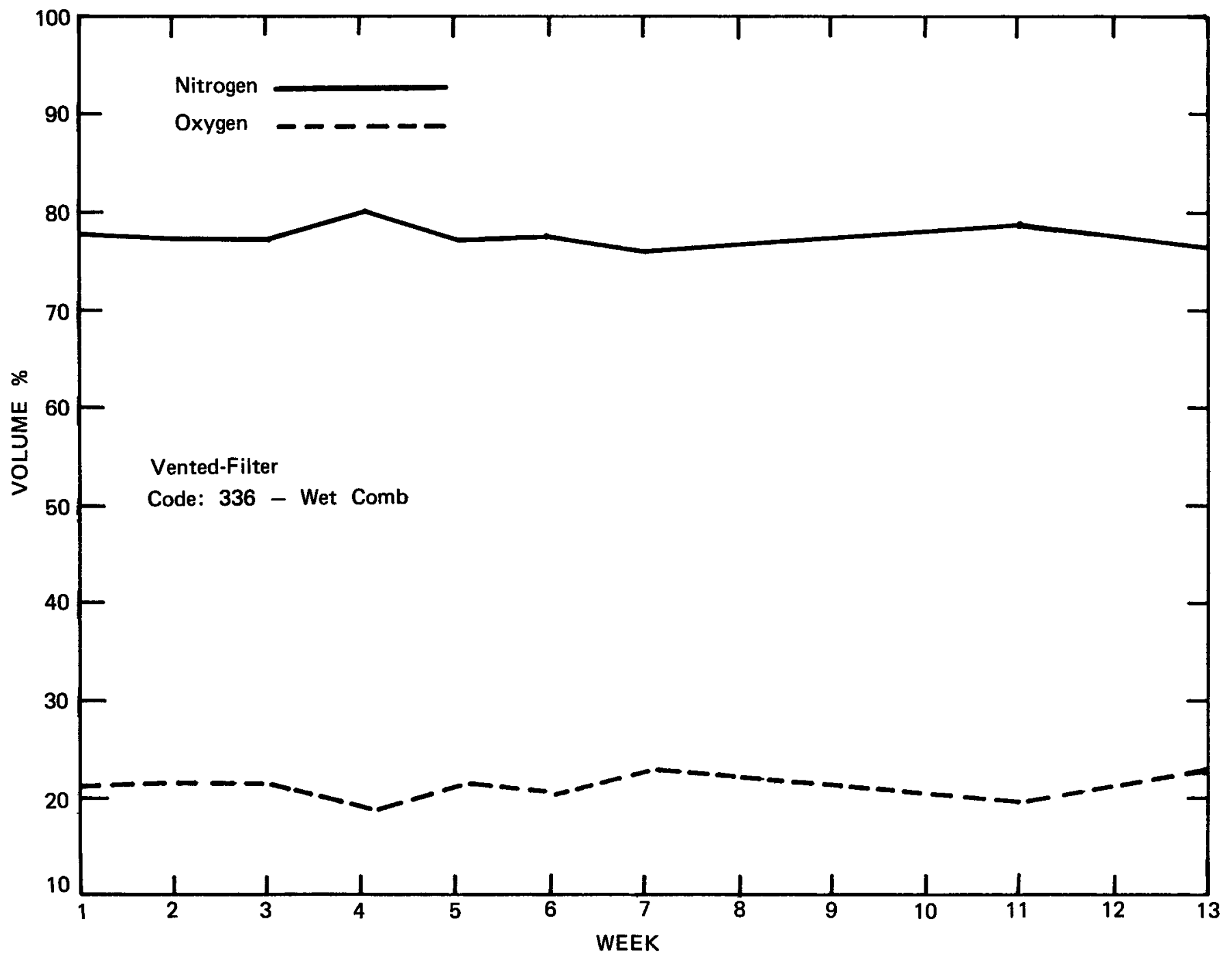

FIGURE A-12b. D31216 Atmosphere: Nitrogen, Oxygen 


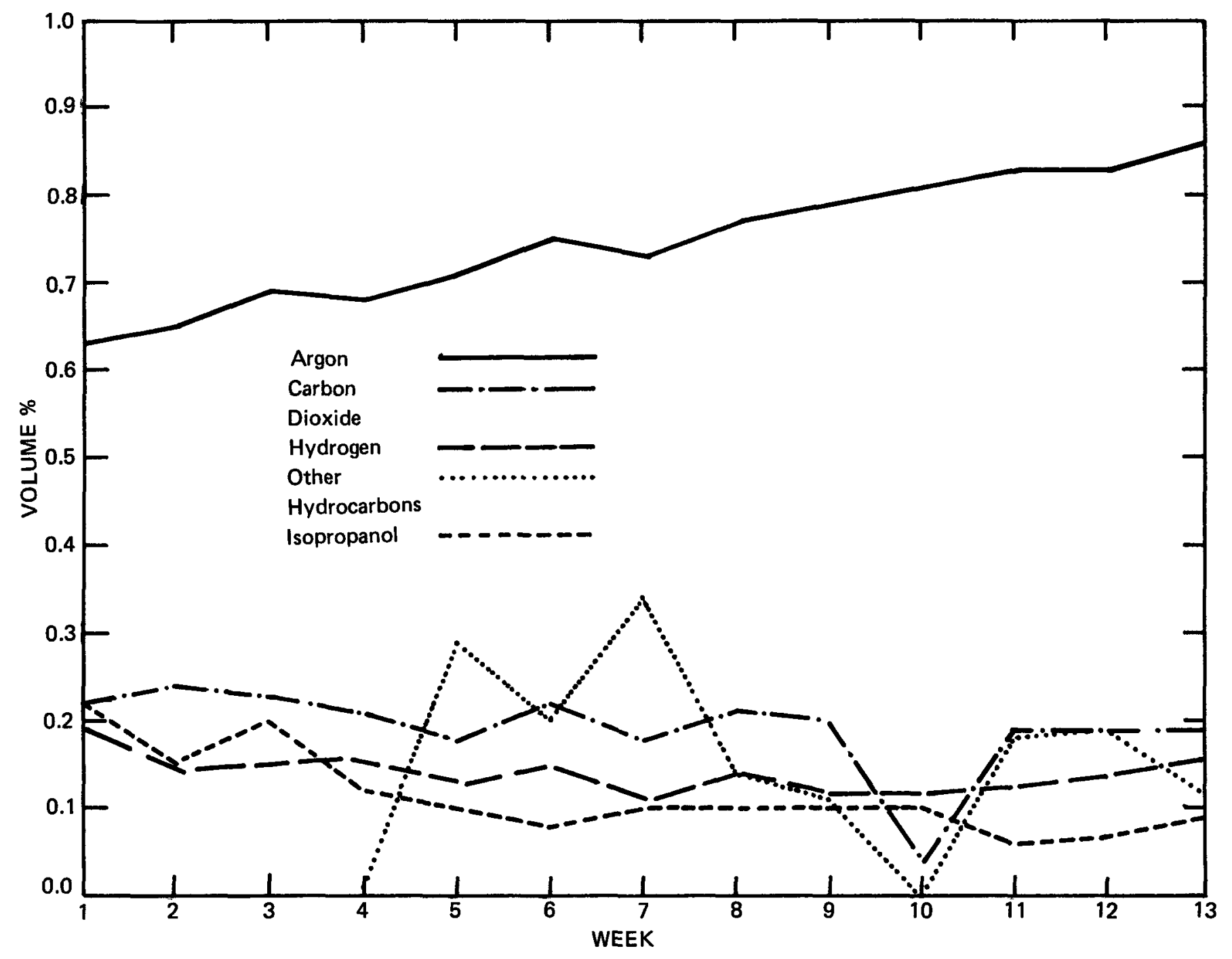

FIGURE A-12c. D31216 Atmosphere: Argon, Carbon Dioxide, Hydrogen, Other Hydrocarbons, Isopropanol 
RFP-3739

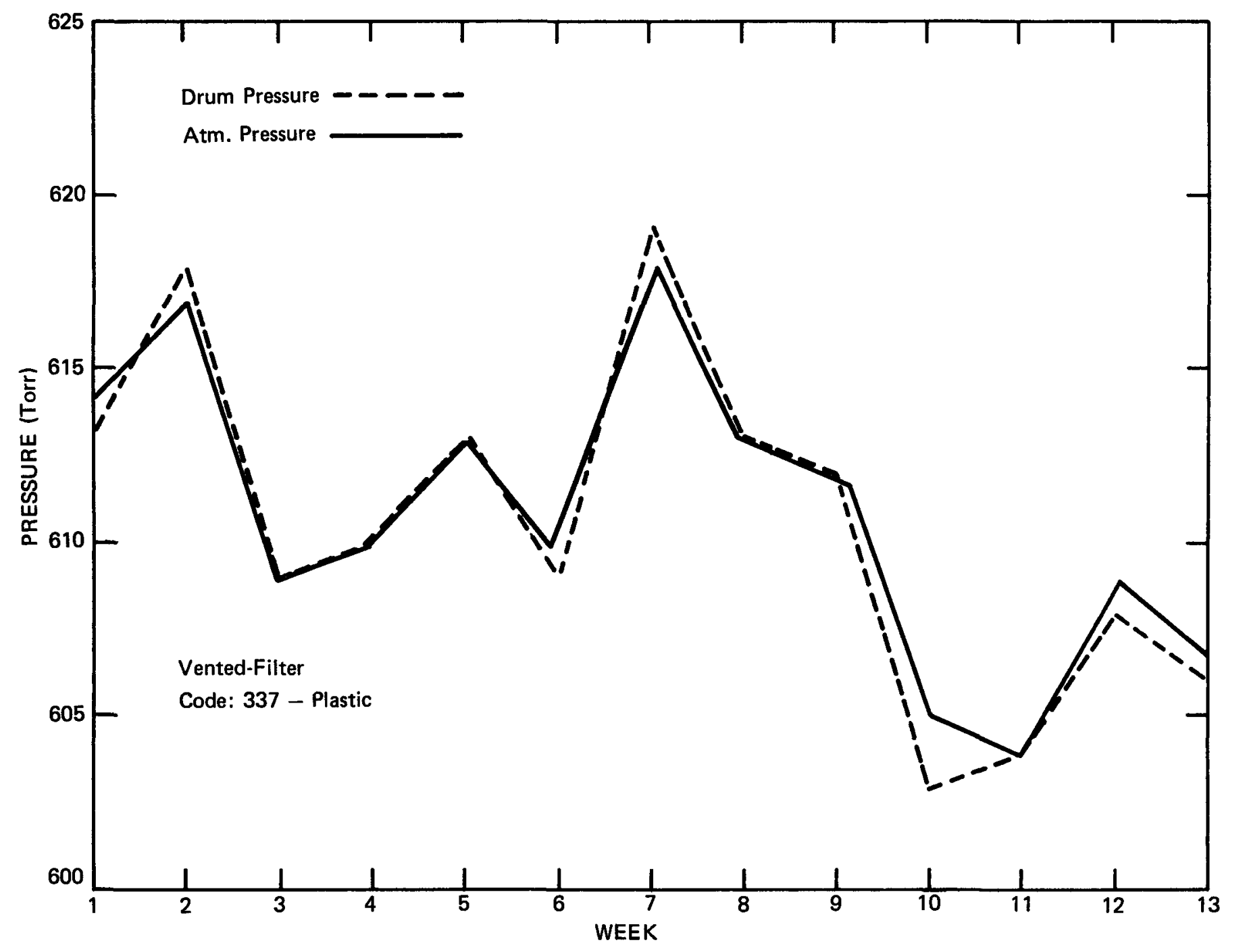

FIGURE A-13a. D25691 Pressure 


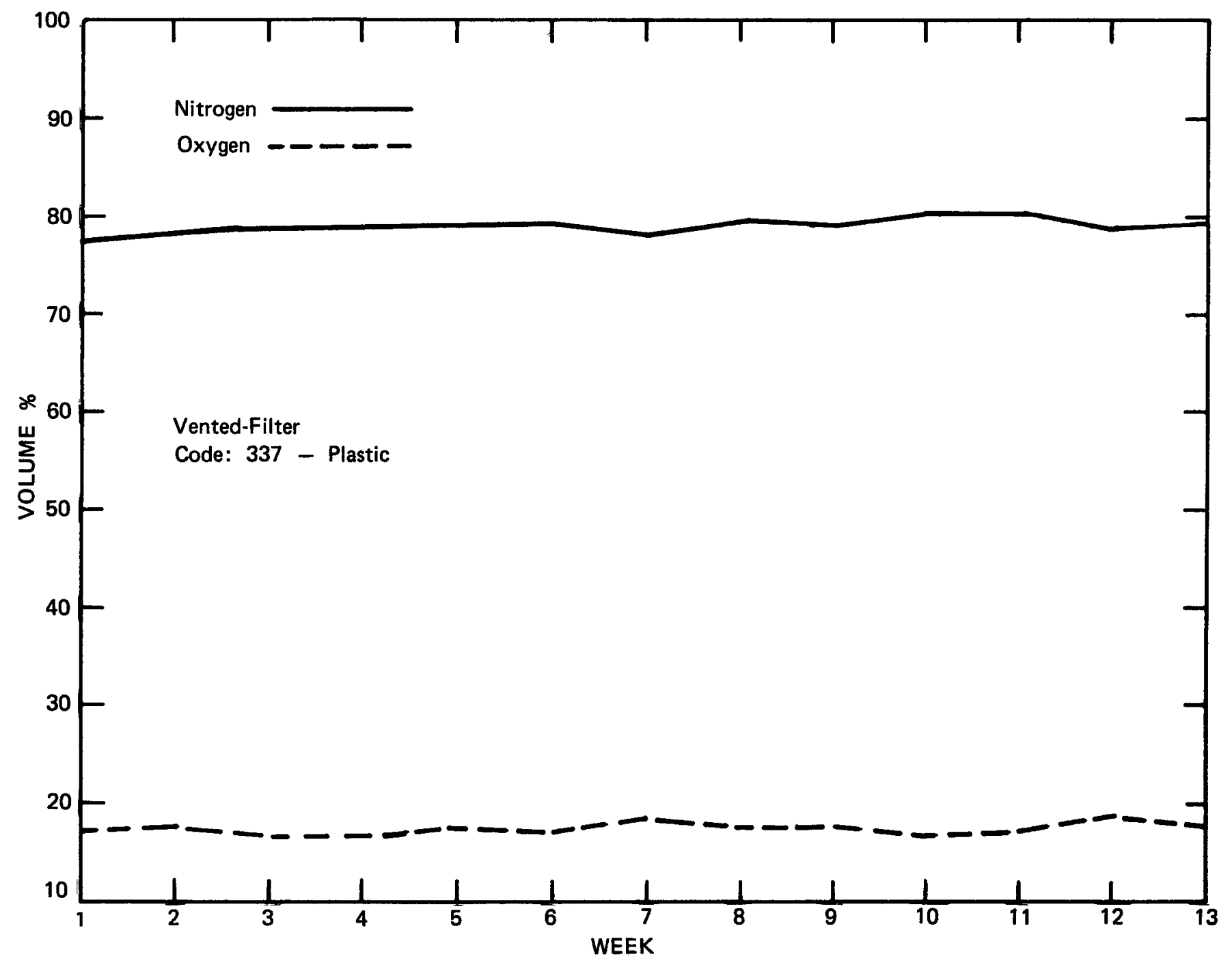

FIGURE A-13b. D25691 Atmosphere: Nitrogen, Oxygen 


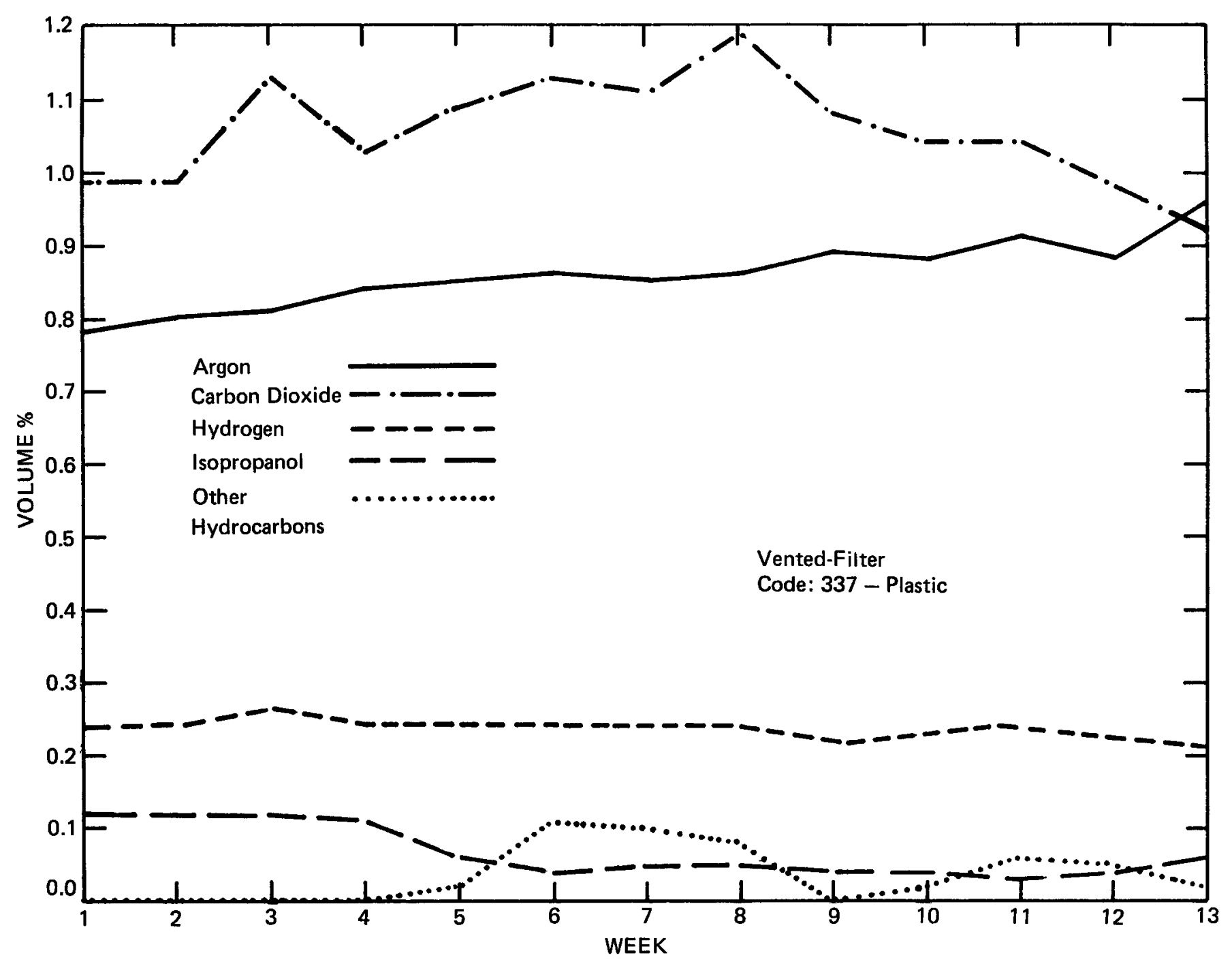

FIGURE A-13c. D25691 Atmosphere: Argon, Carbon Dioxide, Hydrogen, Isopropanol, Other Hydrocarbons 


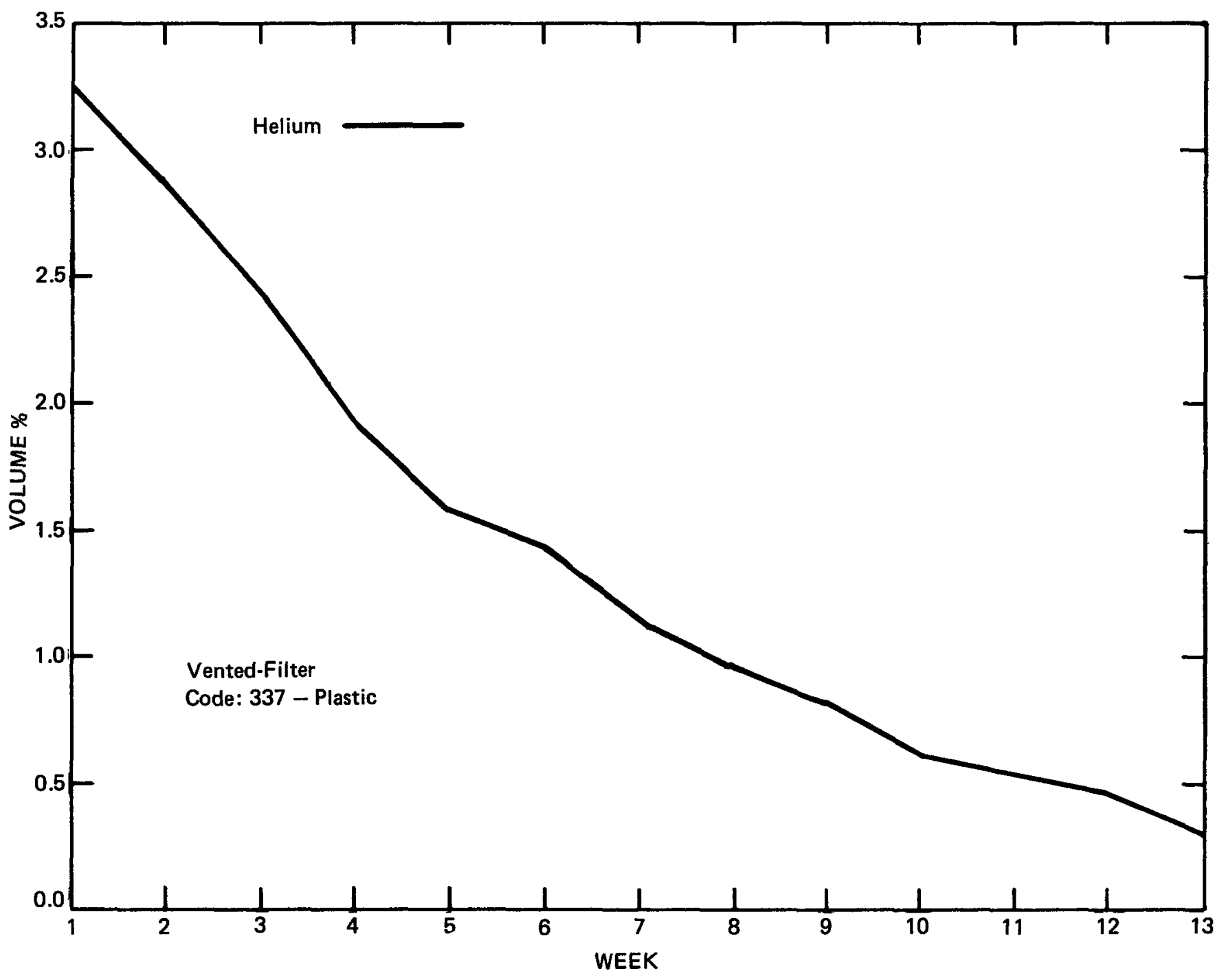

FIGURE A-13d. D25691 Atmosphere: Helium 


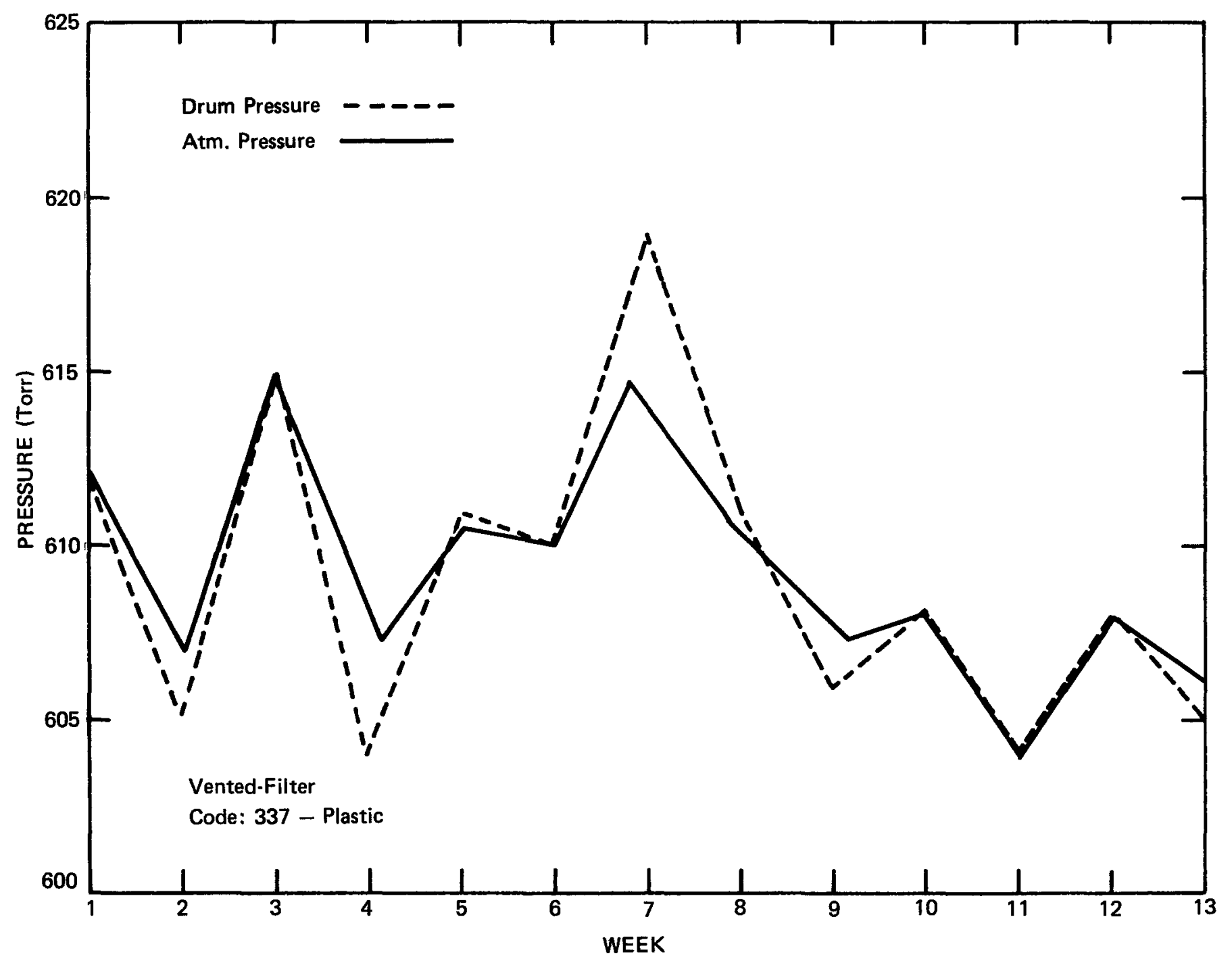

FIGURE A-14a. D30688 Pressure 


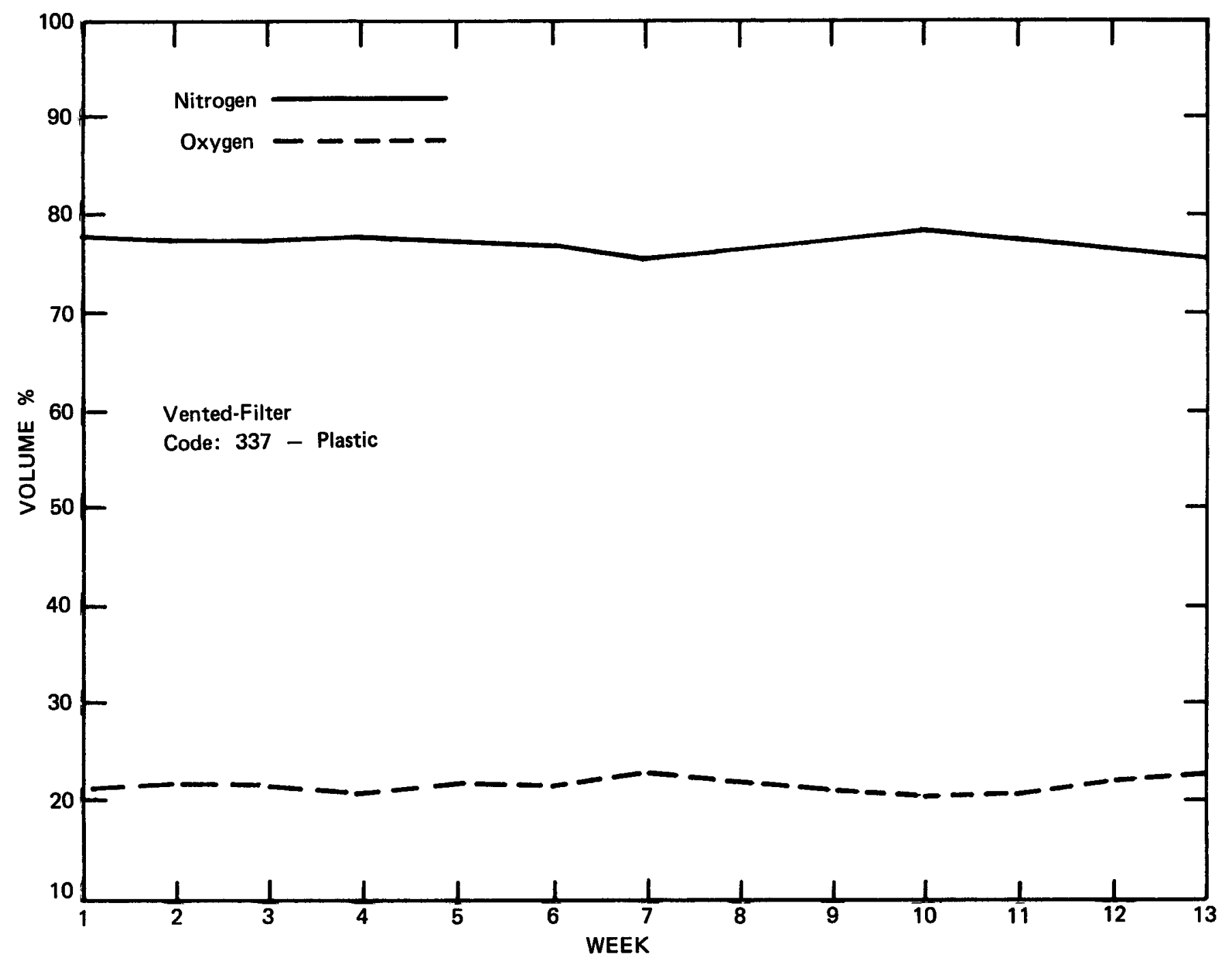

FIGURE A-14b. D30688 Atmosphere: Nitrogen, Oxygen 


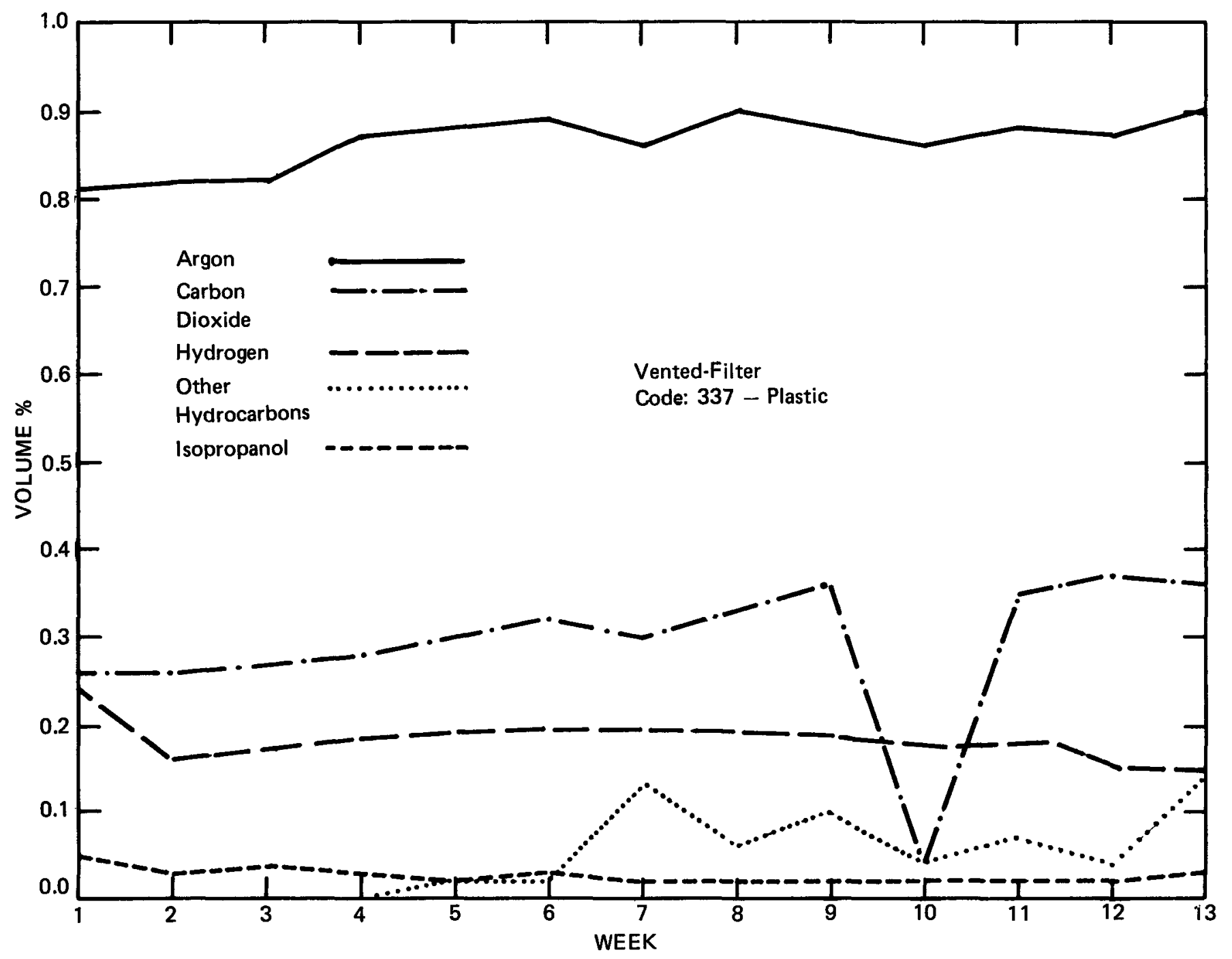

FIGURE A-14c. D30688 Atmosphere: Argon, Carbon Dioxide, Hydrogen, Other Hydrocarbons, Isopropanol 


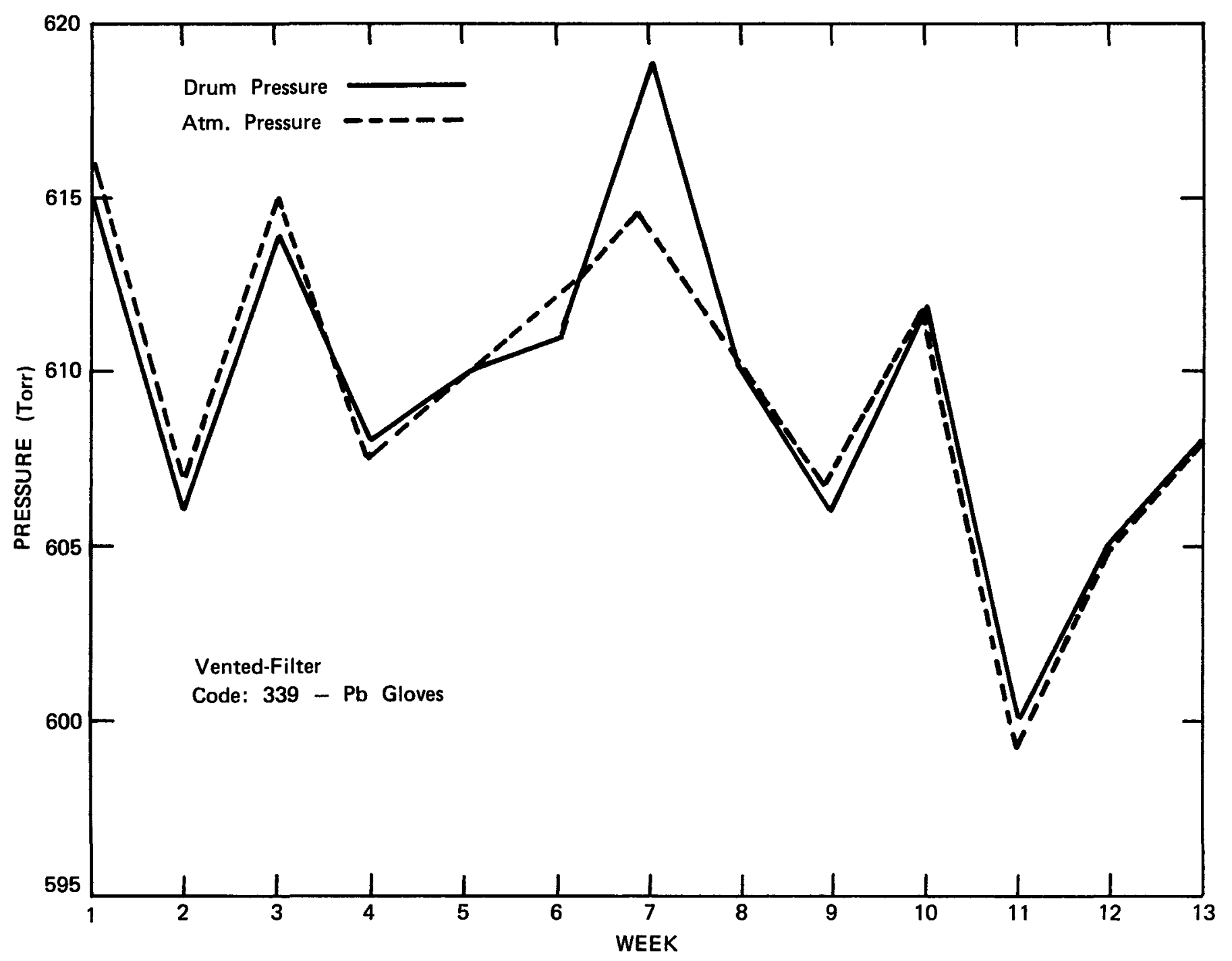

FIGURE A-15a. D29758 Pressure 
RFP-3739

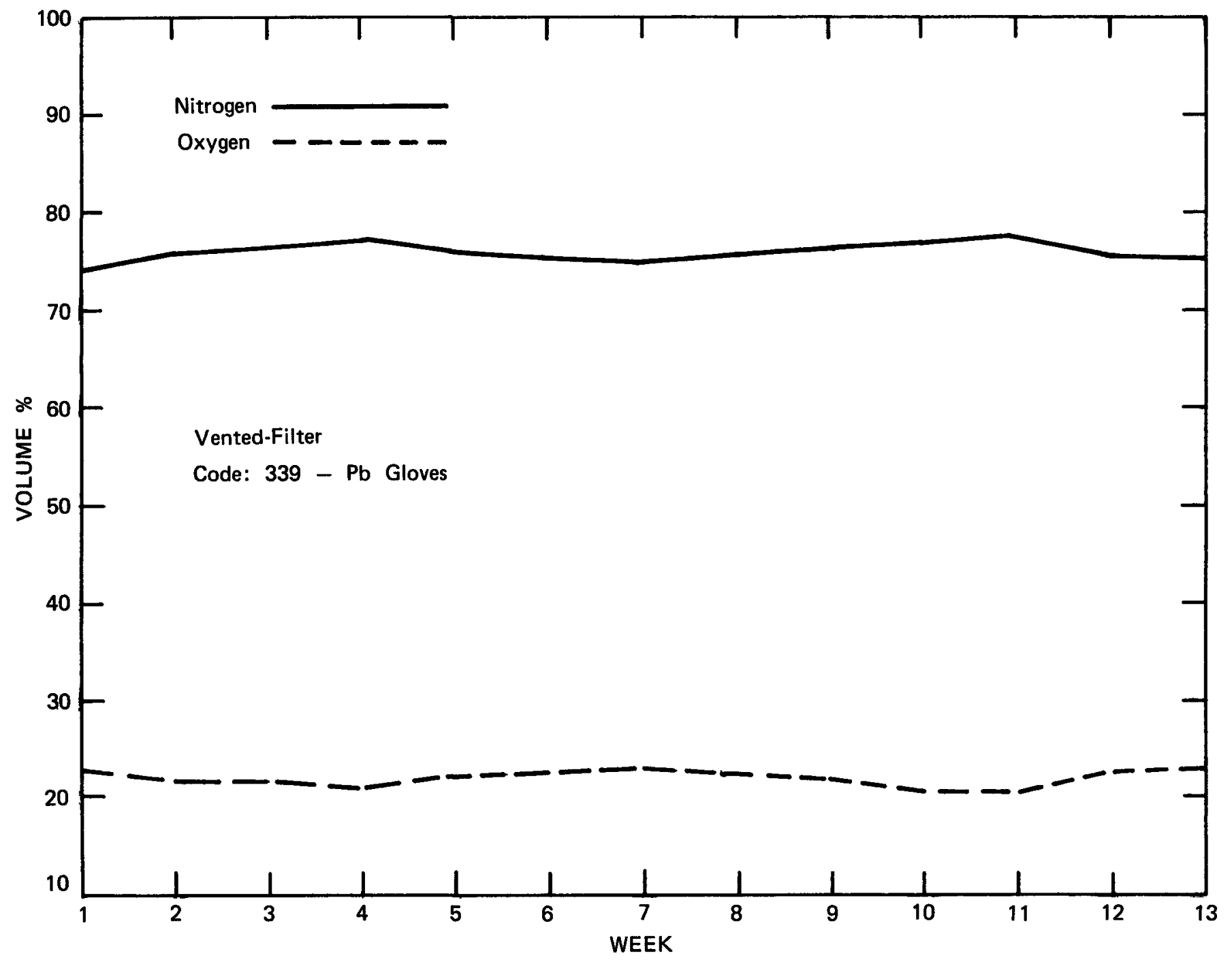

FIGURE A-15b. D29758 Atmosphere: Nitrogen, Oxygen 


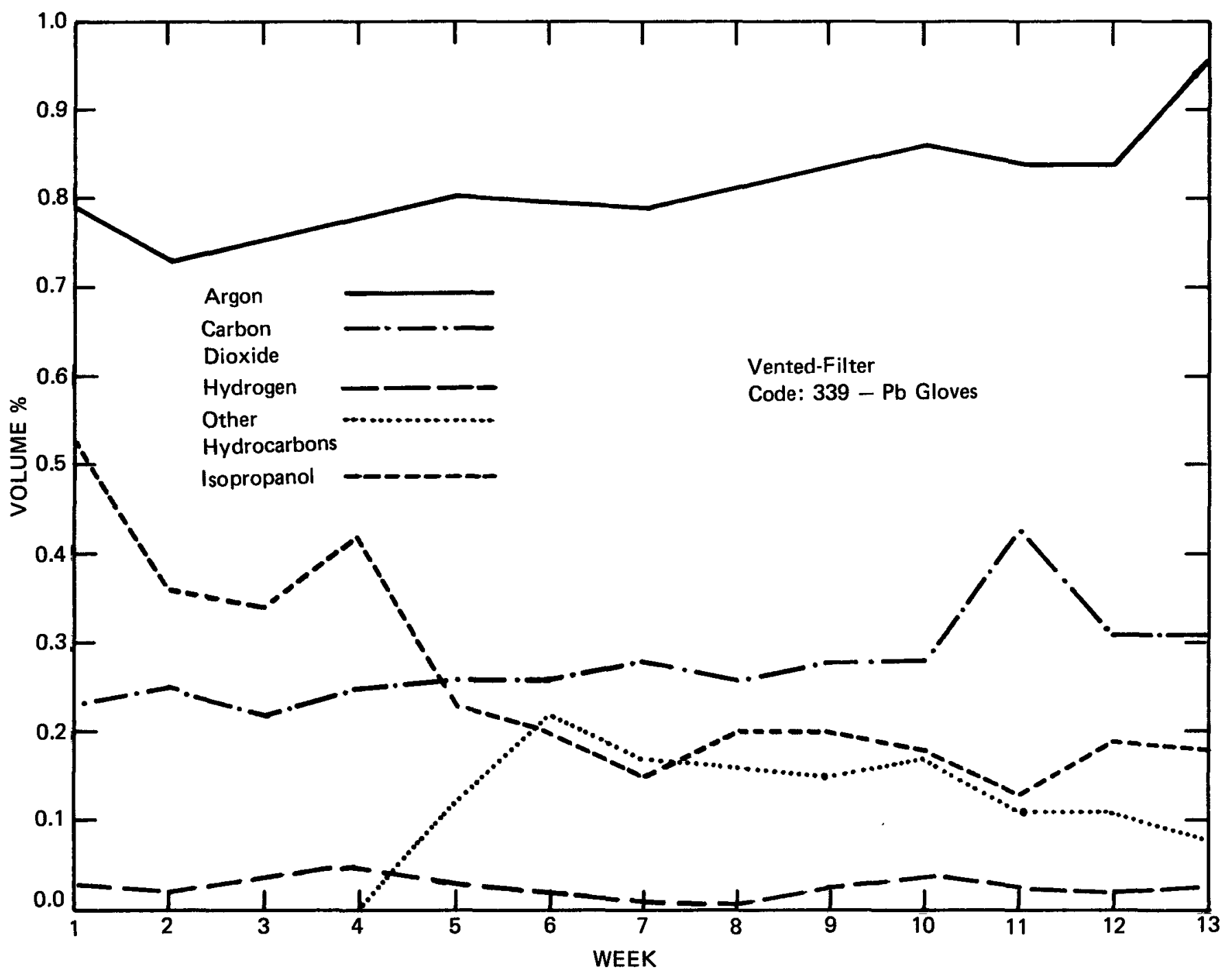

FIGURE A-15c. D29758 Atmosphere: Argon, Carbon Dioxide, Hydrogen, Other Hydrocarbons, Isopropanol 


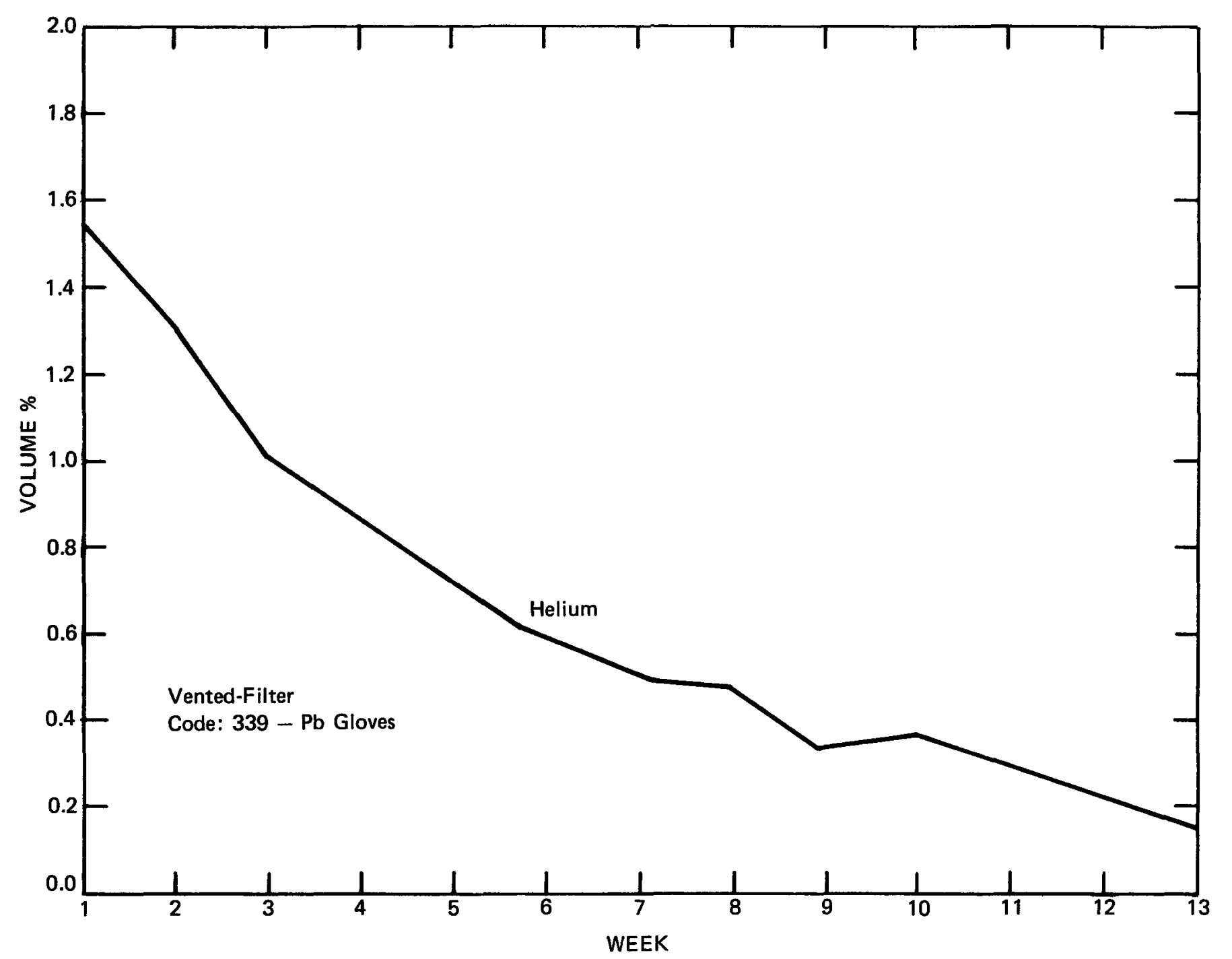

FIGURE A-15d. D29758 Atmosphere: Helium 


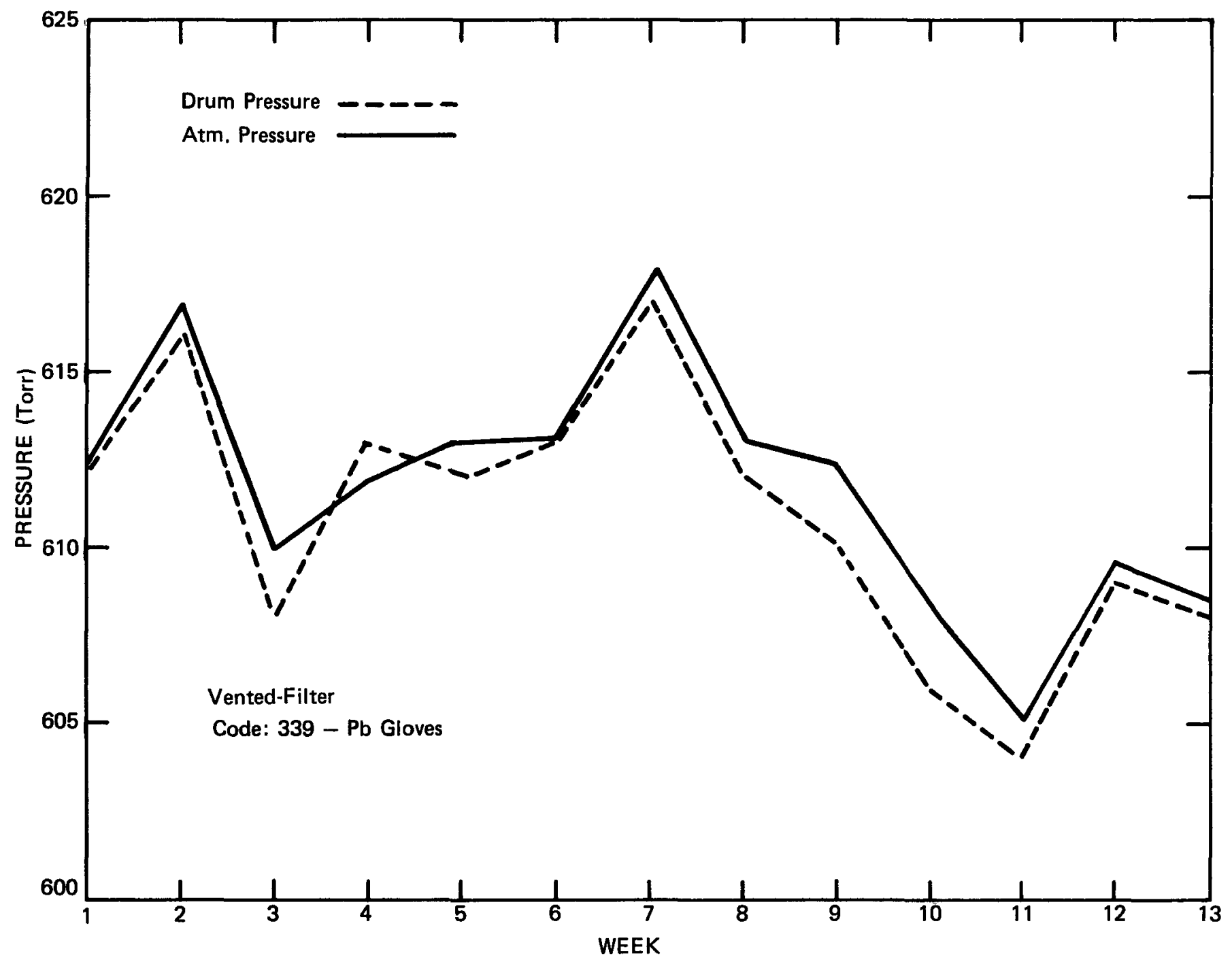

FIGURE A-16a. D30175 Pressure 


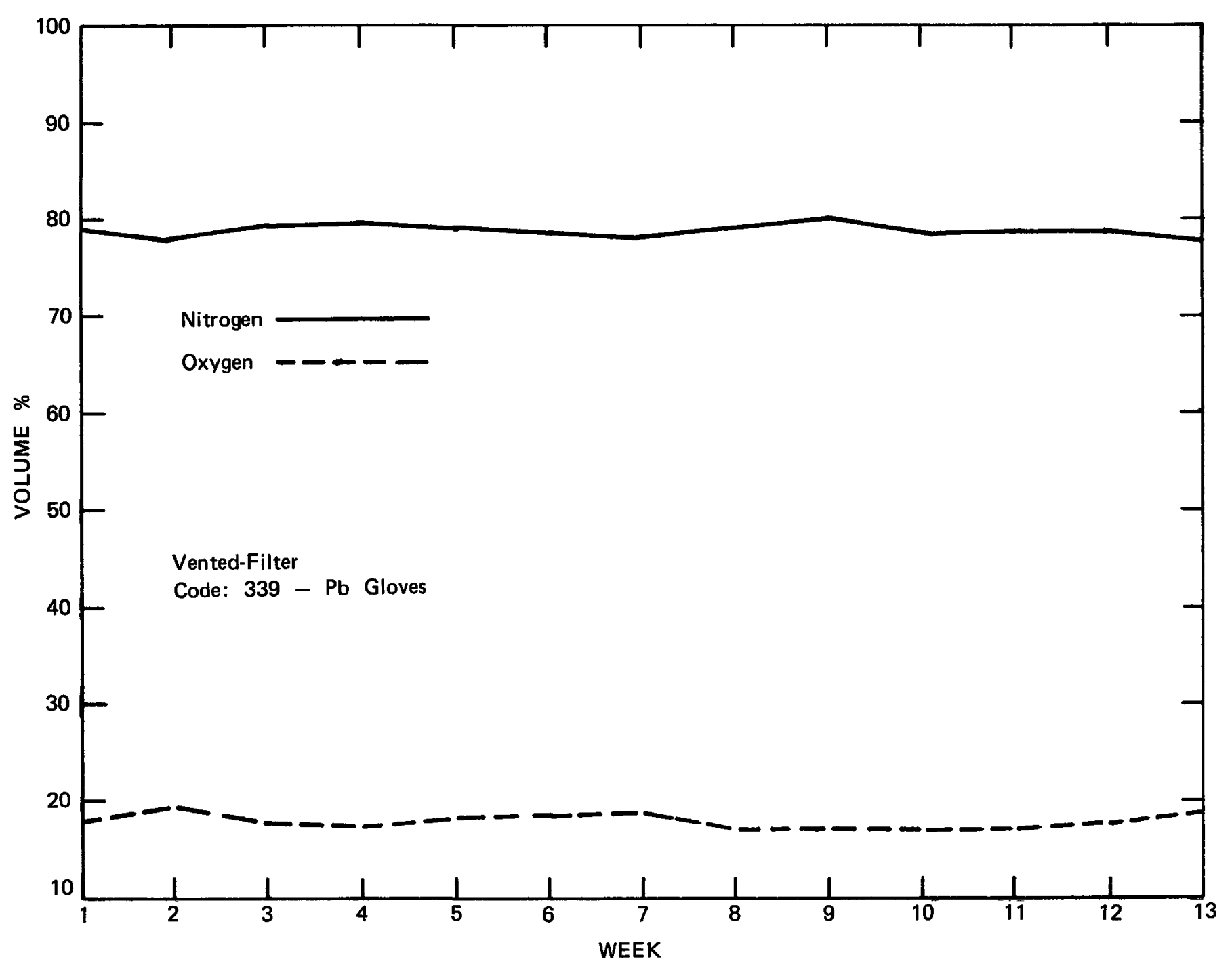

FIGURE A-16b. D30175 Atmosphere: Nitrogen, Oxygen 


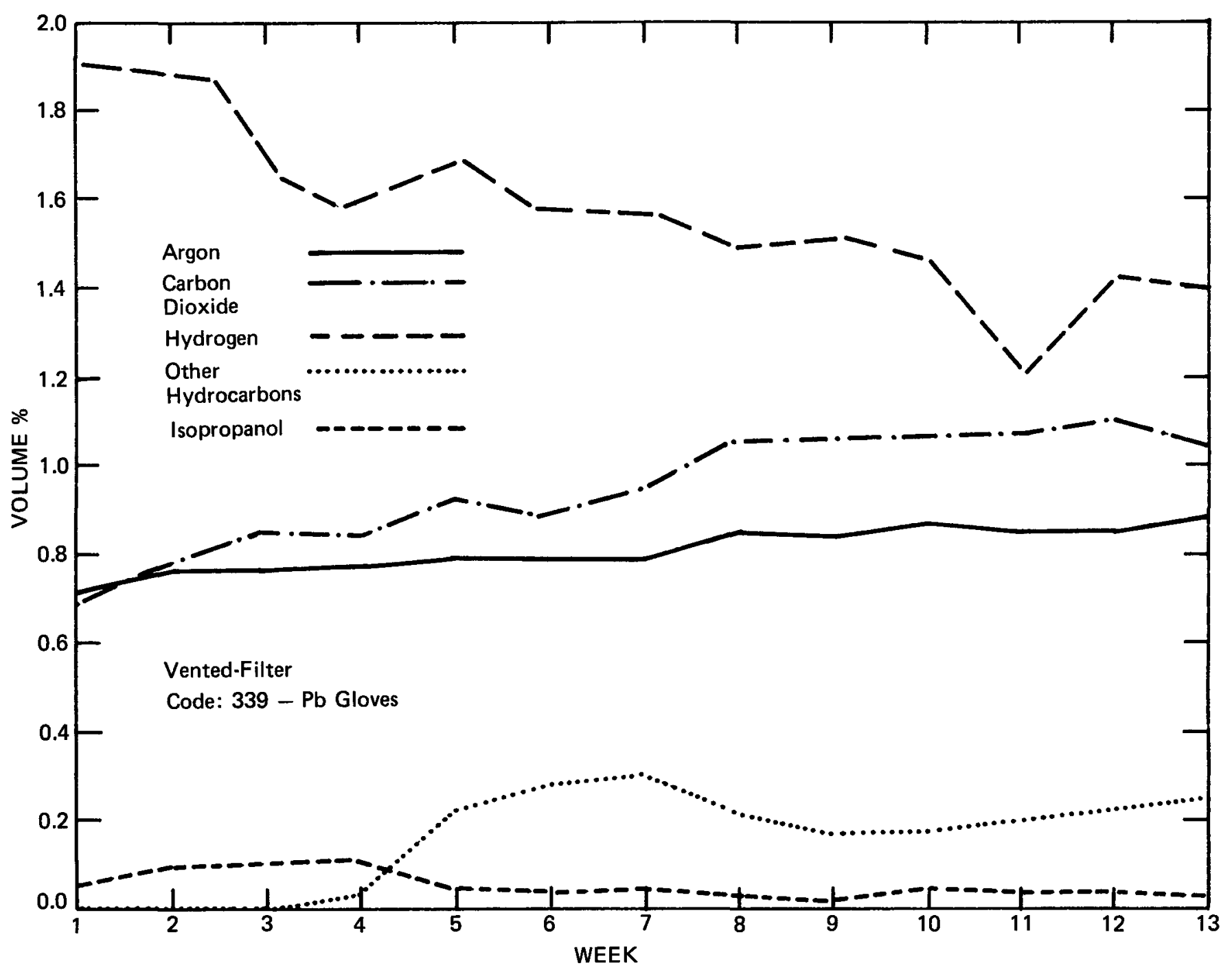

FIGURE A-16c. D30175 Atmosphere: Argon, Carbon Dioxide, Hydrogen, Other Hydrocarbons, Isopropanol 


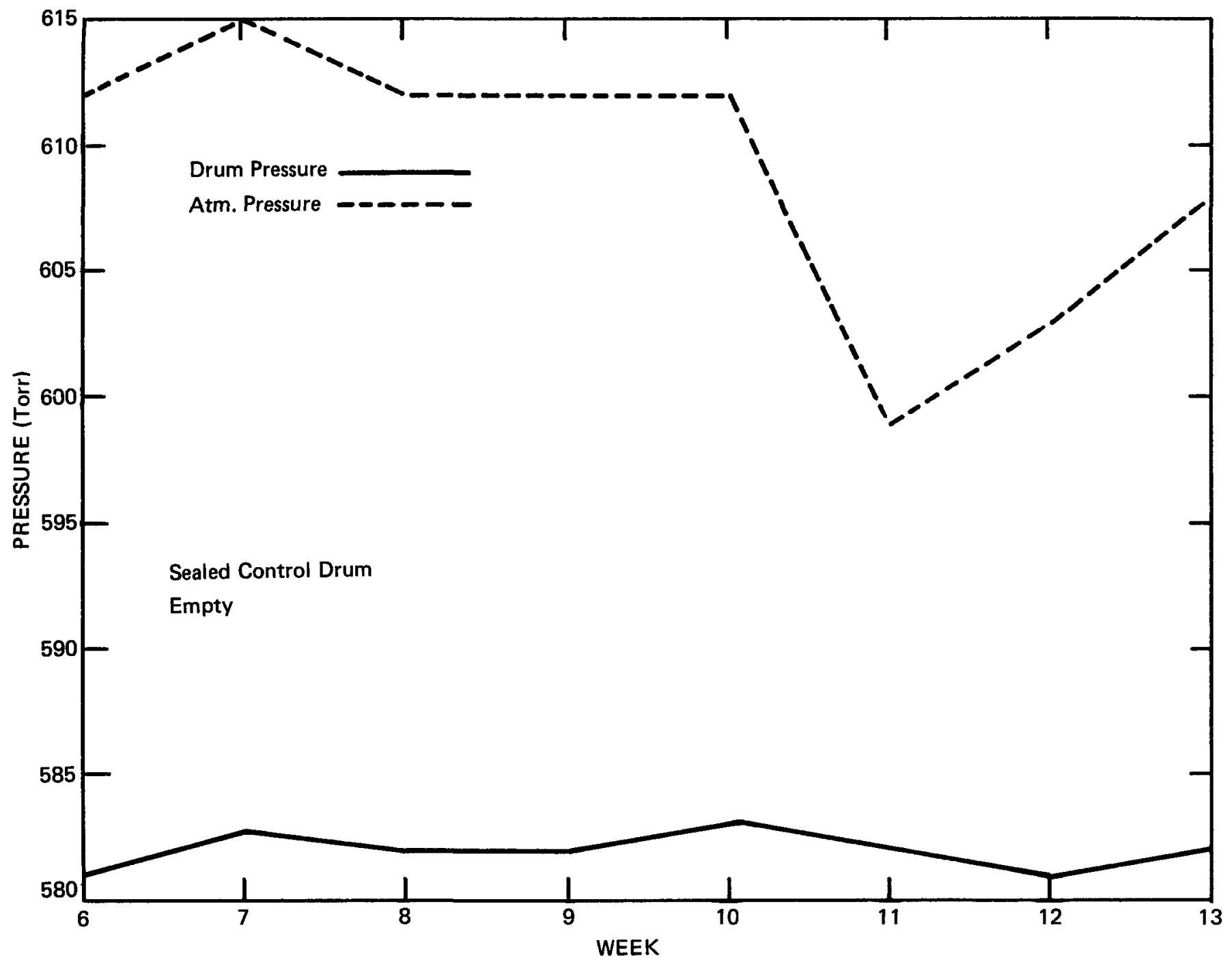

FIGURE A-17a. D32538 Pressure 


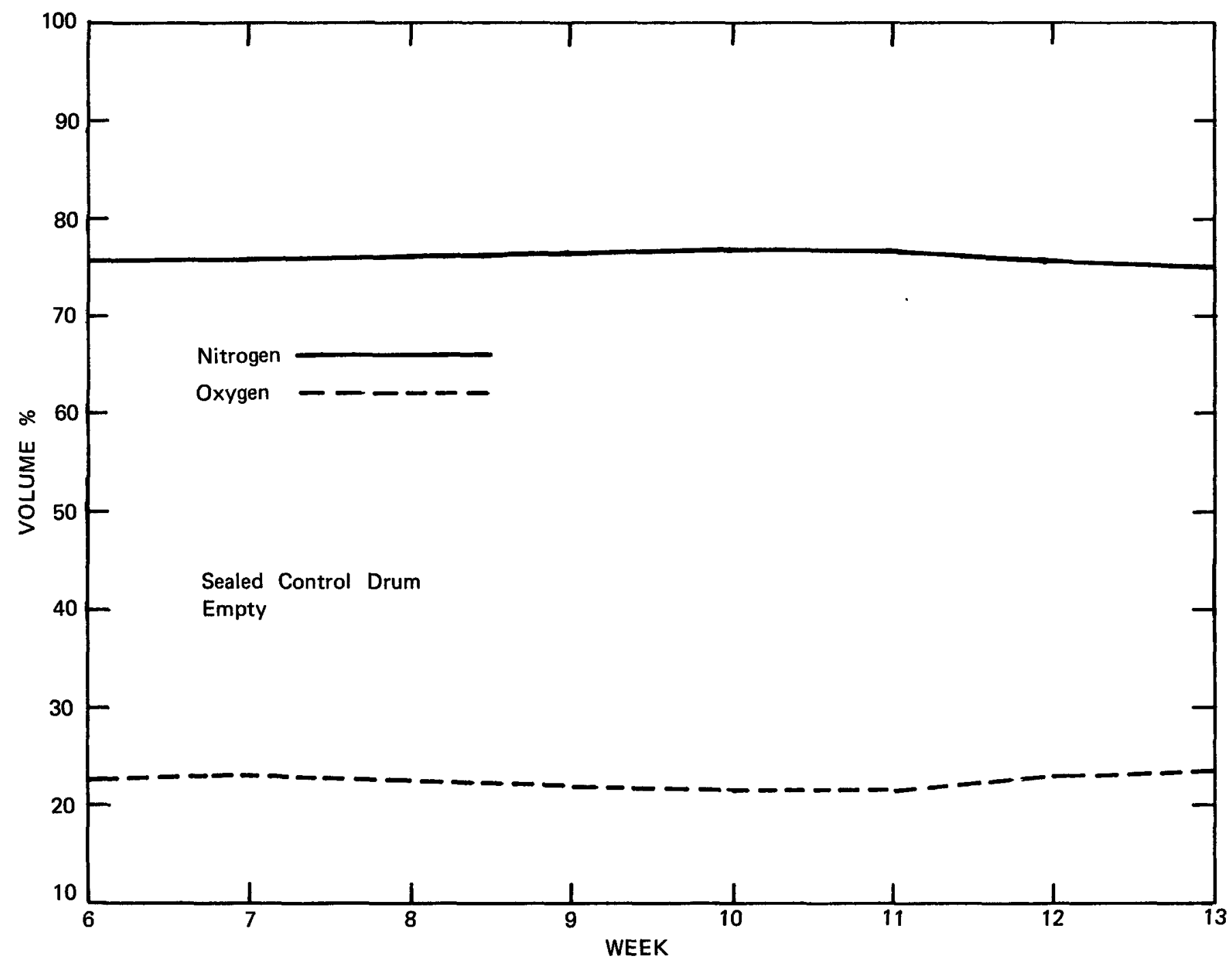

FIGURE A-17b. D32538 Atmosphere: Nitrogen, Oxygen 


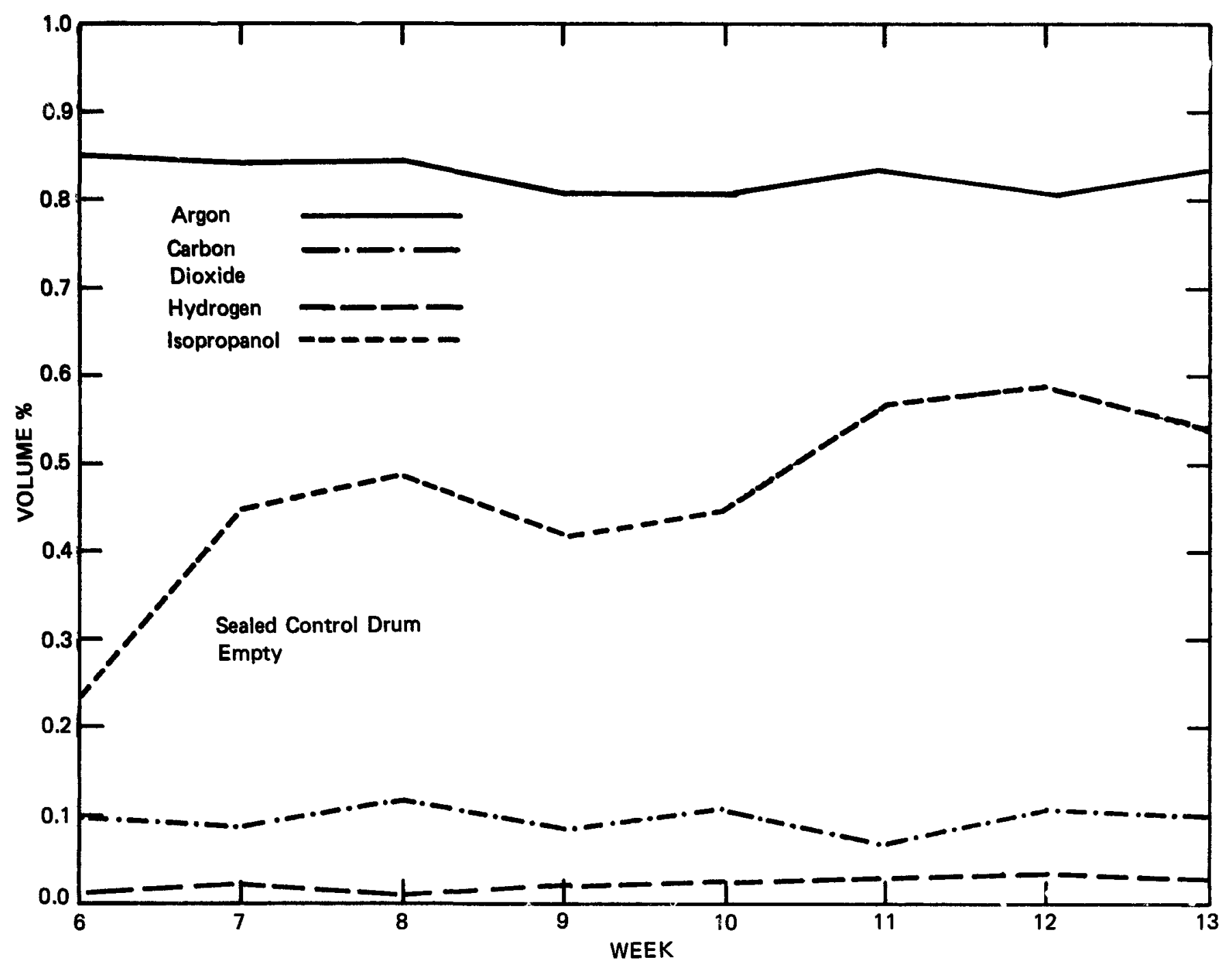

FIGURE A-17c. D32538 Atmosphere: Argon, Carbon Dioxide, Hydrogen, Isopropanol 


\section{APPENDIX B}

Results of Phase II, Gas Generation, Tests of Tasks 5 and 7

for the TRU Waste Sampling Program

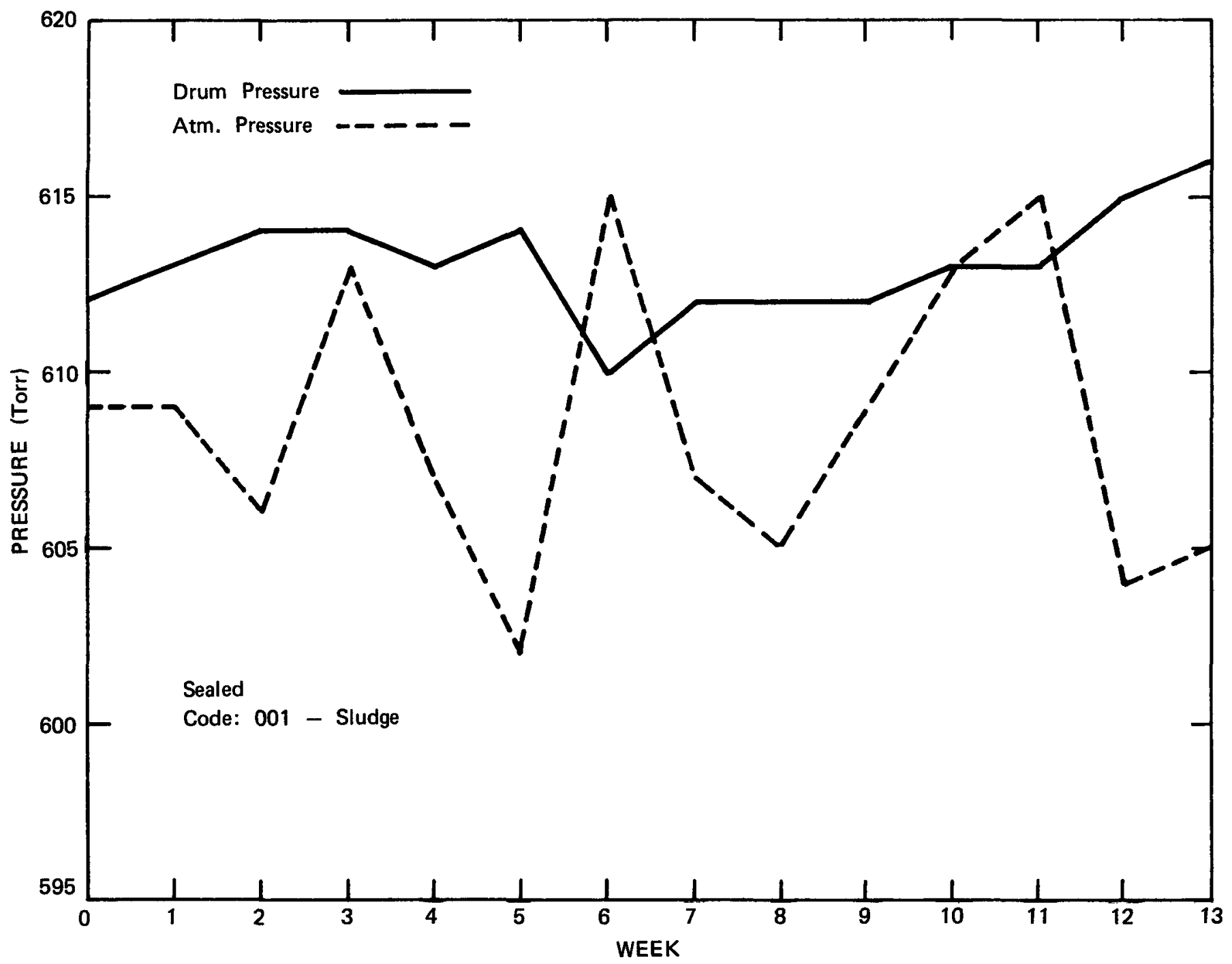

FIGURE B-1a. D29258 Pressure 


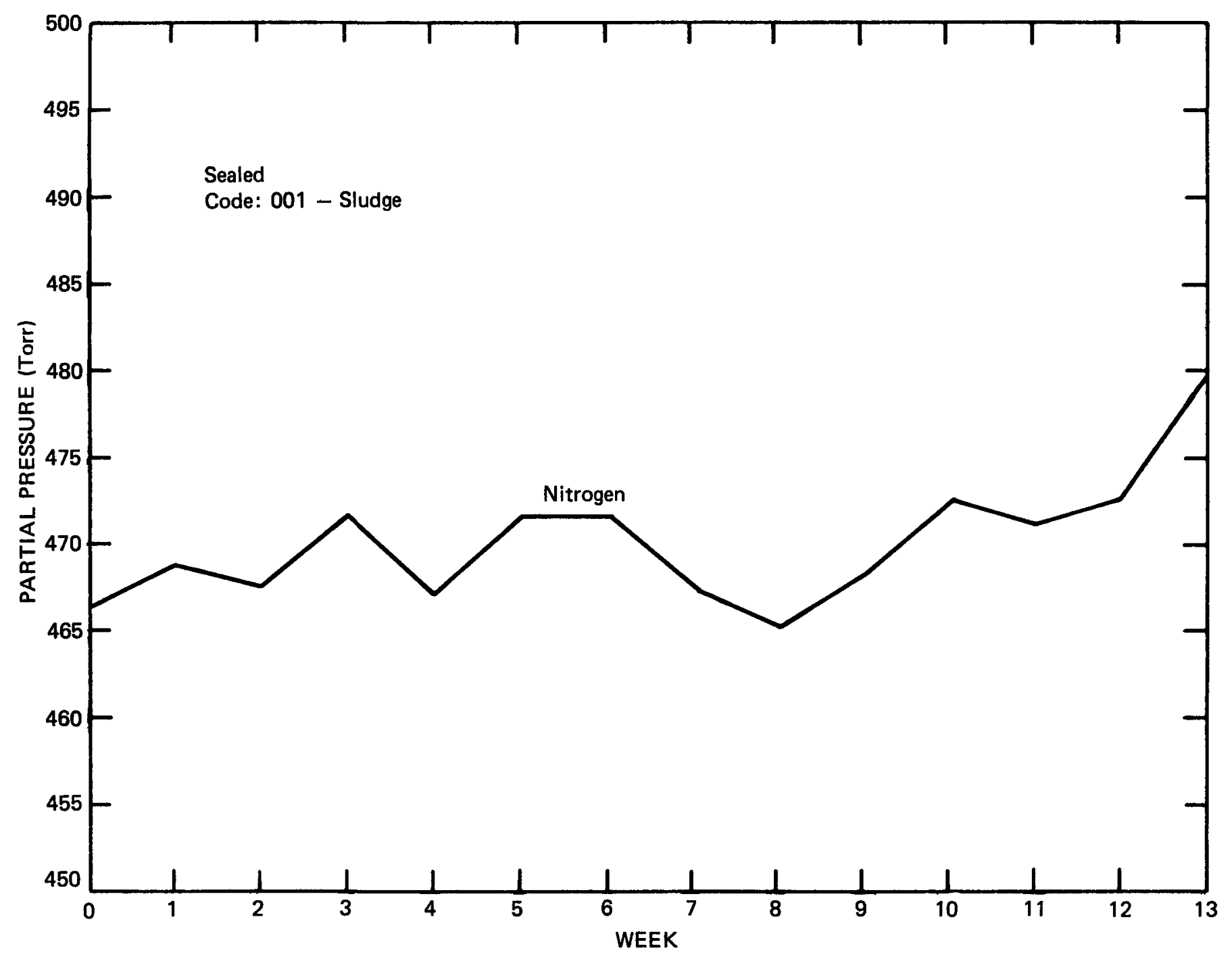

FIGURE B-1b. D29258 Atmosphere: Nitrogen 


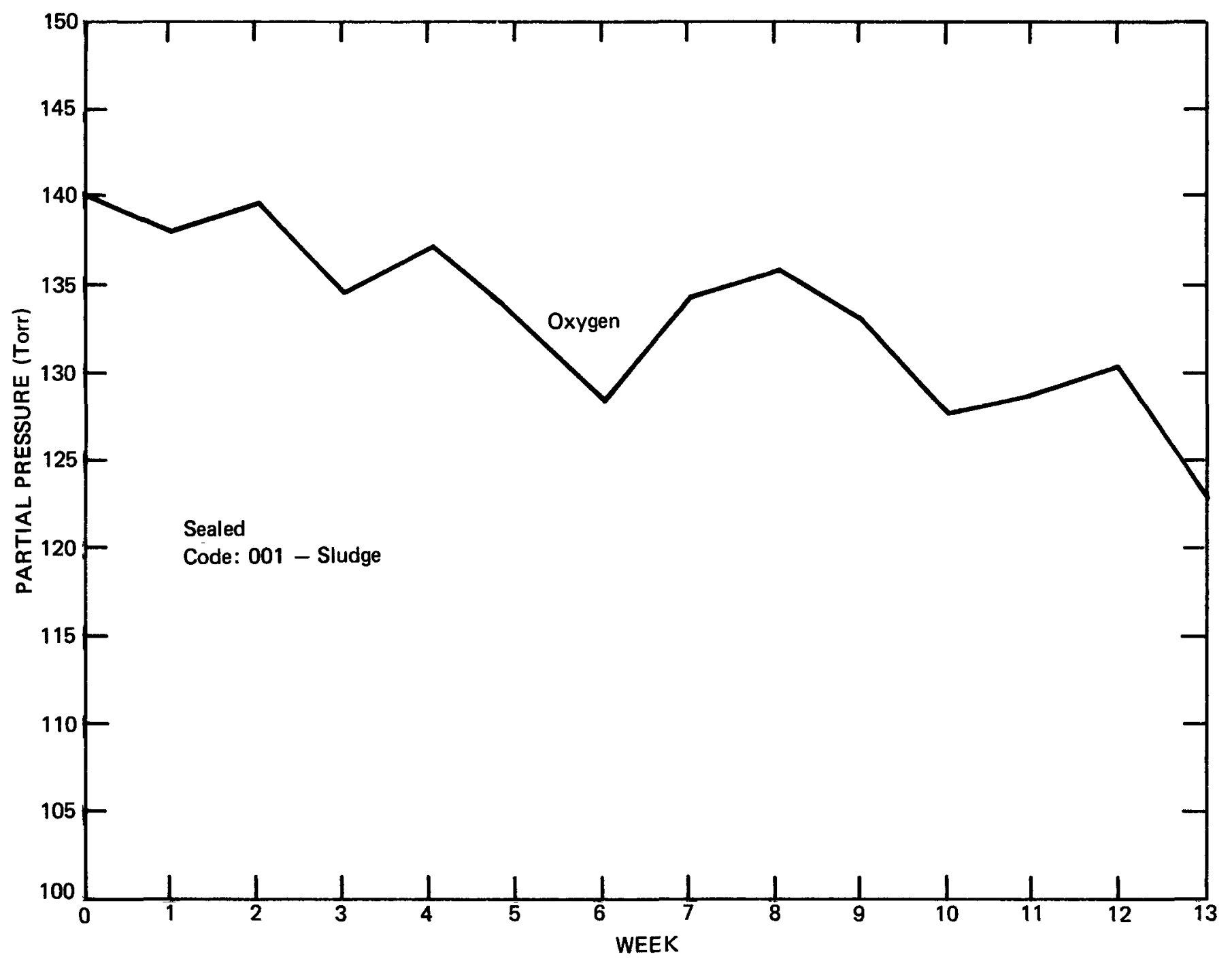

FIGURE B-1c. D29258 Atmosphere: Oxygen 


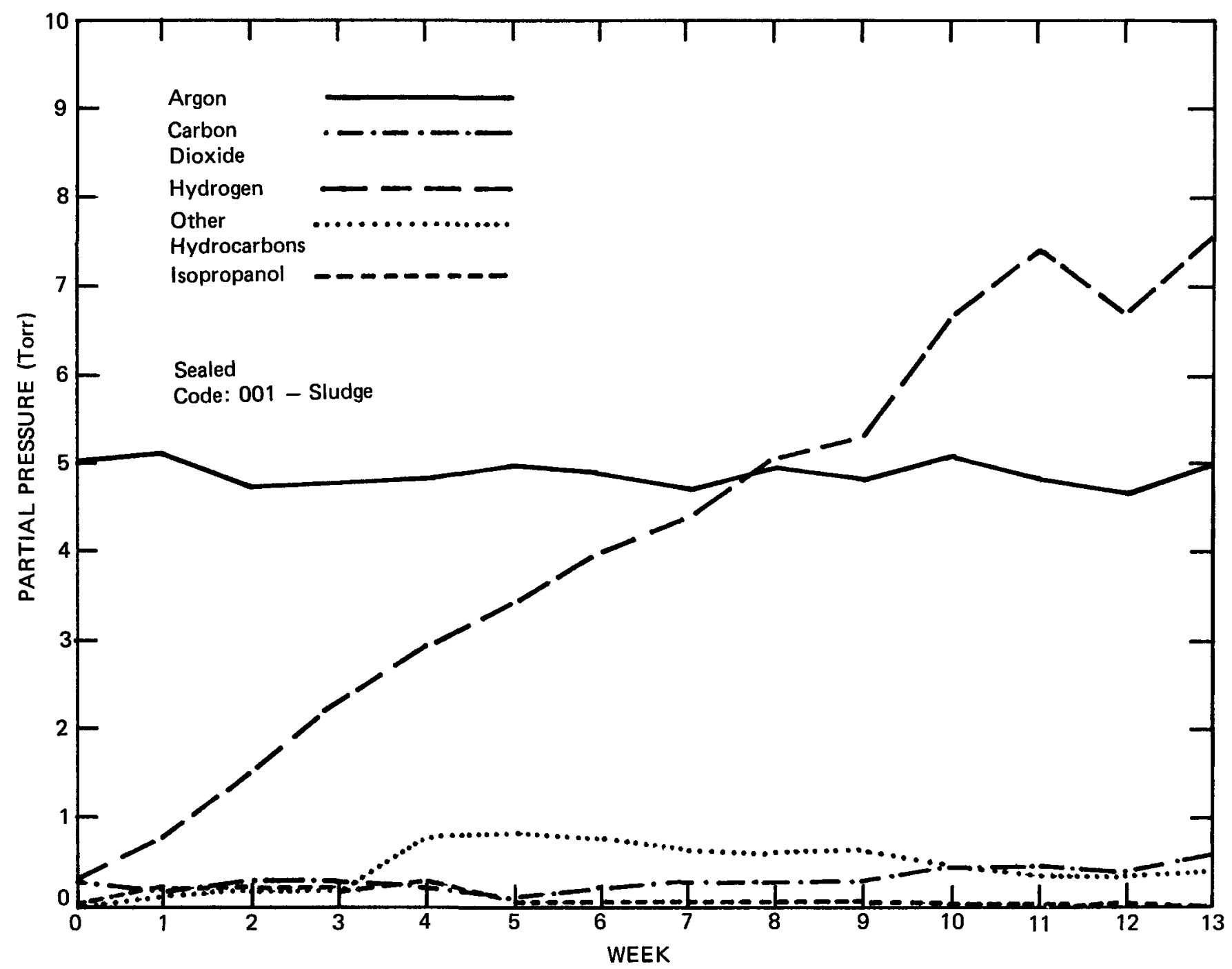

FIGURE B-1d. D29258 Atmosphere: Argon, Carbon Dioxide, Hydrogen, Other Hydrocarbons, Isopropanol 
TABLE B-1. D29258 TRU Gas Generation Volume Percent

\begin{tabular}{|c|c|c|c|c|c|c|c|c|c|c|c|}
\hline \multirow{2}{*}{$\begin{array}{l}\text { Phase II } \\
\text { Week } \\
\end{array}$} & \multicolumn{11}{|c|}{$\begin{array}{c}\text { Gas Analy sis } \\
\text { (Vol \%) }\end{array}$} \\
\hline & $\mathrm{N}_{2}$ & $\mathrm{O}_{2}$ & $\mathrm{Ar}$ & $\mathrm{CO}_{2}$ & $\mathrm{H}_{2}$ & $\mathrm{HC}$ & Tric & $\mathrm{CH}_{2} \mathrm{Cl}_{2}$ & $\mathrm{CCl}_{4}$ & Freon & $\mathrm{C}_{3} \mathrm{H}_{7} \mathrm{OH}$ \\
\hline 0 & 76.20 & 22.88 & 0.82 & 0.05 & 0.05 & -- & -- & --- & --- & --- & --- \\
\hline 1 & 76.44 & 22.51 & 0.83 & 0.03 & 0.13 & 0.02 & -- & ---- & -- & $-\cdots$ & 0.04 \\
\hline 2 & 76.13 & 22.73 & 0.77 & 0.05 & 0.25 & 0.04 & --- & --- & --- & --- & 0.03 \\
\hline 3 & 76.82 & 21.90 & 0.78 & 0.05 & 0.38 & 0.03 & -- & ---- & --- & --- & 0.04 \\
\hline 4 & 76.14 & 22.37 & 0.79 & 0.04 & 0.48 & 0.13 & -- & ---- & --- & --- & 0.05 \\
\hline 5 & 76.79 & 21.67 & 0.81 & 0.02 & 0.56 & 0.14 & $\ldots$ & --- & --- & --- & 0.01 \\
\hline 6 & 77.33 & 21.03 & 0.80 & 0.04 & 0.66 & 0.13 & -- & $-\cdots$ & -- & $\ldots$ & 0.01 \\
\hline 7 & 76.39 & 21.95 & 0.77 & 0.05 & 0.72 & 0.11 & --- & ---- & -- & --- & 0.01 \\
\hline 8 & 76.01 & 22.19 & 0.81 & 0.05 & 0.83 & 0.10 & -- & ---- & -- & $-\ldots$ & 0.01 \\
\hline 9 & 76.46 & 21.71 & 0.79 & 0.05 & 0.87 & 0.11 &.- & ---- & -- & $\ldots$ & 0.01 \\
\hline 10 & 77.08 & 20.83 & 0.83 & 0.08 & 1.09 & 0.08 & --- & --- & -- & $\ldots-$ & 0.01 \\
\hline 11 & 76.85 & 21.00 & 0.79 & 0.08 & 1.21 & 0.06 & $\ldots$ & $-\cdots$ & -- & --- & 0.01 \\
\hline 12 & 76.83 & 21.18 & 0.76 & 0.07 & 1.09 & 0.06 & -- & --- & --- & --- & 0.01 \\
\hline 13 & 77.84 & 19.95 & 0.81 & 0.10 & 1.23 & 0.07 & -- & ---- & -- & --- & --- \\
\hline
\end{tabular}

Sealed

Code: 001-sludge 
RFP-3739

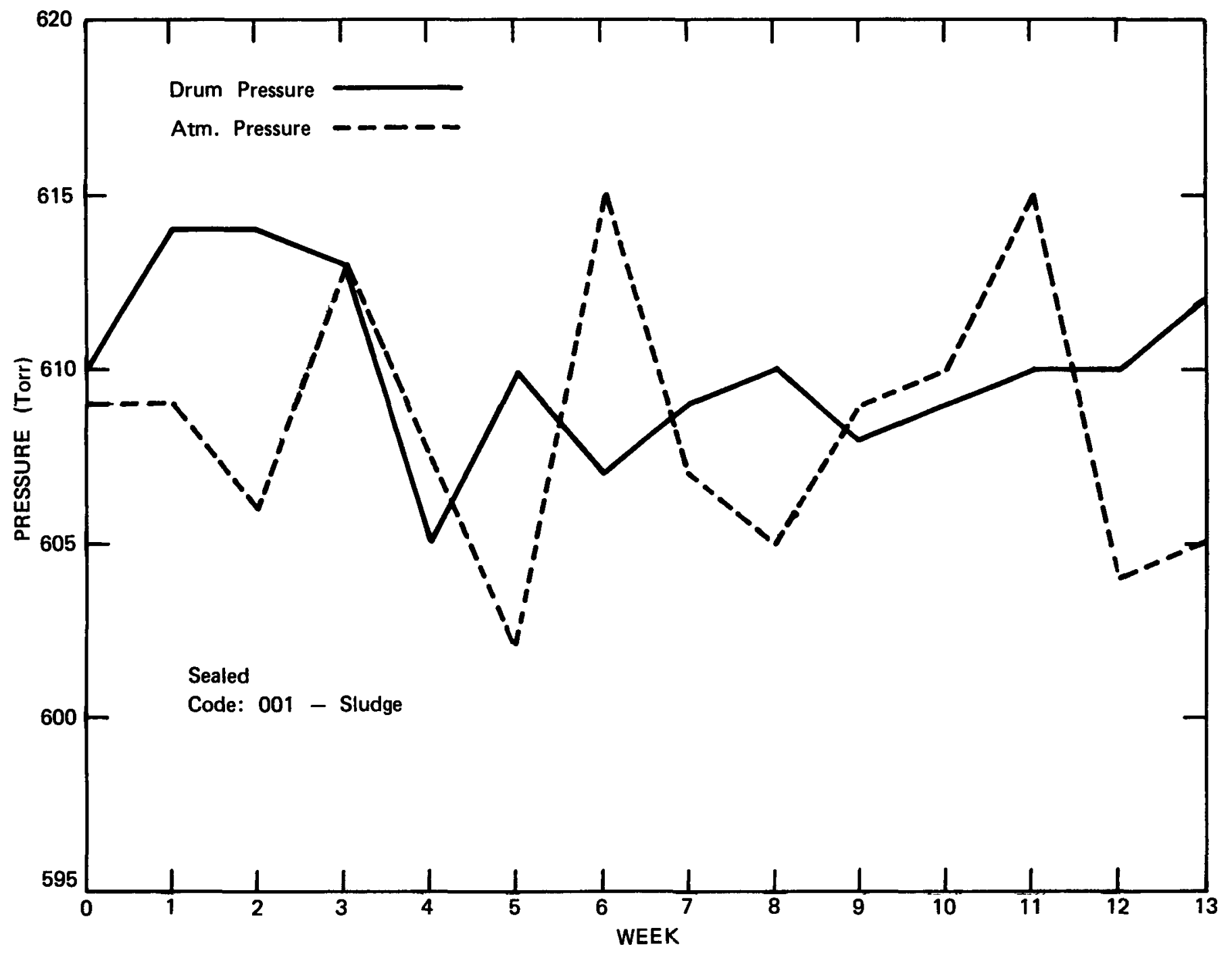

FIGURE B-2a. D31 528 Pressure 


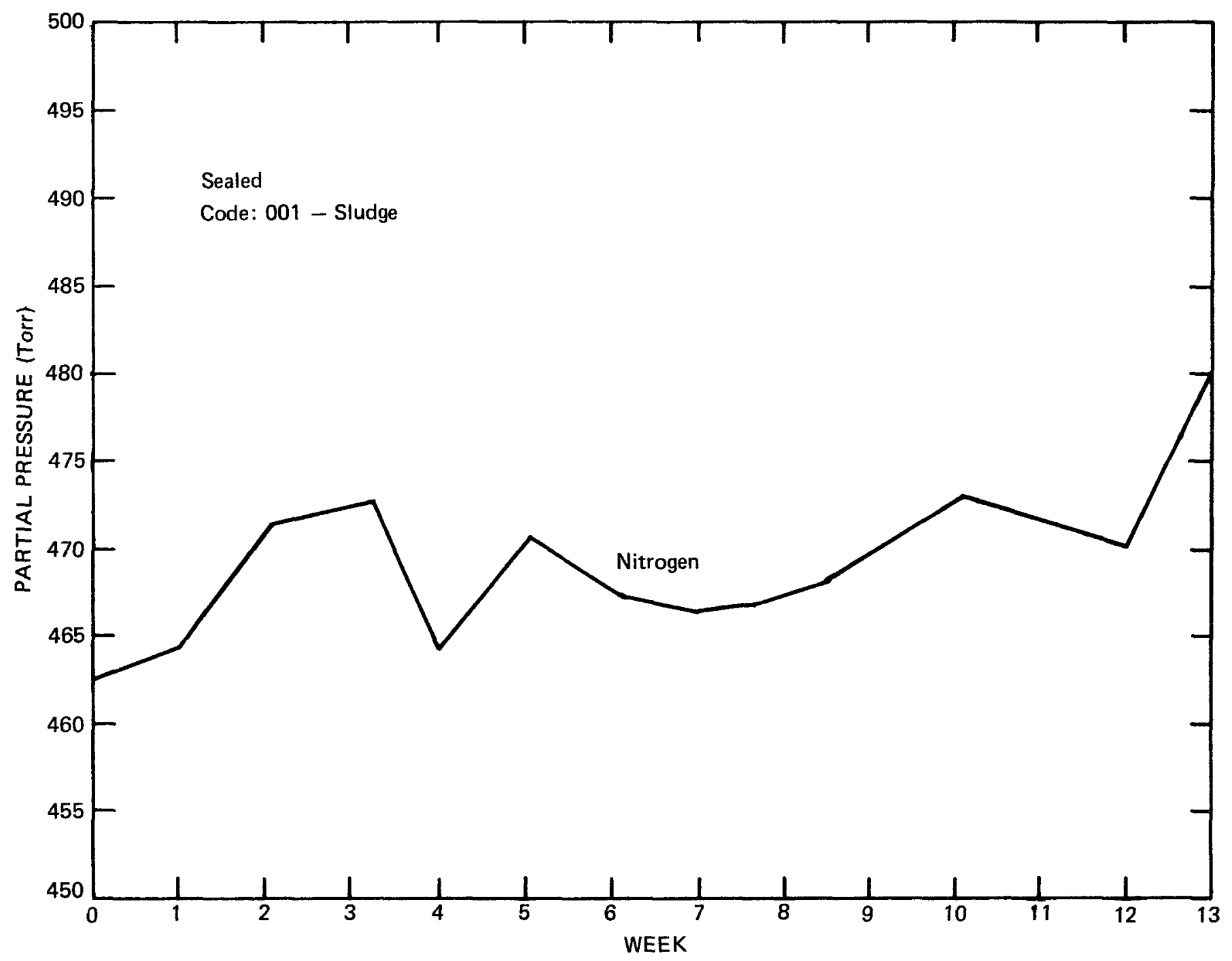

FIGURE B-2b. D31528 Atmosphere: Nitrogen 
RFP-3739

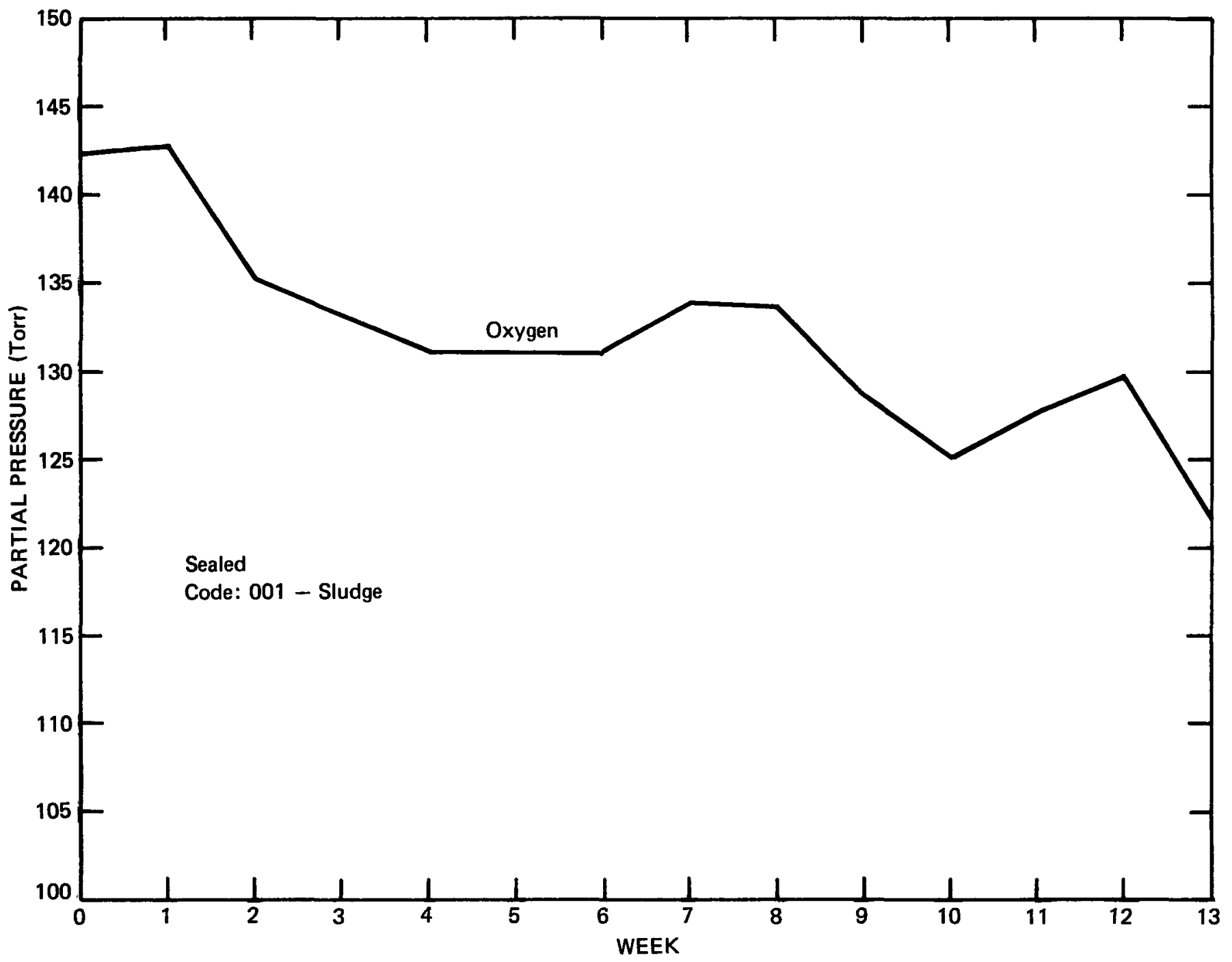

FIGURE B-2c. D31528 Atmosphere: Oxygen 


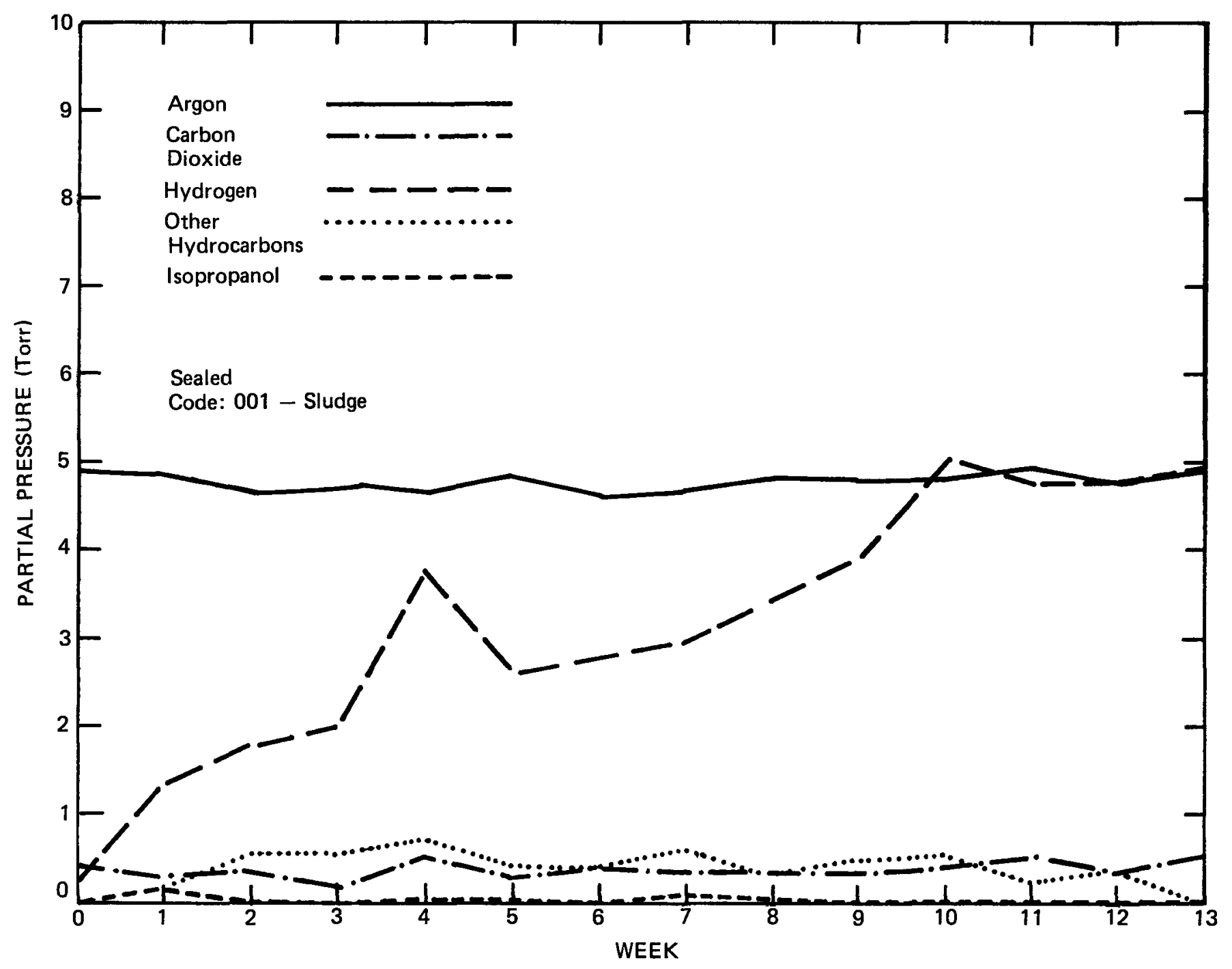

FIGURE B-2d. D31528 Atmosphere: Argon, Carbon Dioxide, Hydrogen, Other Hydrocarbons, Isopropanol 
RFP-3739

TABLE B-2. D31528 TRU Gas Generation Volume Percent

\begin{tabular}{|c|c|c|c|c|c|c|c|c|c|c|c|}
\hline \multicolumn{6}{|c|}{ Phase II Results } & \multicolumn{6}{|c|}{$\begin{array}{c}\text { Gas Analysis } \\
\text { (Vol \%) }\end{array}$} \\
\hline Week & $\mathbf{N}_{2}$ & $\mathrm{O}_{2}$ & $\mathrm{Ar}$ & $\mathrm{CO}_{2}$ & $\mathrm{H}_{2}$ & $\mathrm{HC}$ & Tric & $\mathrm{CH}_{2} \mathrm{Cl}_{2}$ & $\mathrm{CCl}_{4}$ & Freon & $\mathrm{C}_{3} \mathrm{H}_{7} \mathrm{OH}$ \\
\hline 0 & 75.80 & 23.29 & 0.80 & 0.07 & 0.04 & -- & -- & ---- & -- & --- & $\ldots$ \\
\hline 1 & 75.64 & 23.24 & 0.79 & 0.05 & 0.22 & 0.03 & --- & ---- & --- & ---- & 0.03 \\
\hline 2 & 76.77 & 22.03 & 0.76 & 0.06 & 0.29 & 0.09 & --- & ---- & --- & ---- & --- \\
\hline 3 & 77.03 & 21.75 & 0.77 & 0.03 & 0.33 & 0.09 & -- & ---- & --- & --- & $-\infty$ \\
\hline 4 & 76.70 & 21.69 & 0.77 & 0.09 & 0.62 & 0.12 & --- & ---- & --- & ---- & 0.01 \\
\hline 5 & 77.68 & 21.47 & 0.79 & 0.05 & 0.43 & 0.07 & --- & ---- & --- & --- & 0.01 \\
\hline 6 & 77.02 & 21.62 & 0.76 & 0.07 & 0.46 & 0.07 & -- & ---- & --- & --- & --- \\
\hline 7 & 76.58 & 21.98 & 0.77 & 0.06 & 0.49 & 0.10 & --- & ---- & --- & ---- & 0.02 \\
\hline 8 & 76.62 & 21.90 & 0.79 & 0.06 & 0.57 & 0.05 & --- & --- & --- & ---- & 0.01 \\
\hline 9 & 77.27 & 21.15 & 0.79 & 0.06 & 0.65 & 0.08 & --- & ---- & --- & $-\cdots$ & -- \\
\hline 10 & 77.68 & 20.54 & 0.79 & 0.07 & 0.83 & 0.09 & --- & ---- & --- & --- & --- \\
\hline 11 & 77.34 & 20.94 & 0.81 & 0.09 & 0.78 & 0.04 & --- & $-\cdots$ & --- & $-\cdots$ & --- \\
\hline 12 & 77.06 & 21.26 & 0.78 & 0.06 & 0.78 & 0.06 & --- & --- & --- & --- & --- \\
\hline 13 & 78.45 & 19.86 & 0.80 & 0.09 & 0.80 & $-\cdots$ & --- & --- & --- & ---- & --- \\
\hline
\end{tabular}

Sealed

Code: 001-sludge 


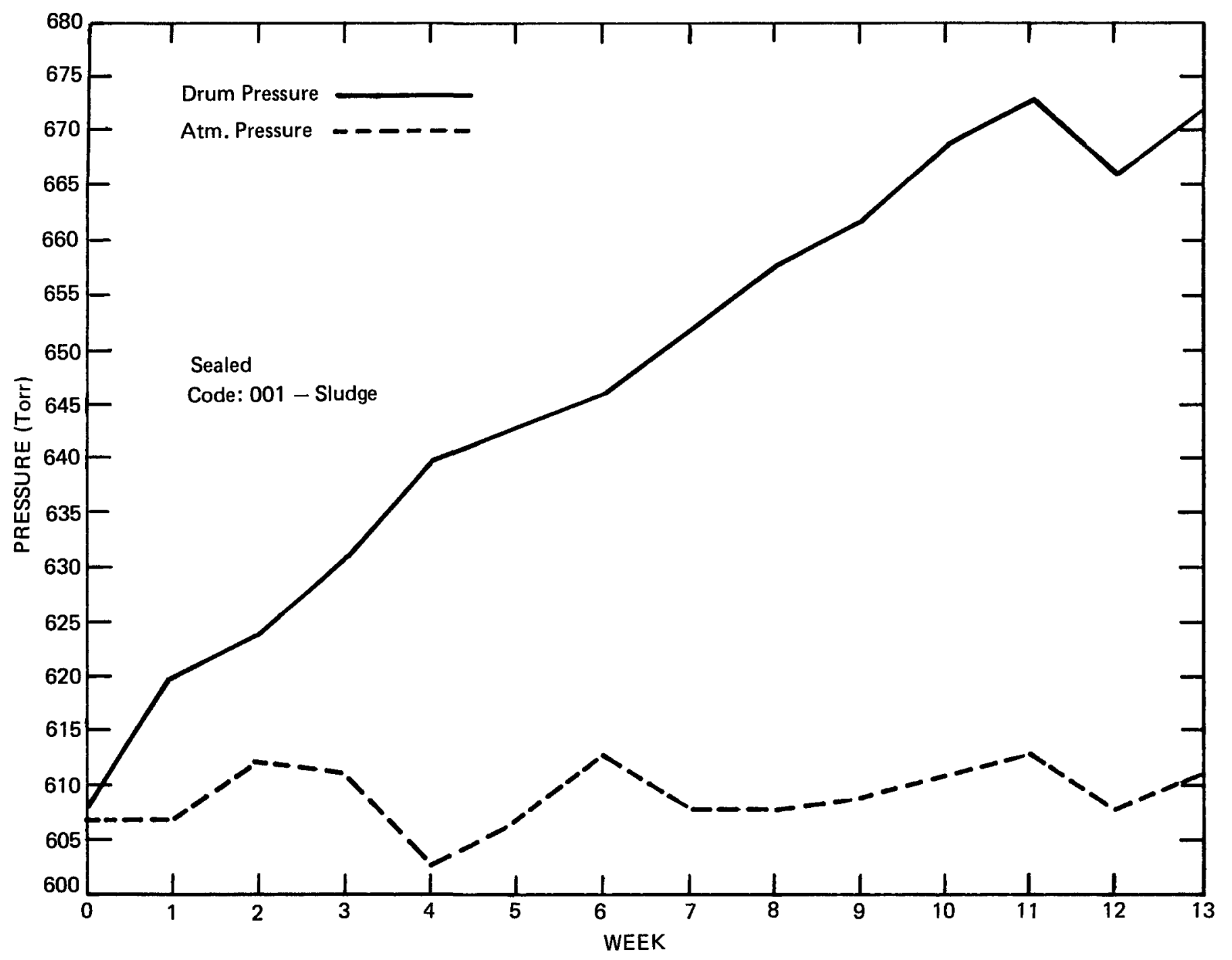

FIGURE B-3a. D32180 Pressure 
RFP-3739

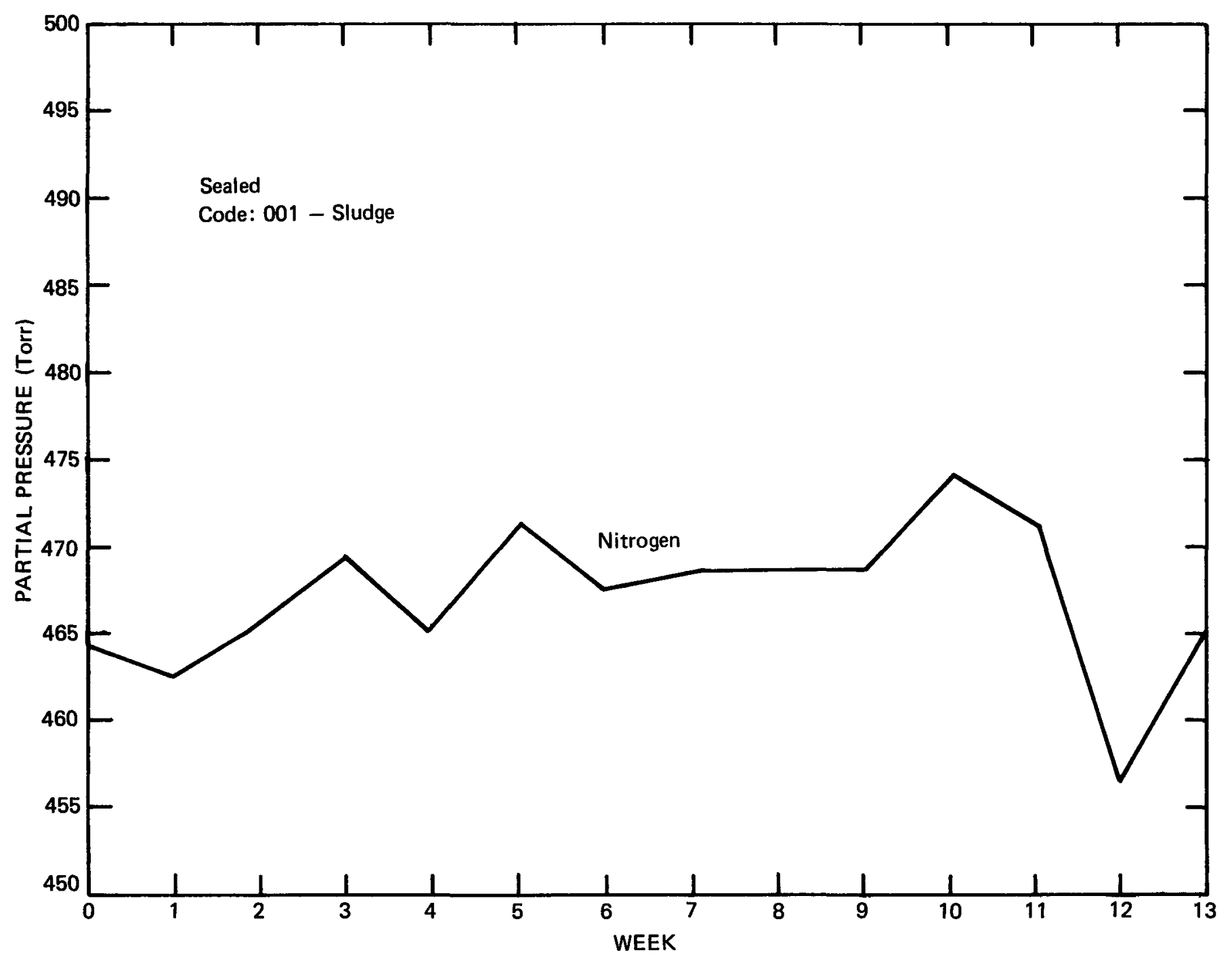

FIGURE B-3b. D32180 Atmosphere: Nitrogen 


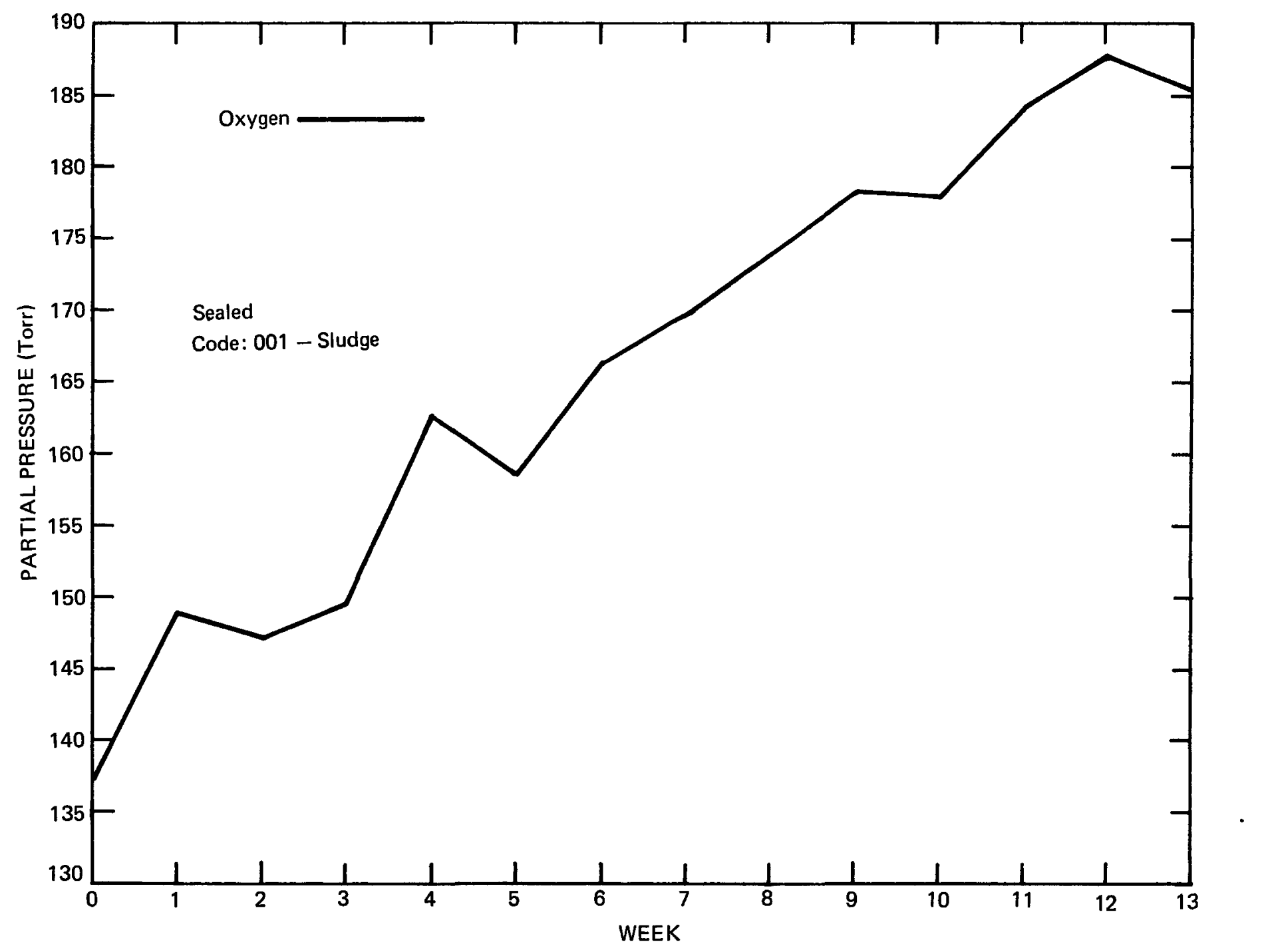

FIGURE B-3c. D32180 Atmosphere: Oxygen 
RFP-3739

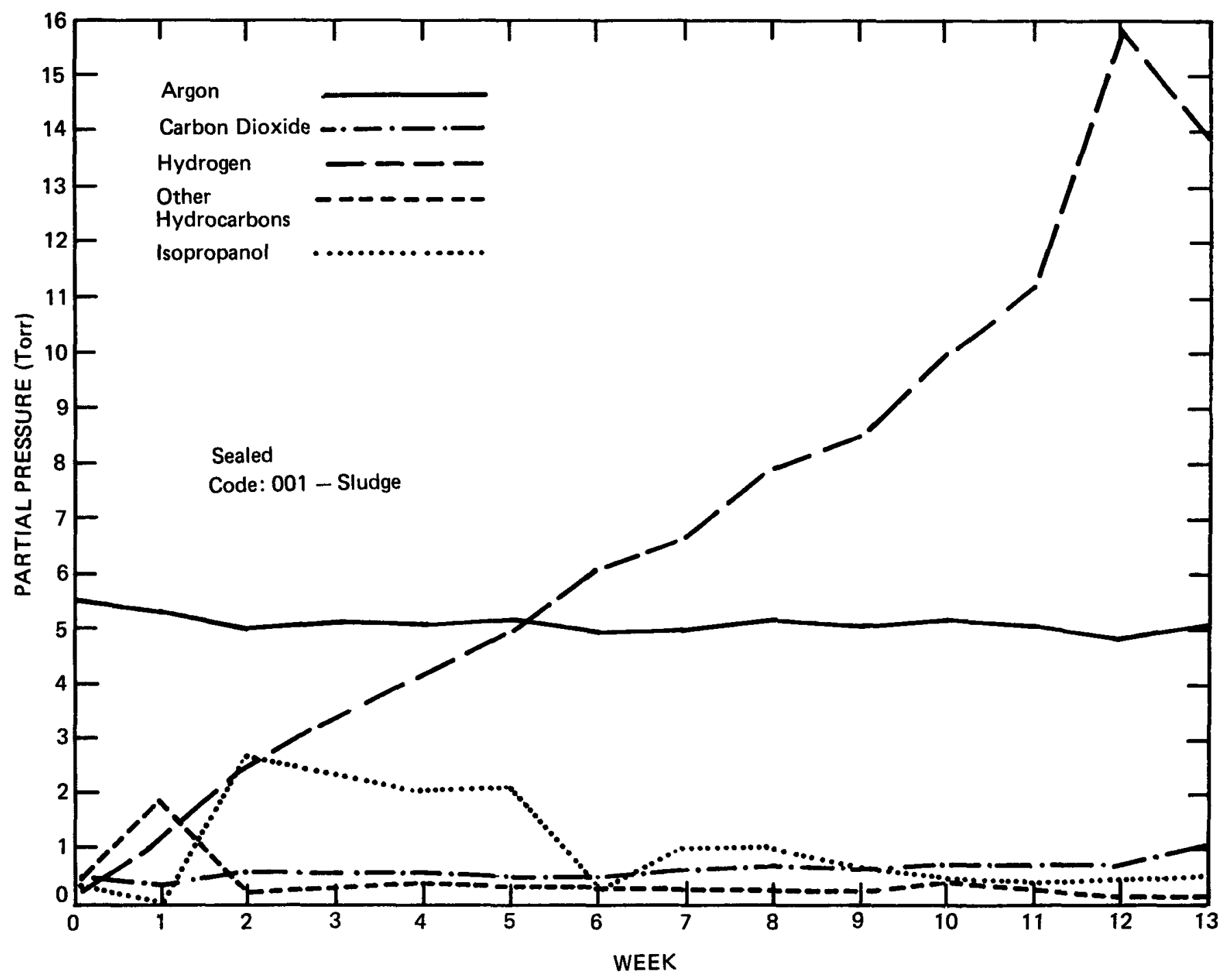

FIGURE B-3d. D32180 Atmosphere: Argon, Carbon Dioxide, Hydrogen, Other Hydrocarbons, Isopropanol 
TABLE B-3. D32180 TRU Gas Generation Volume Percent

\begin{tabular}{|c|c|c|c|c|c|c|c|c|c|c|c|}
\hline \multicolumn{6}{|c|}{ Phase II Results } & \multicolumn{6}{|c|}{$\begin{array}{c}\text { Gas Analysis } \\
\text { (Vol \%) }\end{array}$} \\
\hline Week & $\mathrm{N}_{2}$ & $\mathrm{O}_{2}$ & $\mathrm{Ar}$ & $\mathrm{CO}_{2}$ & $\mathrm{H}_{2}$ & $\mathrm{HC}$ & Tric & $\mathrm{CH}_{2} \mathrm{O}_{2}$ & $\mathrm{CO}_{4}$ & Freon & $\mathrm{C}_{3} \mathrm{H}_{7} \mathrm{OH}$ \\
\hline 0 & 76.35 & 22.53 & 0.90 & 0.08 & 0.02 & 0.06 & --- & ---- & --- & --- & 0.06 \\
\hline 1 & 74.61 & 24.00 & 0.85 & 0.06 & 0.18 & 0.30 & -- & ---- & --- & --- & --- \\
\hline 2 & 74.63 & 23.61 & 0.80 & 0.10 & 0.40 & 0.03 & -- & ---- & -- & --- & 0.43 \\
\hline 3 & 74.41 & 23.73 & 0.81 & 0.09 & 0.54 & 0.05 & -- & --- & -- & --- & 0.37 \\
\hline 4 & 72.62 & 25.42 & 0.79 & 0.09 & 0.65 & 0.06 & -- & ---- & -- & --- & 0.32 \\
\hline 5 & 73.32 & 24.65 & 0.80 & 0.08 & 0.77 & 0.05 & $\ldots$ & --- & -- & --- & 0.33 \\
\hline 6 & 72.38 & 25.74 & 0.76 & 0.08 & 0.94 & 0.05 & -- & ---- & -- & ---- & 0.05 \\
\hline 7 & 71.87 & 26.05 & 0.76 & 0.10 & 1.02 & 0.04 & $\ldots$ & --- & -- & - - - & 0.16 \\
\hline 8 & 71.26 & 26.45 & 0.78 & 0.11 & 1.20 & 0.04 & $\ldots$ & --- & $\ldots$ & $\ldots-$ & 0.16 \\
\hline 9 & 70.78 & 26.94 & 0.76 & 0.10 & 1.28 & 0.04 & $\ldots$ & $-\cdots$ & -- & $\ldots$ & 0.10 \\
\hline 10 & 70.90 & 26.60 & 0.72 & 0.11 & 1.49 & 0.06 & -- & --- & $\ldots$ & $\ldots$ & 0.07 \\
\hline 11 & 70.01 & 27.37 & 0.75 & 0.11 & 1.66 & 0.04 & -- & --- & -- & $\ldots-$ & 0.06 \\
\hline 12 & 68.52 & 28.19 & 0.72 & 0.11 & 2.37 & 0.02 & -- & --- &.- & --- & 0.07 \\
\hline 13 & 69.36 & 27.57 & 0.75 & 0.16 & 2.06 & 0.02 & -- & --- & -- & --- & 0.06 \\
\hline
\end{tabular}

Sealed

Code: 001-sludge 
RFP-3739

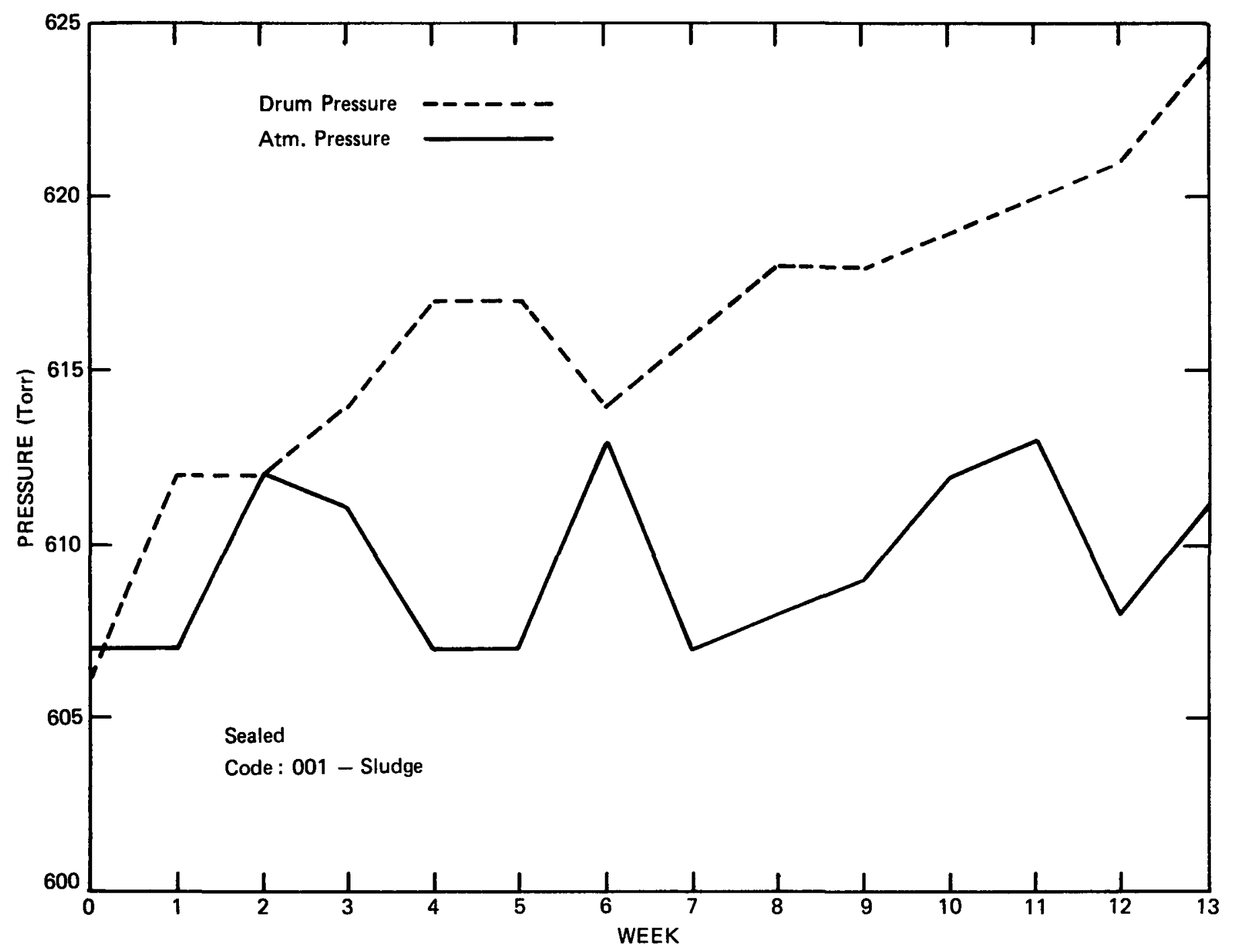

FIGURE B-4a. D32186 Pressure 


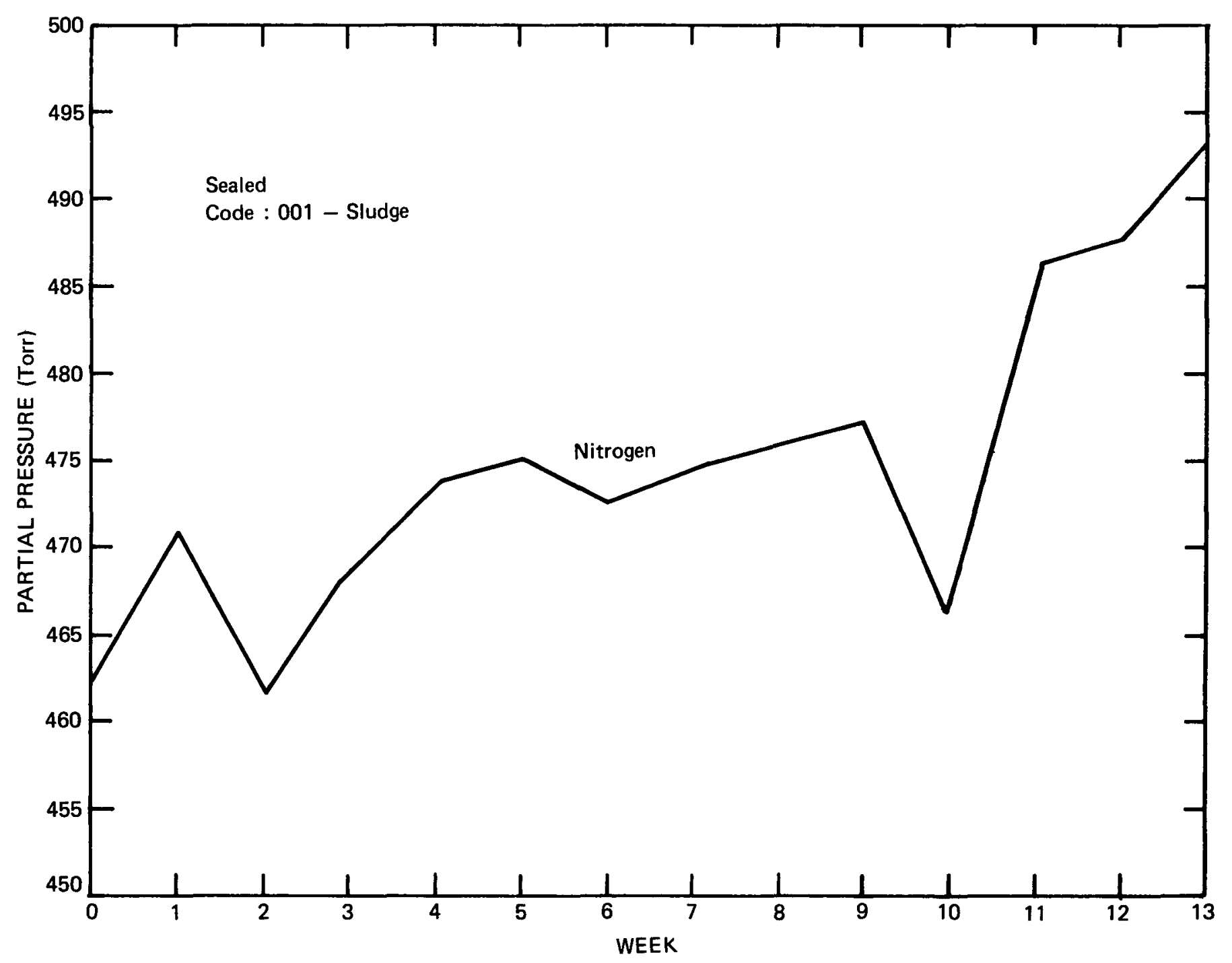

FIGURE B-4b. D32186 Atmosphere: Nitrogen 


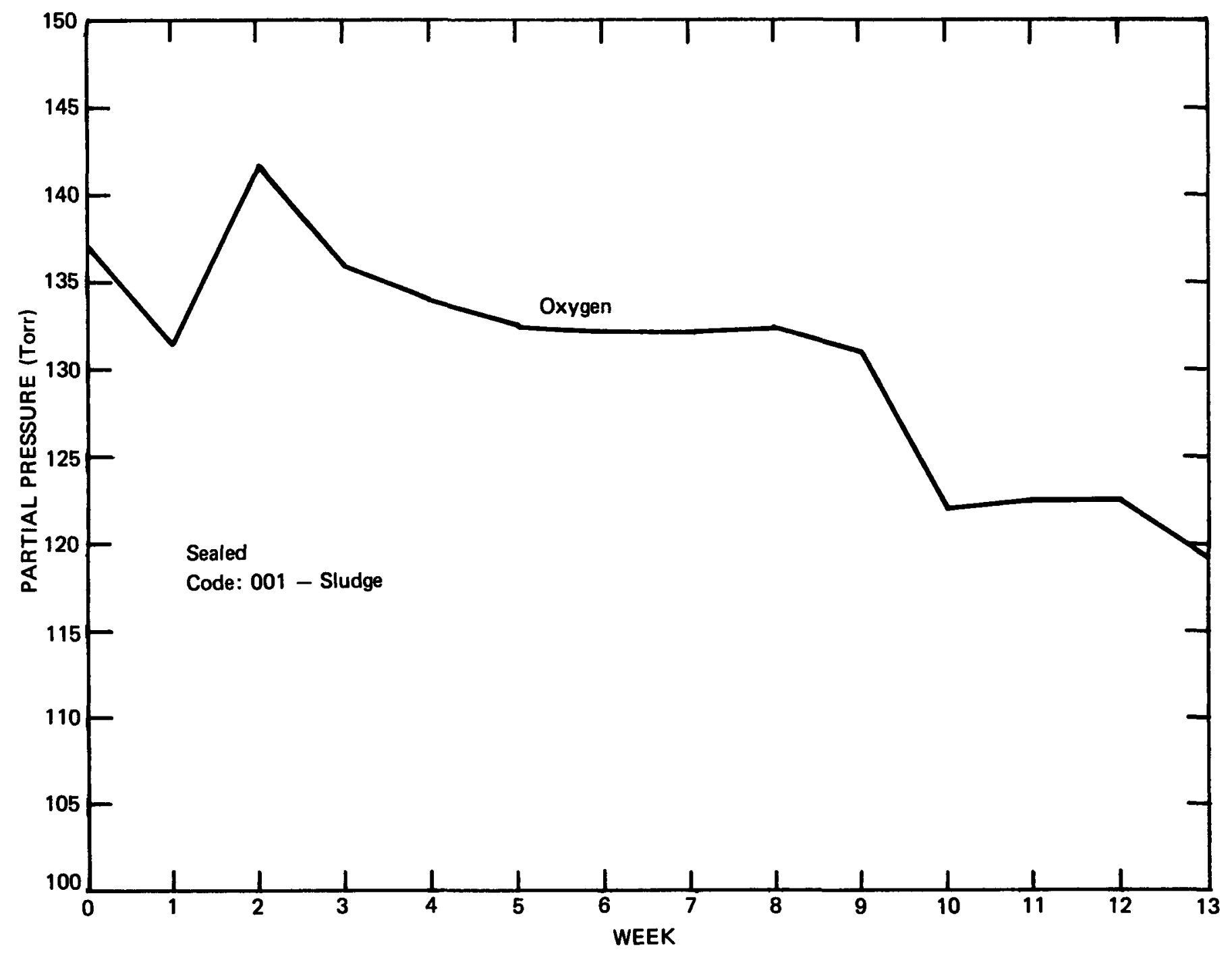

FIGURE B-4c. D32186 Atmosphere: Oxygen 


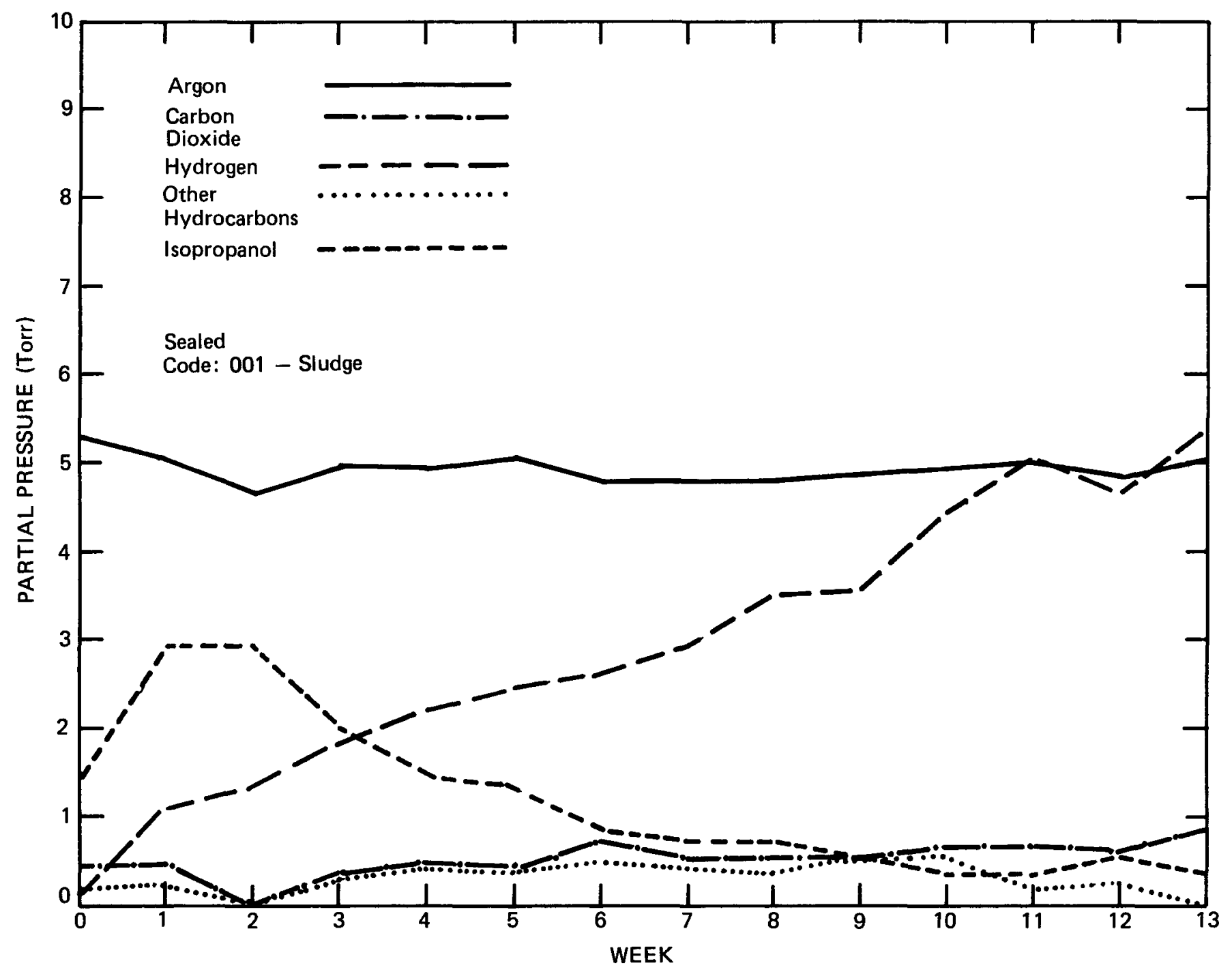

FIGURE B-4d. D32186 Atmosphere: Argon, Carbon Dioxide, Hydrogen, Other Hydrocarbons, Isopropanol 
RFP-3739

TABLE B-4. D32186 TRU Gas Generation Volume Percent

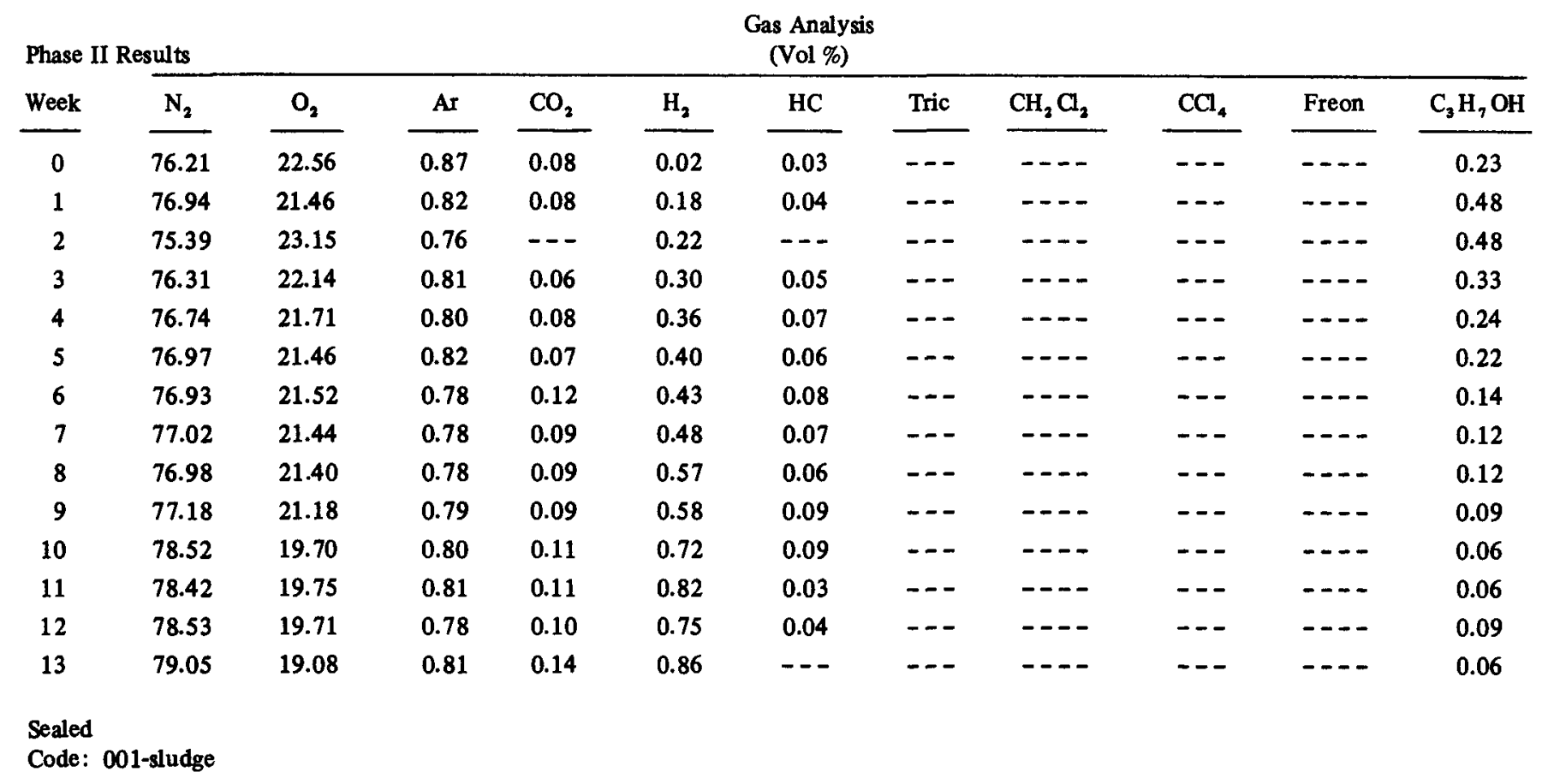




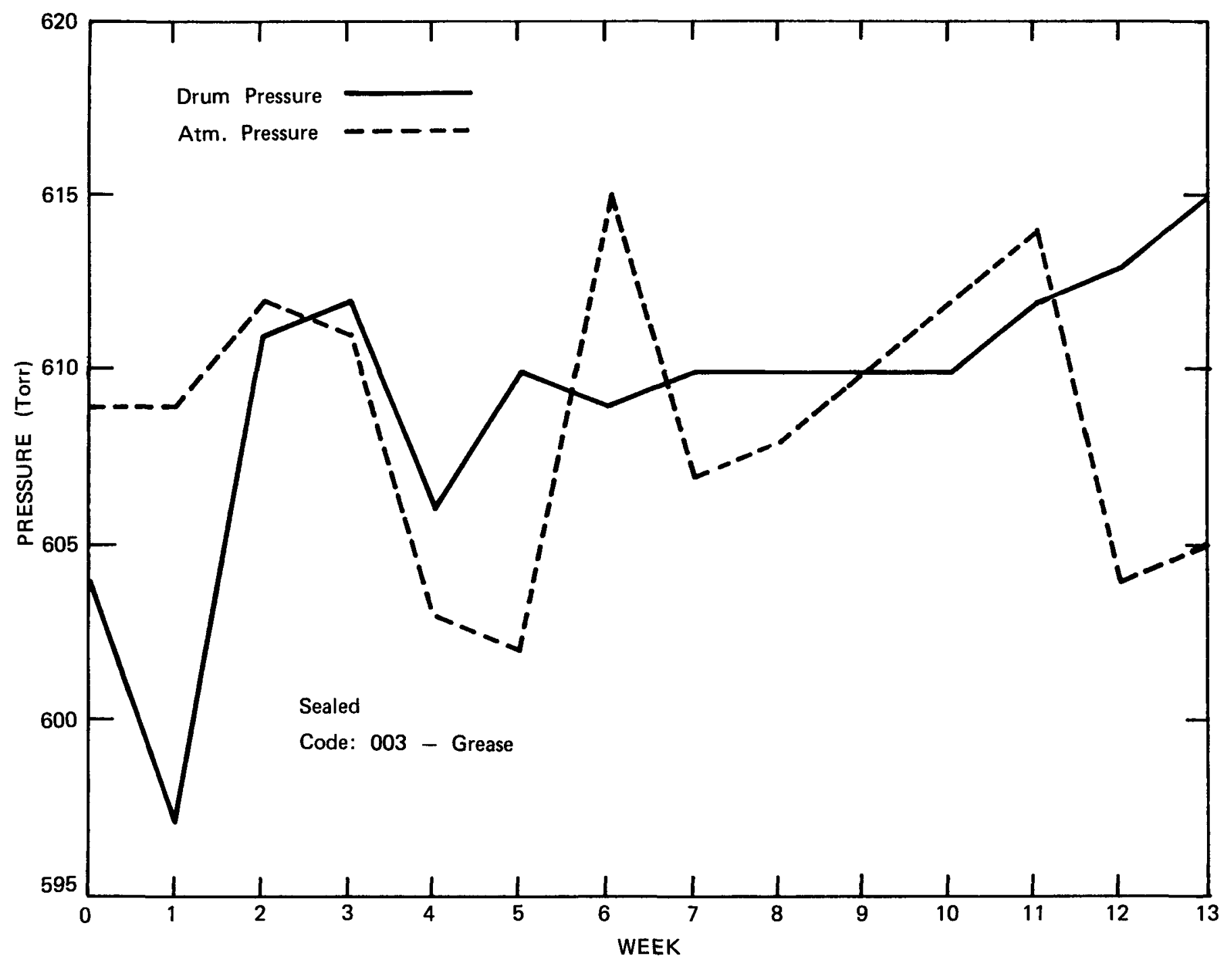

FIGURE B-5a. D31254 Pressure 
RFP-3739

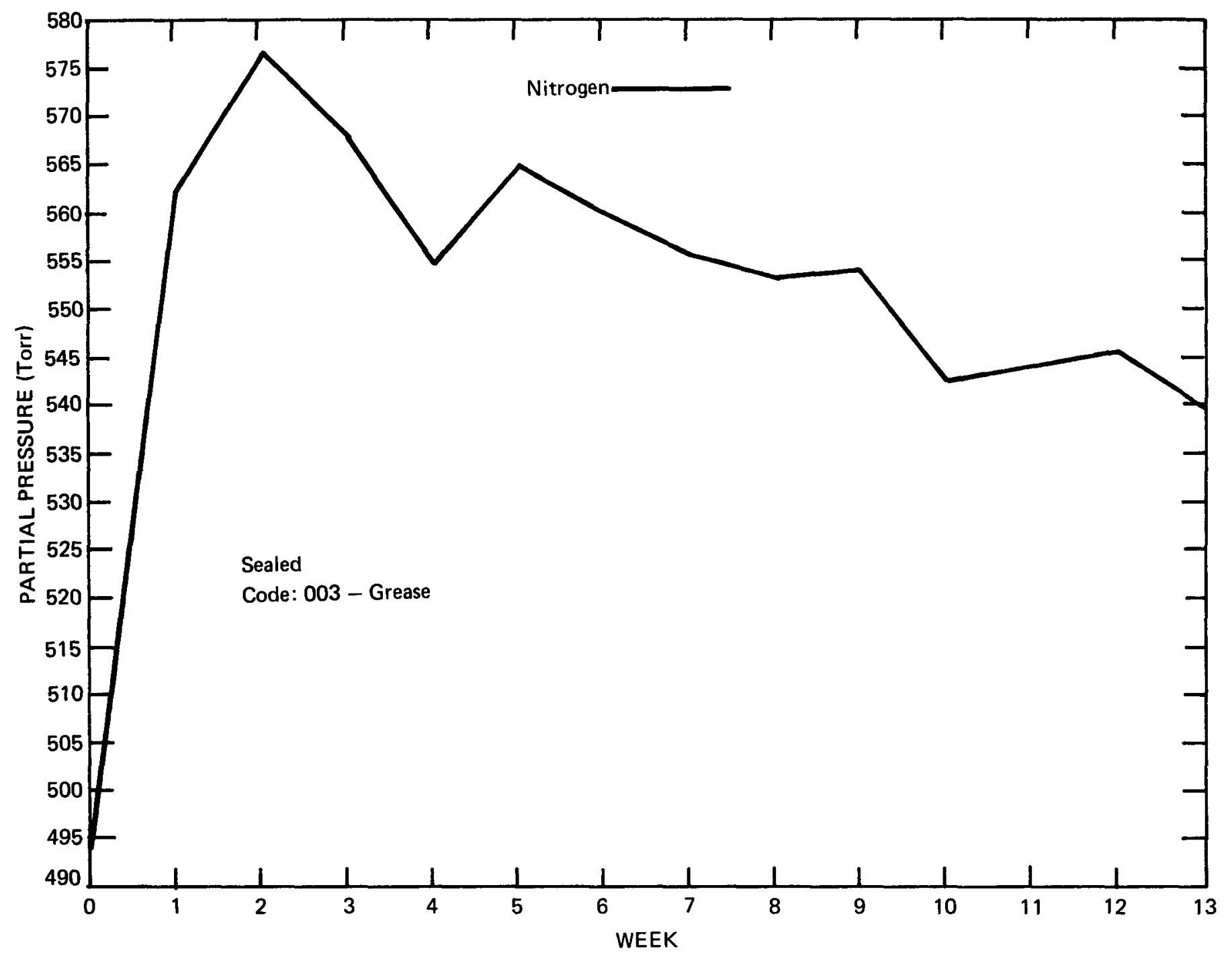

FIGURE B-5b. D31254 Atmosphere: Nitrogen 


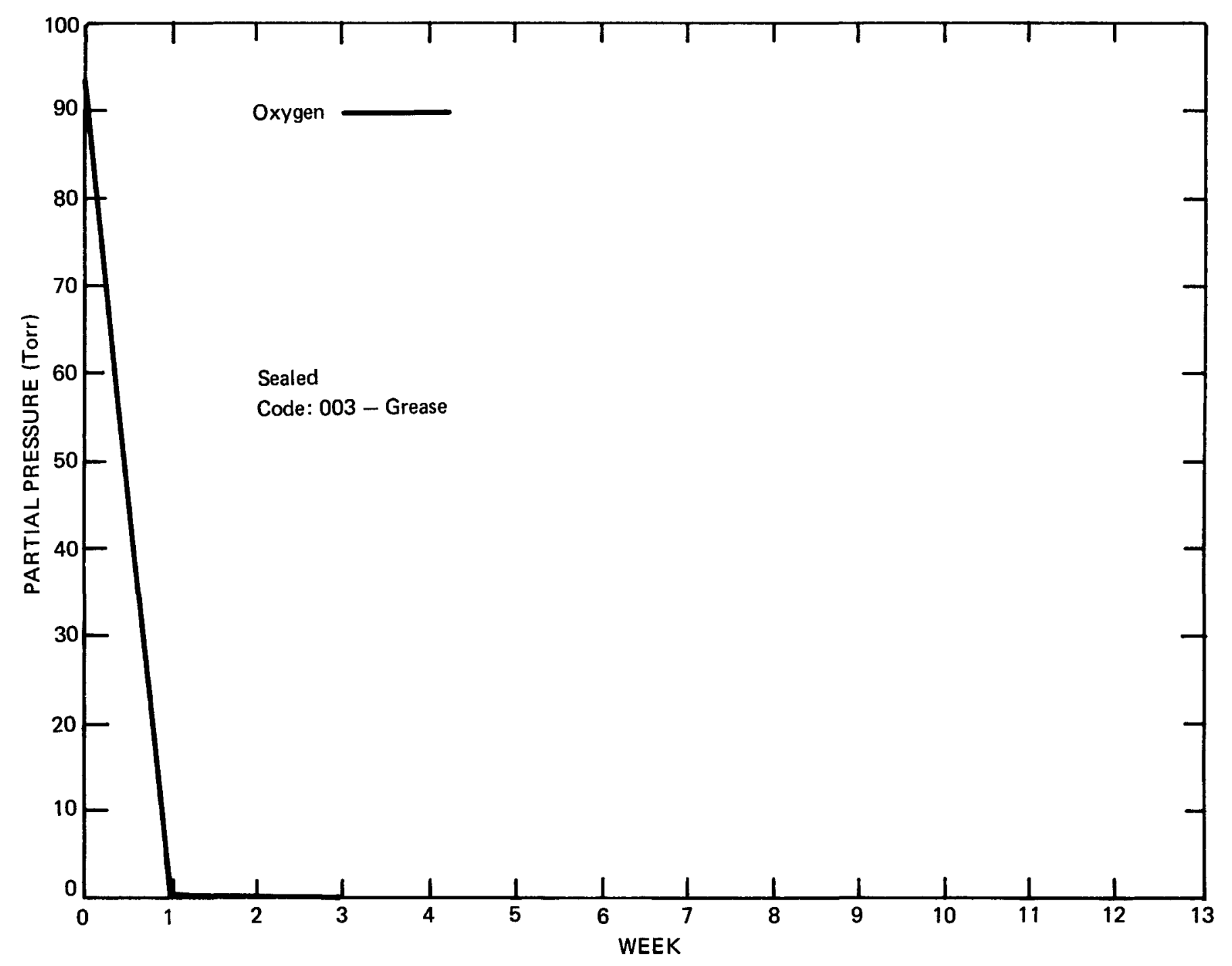

FIGURE B-5c. D31254 Atmosphere: Oxygen 
RFP-3739

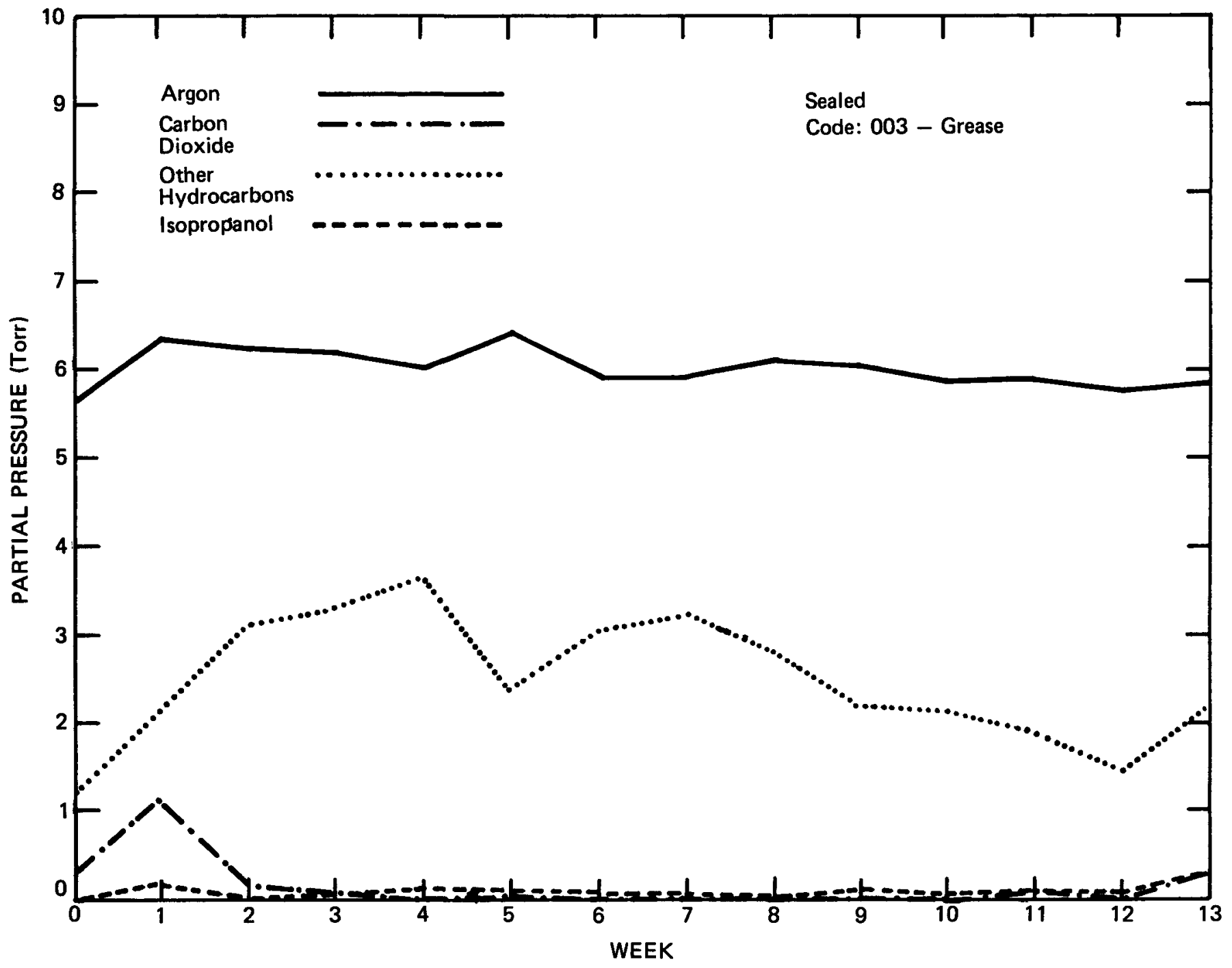

FIGURE B-5d. D31254 Atmosphere: Argon, Carbon Dioxide, Other Hydrocarbons, Isopropanol 


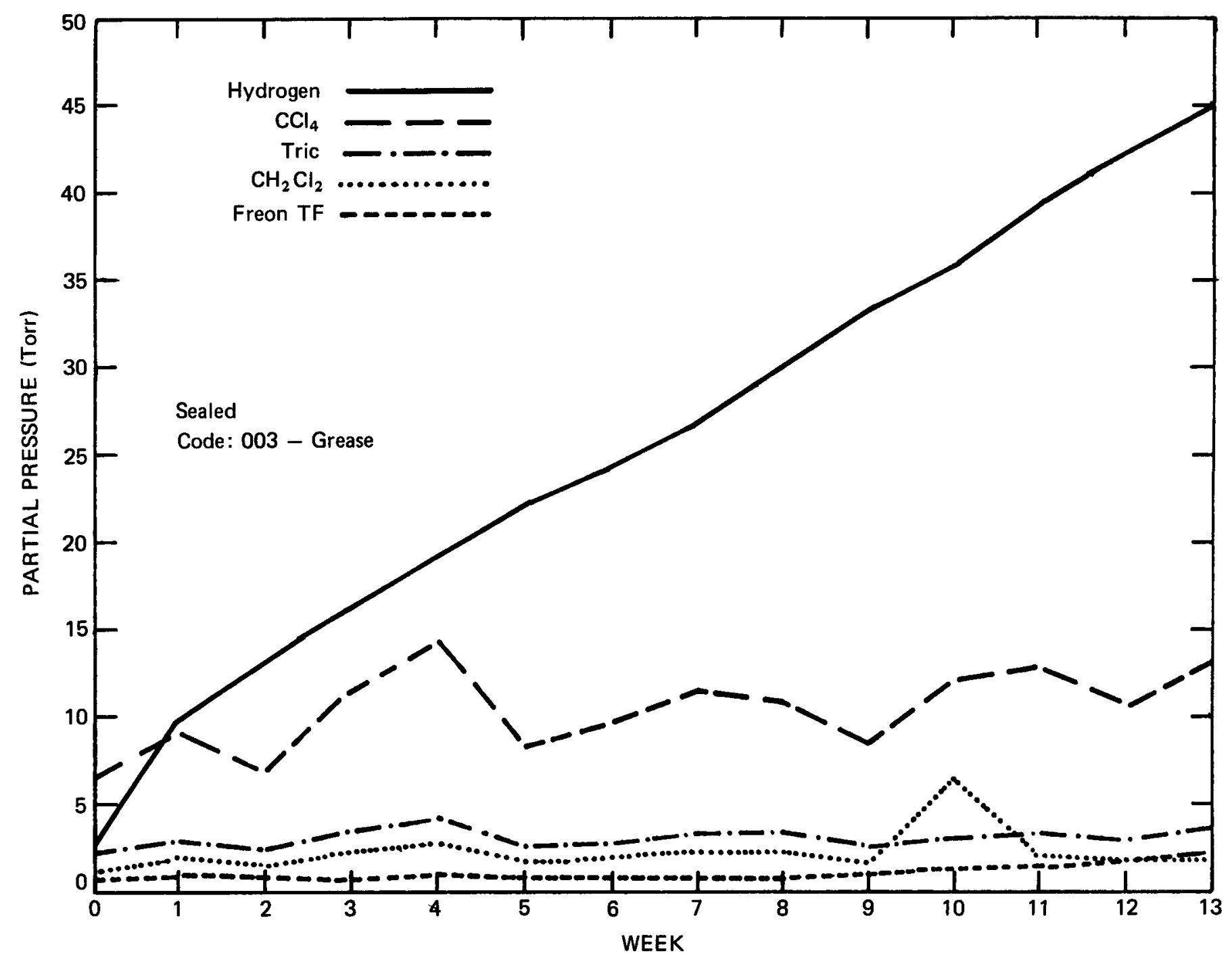

FIGURE B-5e. D31254 Atmosphere: Tric, $\mathrm{CCl}_{4}$, Hydrogen, $\mathrm{CH}_{2} \mathrm{Cl}_{2}$, Freon TF 
RFP-3739

TABLE B-5. D31254 TRU Gas Generation Volume Percent

\begin{tabular}{|c|c|c|c|c|c|c|c|c|c|c|c|}
\hline \multicolumn{6}{|c|}{ Phase II Results } & \multicolumn{6}{|c|}{$\begin{array}{c}\text { Gas Analysis } \\
\text { (Vol \%) }\end{array}$} \\
\hline Week & $\mathbf{N}_{2}$ & $\mathrm{O}_{2}$ & $\mathbf{A r}$ & $\mathrm{CO}_{2}$ & $\mathrm{H}_{2}$ & HC & Tric & $\mathrm{CH}_{2} \mathrm{Cl}_{2}$ & $\mathrm{CCl}_{4}$ & Freon & $\mathrm{C}_{3} \mathrm{H}_{7} \mathrm{OH}$ \\
\hline 0 & 81.65 & 14.97 & 0.93 & 0.05 & 0.43 & 0.19 & 0.35 & 0.23 & 1.09 & 0.11 & --- \\
\hline 1 & 94.11 & 0.07 & 1.06 & 0.19 & 1.66 & 0.36 & 0.47 & 0.35 & 1.55 & 0.15 & 0.03 \\
\hline 2 & 94.34 & 0.02 & 1.02 & 0.03 & 2.14 & 0.51 & 0.39 & 0.27 & 1.14 & 0.14 & --- \\
\hline 3 & 92.73 & 0.04 & 1.01 & 0.01 & 0.54 & 0.54 & 0.56 & 0.41 & 1.91 & 0.12 & 0.01 \\
\hline 4 & 91.50 & 0.04 & 0.99 & --- & 3.18 & 0.60 & 0.68 & 0.49 & 2.37 & 0.17 & 0.02 \\
\hline 5 & 92.61 & 0.07 & 1.05 & 0.01 & 3.64 & 0.39 & 0.43 & 0.31 & 1.39 & 0.13 & 0.02 \\
\hline 6 & 91.94 & 0.01 & 0.97 & --- & 4.01 & 0.50 & 0.46 & 0.34 & 1.61 & 0.14 & 0.01 \\
\hline 7 & 91.08 & 0.02 & 0.97 & --- & 4.41 & 0.53 & 0.55 & 0.41 & 1.89 & 0.13 & 0.01 \\
\hline 8 & 90.76 & 0.02 & 1.00 & --- & 4.92 & 0.46 & 0.56 & 0.40 & 1.79 & 0.14 & -- \\
\hline 9 & 90.82 & 0.02 & 0.99 & --- & 5.48 & 0.36 & 0.43 & 0.30 & 1.41 & 0.17 & 0.02 \\
\hline 10 & 88.94 & 0.03 & 0.96 & -- & 5.89 & 0.35 & 0.51 & 1.08 & 2.01 & 0.22 & 0.01 \\
\hline 11 & 88.92 & 0.03 & 0.96 & 0.02 & 6.44 & 0.31 & 0.55 & 0.37 & 2.12 & 0.26 & 0.01 \\
\hline 12 & 89.04 & 0.02 & 0.94 & --- & 6.90 & 0.24 & 0.49 & 0.31 & 1.78 & 0.30 & 0.01 \\
\hline 13 & 87.79 & 0.03 & 0.95 & 0.05 & 7.31 & 0.36 & 0.60 & 0.40 & 2.18 & 0.31 & 0.04 \\
\hline
\end{tabular}

Seaied

Code: 003-Grease 


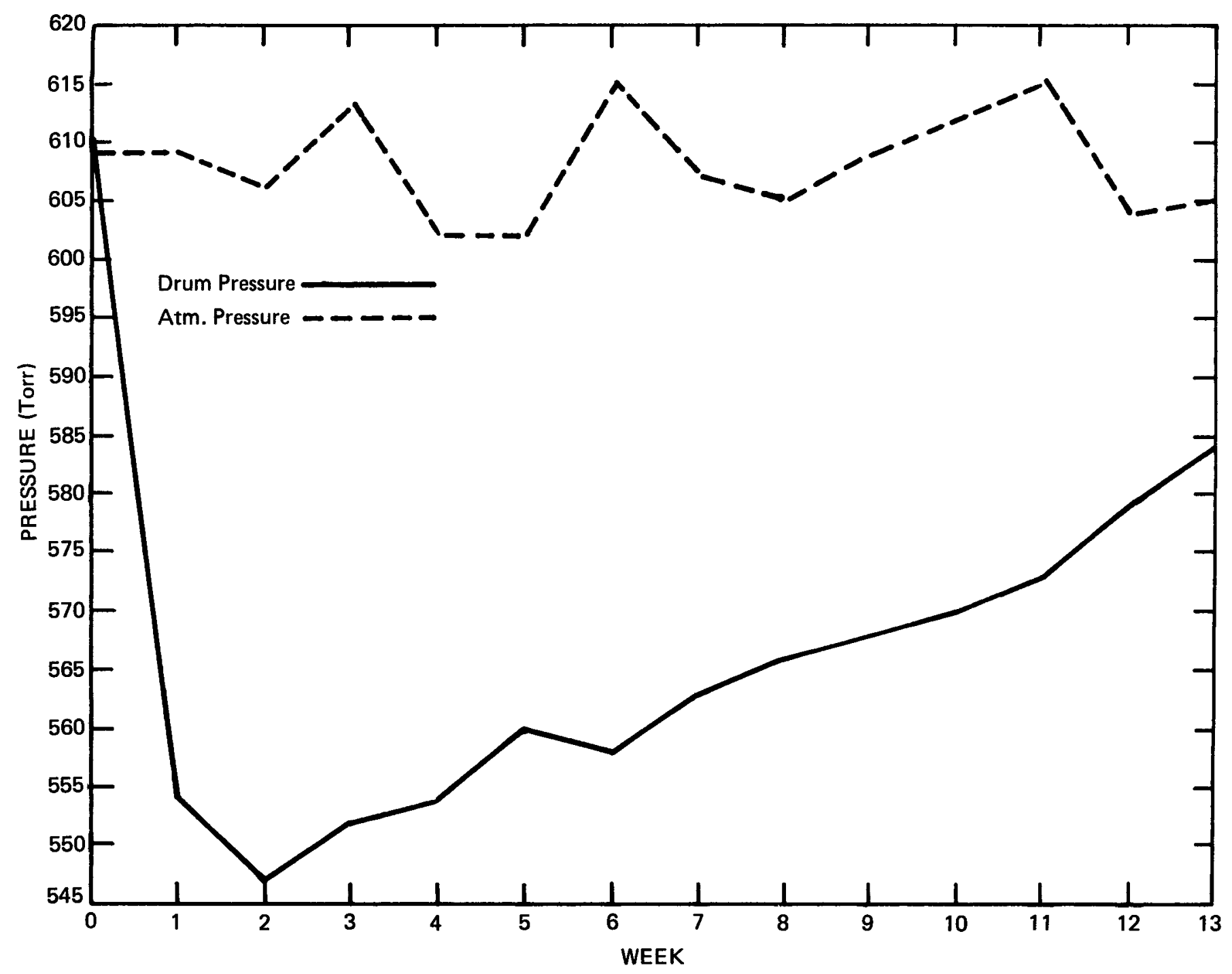

FIGURE B-6a. D31403 Pressure 


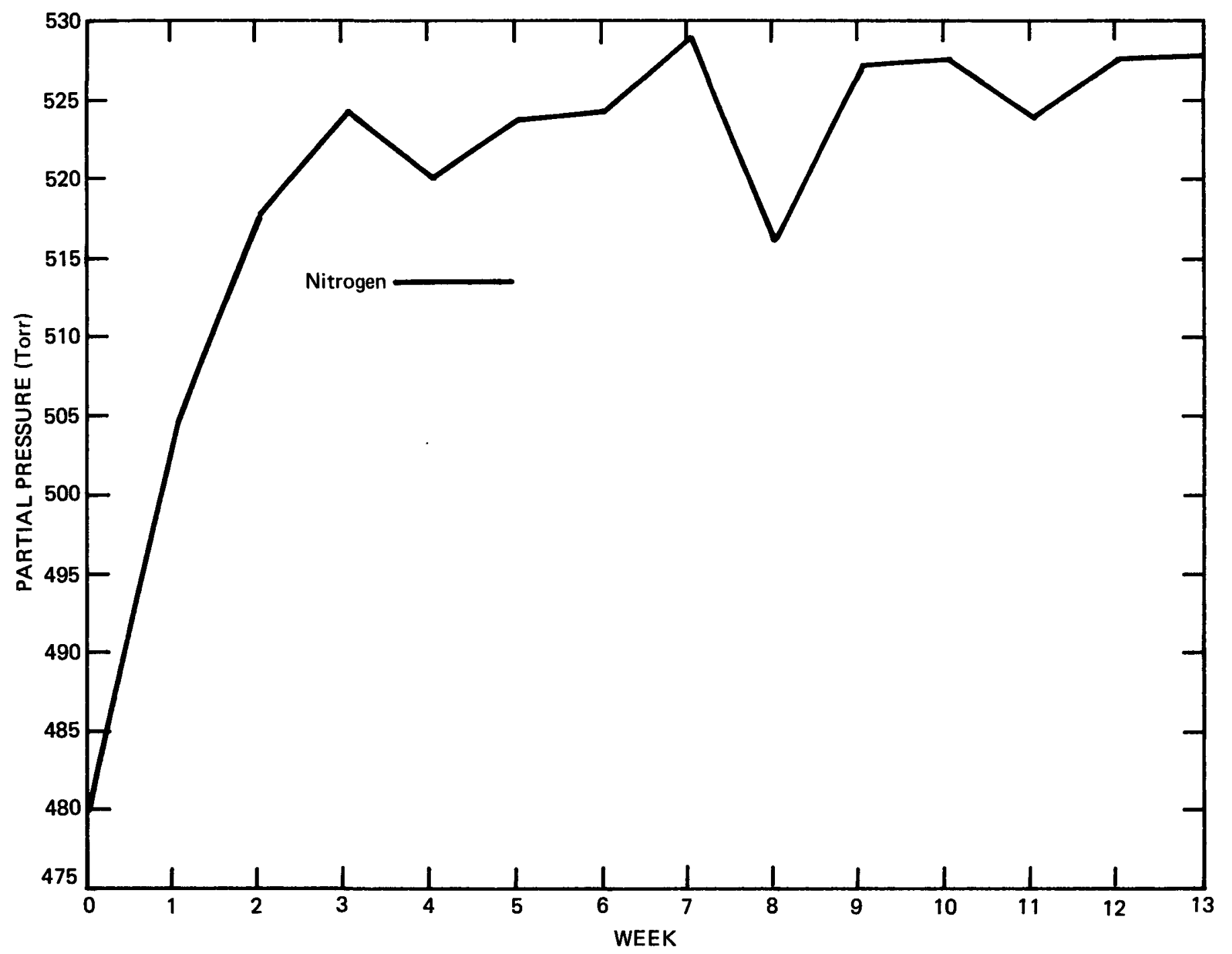

FIGURE B-6b. D31403 Atmosphere: Nitrogen 


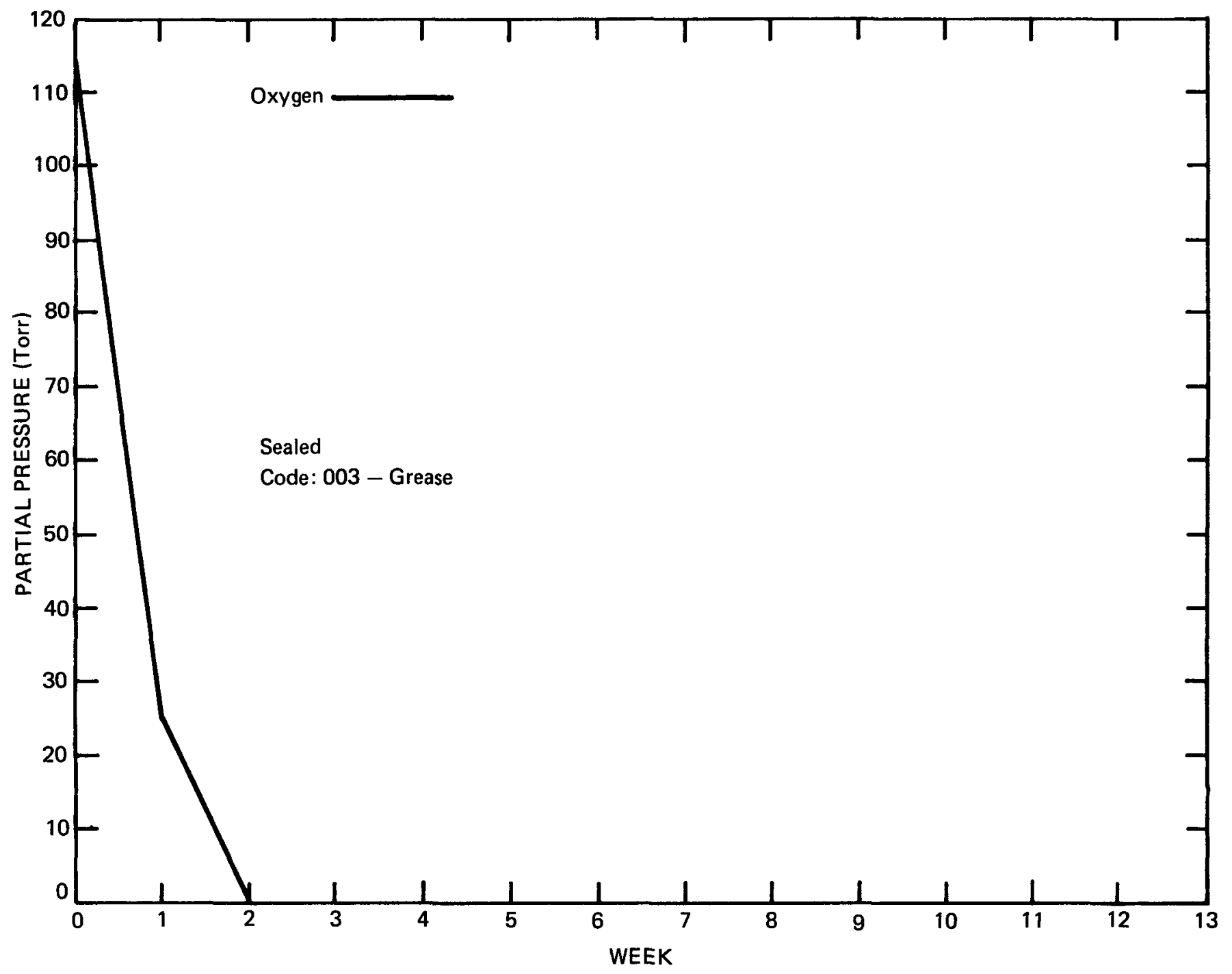

FIGURE B-6c. D31403 Atmosphere: Oxygen 
RFP-3739

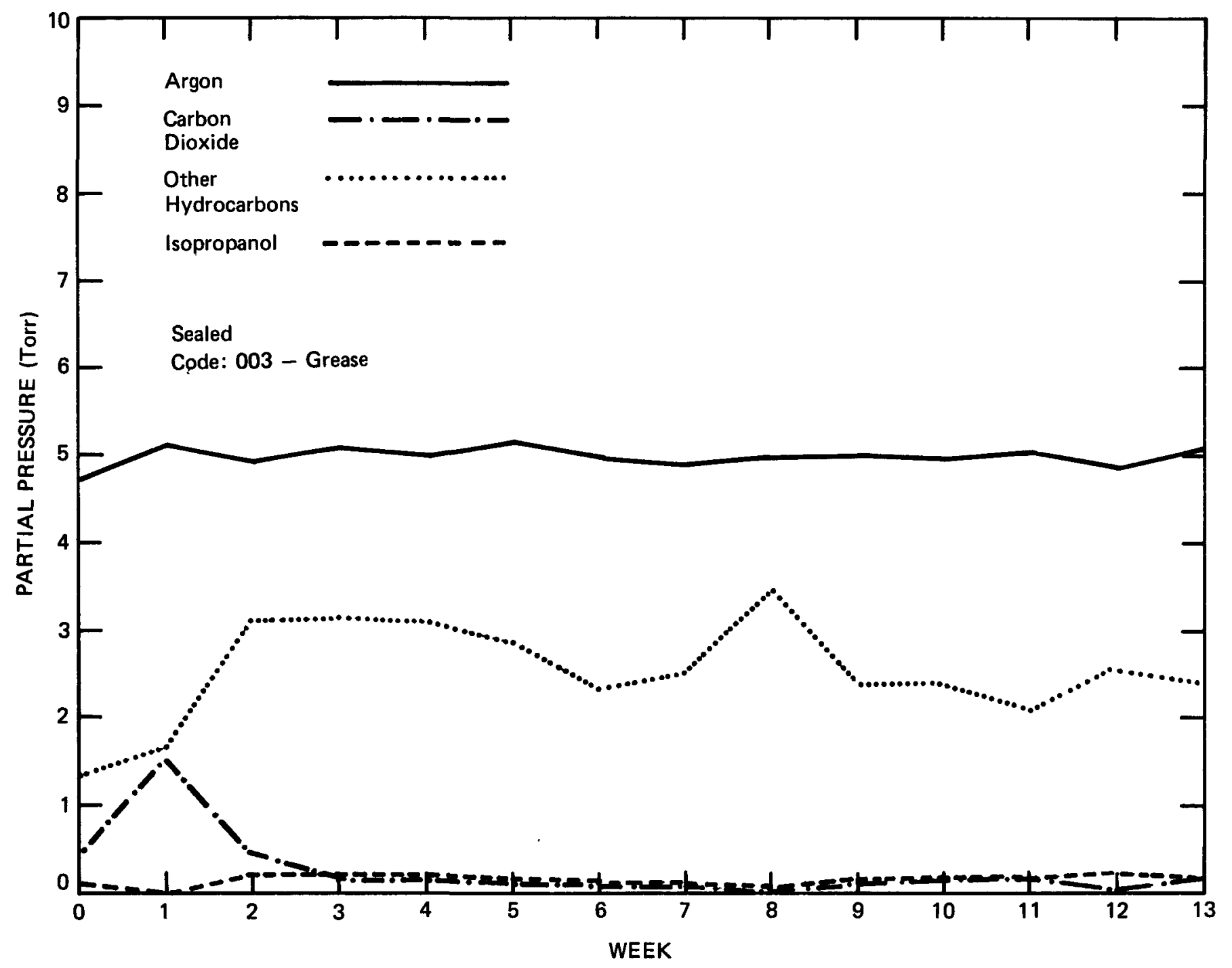

FIGURE B-6d. D31403 Atmosphere: Argon, Carbon Dioxide, Other Hydrocarbons, Isopropanol 


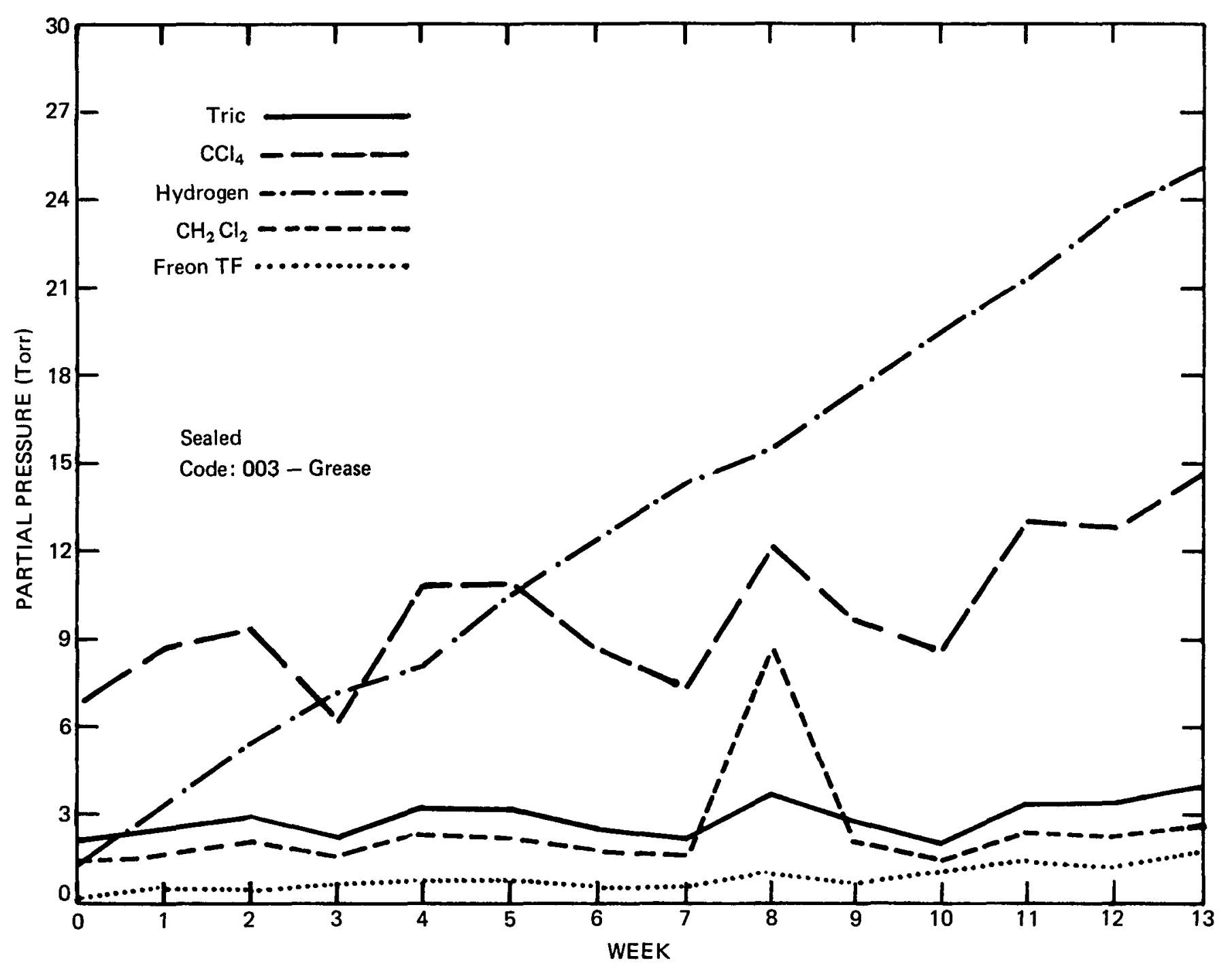

FIGURE B-6e. D31403 Atmosphere: Tric, $\mathrm{CCl}_{4}, \mathrm{Hydrogen}, \mathrm{CH}_{2} \mathrm{Cl}_{2}$, Freon TF 
RFP-3739

TABLE B-6. D31403 TRU Gas Generation Volume Percent

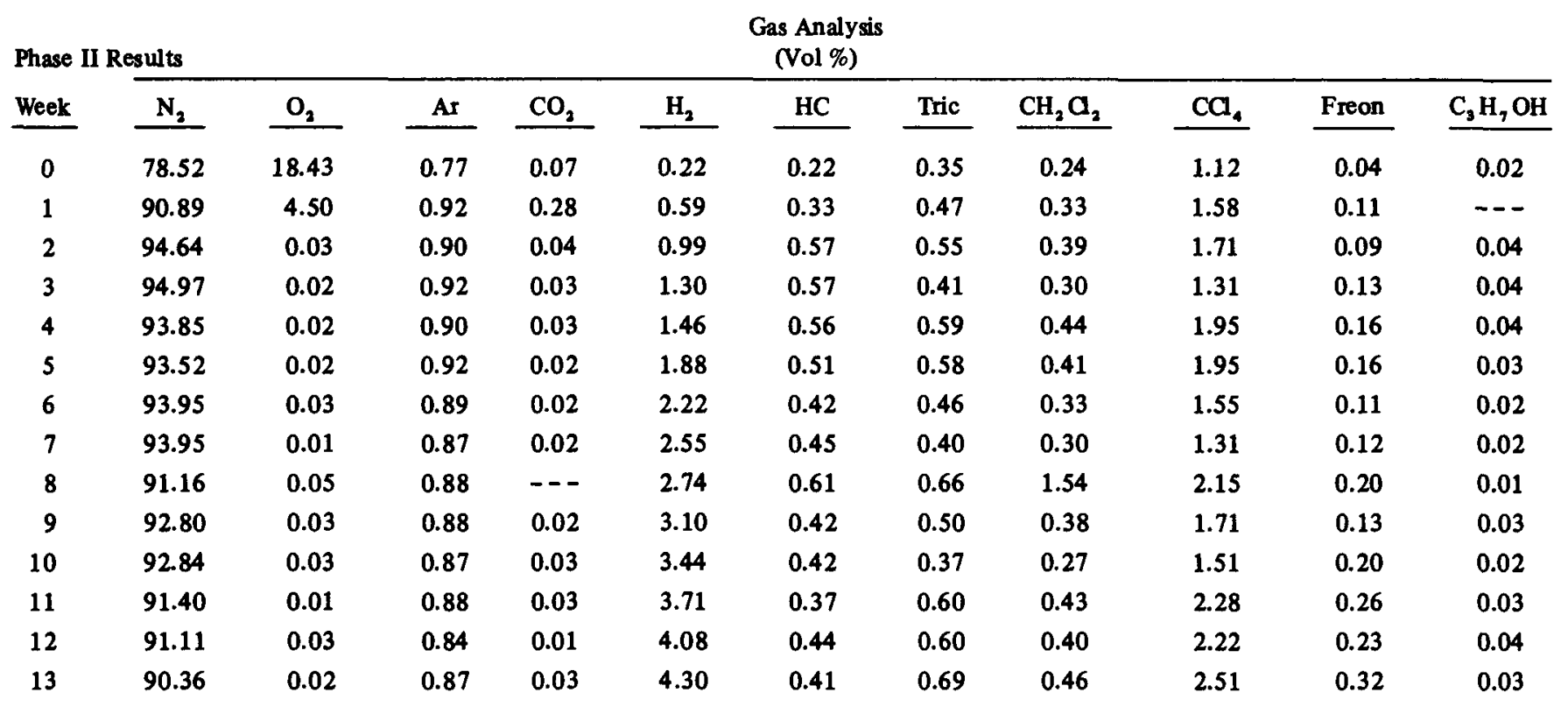

Sealed

Code: 003-Grease 


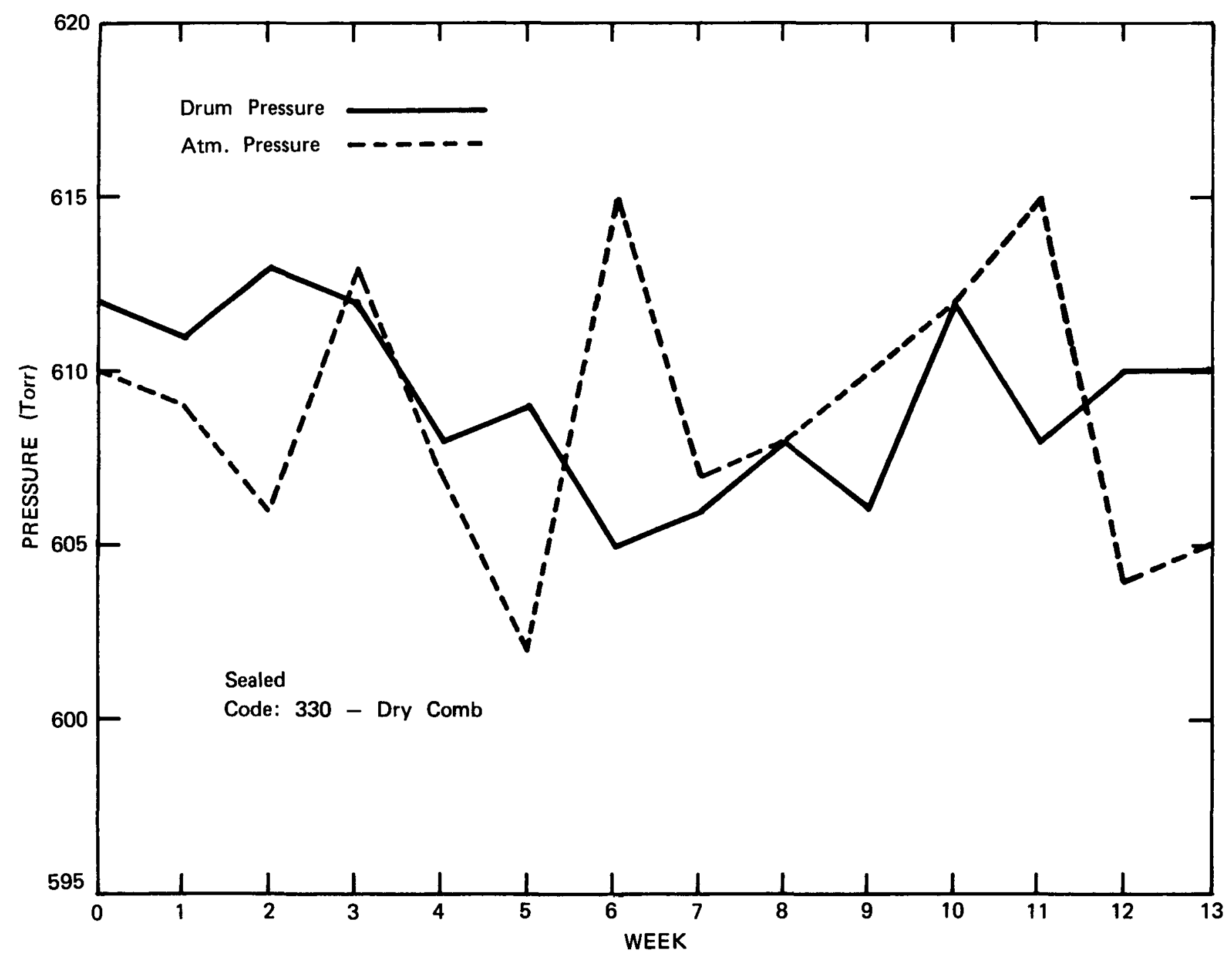

FIGURE B-7a. D24545 Pressure 
RFP-3739

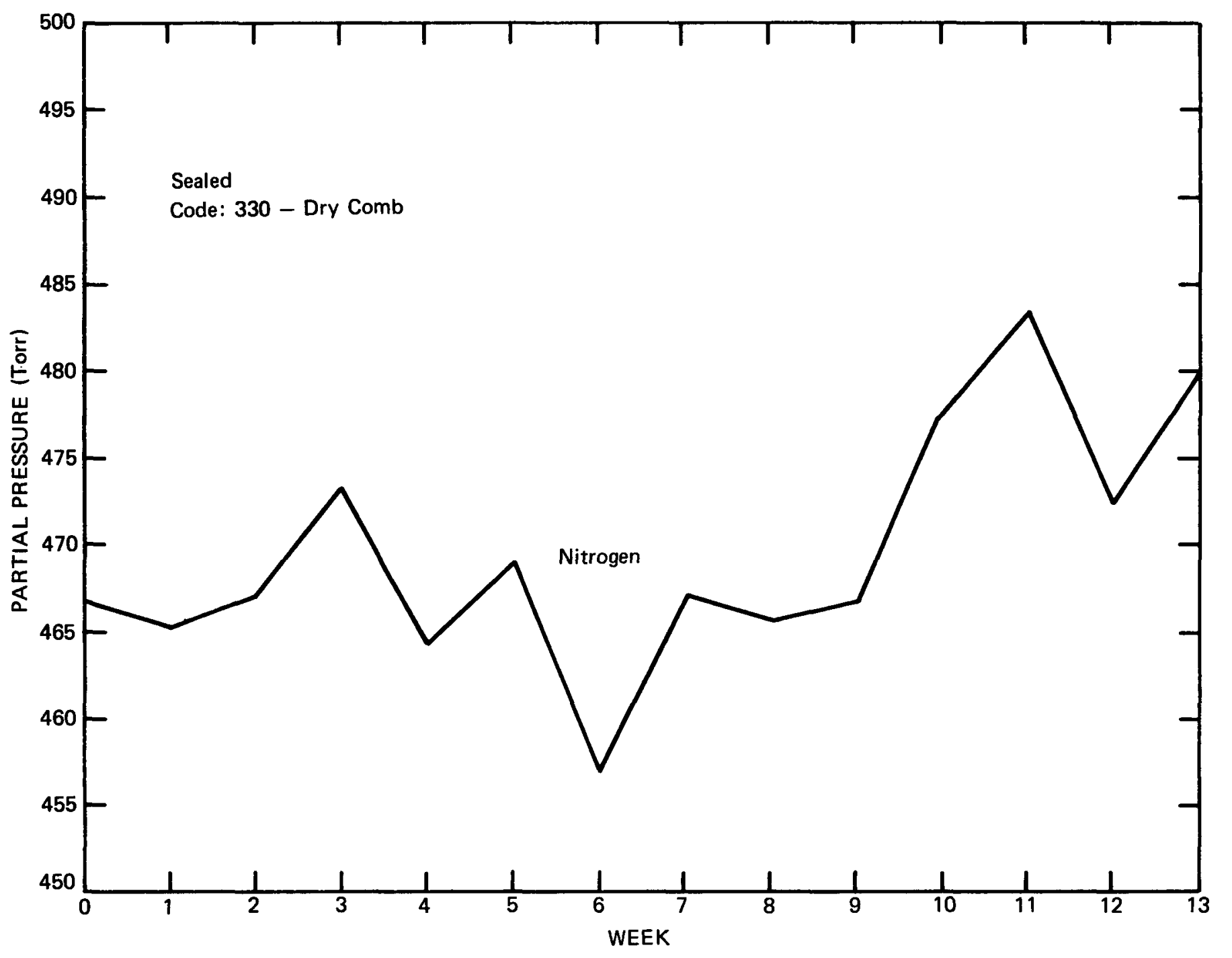

FIGURE B-7b. D24545 Atmosphere: Nitrogen 


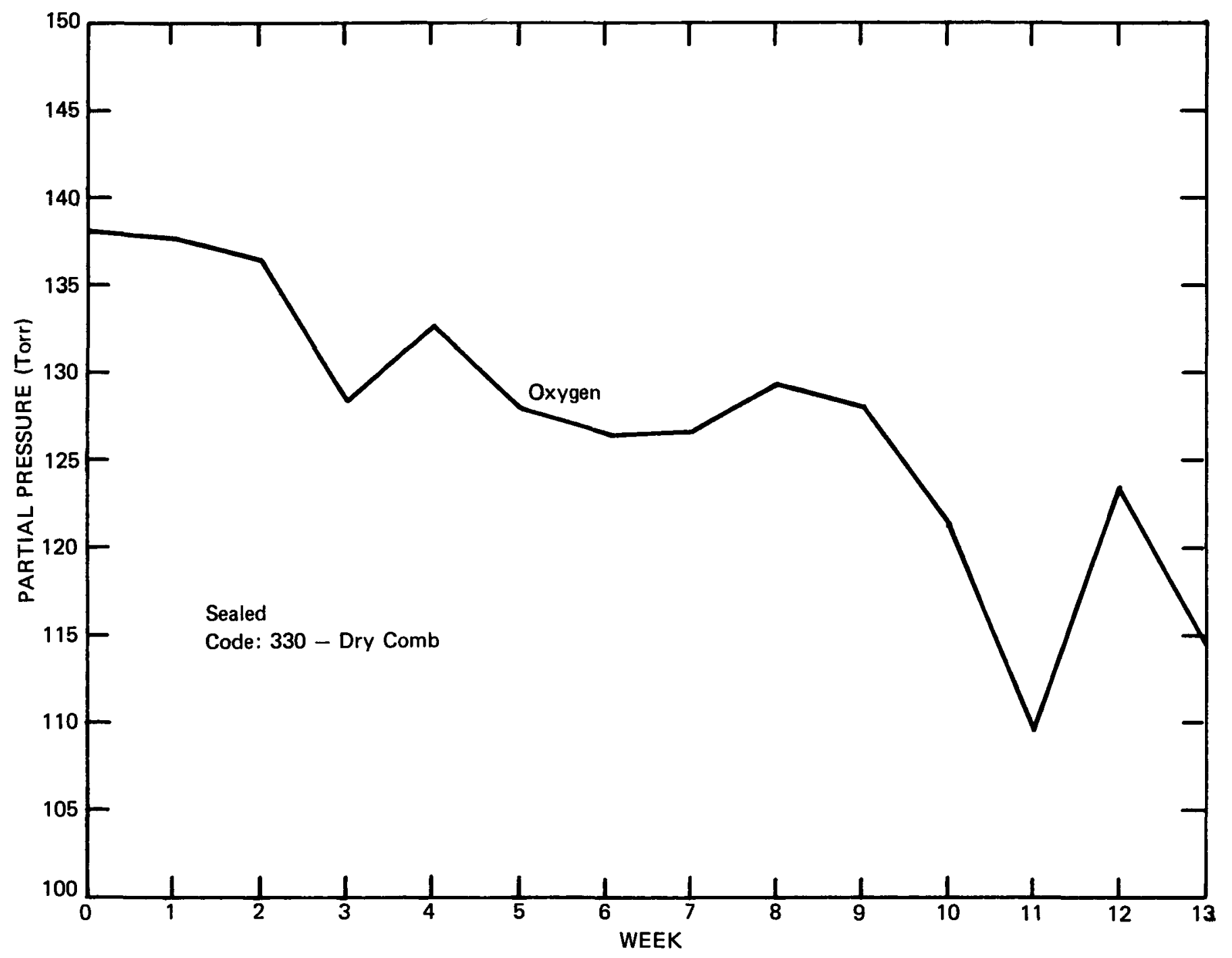

FIGURE B-7c. D24545 Atmosphere: Oxygen 
RFP-3739

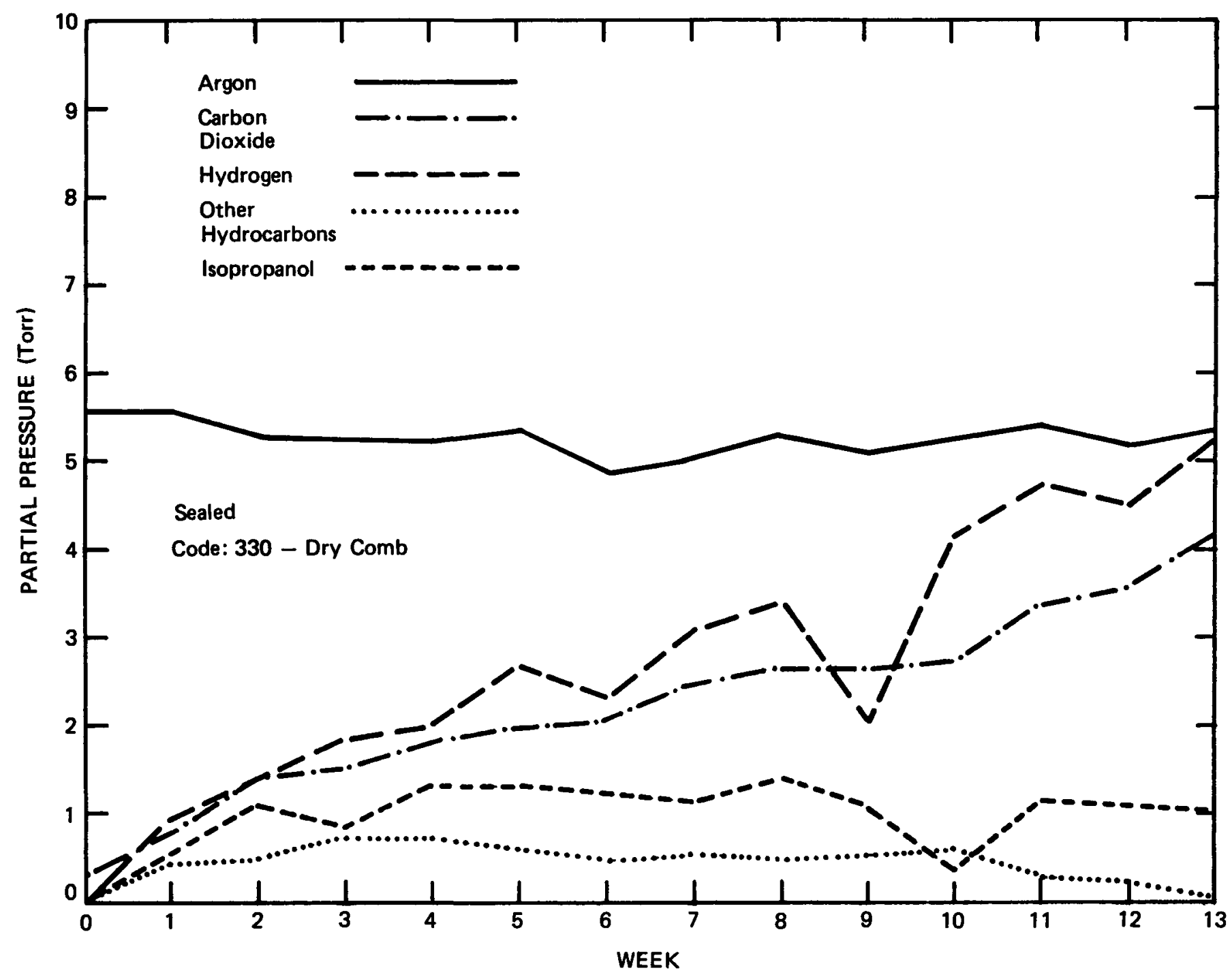

FIGURE B-7d. D24545 Atmosphere: Argon, Carbon Dioxide, Hydrogen, Other Hydrocarbons, Isopropanol 
TABLE B-7. D24545 TRU Gas Generation Volume Percent

\begin{tabular}{|c|c|c|c|c|c|c|c|c|c|c|c|}
\hline \multicolumn{6}{|c|}{ Phase II Results } & \multicolumn{6}{|c|}{$\begin{array}{c}\text { Gas Analysis } \\
\text { (Vol \%) }\end{array}$} \\
\hline Week & $\mathrm{N}_{2}$ & $\mathrm{O}_{2}$ & Ar & $\mathrm{CO}_{2}$ & $\mathrm{H}_{2}$ & $\mathrm{HC}$ & Tric & $\mathrm{CH}_{2} \mathrm{O}_{2}$ & $\mathrm{CCl}_{4}$ & Freon & $\mathrm{C}_{3} \mathrm{H}_{7} \mathrm{OH}$ \\
\hline 0 & 76.50 & 22.54 & 0.96 & 0.05 & 0 & -- & -- & --- & -- & --- & --- \\
\hline 1 & 76.13 & 22.52 & 0.91 & 0.13 & 0.15 & 0.07 & --- & ---- & --- & ---- & 0.09 \\
\hline 2 & 76.19 & 22.23 & 0.86 & 0.23 & 0.23 & 0.08 & -- & --- & -- & ---- & 0.18 \\
\hline 3 & 77.35 & 20.97 & 0.86 & 0.25 & 0.30 & 0.12 & -- & --- & --- & ---- & 0.14 \\
\hline 4 & 76.35 & 21.82 & 0.86 & 0.30 & 0.33 & 0.12 & -- & --- & --- & ---- & 0.22 \\
\hline 5 & 77.03 & 21.00 & 0.88 & 0.33 & 0.44 & 0.10 & --- & --- & --- & --- & 0.22 \\
\hline 6 & 76.87 & 21.28 & 0.82 & 0.35 & 0.39 & 0.08 & $-\cdots$ & ---- & -- & ---- & 0.21 \\
\hline 7 & 77.08 & 20.89 & 0.83 & 0.41 & 0.51 & 0.09 & --- & ---- & --- & ---- & 0.19 \\
\hline 8 & 76.56 & 21.26 & 0.87 & 0.44 & 0.56 & 0.08 & -- & --- & -- & --- & 0.23 \\
\hline 9 & 77.00 & 21.11 & 0.84 & 0.44 & 0.34 & 0.09 & -- & ---- & --- & ---- & 0.18 \\
\hline 10 & 78.04 & 19.81 & 0.86 & 0.45 & 0.68 & 0.10 & -- & ---- & --- & ---- & 0.06 \\
\hline 11 & 79.52 & 18.01 & 0.89 & 0.56 & 0.78 & 0.05 & -- & --- & -- & $-\cdots$ & 0.19 \\
\hline 12 & 77.39 & 20.21 & 0.85 & 0.59 & 0.74 & 0.04 & $\ldots$ & --- & --- & --- & 0.18 \\
\hline 13 & 78.65 & 18.74 & 0.88 & 0.69 & 0.86 & 0.01 & -- & ---- & -- & --- & 0.17 \\
\hline
\end{tabular}

Sealed

Code: 330-Dry Comb 
RFP-3739

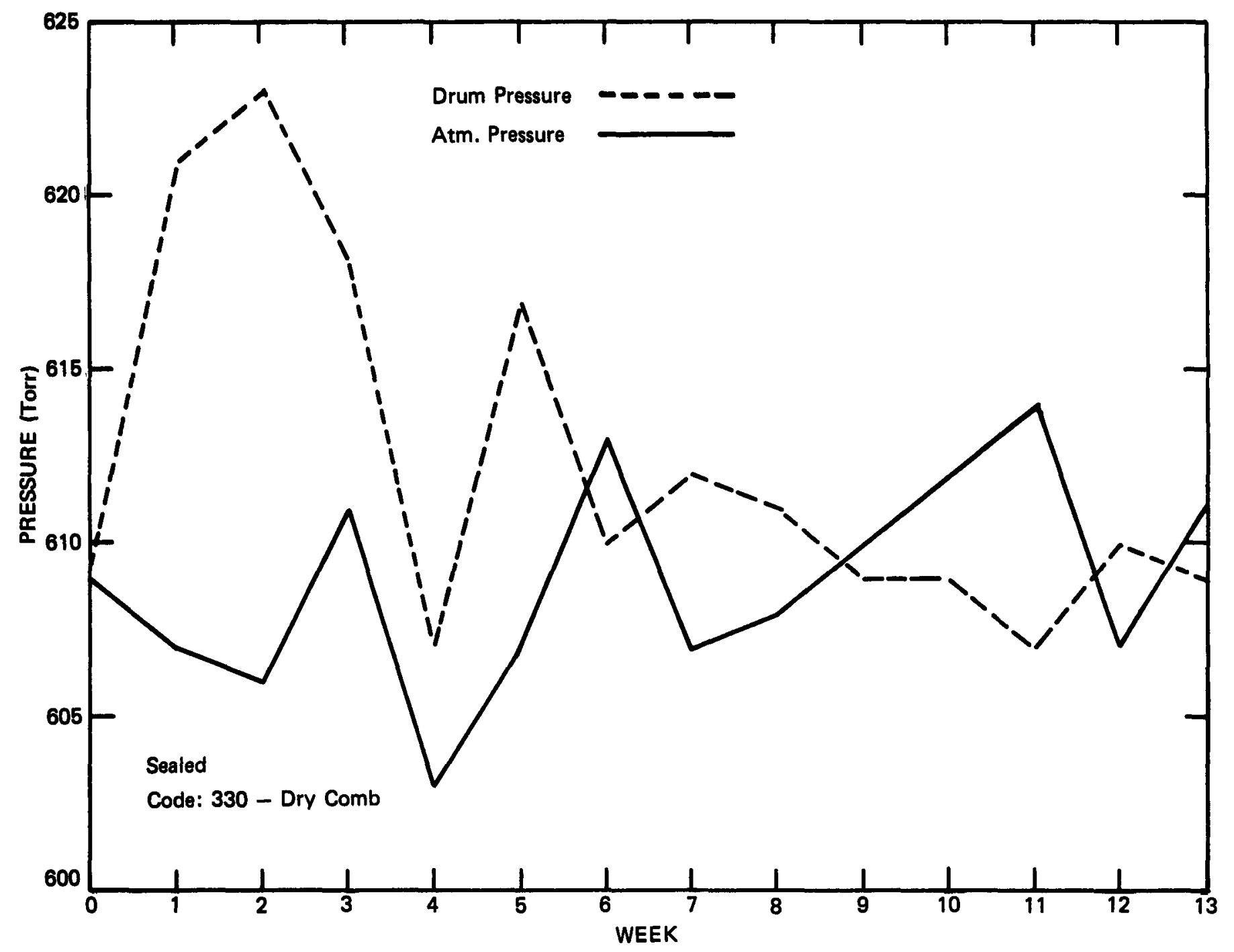

FIGURE B-8a. D31042 Pressure 


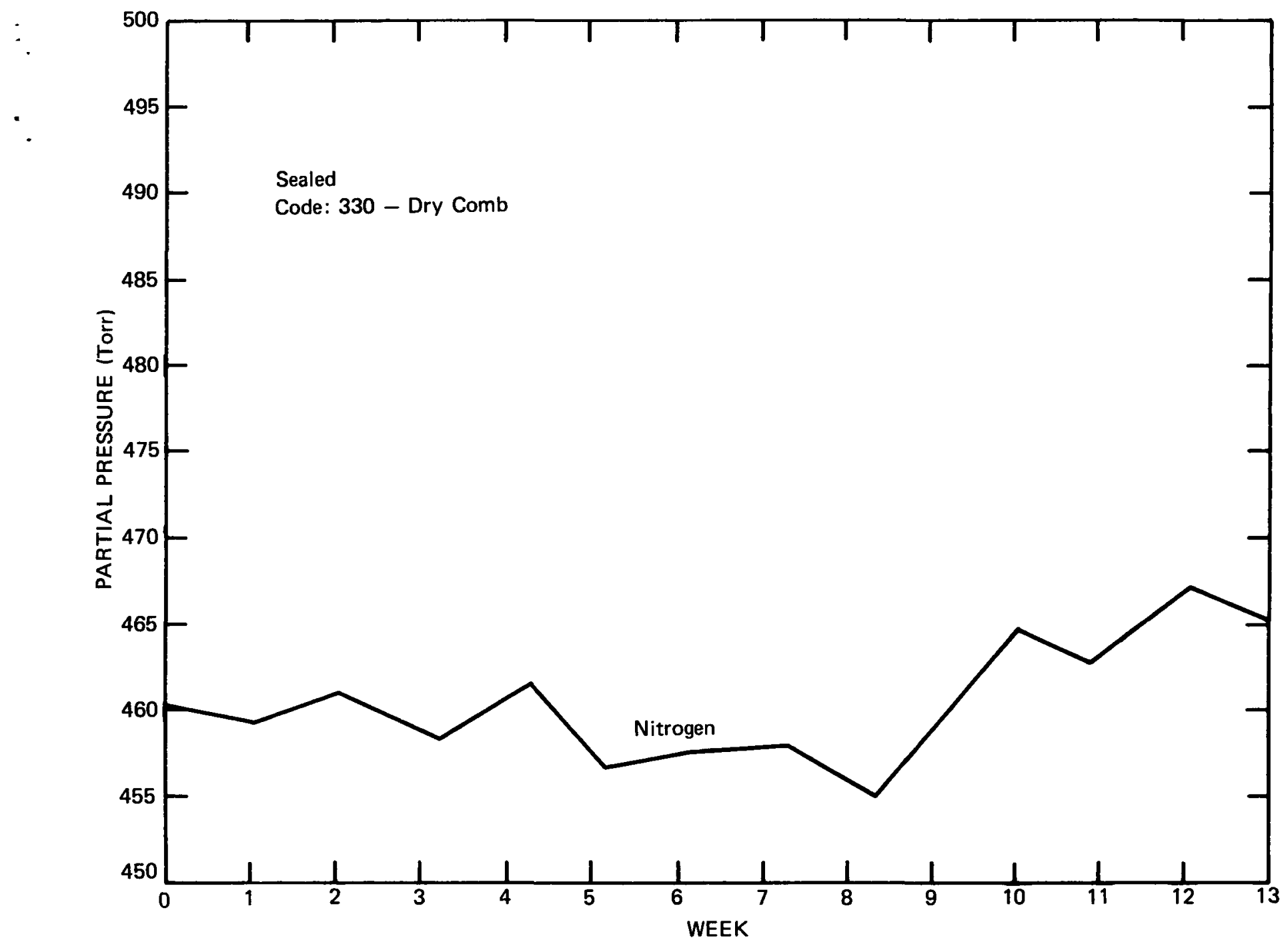

FIGURE B-8b. D31042 Atmosphere: Nitrogen 
RFP-3739

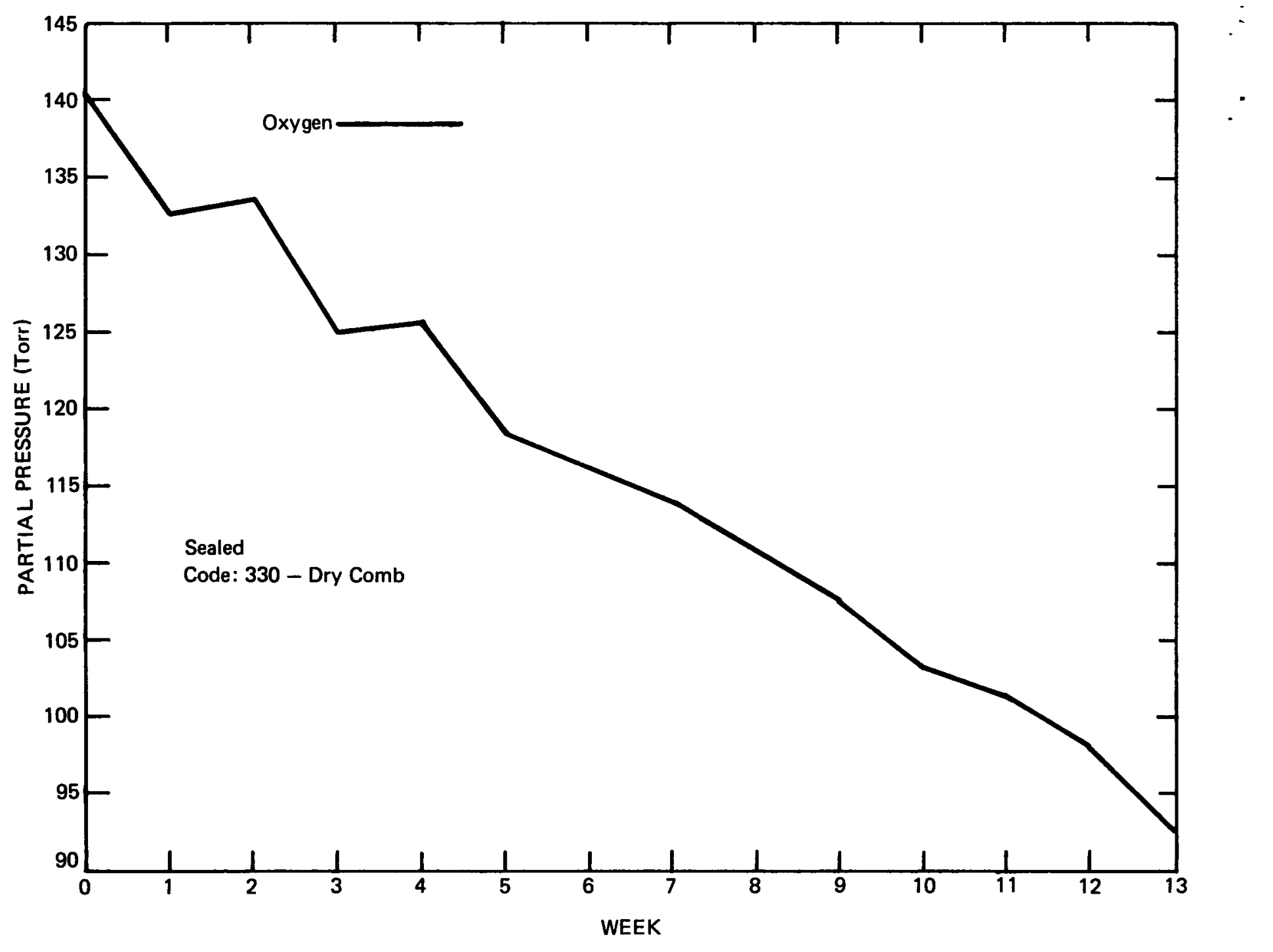

FIGURE B-8c. D31042 Atmosphere: Oxygen 


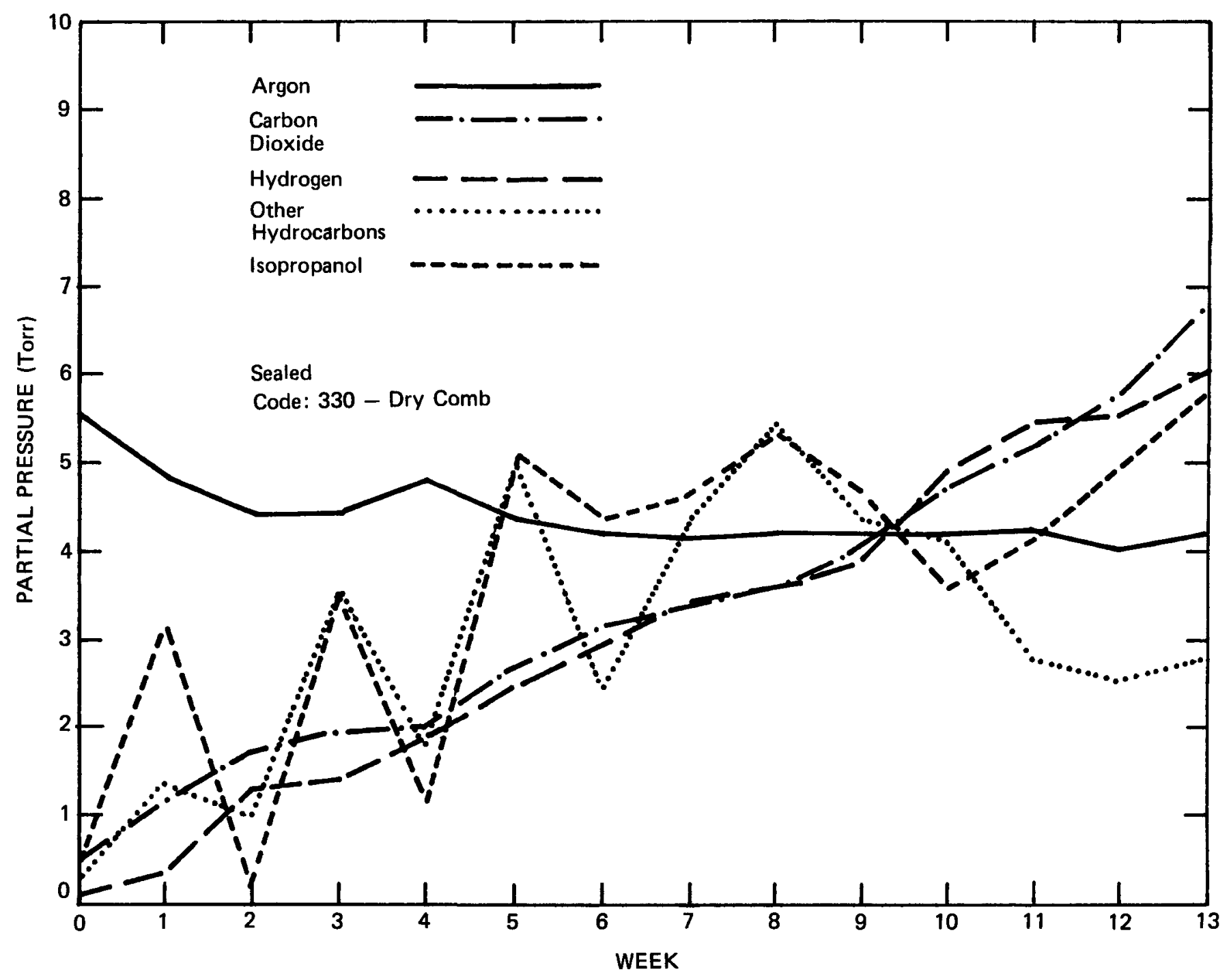

FIGURE B-8d. D31042 Atmosphere: Argon, Carbon Dioxide, Hydrogen, Other Hydrocarbons, Isopropanol 


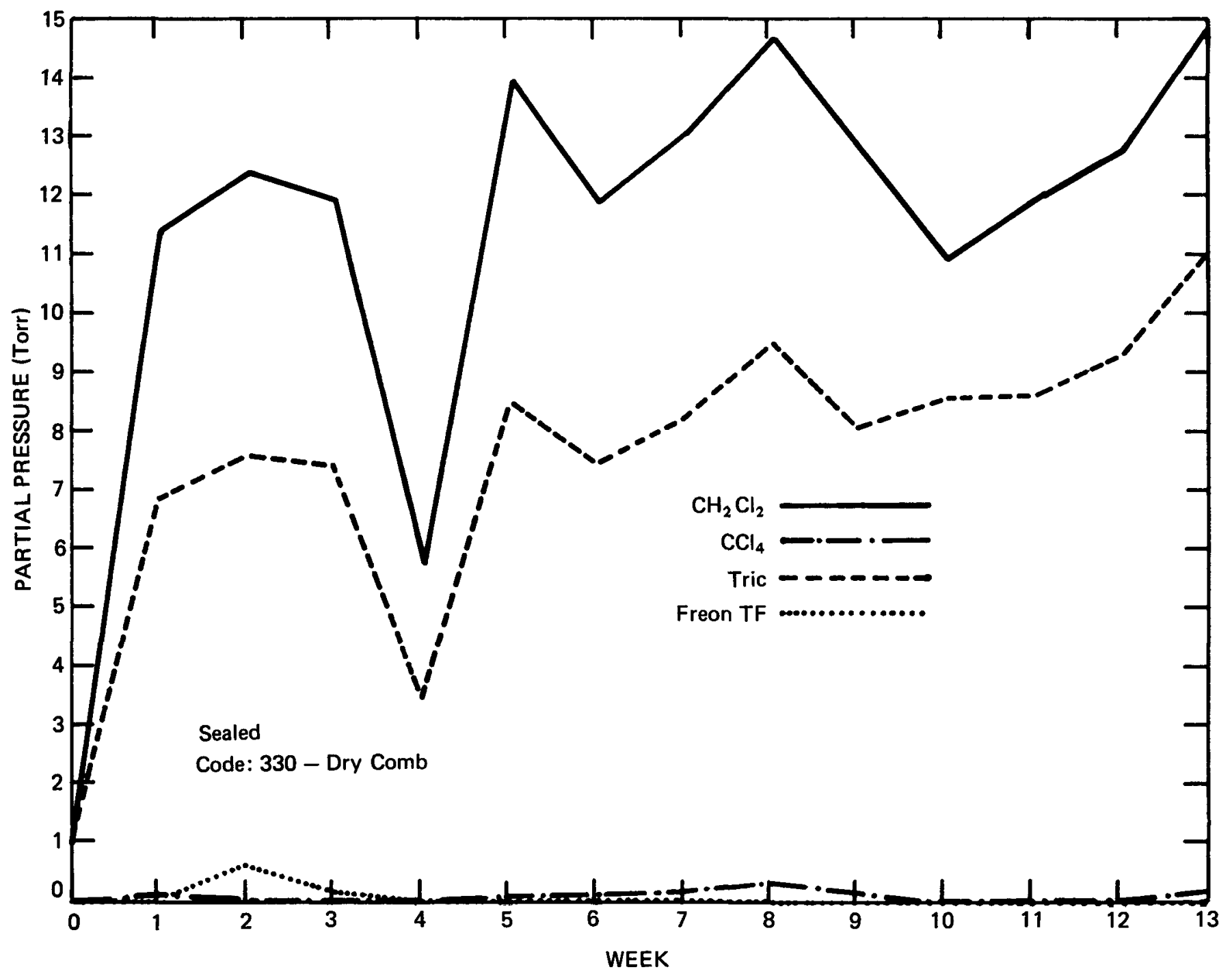

FIGURE B-8e. D31042 Atmosphere: Tric, $\mathrm{CCl}_{4}, \mathrm{CH}_{2} \mathrm{Cl}_{2}$, Freon TF 
TABLE B-8. D31042 TRU Gas Generation Volume Percent

\begin{tabular}{|c|c|c|c|c|c|c|c|c|c|c|c|}
\hline \multicolumn{6}{|c|}{ Phase II Results } & \multicolumn{6}{|c|}{$\begin{array}{c}\text { Gas Analysis } \\
\text { (Vol \%) }\end{array}$} \\
\hline Week & $\mathrm{N}_{2}$ & $\mathrm{O}_{2}$ & $\mathrm{Ar}$ & $\mathrm{CO}_{2}$ & $\mathbf{H}_{2}$ & $\mathrm{HC}$ & Tric & $\mathrm{CH}_{2} \mathrm{O}_{2}$ & $\mathrm{CCl}_{4}$ & Freon & $\mathrm{C}_{3} \mathrm{H}_{7} \mathrm{OH}$ \\
\hline 0 & 75.57 & 23.01 & 0.91 & 0.08 & 0.02 & 0.05 & 0.16 & 0.14 & -- & ---- & 0.06 \\
\hline 1 & 73.95 & 21.34 & 0.78 & 0.19 & 0.06 & 0.22 & 1.10 & 1.83 & 0.02 & --- & 0.51 \\
\hline 2 & 73.96 & 21.43 & 0.71 & 0.28 & 0.21 & 0.16 & 1.21 & 1.98 & 0.01 & 0.01 & 0.04 \\
\hline 3 & 74.24 & 20.21 & 0.72 & 0.32 & 0.23 & 0.58 & 1.19 & 1.92 & 0.01 & 0.02 & 0.56 \\
\hline 4 & 75.90 & 20.68 & 0.79 & 0.34 & 0.31 & 0.29 & 0.56 & 0.94 & --- & ---- & 0.19 \\
\hline 5 & 73.95 & 19.20 & 0.71 & 0.44 & 0.40 & 0.81 & 1.38 & 2.26 & 0.02 & --- & 0.83 \\
\hline 6 & 74.99 & 19.03 & 0.69 & 0.52 & 0.48 & 0.39 & 1.22 & 1.94 & 0.02 & ---- & 0.72 \\
\hline 7 & 74.60 & 18.63 & 0.68 & 0.56 & 0.56 & 0.71 & 1.34 & 2.13 & 0.03 & --- & 0.76 \\
\hline 8 & 74.25 & 18.12 & 0.69 & 0.59 & 0.59 & 0.89 & 1.55 & 2.40 & 0.05 & ---- & 0.87 \\
\hline 9 & 75.40 & 17.66 & 0.69 & 0.67 & 0.64 & 0.72 & 1.32 & 2.10 & 0.03 & --- & 0.77 \\
\hline 10 & 76.31 & 16.96 & 0.69 & 0.78 & 0.81 & 0.67 & 1.40 & 1.79 & --- & $-\cdots$ & 0.59 \\
\hline 11 & 76.33 & 16.69 & 0.70 & 0.86 & 0.90 & 0.46 & 1.42 & 1.96 & -- & --- & 0.68 \\
\hline 12 & 76.55 & 16.08 & 0.66 & 0.95 & 0.91 & 0.42 & 1.53 & 2.09 & -- & --- & 0.81 \\
\hline 13 & 76.26 & 15.24 & 0.69 & 1.12 & 0.99 & 0.46 & 1.82 & 2.44 & 0.03 & $\ldots$ & 0.95 \\
\hline
\end{tabular}

Sealed

Code: 330-Dry Comb 
RFP-3739

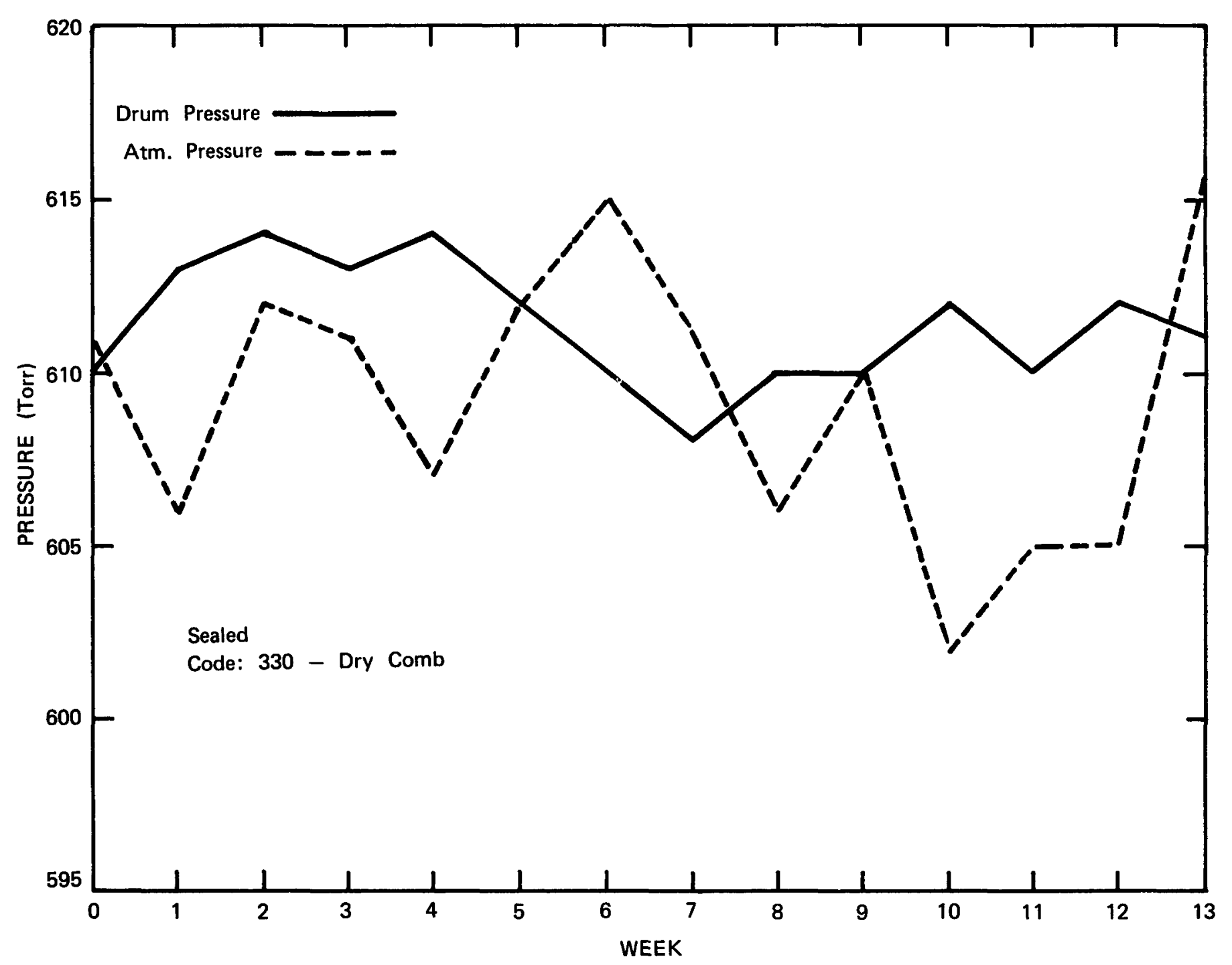

FIGURE B-9a. D26048 Pressure 


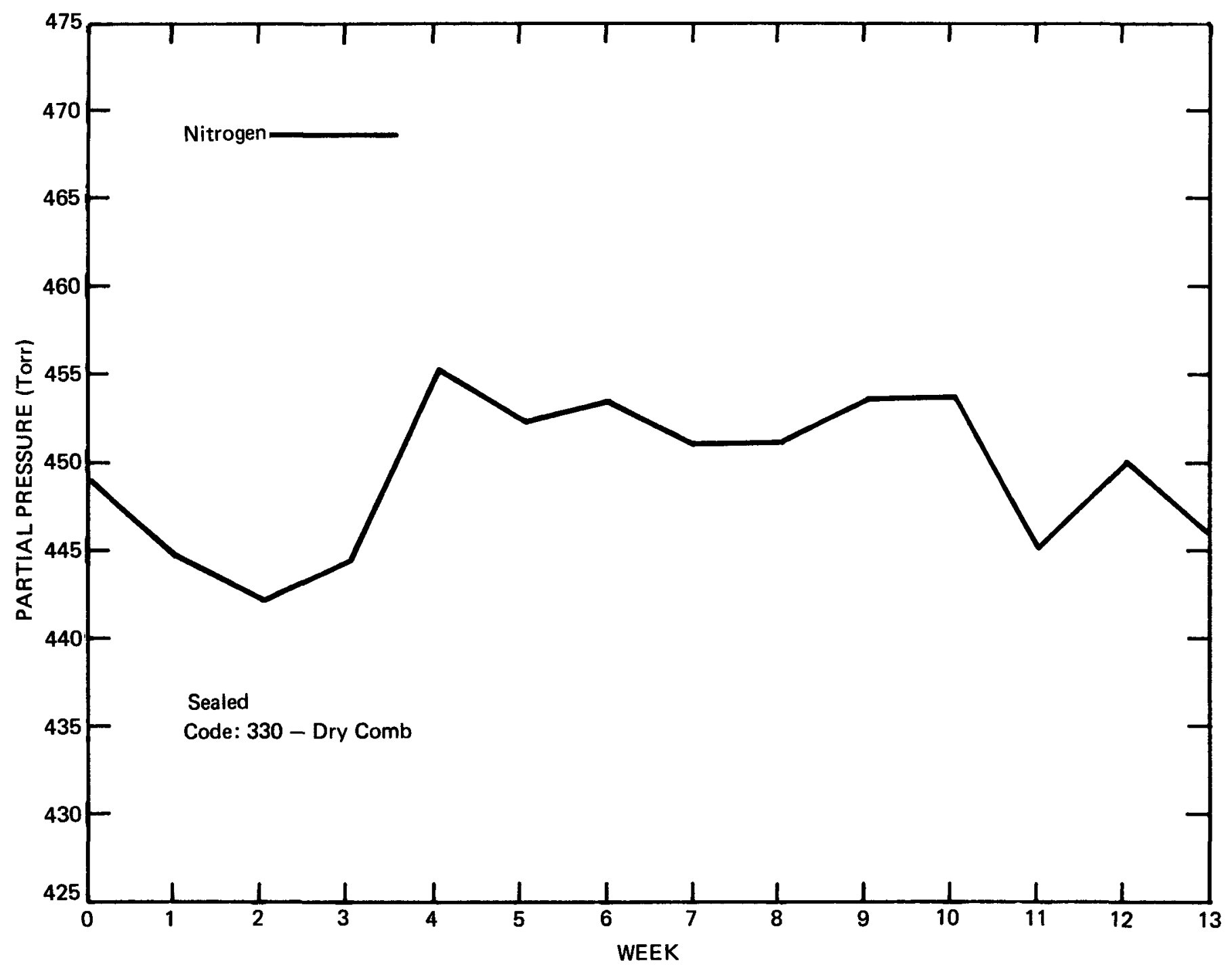

FIGURE B-9b. D26048 Atmosphere: Nitrogen 
RFP-3739

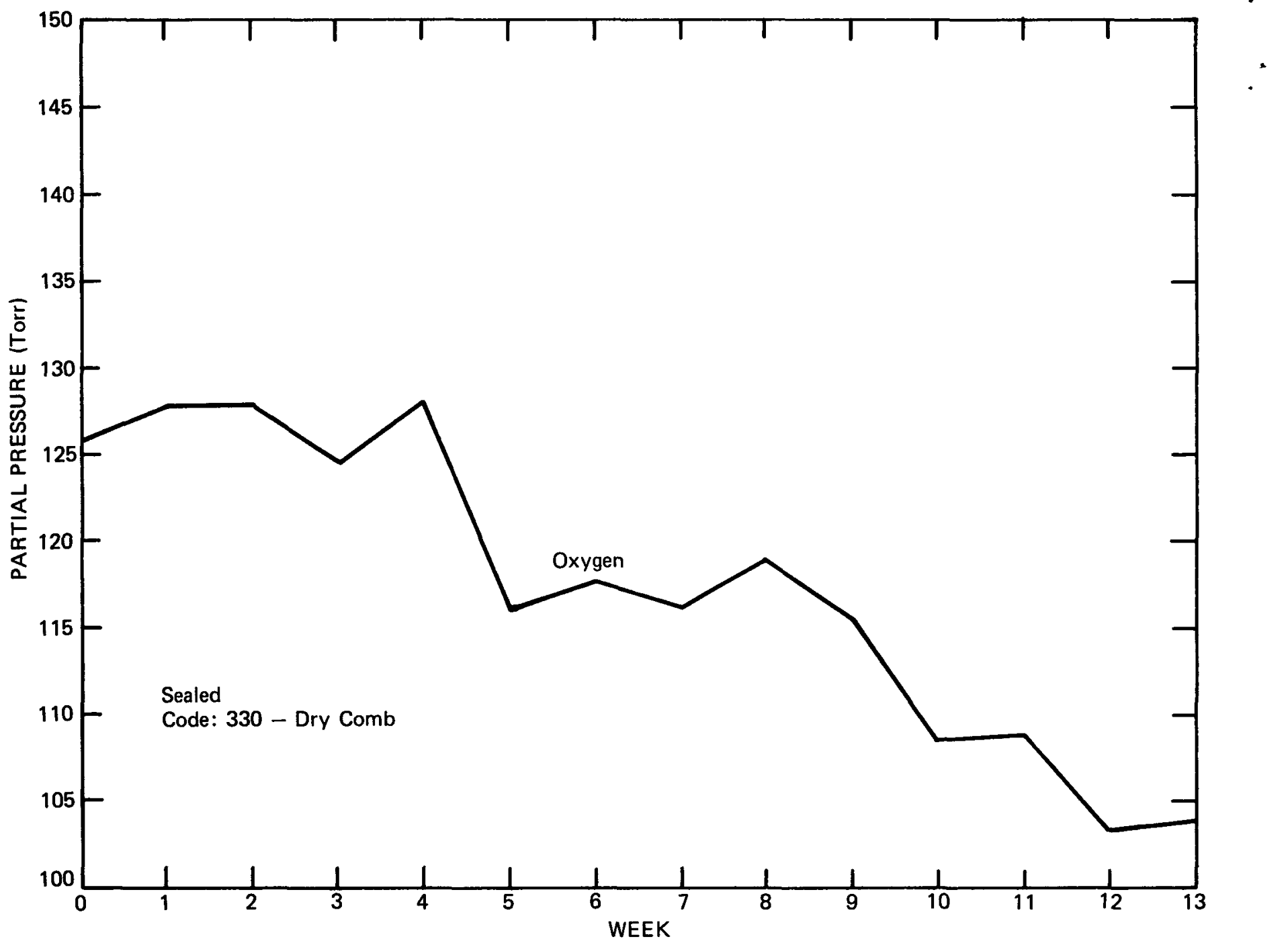

FIGURE B-9c. D26048 Atmosphere: Oxygen 


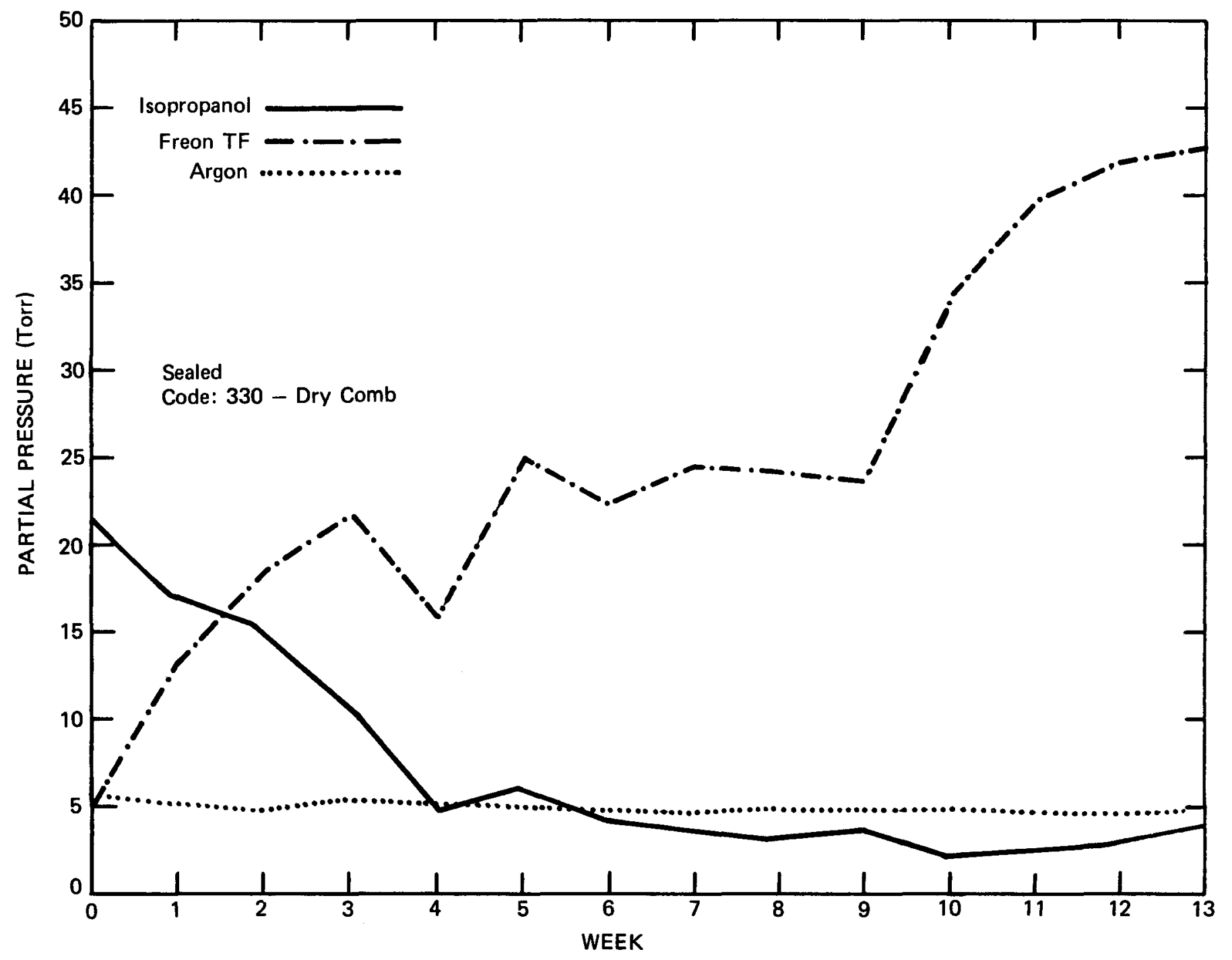

FIGURE B-9d. D26048 Atmosphere: Argon, Freon TF, Isopropanol 
RFP-3739

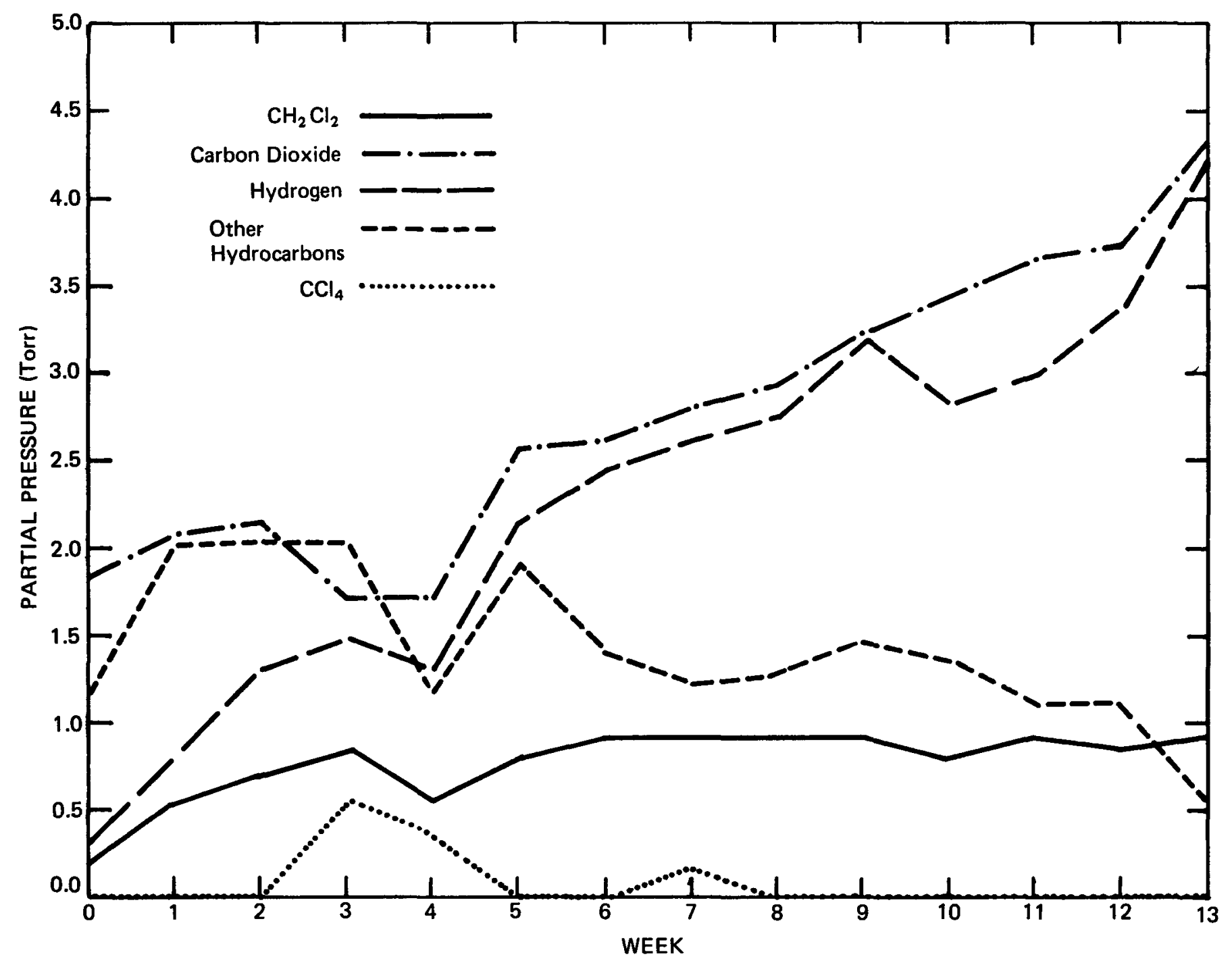

FIGURE B-9e. D26048 Atmosphere: $\mathrm{CH}_{2} \mathrm{Cl}_{2}$, Carbon Dioxide, Hydrogen, Other Hydrocarbons, $\mathrm{CCl}_{4}$ 
RFP-3739

TABLE B-9. D26048 TRU Gas Generation Volume Percent

\begin{tabular}{|c|c|c|c|c|c|c|c|c|c|c|c|}
\hline \multicolumn{6}{|c|}{ Phase II Results } & \multicolumn{6}{|c|}{$\begin{array}{c}\text { Gas Analysis } \\
\text { (Vol \%) }\end{array}$} \\
\hline Week & $\mathbf{N}_{2}$ & $\mathrm{O}_{2}$ & $\mathbf{A r}$ & $\mathrm{CO}_{2}$ & $\mathrm{H}_{2}$ & $\mathrm{HC}$ & Tric & $\mathrm{CH}_{2} \mathrm{C}_{2}$ & $\mathrm{CO}_{4}$ & Freon & $\mathrm{C}_{3} \mathrm{H}_{7} \mathrm{OH}$ \\
\hline $\mathbf{0}$ & 73.58 & 20.60 & 0.93 & 0.30 & 0.05 & 0.19 & --- & 0.03 & -- & 0.82 & 3.50 \\
\hline 1 & 72.52 & 20.83 & 0.83 & 0.34 & 0.13 & 0.33 & --- & 0.09 & --- & 2.20 & 2.73 \\
\hline 2 & 71.99 & 20.80 & 0.77 & 0.35 & 0.21 & 0.33 & --- & 0.11 & --- & 3.03 & 2.41 \\
\hline 3 & 72.47 & 20.31 & 0.88 & 0.28 & 0.24 & 0.33 & -- & 0.14 & 0.09 & 3.56 & 1.70 \\
\hline 4 & 74.16 & 20.83 & 0.83 & 0.28 & 0.21 & 0.17 & --- & 0.09 & 0.06 & 2.58 & 0.77 \\
\hline 5 & 73.95 & 18.96 & 0.83 & 0.42 & 0.35 & 0.31 & -- & 0.13 & --- & 4.09 & 0.96 \\
\hline 6 & 74.34 & 19.29 & 0.78 & 0.43 & 0.40 & 0.23 & $-\cdots$ & 0.15 & --- & 3.67 & 0.71 \\
\hline 7 & 74.17 & 19.11 & 0.77 & 0.46 & 0.43 & 0.20 & -- & 0.15 & 0.03 & 4.04 & 0.64 \\
\hline 8 & 73.94 & 19.49 & 0.80 & 0.48 & 0.45 & 0.21 & -- & 0.15 & --- & 3.97 & 0.51 \\
\hline 9 & 74.37 & 18.92 & 0.80 & 0.53 & 0.52 & 0.24 & -- & 0.15 & --- & 3.88 & 0.59 \\
\hline 10 & 74.14 & 17.72 & 0.80 & 0.56 & 0.46 & 0.22 & $\cdots$ & 0.13 & -- & 5.60 & 0.37 \\
\hline 11 & 72.98 & 17.83 & 0.78 & 0.60 & 0.49 & 0.18 & -- & 0.15 & -- & 6.52 & 0.47 \\
\hline 12 & 73.54 & 16.88 & 0.76 & 0.61 & 0.55 & 0.18 & -- & 0.14 & --- & 6.86 & 0.48 \\
\hline 13 & 72.96 & 16.99 & 0.79 & 0.71 & 0.69 & 0.09 & -- & 0.15 & -- & 6.99 & 0.63 \\
\hline
\end{tabular}

Sealed

Code: 330-Dry Comb 
RFP-3739

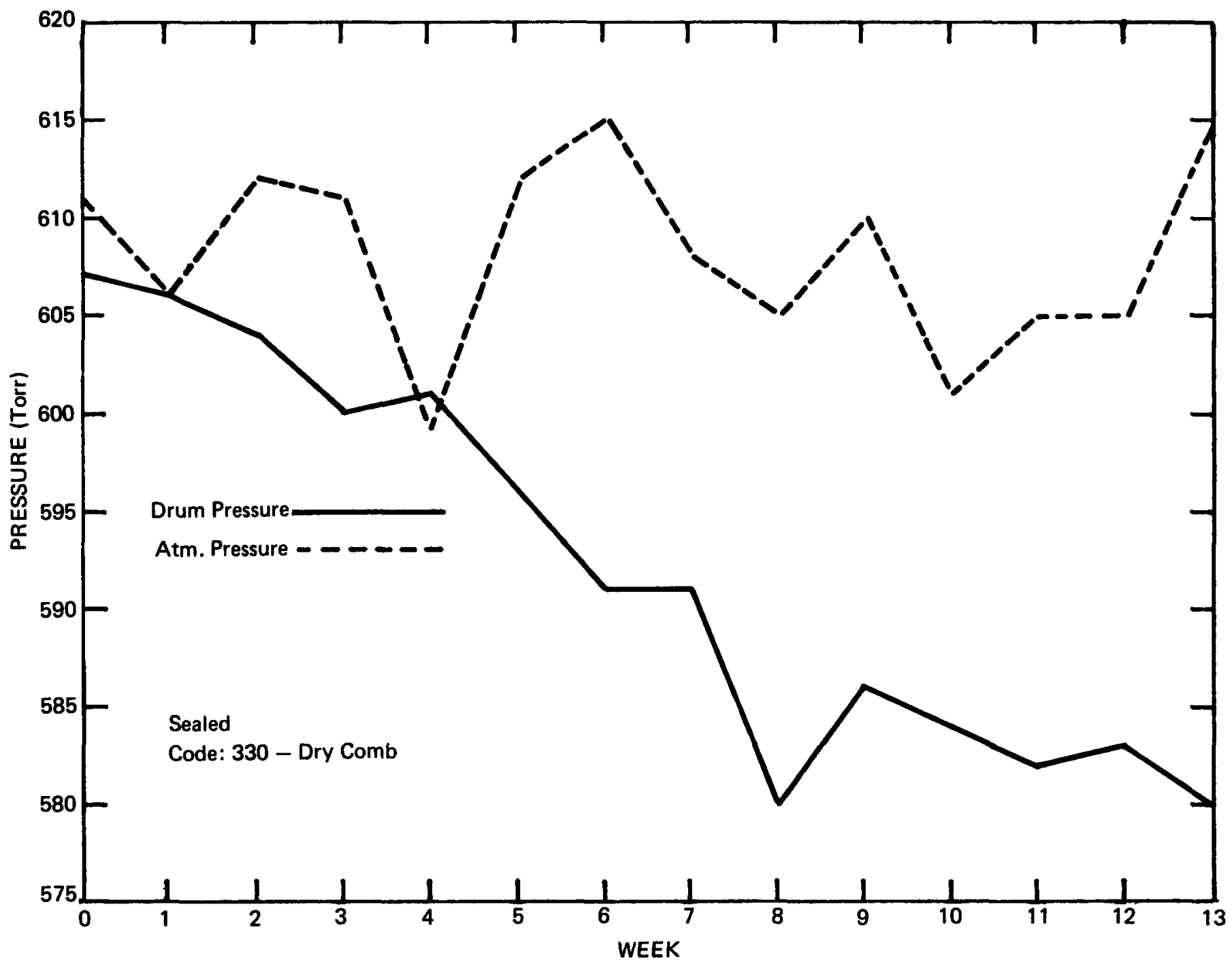

FIGURE B-10a. D31703 Pressure 


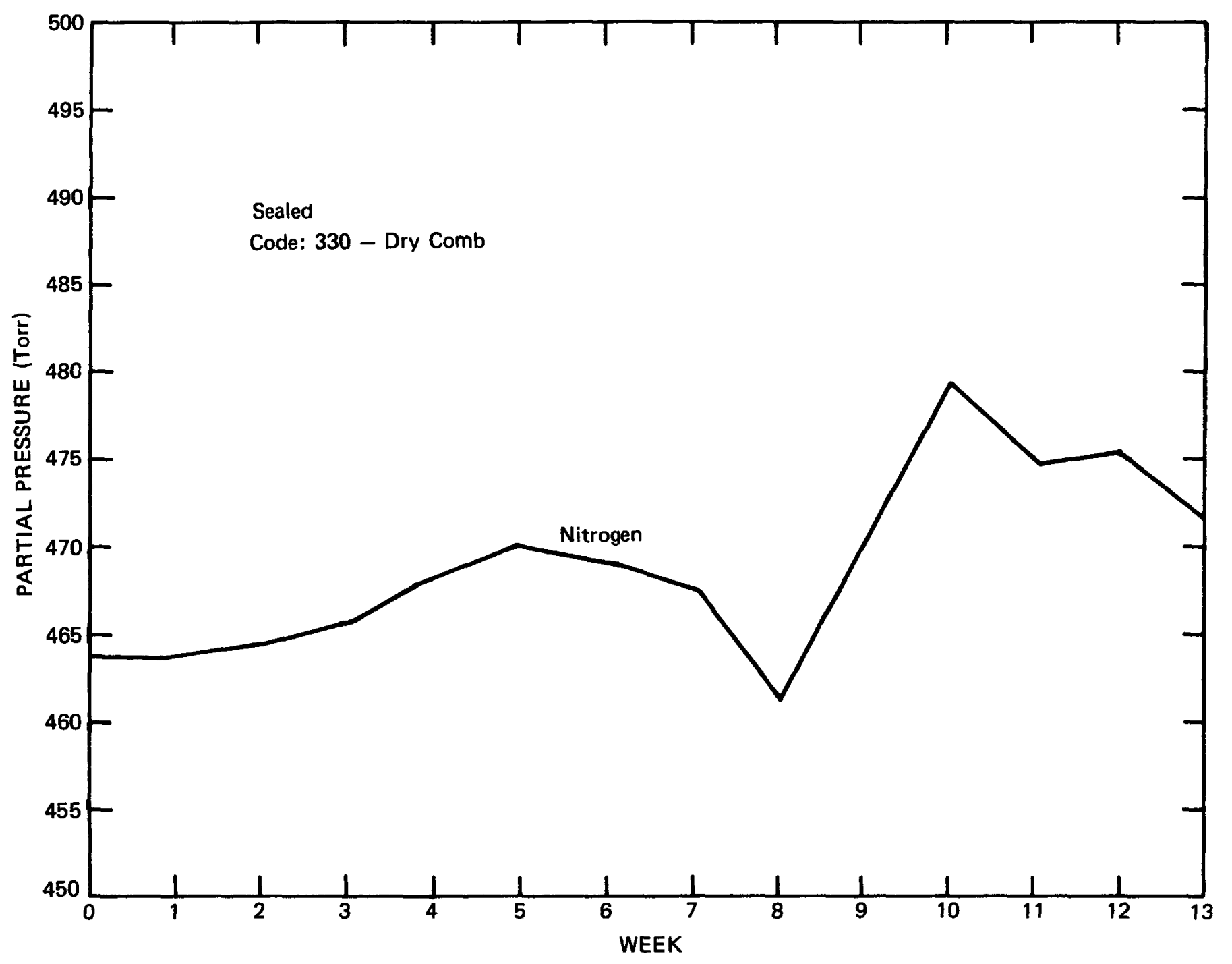

FIGURE B-10b. D31703 Atmosphere: Nitrogen 
RFP-3739

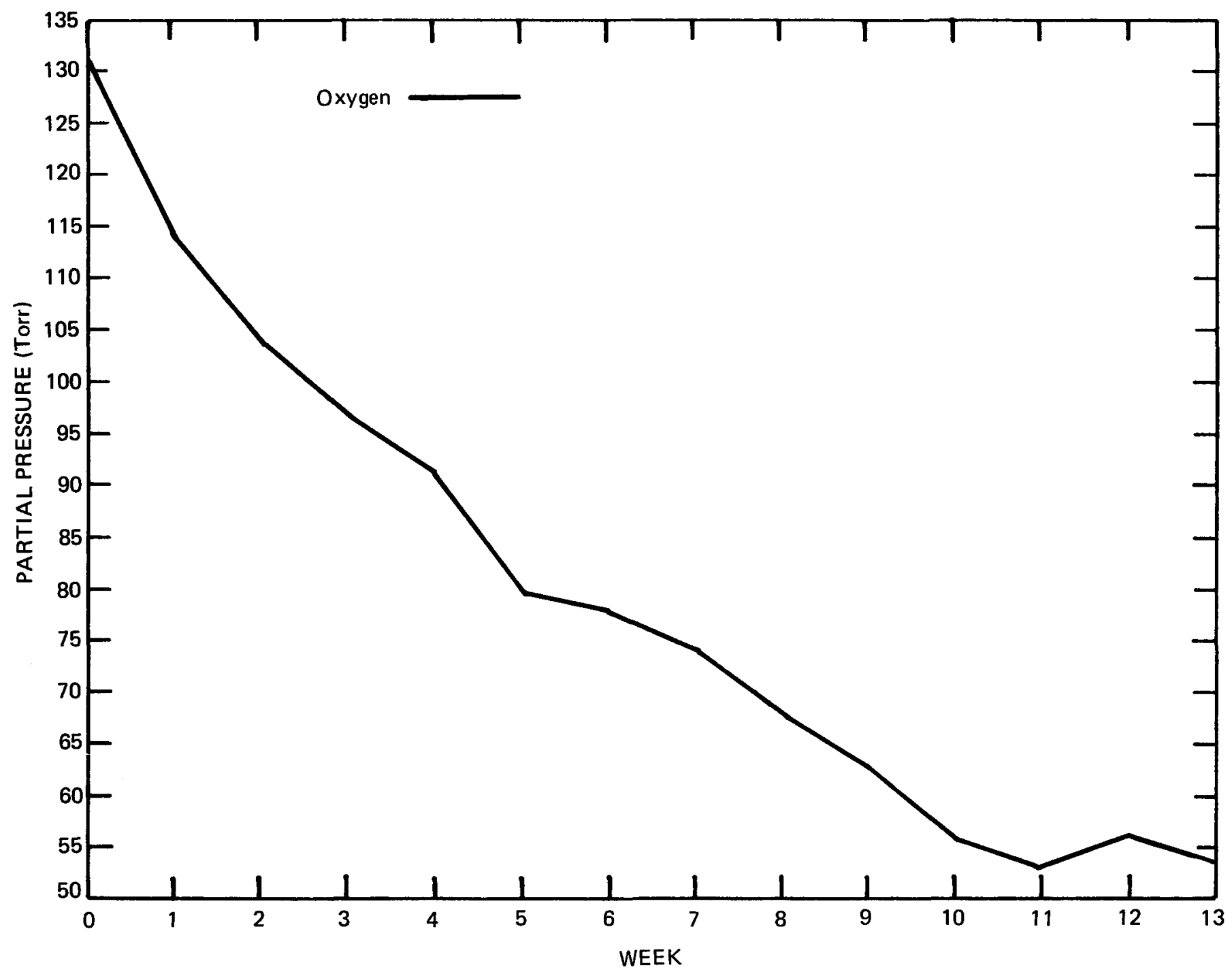

FIGURE B-10c. D31703 Atmosphere: Oxygen 


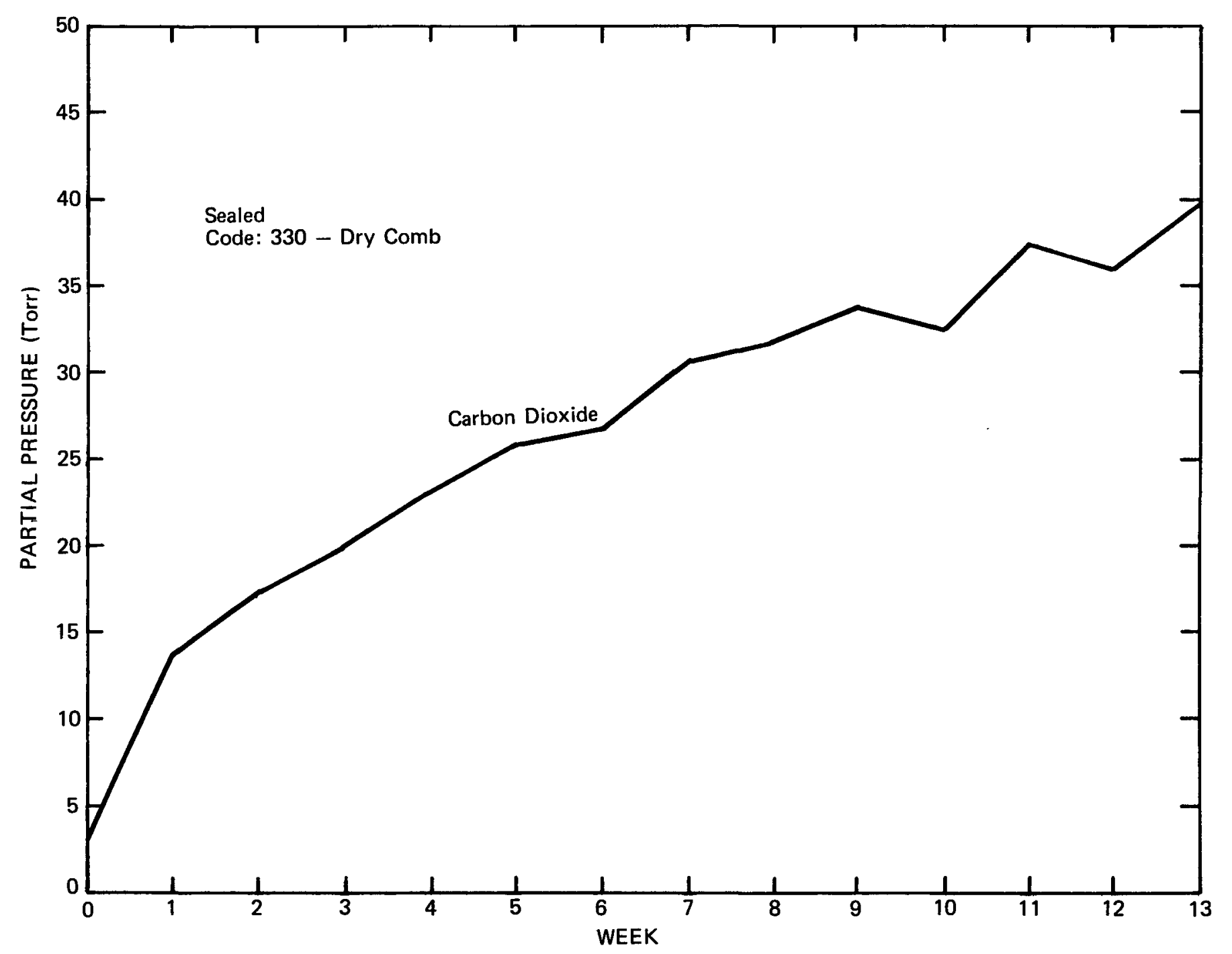

FIGURE B-10d. D31703 Atmosphere: Carbon Dioxide 
RFP-3739

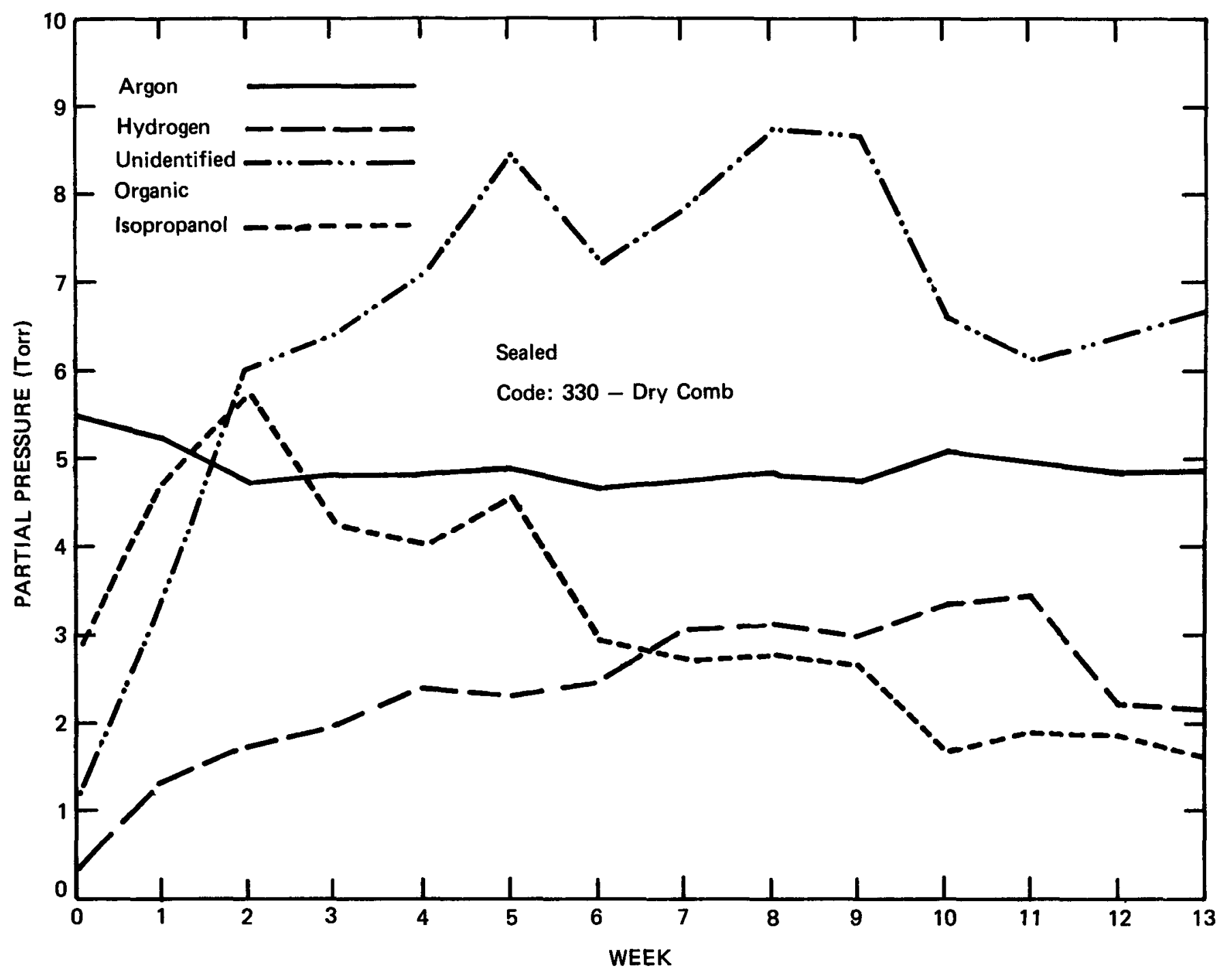

FIGURE B-10e. D31703 Atmosphere: Argon, Unidentified Organic, Hydrogen, Isopropanol 
RFP-3739

TABLE B-10. D31703 TRU Gas Generation Volume Percent

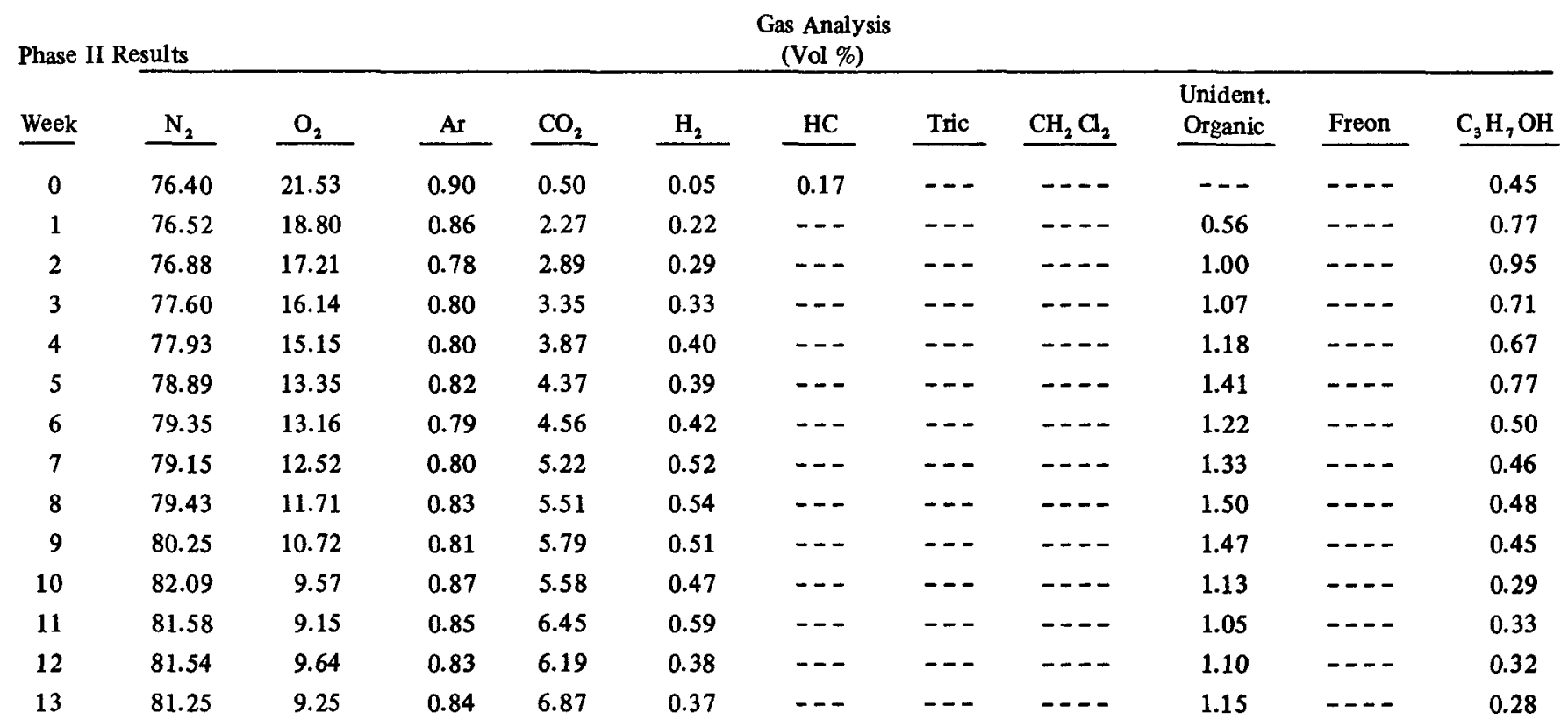

Sealed

Code: 330-Dry Comb 
RFP-3739

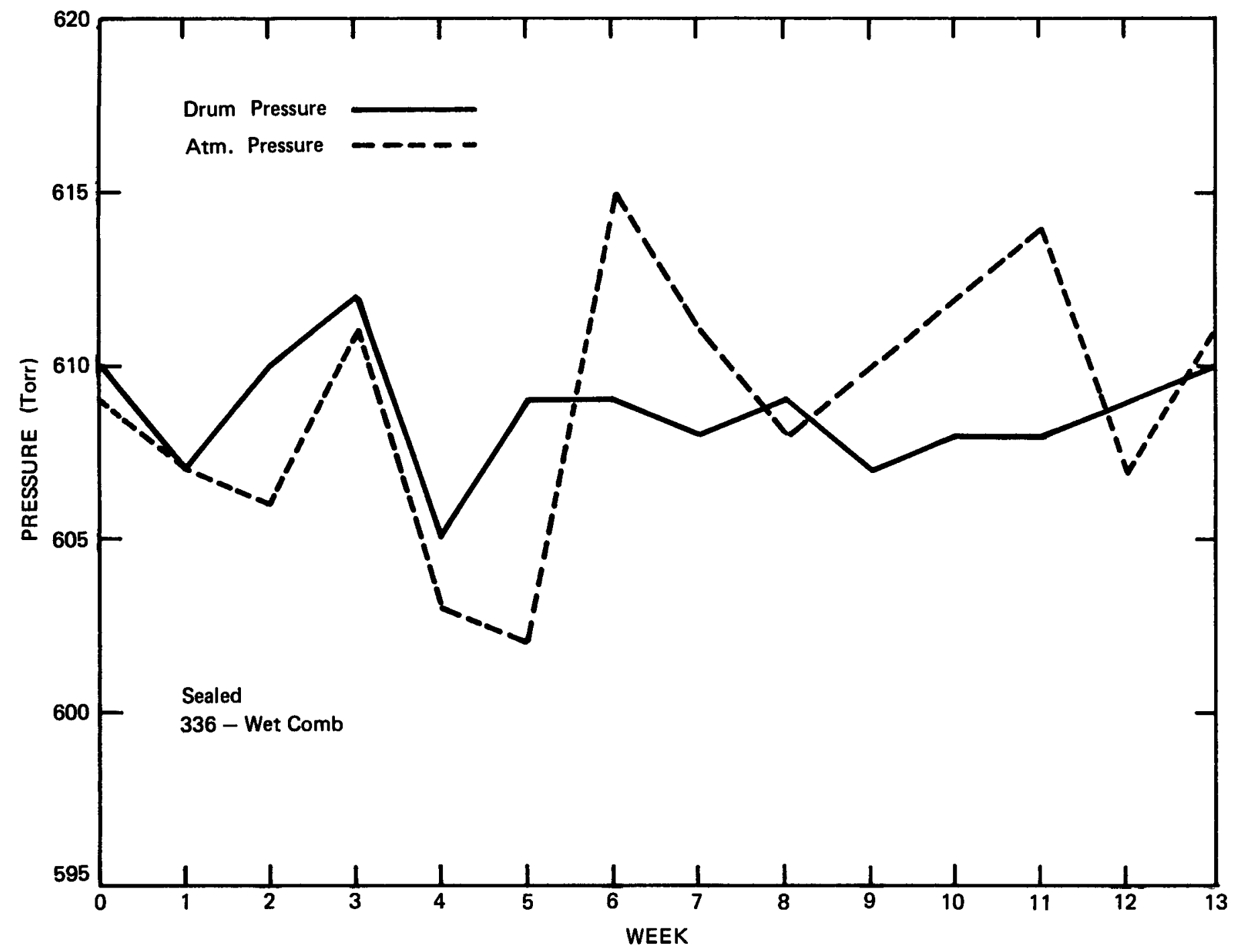

FIGURE B-11a. D25634 Pressure 


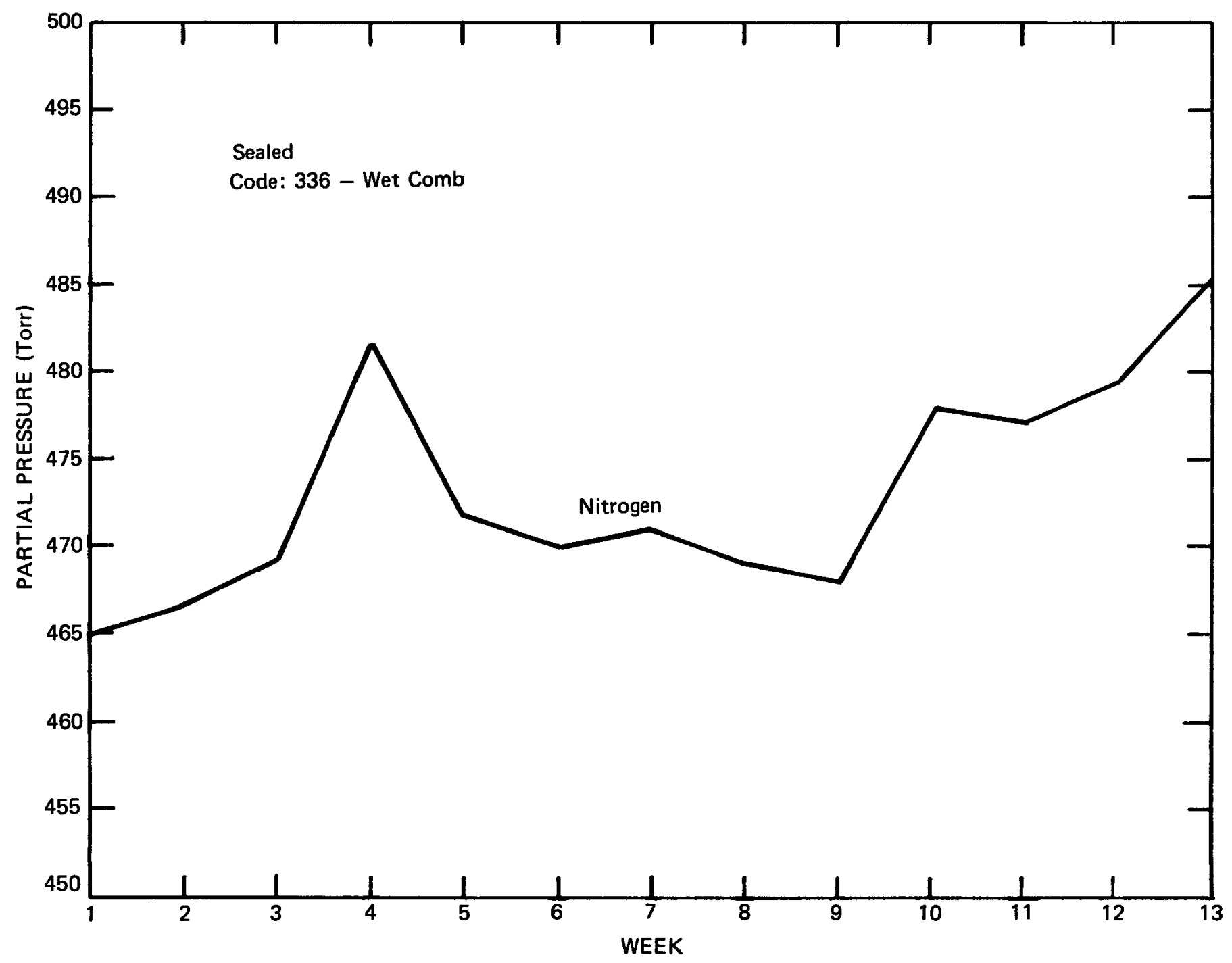

FIGURE B-11b. D25634 Atmosphere: Nitrogen 
RFP-3739

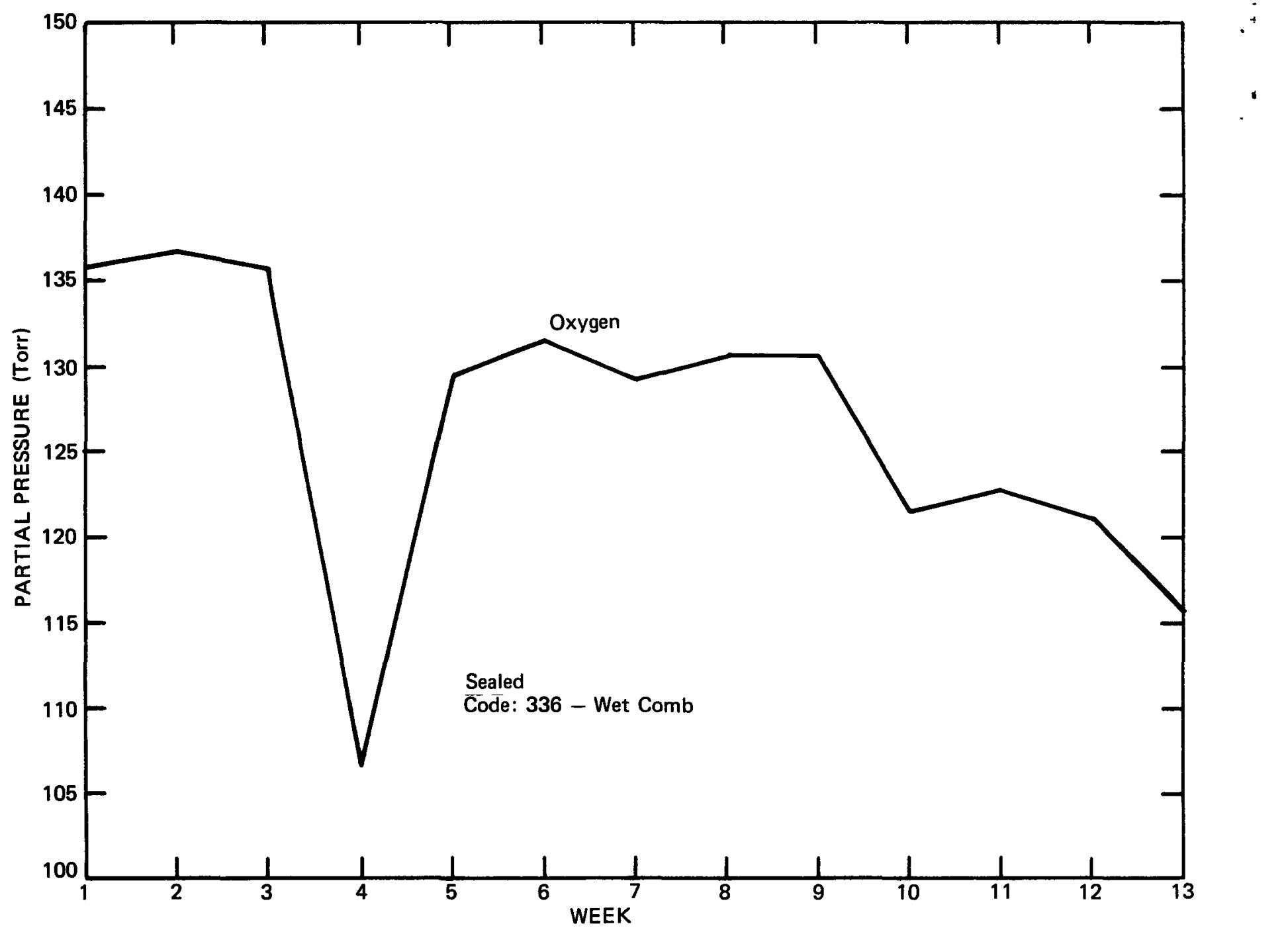

FIGURE B-11c. D25634 Atmosphere: Oxygen 


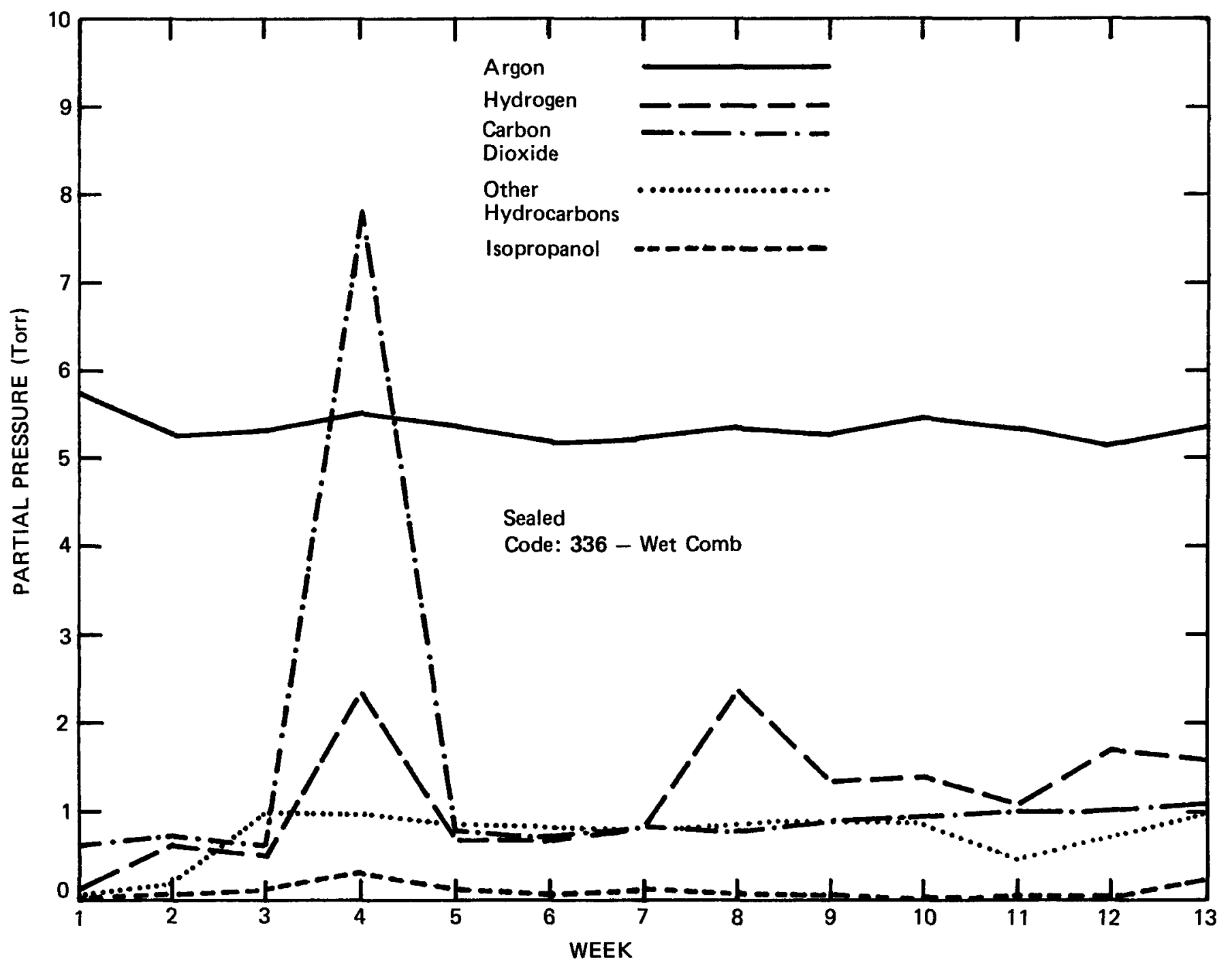

FIGURE B-11d. D25634 Atmosphere: Argon, Carbon Dioxide, Hydrogen, Other Hydrocarbons, Isopropanol 
TABLE B-11. D25634 TRU Gas Generation Volume Percent

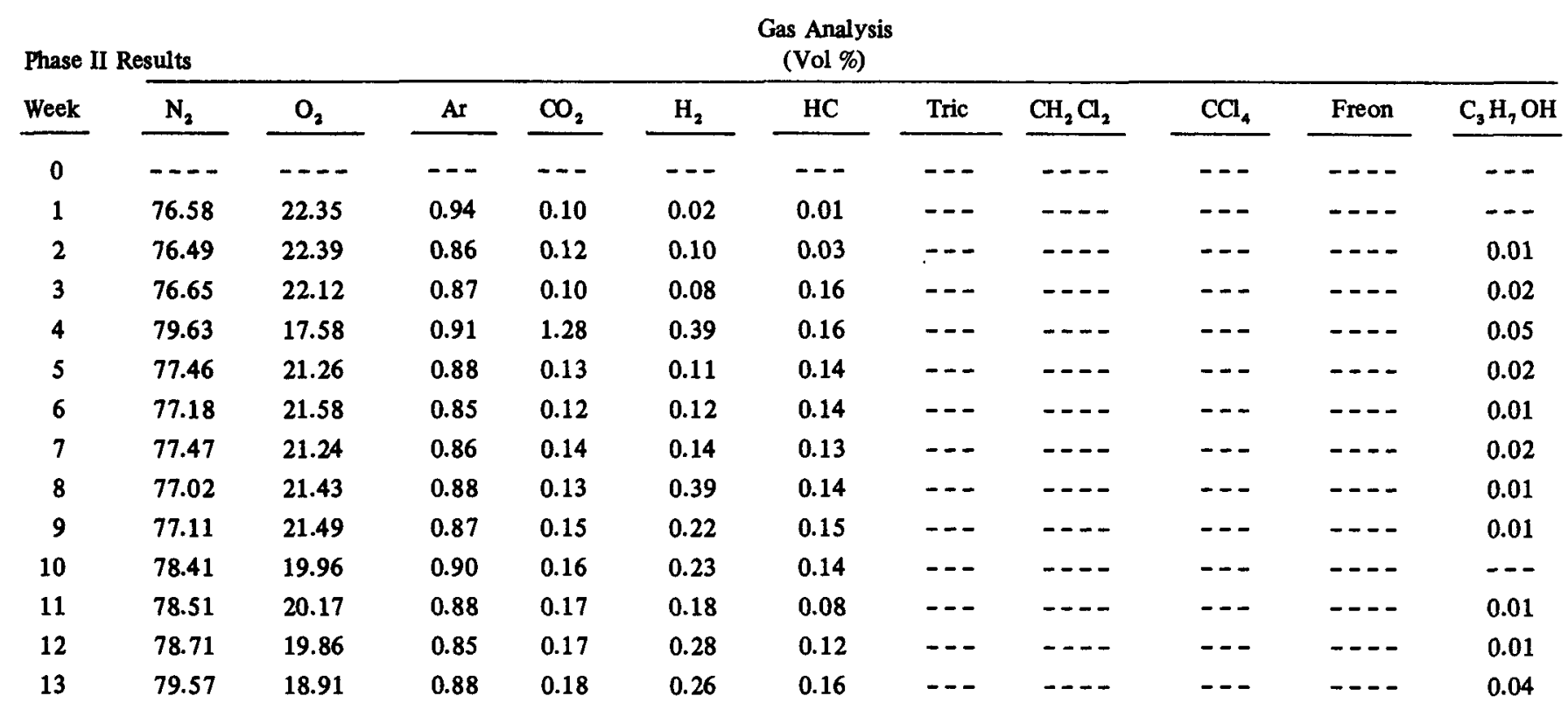

Sealed

Code: 336-Wet Comb 


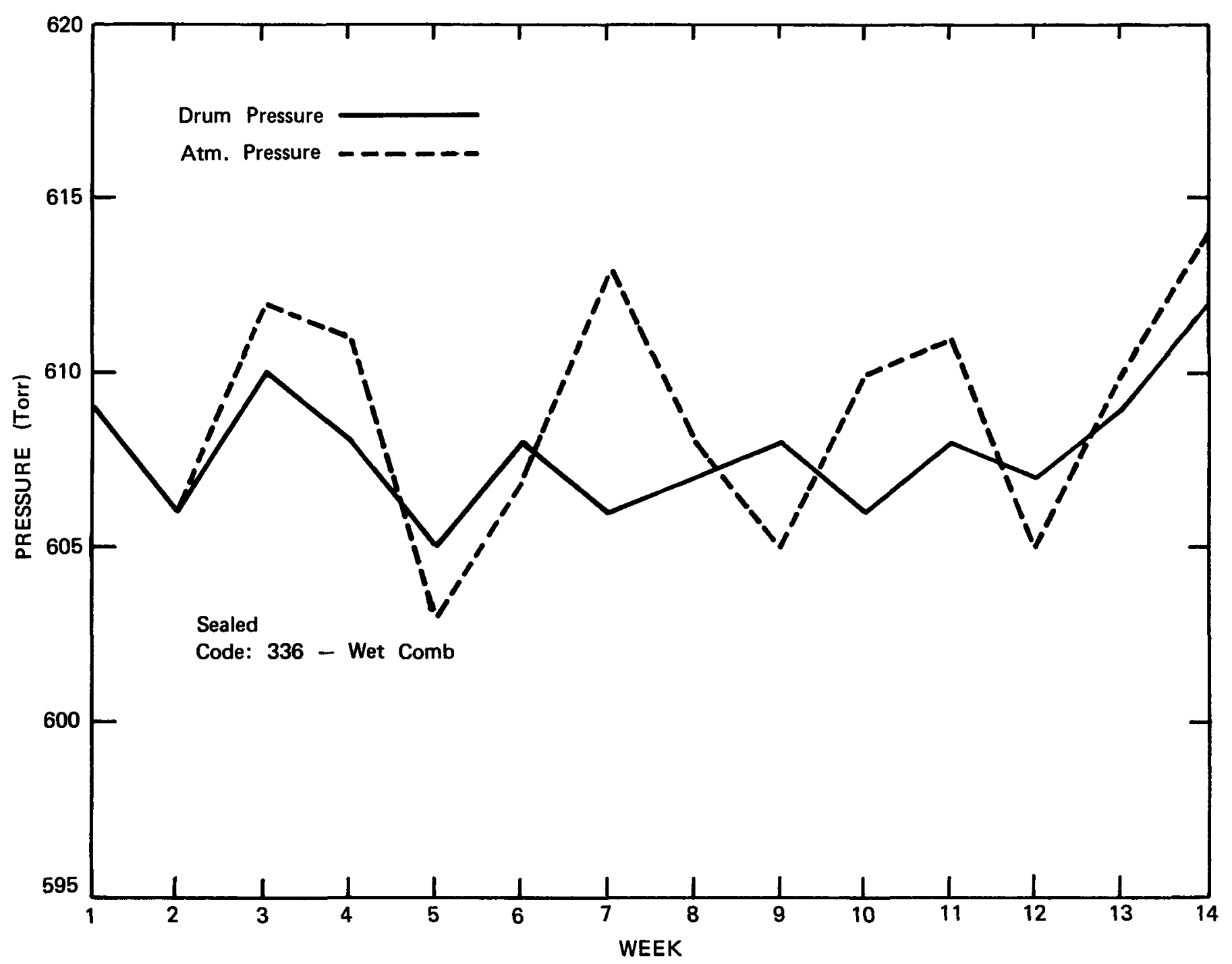

FIGURE B-12a. D31216 Pressure 
RFP-3739

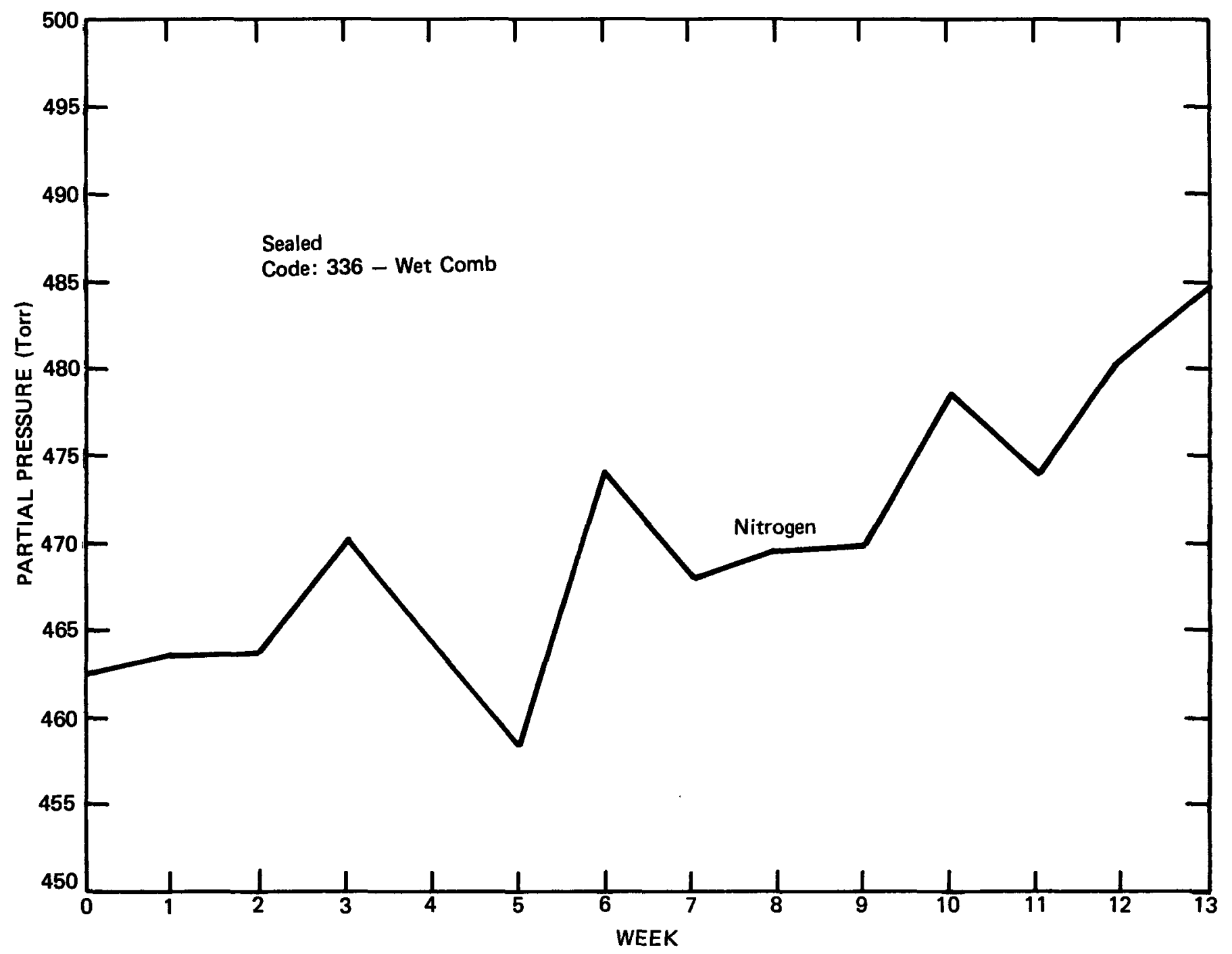

FIGURE B-12b. D31216 Atmosphere: Nitrogen 


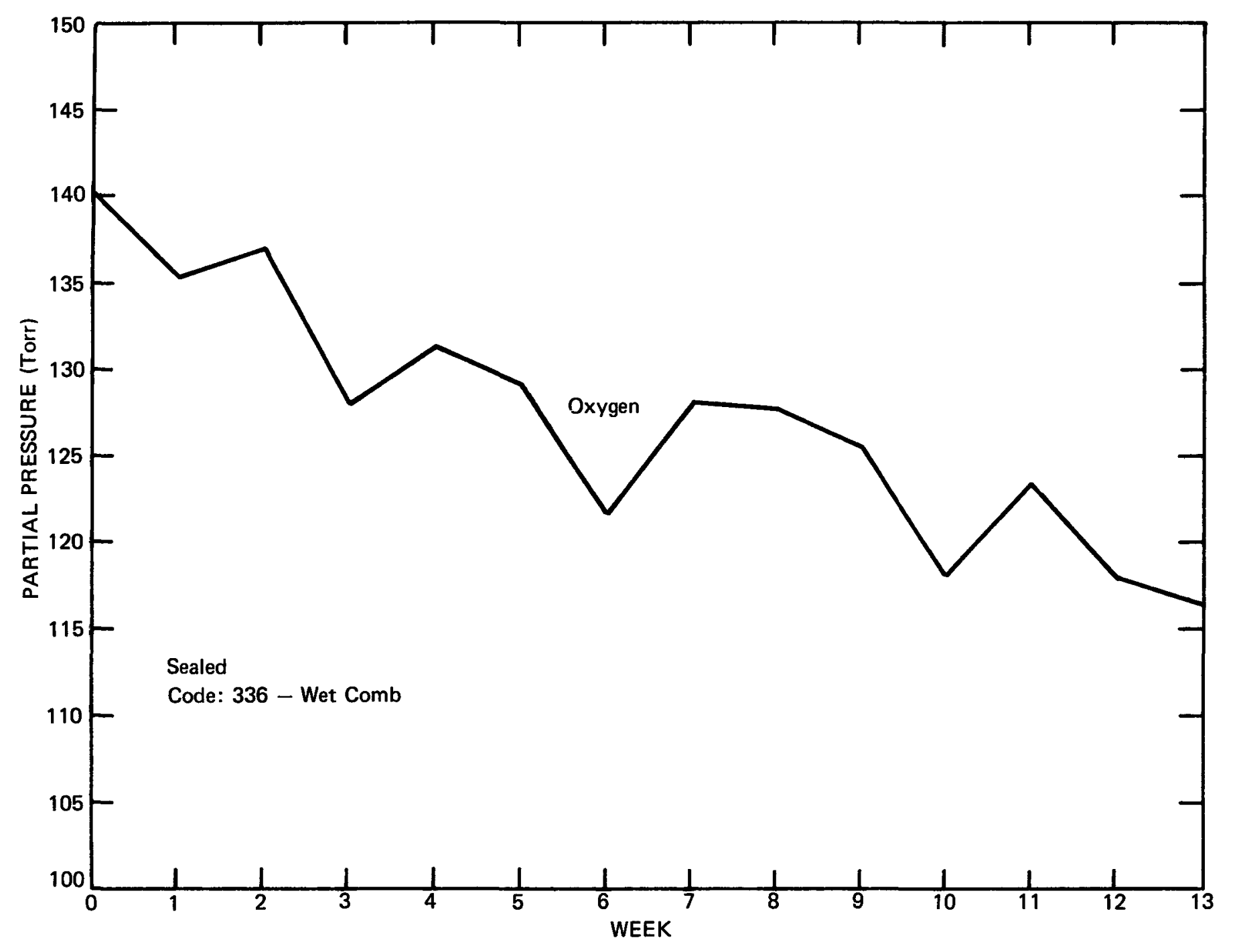

FIGURE B-12c. D31216 Atmosphere: Oxygen 


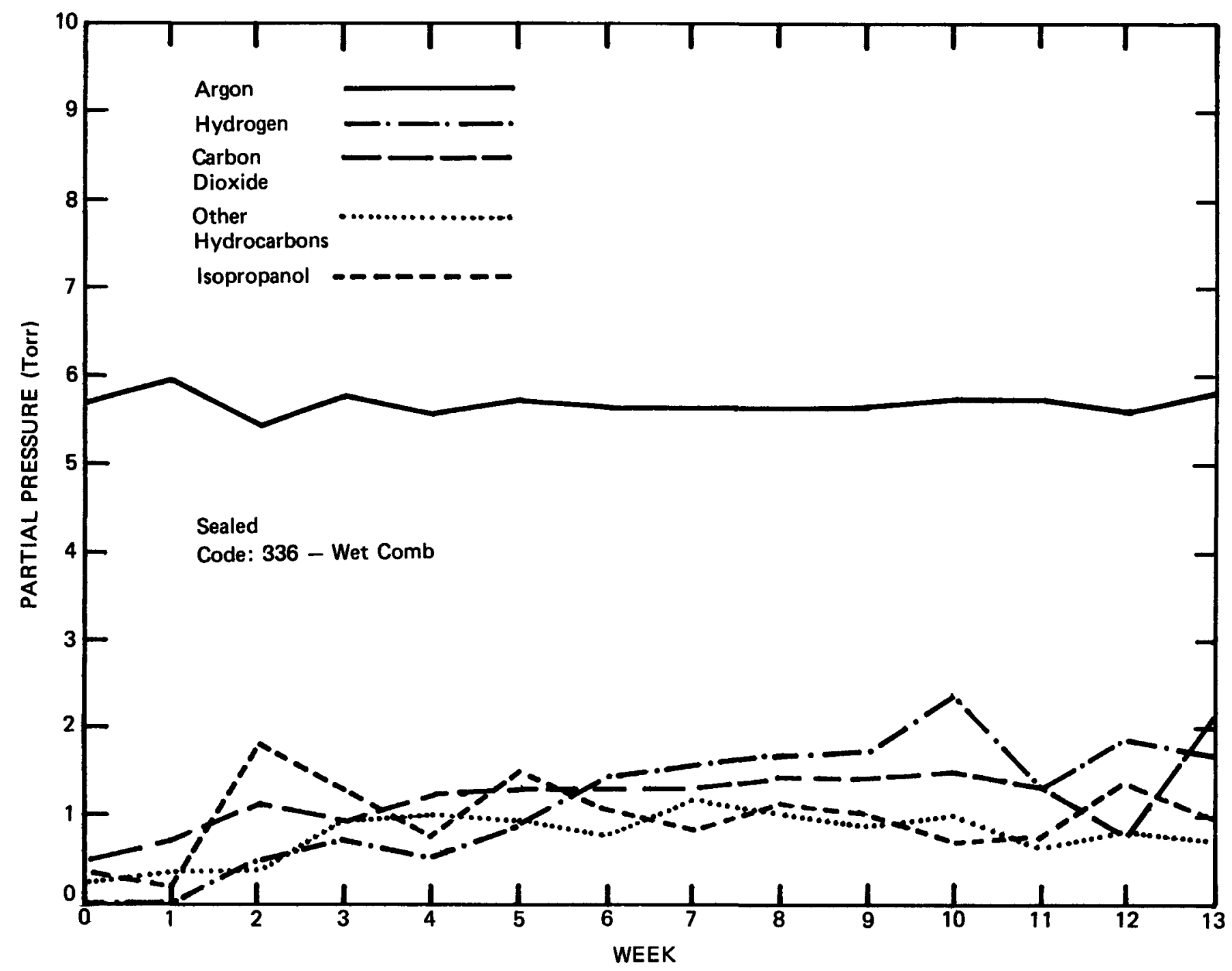

FIGURE B-12d. D31216 Atmosphere: Argon, Carbon Dioxide, Hydrogen, Other Hydrocarbons, Isopropanol 
RFP-3739

TABLE B-12. D31216 TRU Gas Generation Volume Percent

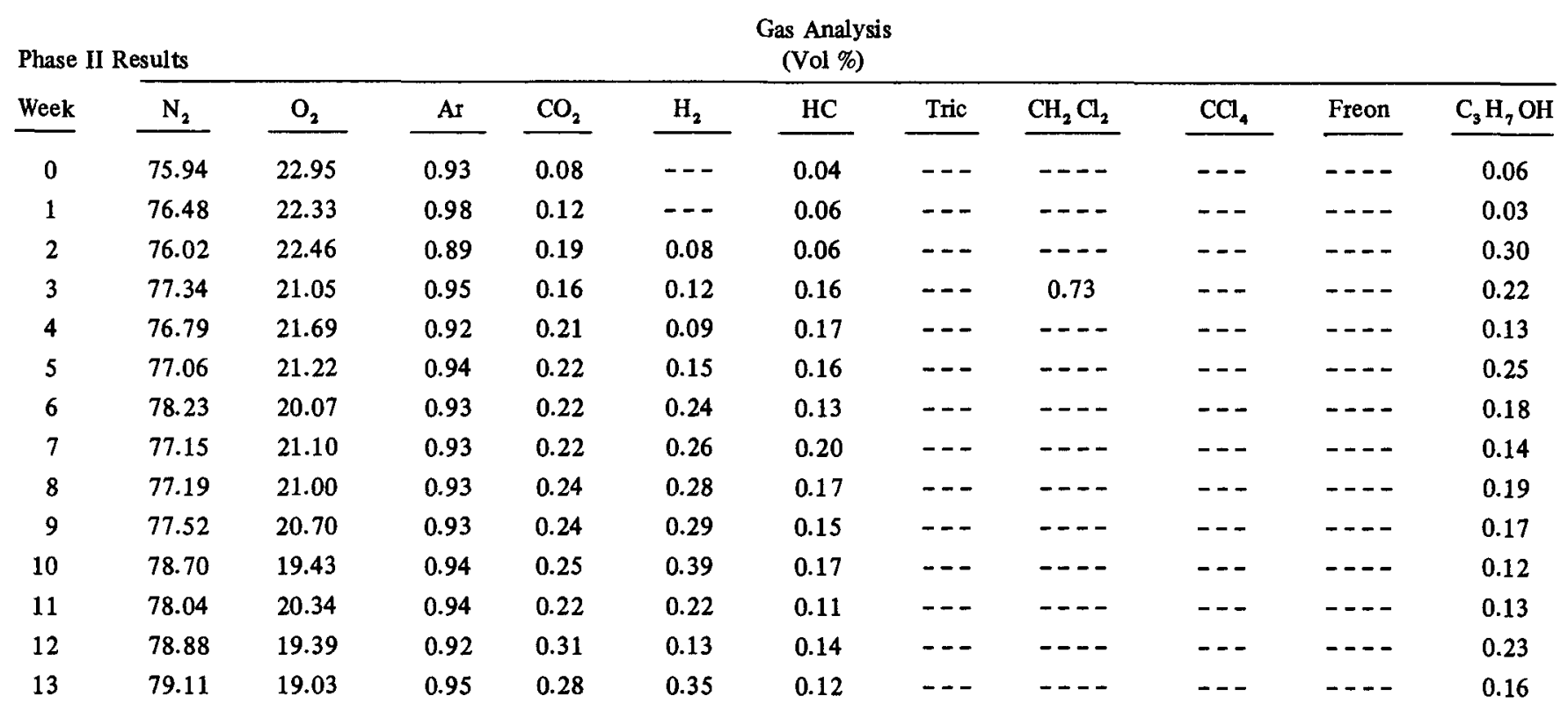

Sealed

Code: 336-Wet Comb 


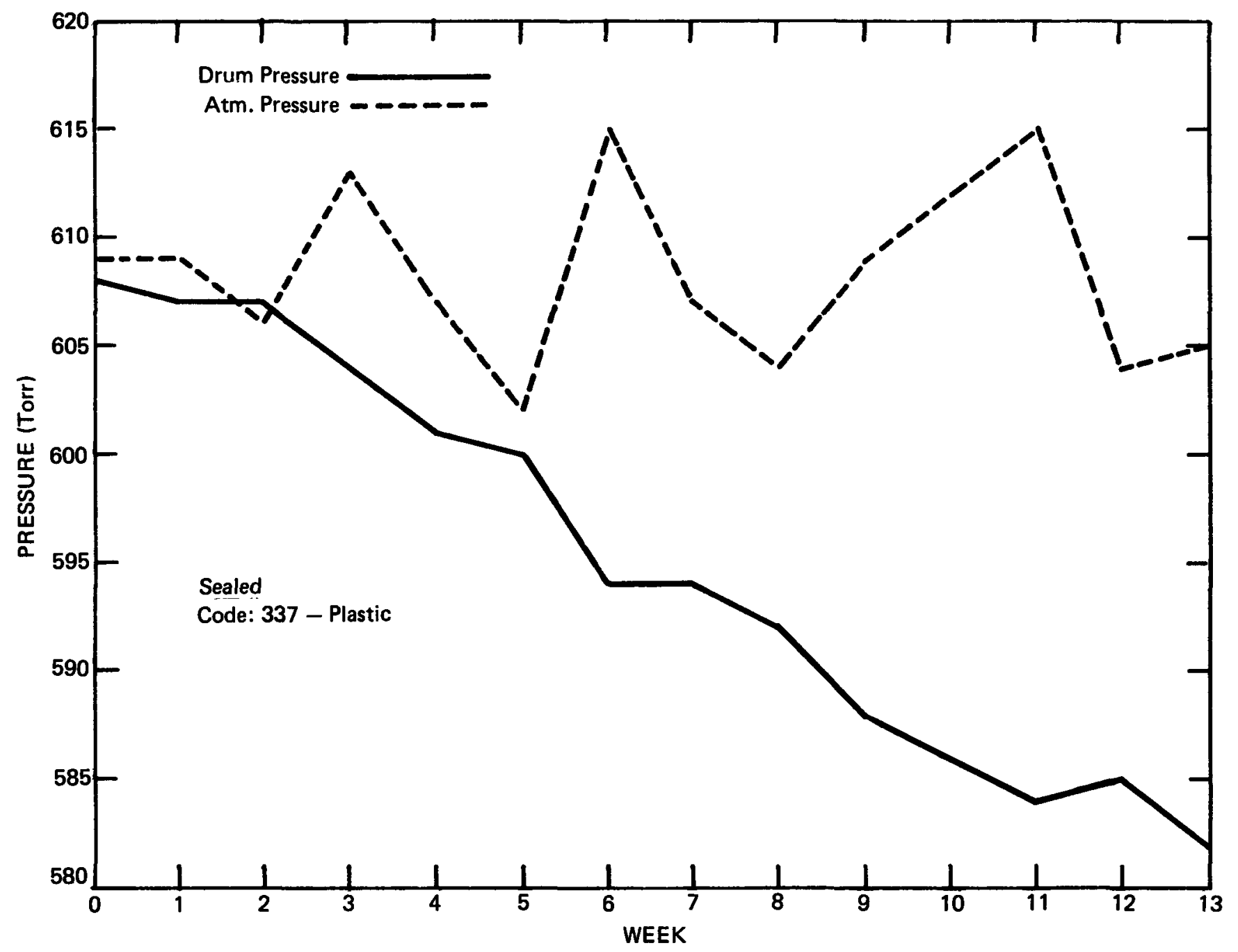

FIGURE B-13a. D25691 Pressure 


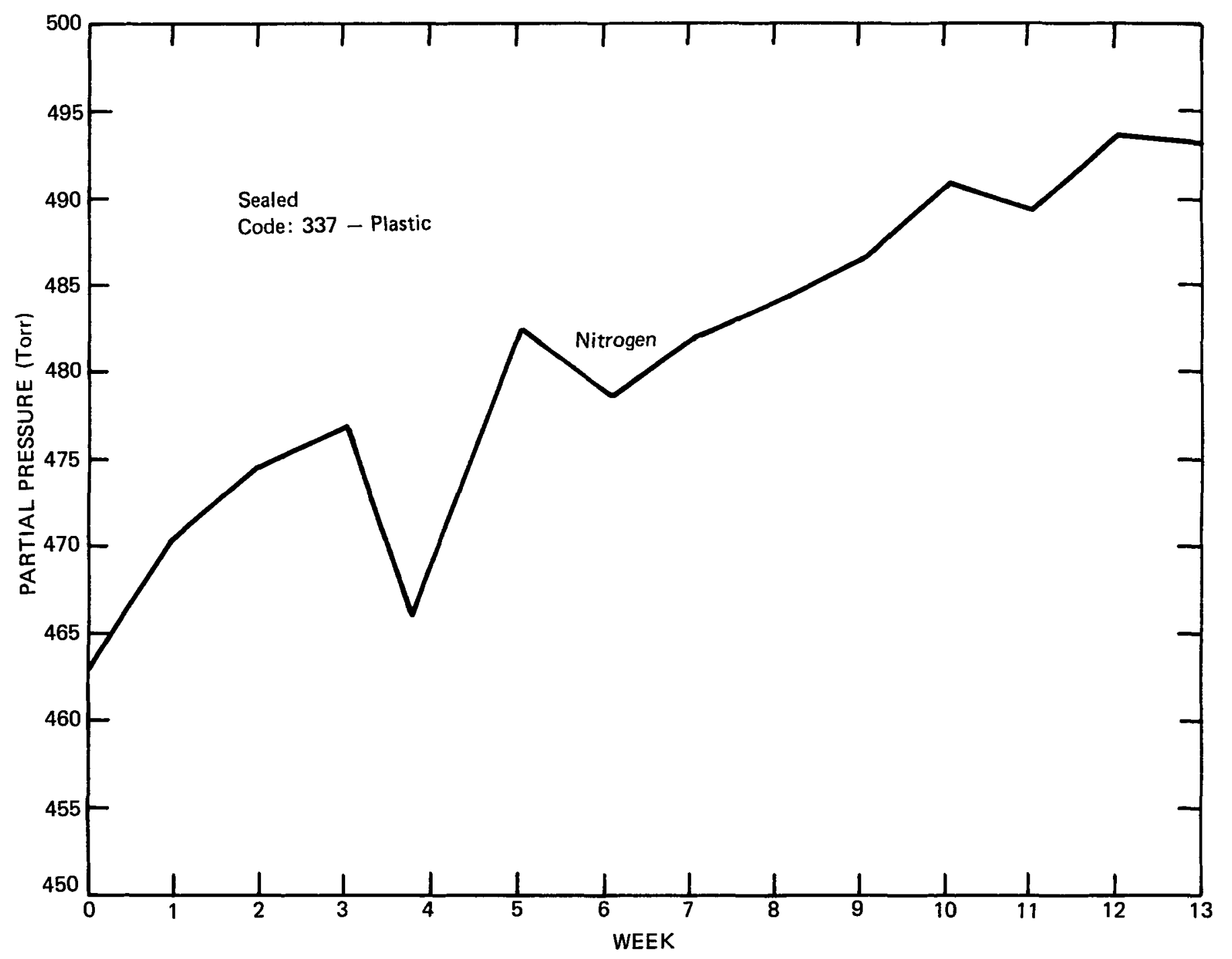

FIGURE B-13b. D25691 Atmosphere: Nitrogen 


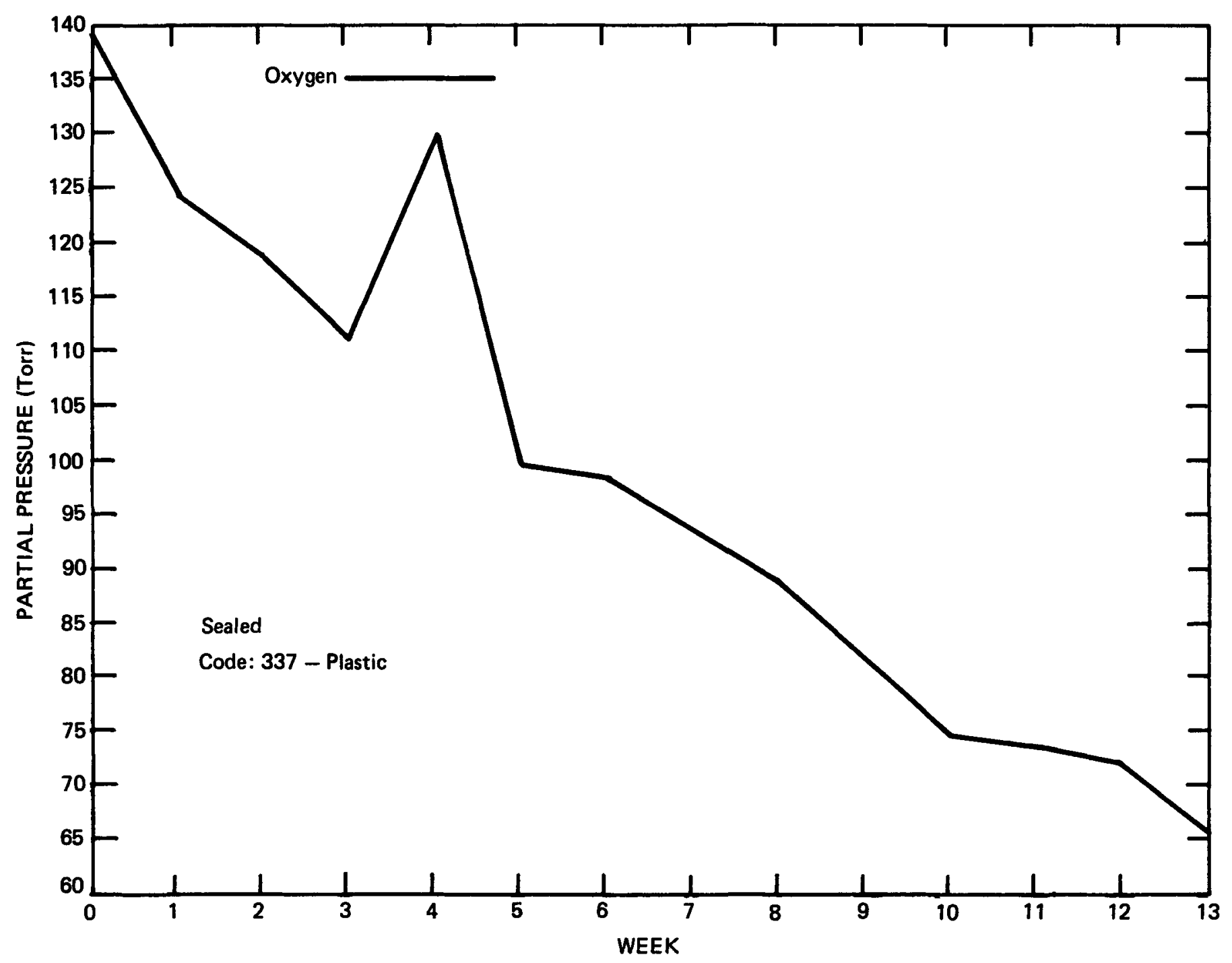

FIGURE B-13c. D25691 Atmosphere: Oxygen 


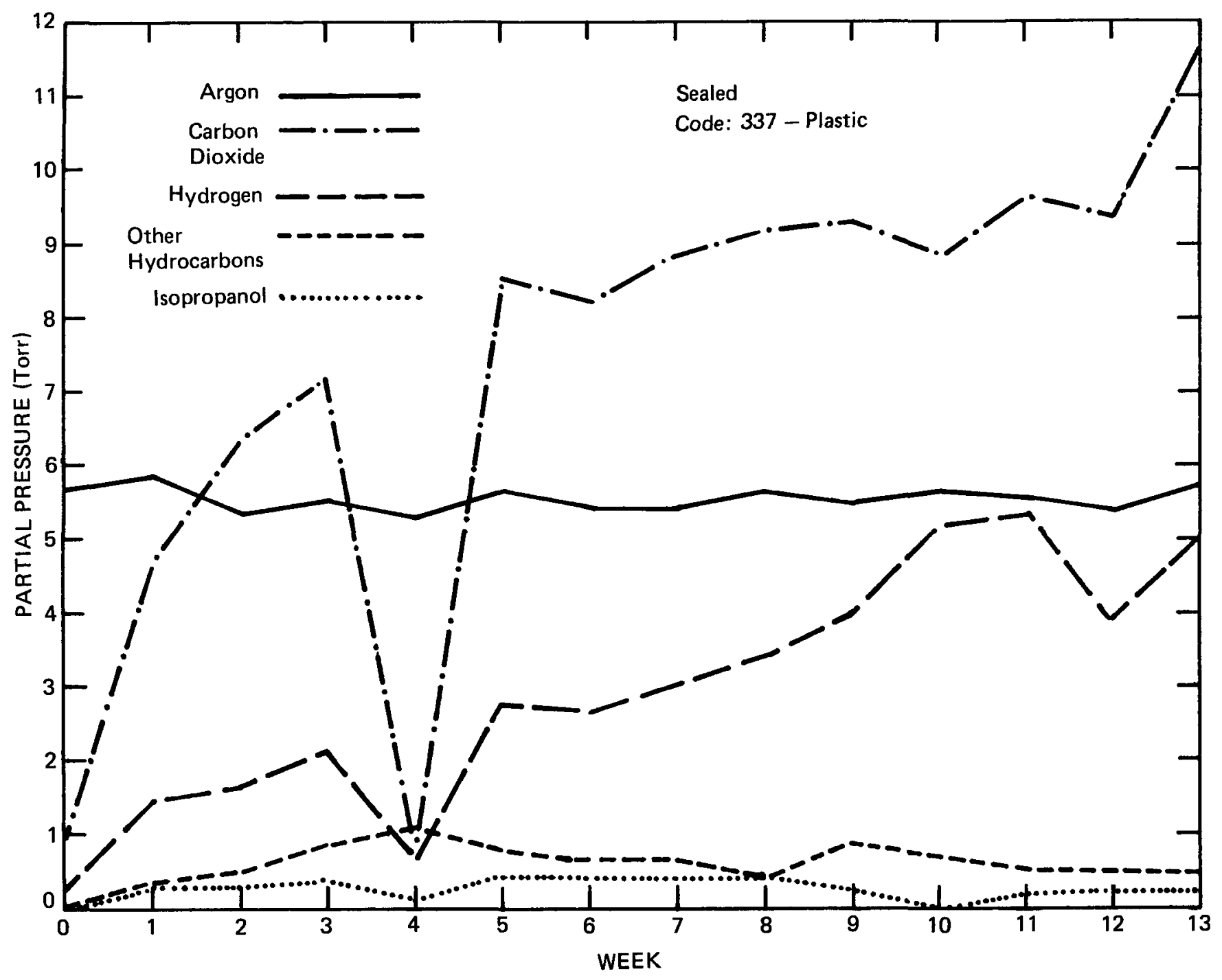

FIGURE B-13d. D25691 Atmosphere: Argon, Carbon Dioxide, Hydrogen, Other Hydrocarbons, Isopropanol 
RFP-3739

TABLE B-13. D25691 TRU Gas Generation Volume Percent

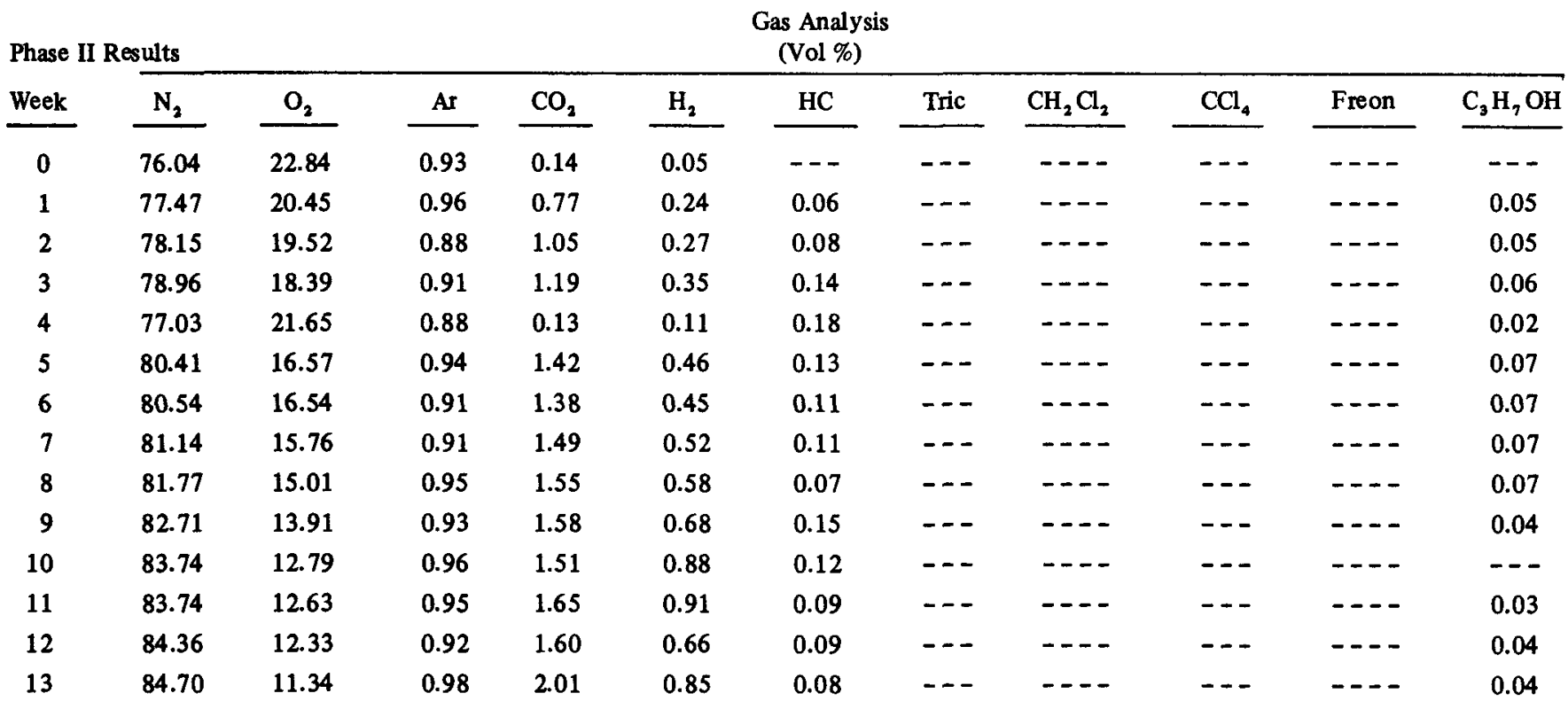

Sealed

Code: 337-Plastic 


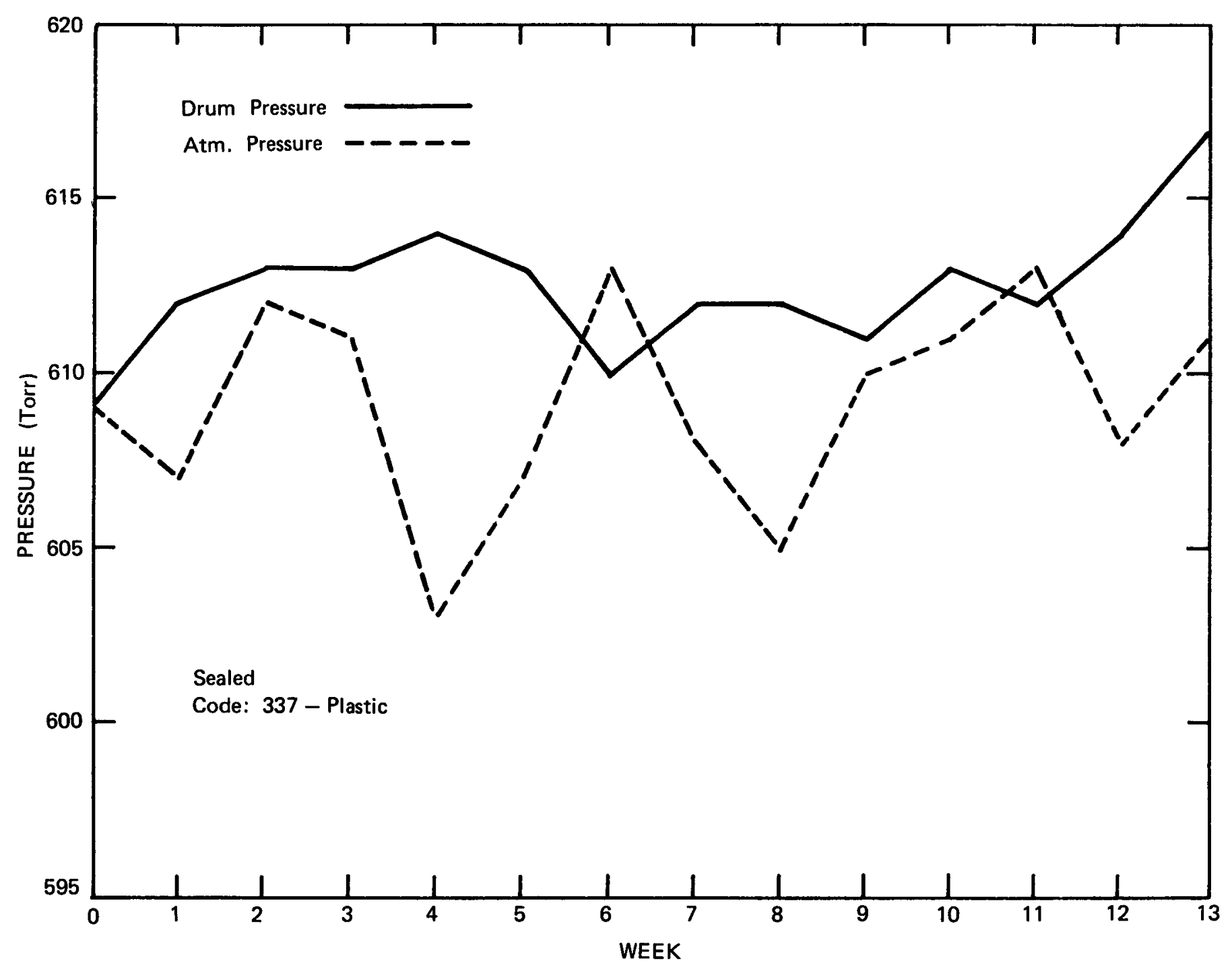

FIGURE B-14a. D30688 Pressure 
RFP-3739

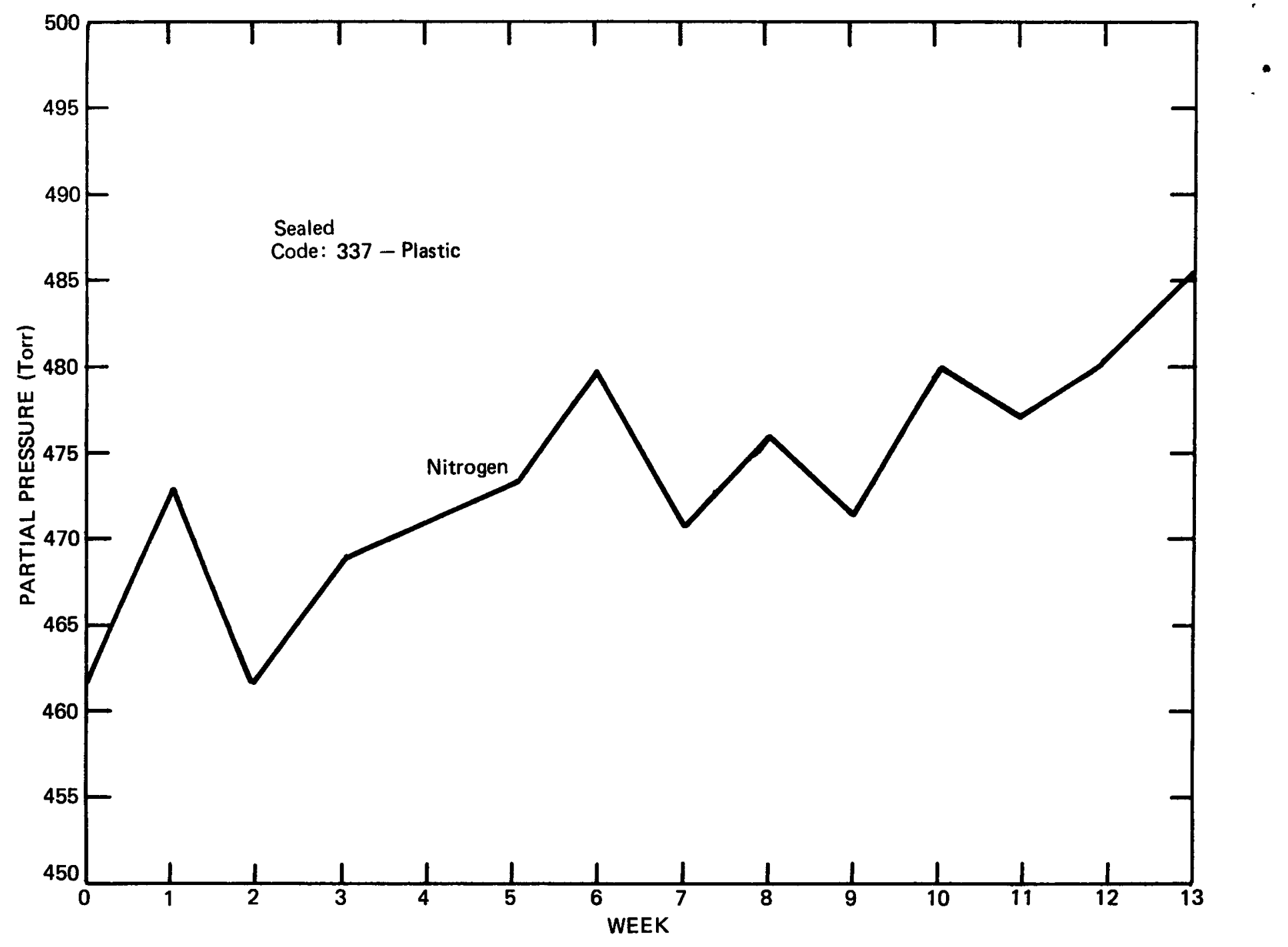

FIGURE B-14b. D30688 Atmosphere: Nitrogen 


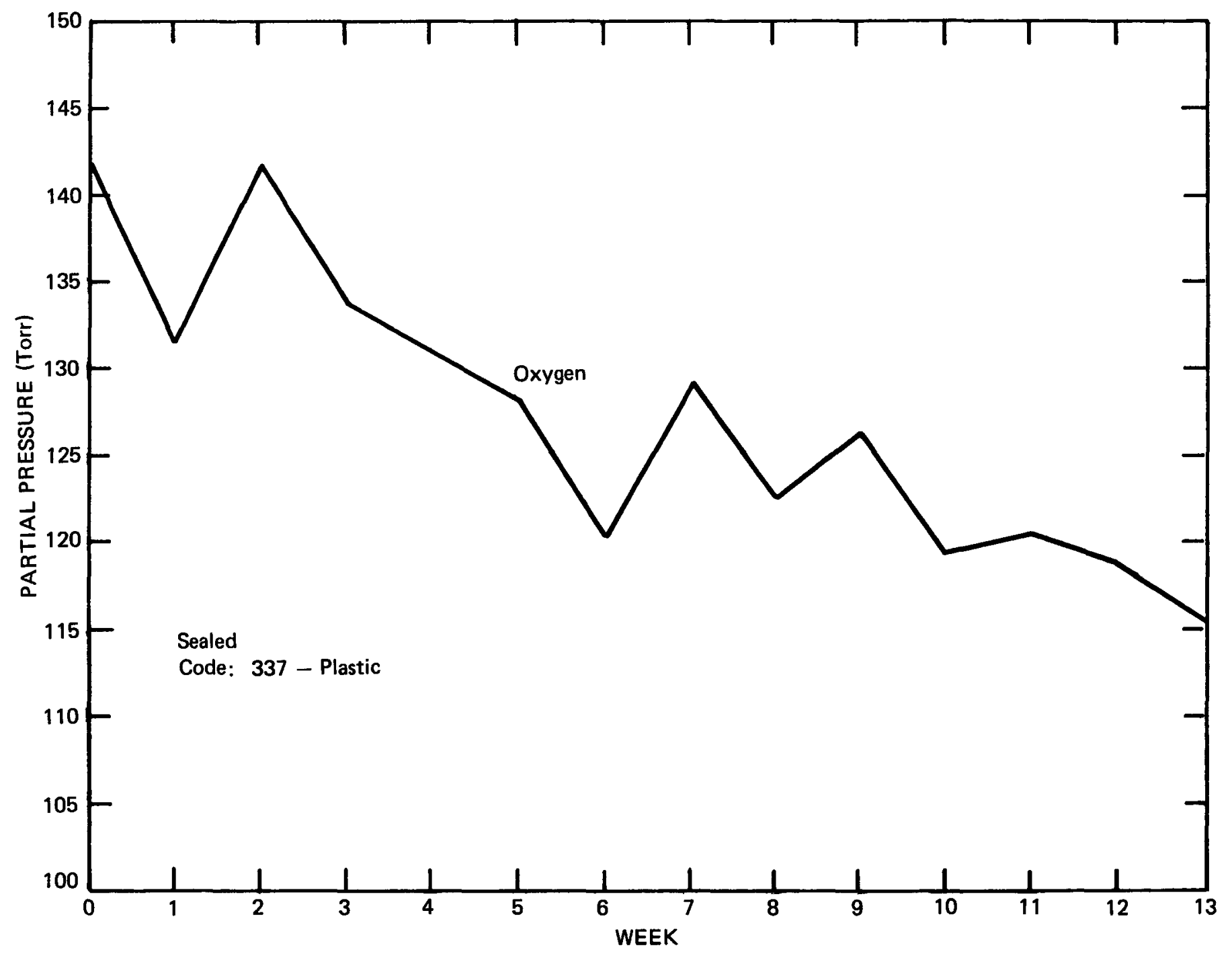

FIGURE B-14c. D30688 Atmosphere: Oxygen 
RFP-3739

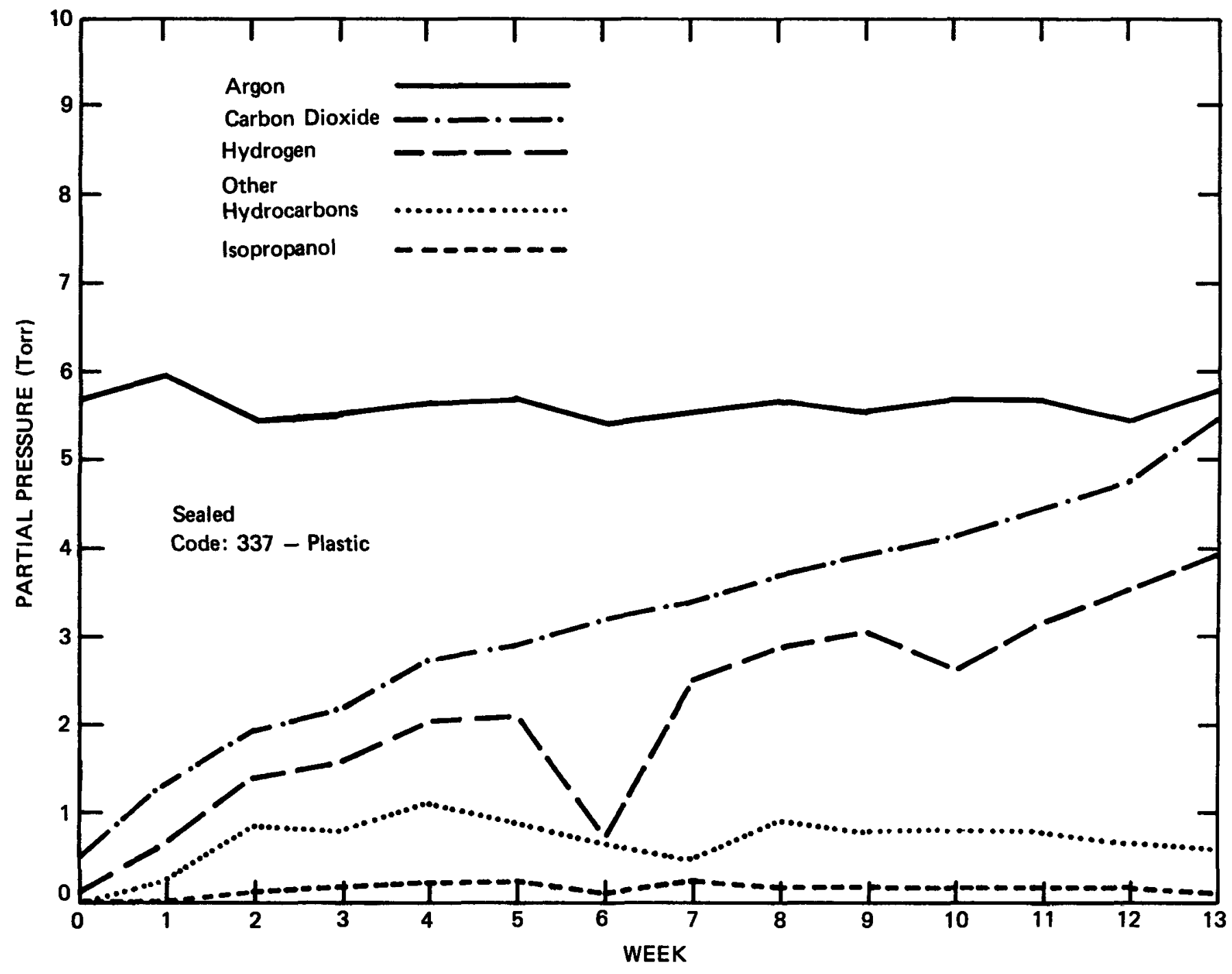

FIGURE B-14d. D30688 Atmosphere: Argon, Carbon Dioxide, Hydrogen, Other Hydrocarbons, Isopropanol 
RFP-3739

TABLE B-14. D30688 TRU Gas Generation Volume Percent

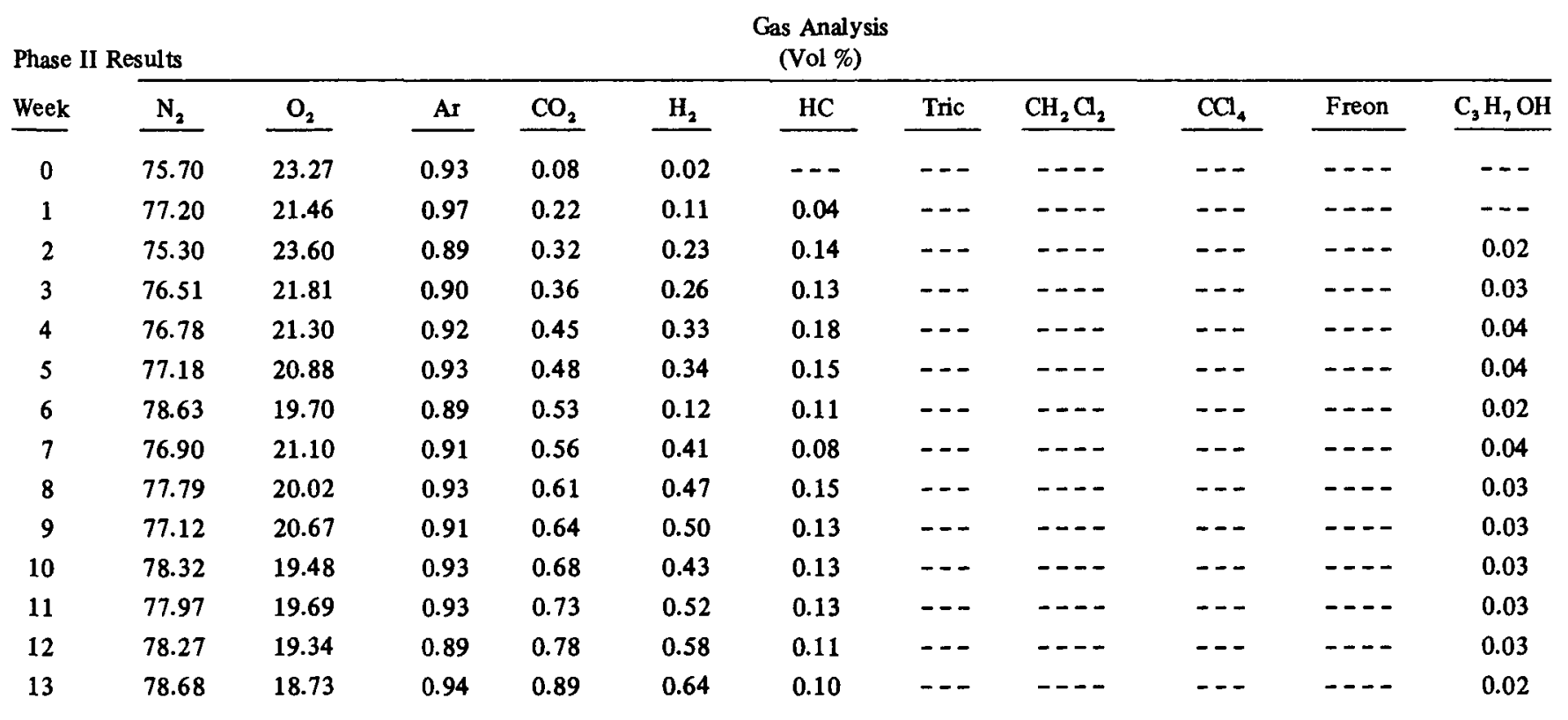

Sealed

Code: 337-Plastic 
RFP-3739

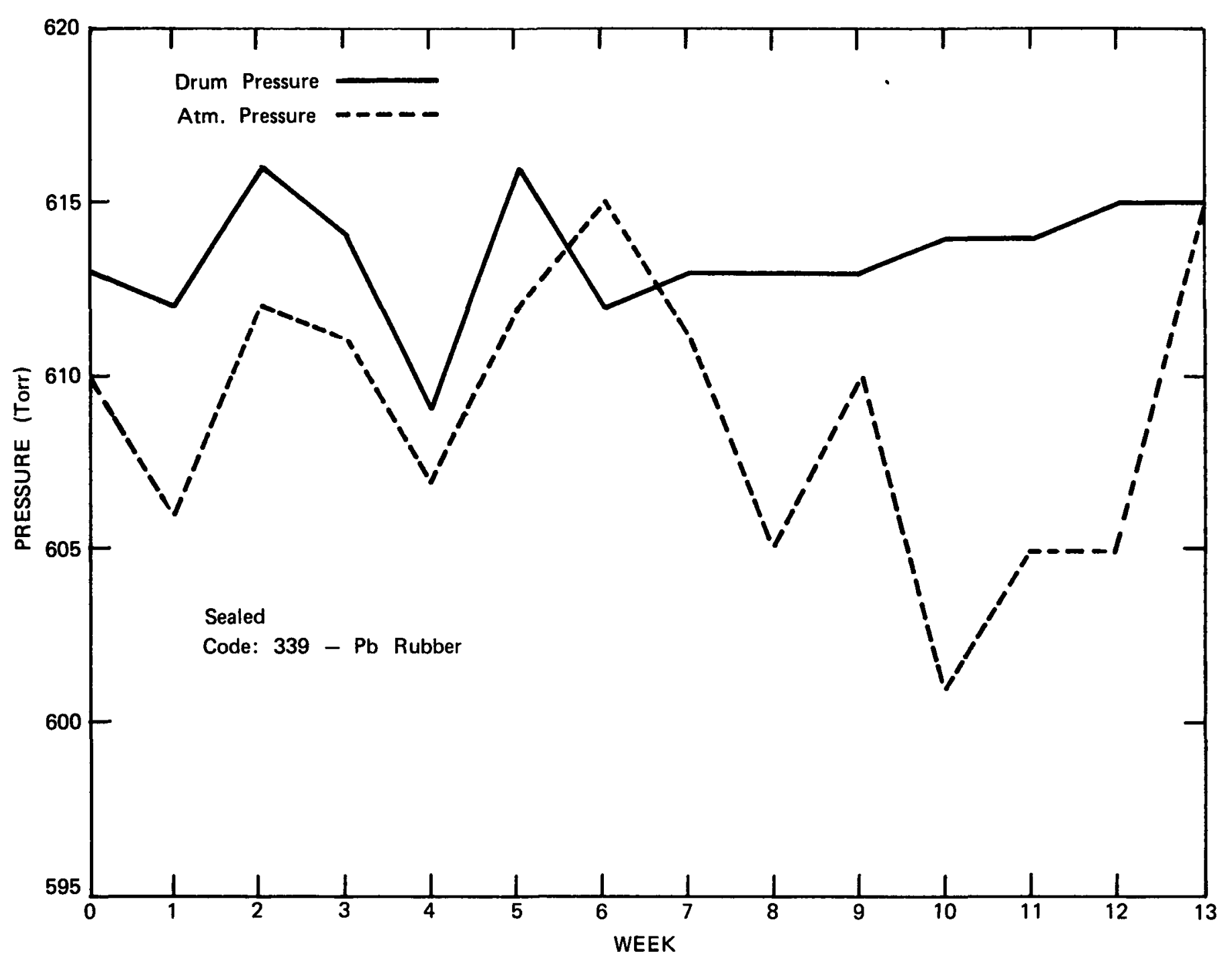

FIGURE B-15a. D29758 Pressure 


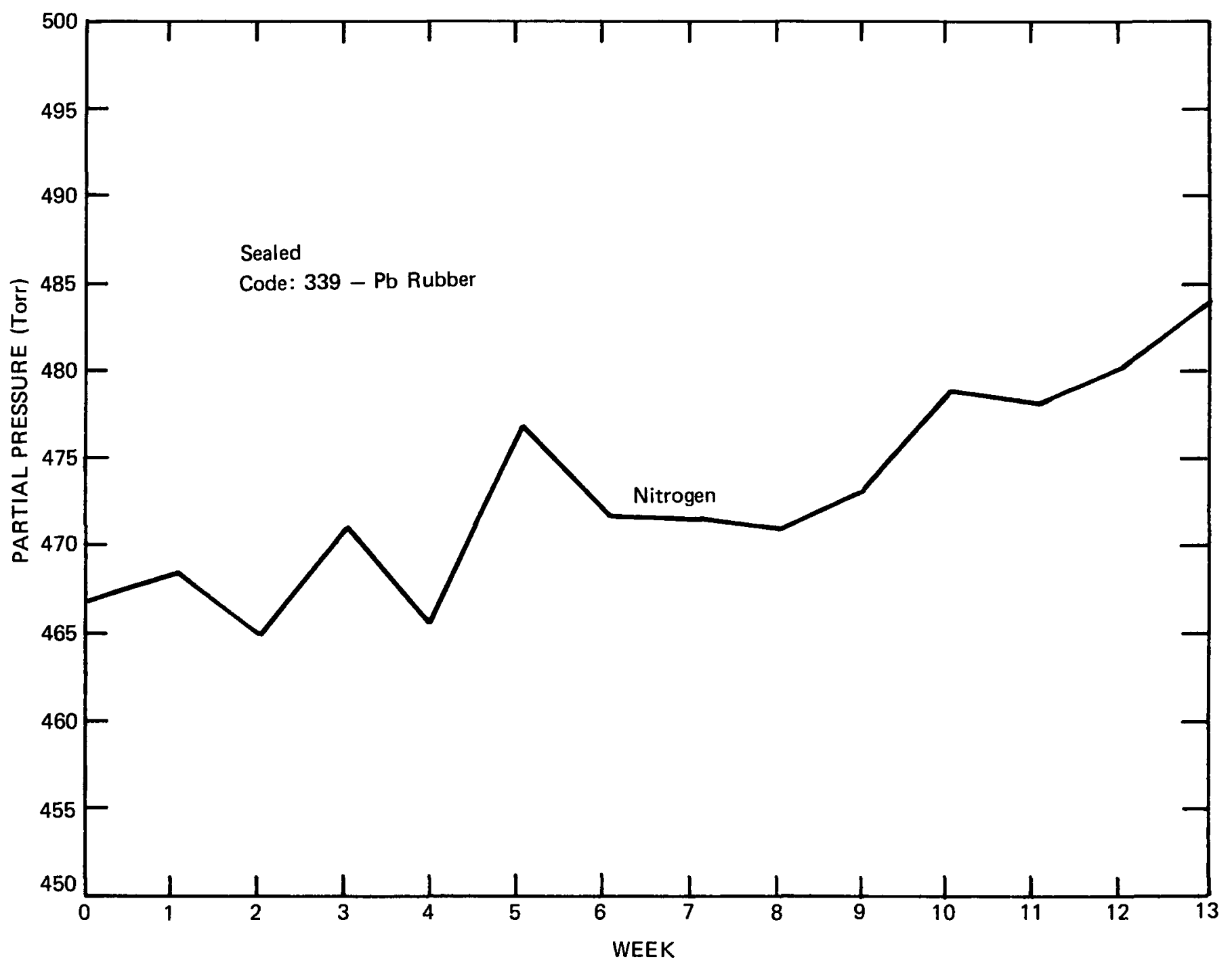

FIGURE B-15b. D29758 Atmosphere: Nitrogen 


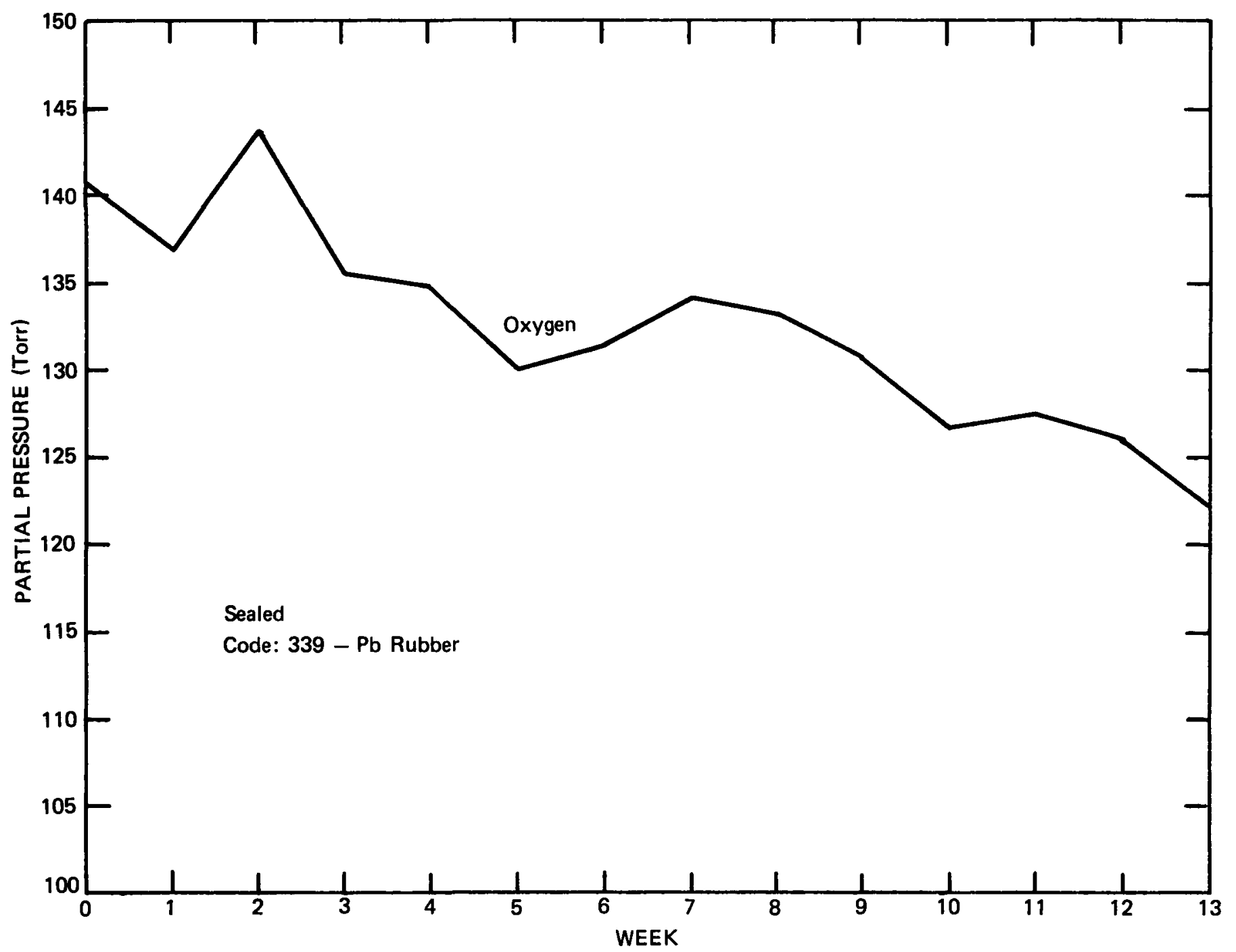

FIGURE B-15c. D29758 Atmosphere: Oxygen 


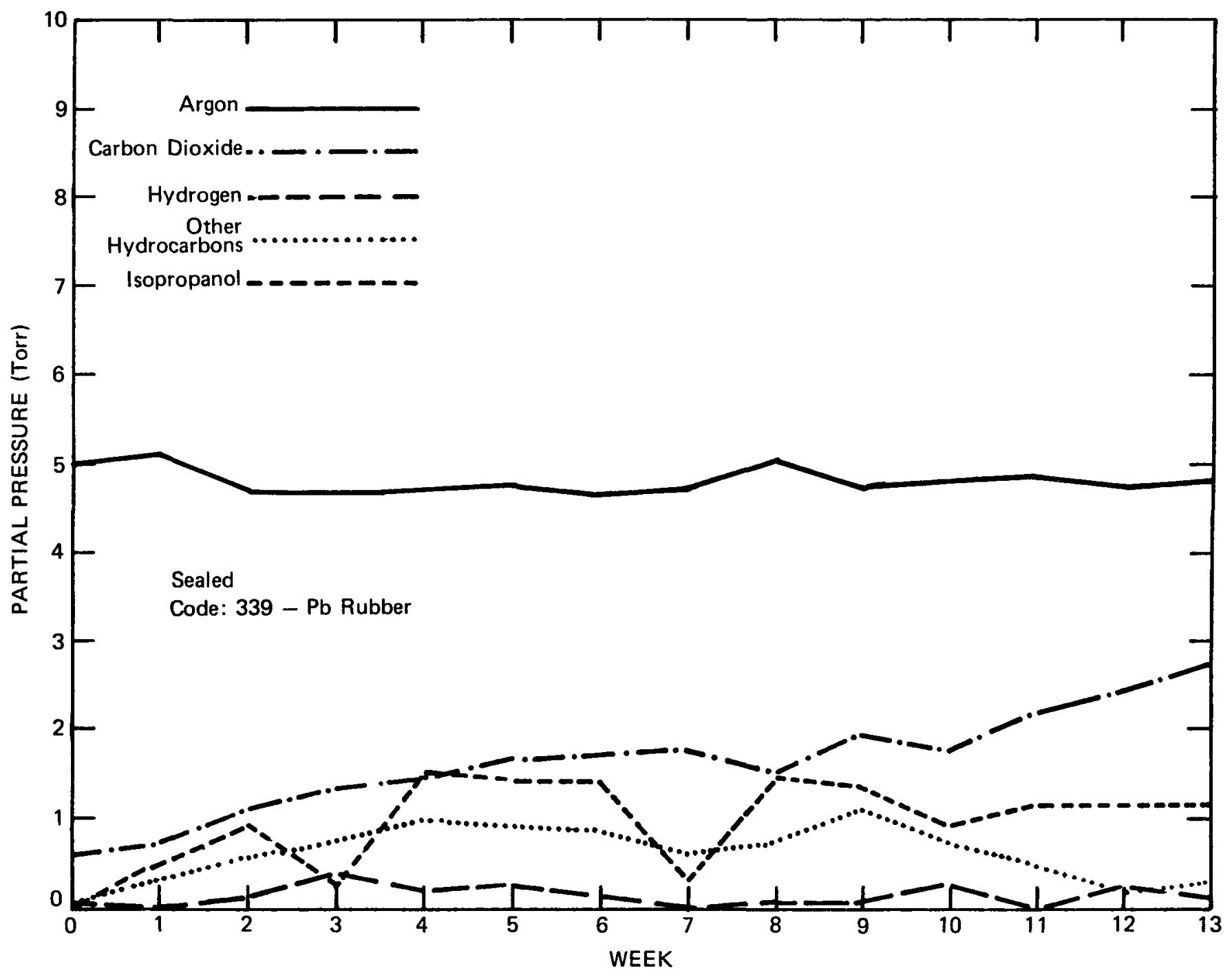

FIGURE B-15d. D29758 Atmosphere: Argon, Carbon Dioxide, Hydrogen, Other Hydrocarbons, Isopropanol 
RFP-3739

TABLE B-15. D29758 TRU Gas Generation Volume Percent

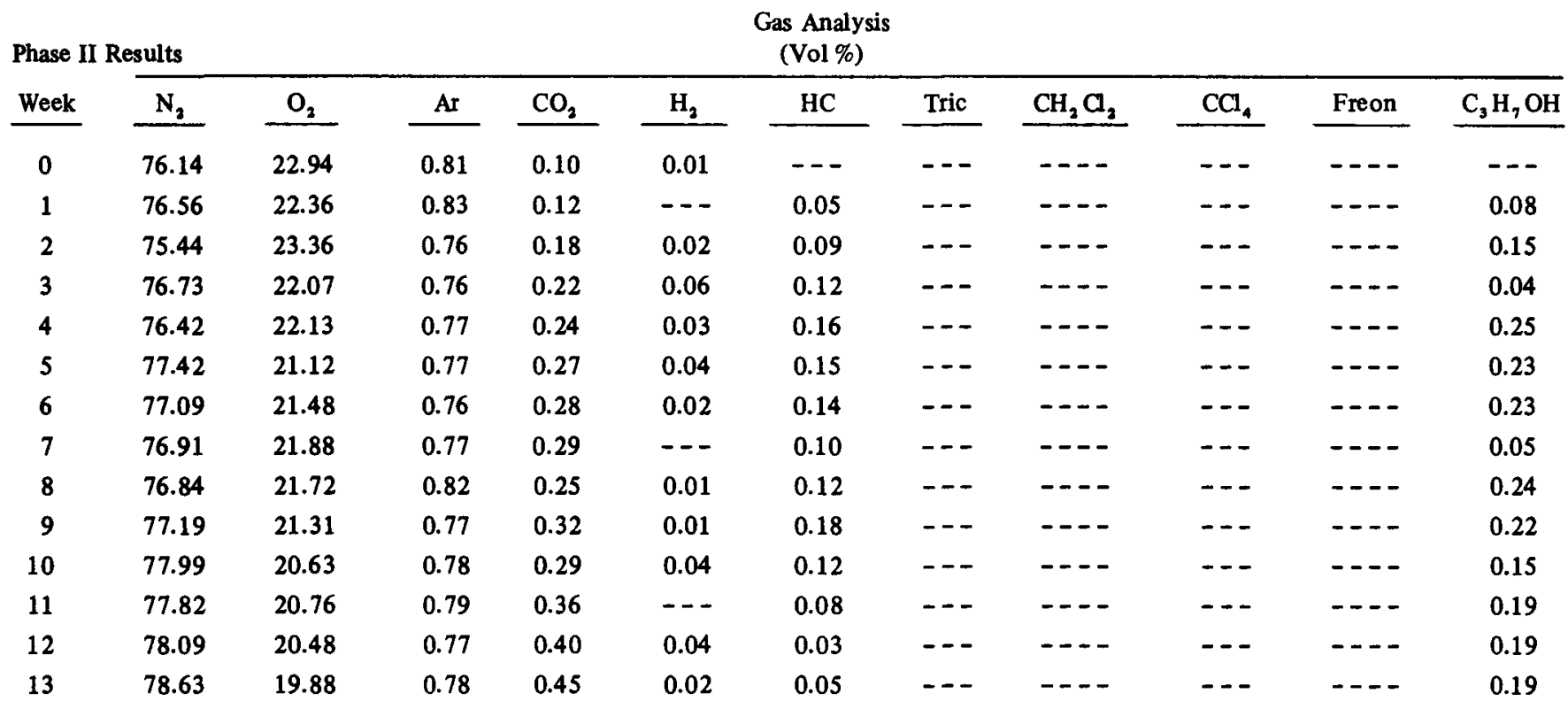

Sealed

Code: 339-Pb Rubber 


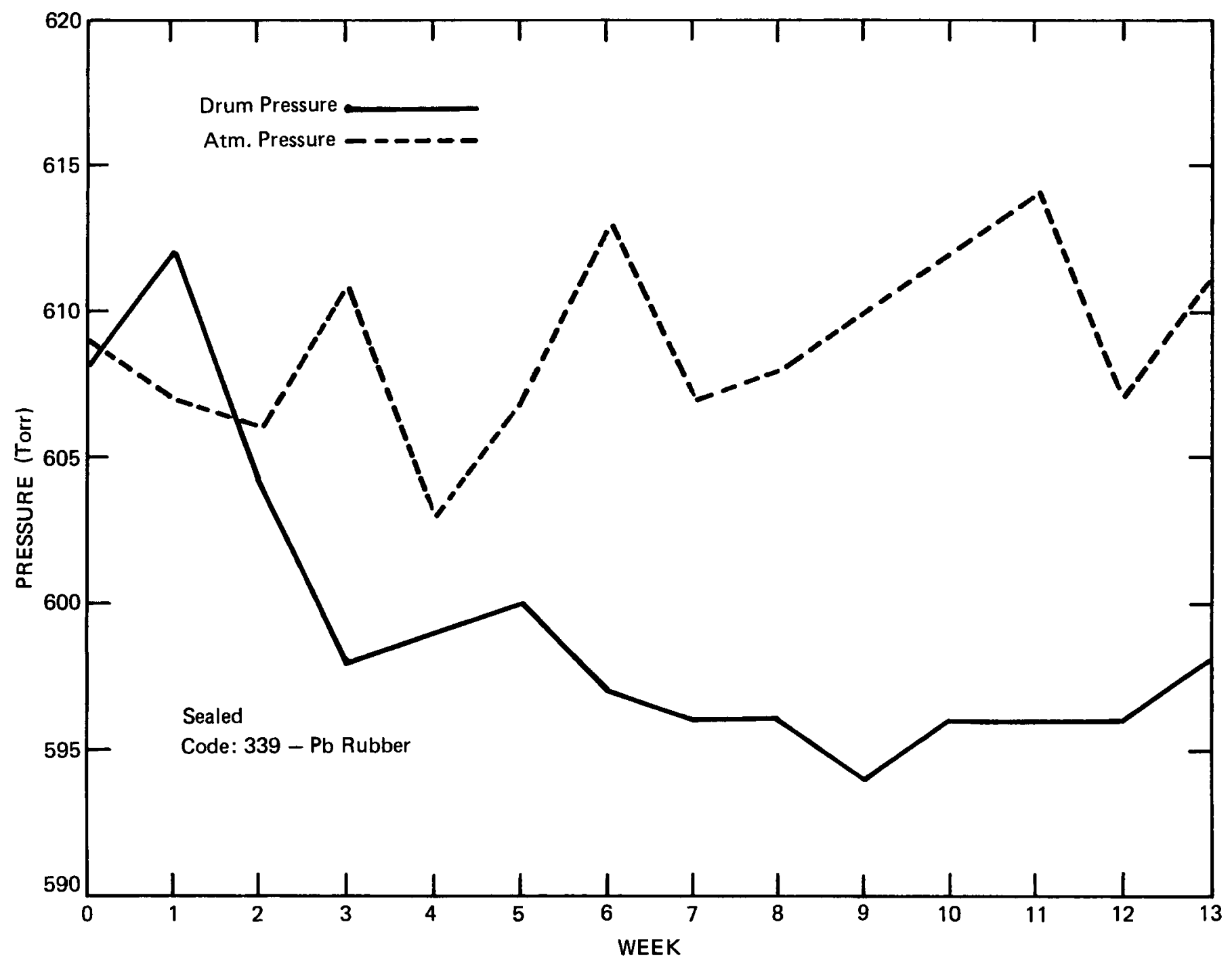

FIGURE B-16a. D30175 Pressure 
RFP-3739

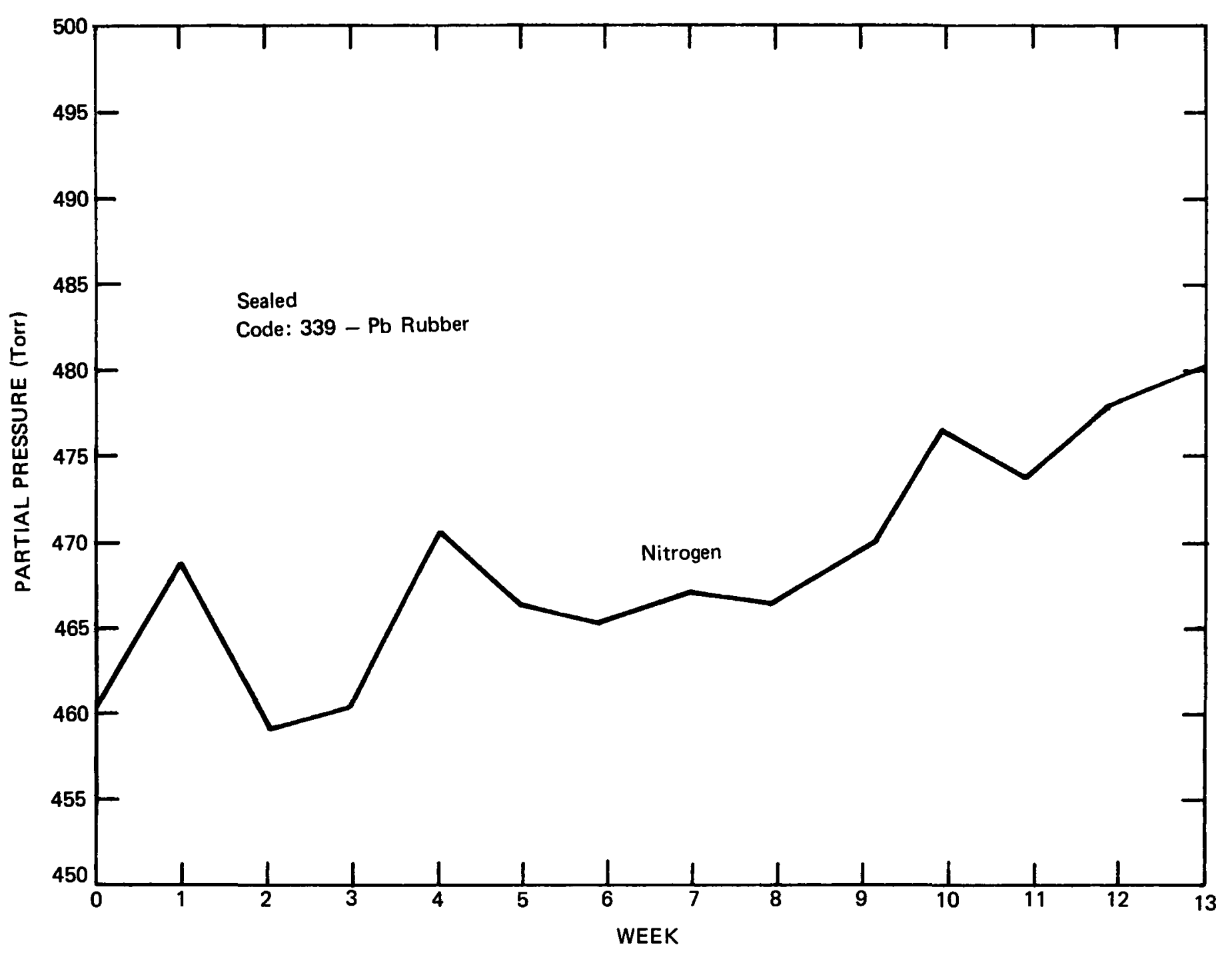

FIGURE B-16b. D30175 Atmosphere: Nitrogen 


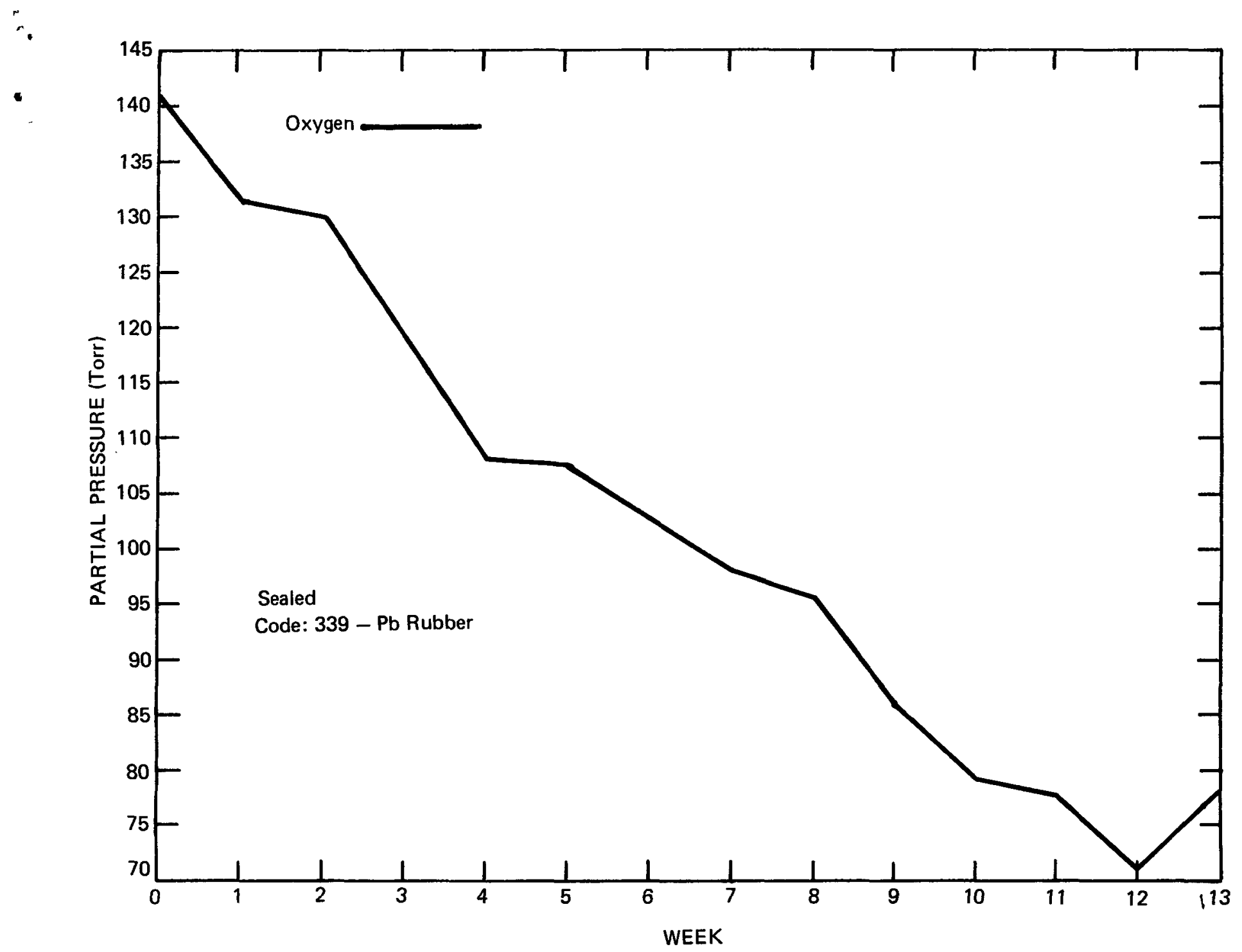

FIGURE B-16c. D30175 Atmosphere: Oxygen 


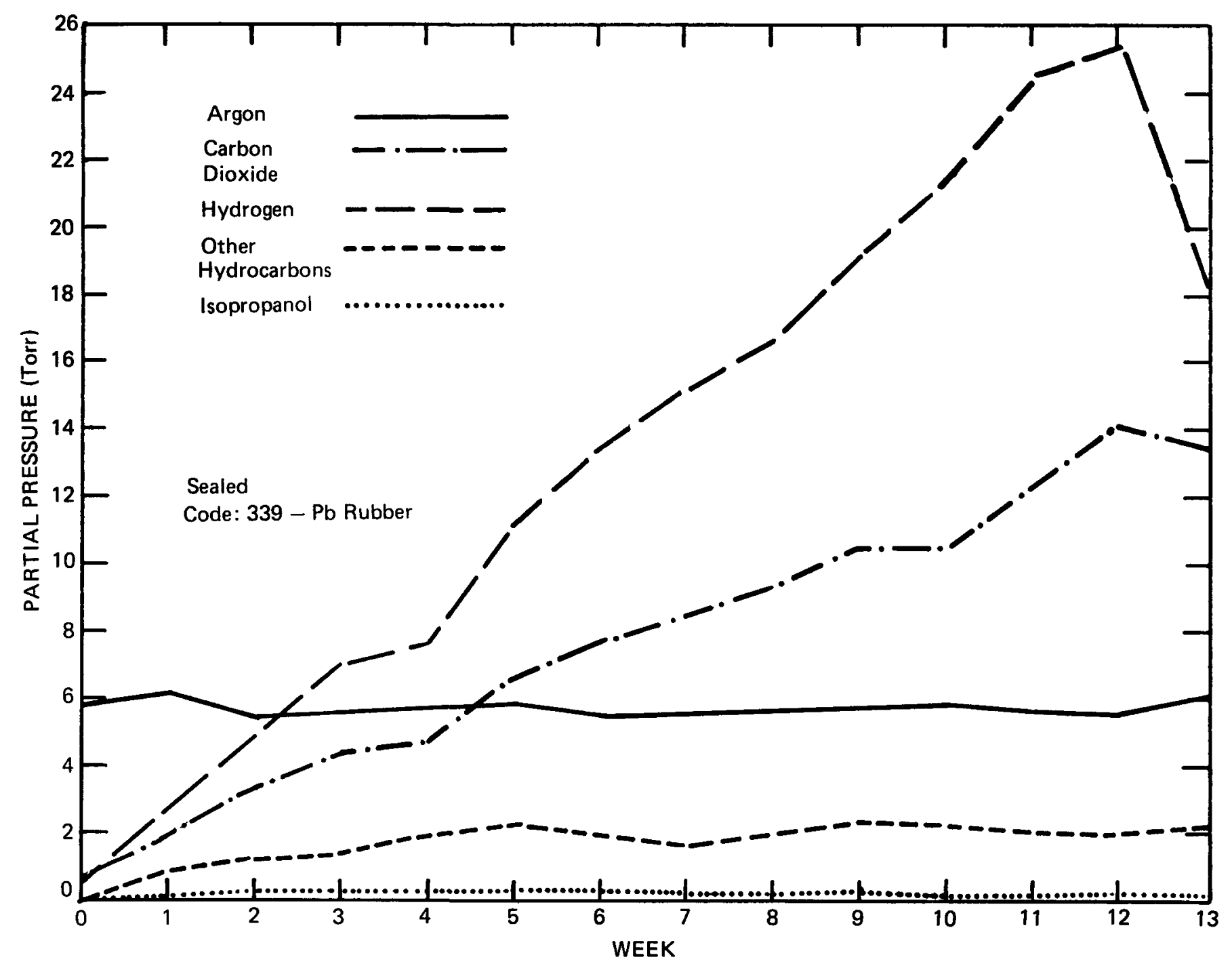

FIGURE B-16d. D30175 Atmosphere: Argon, Carbon Dioxide, Hydrogen, Other Hydrocarbons, Isopropanol 
RFP-3739

TABLE B-16. D30175 TRU Gas Generation Volume Percent

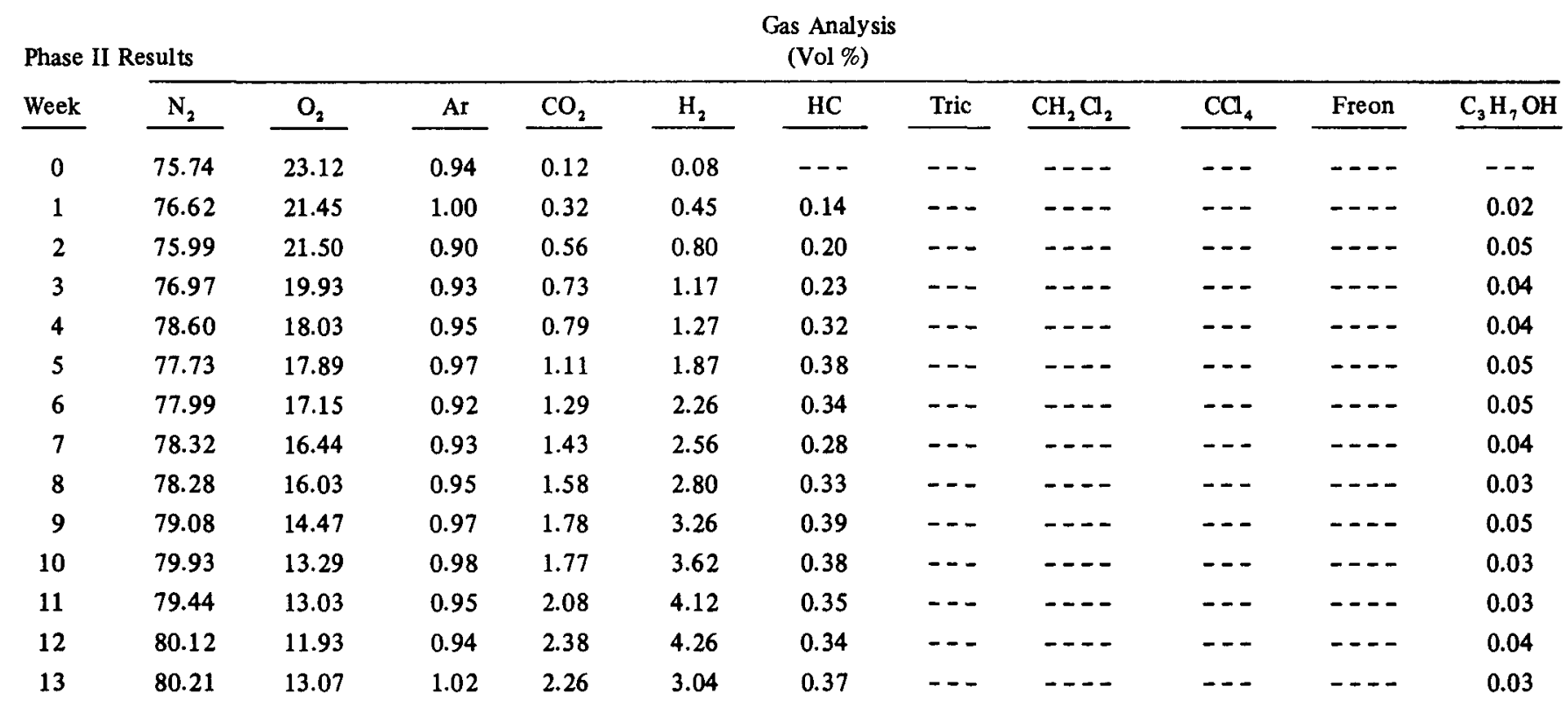

Sealed

Code: 339-Pb Rubber 


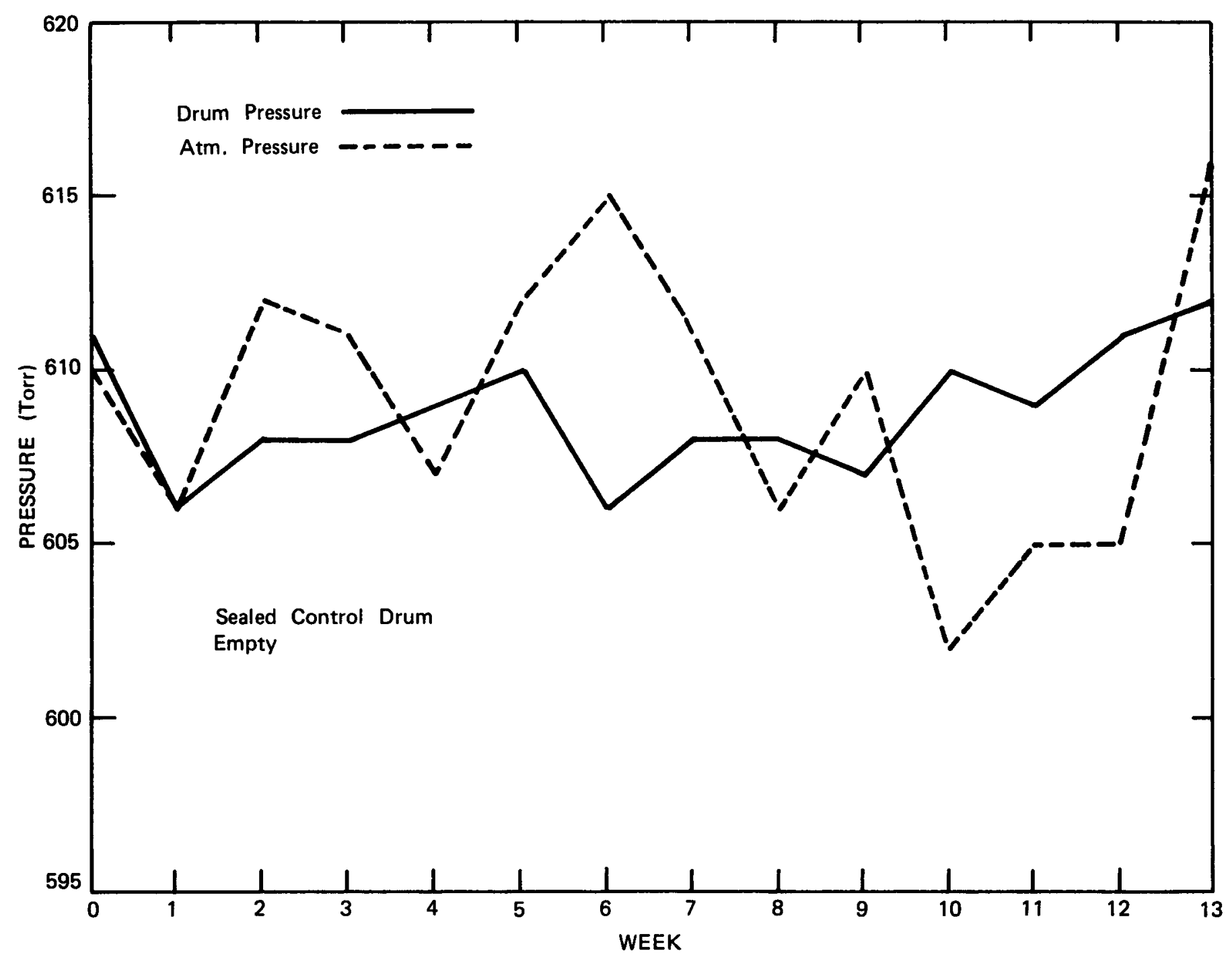

FIGURE B-17a. D32538 Pressure 
a.

-

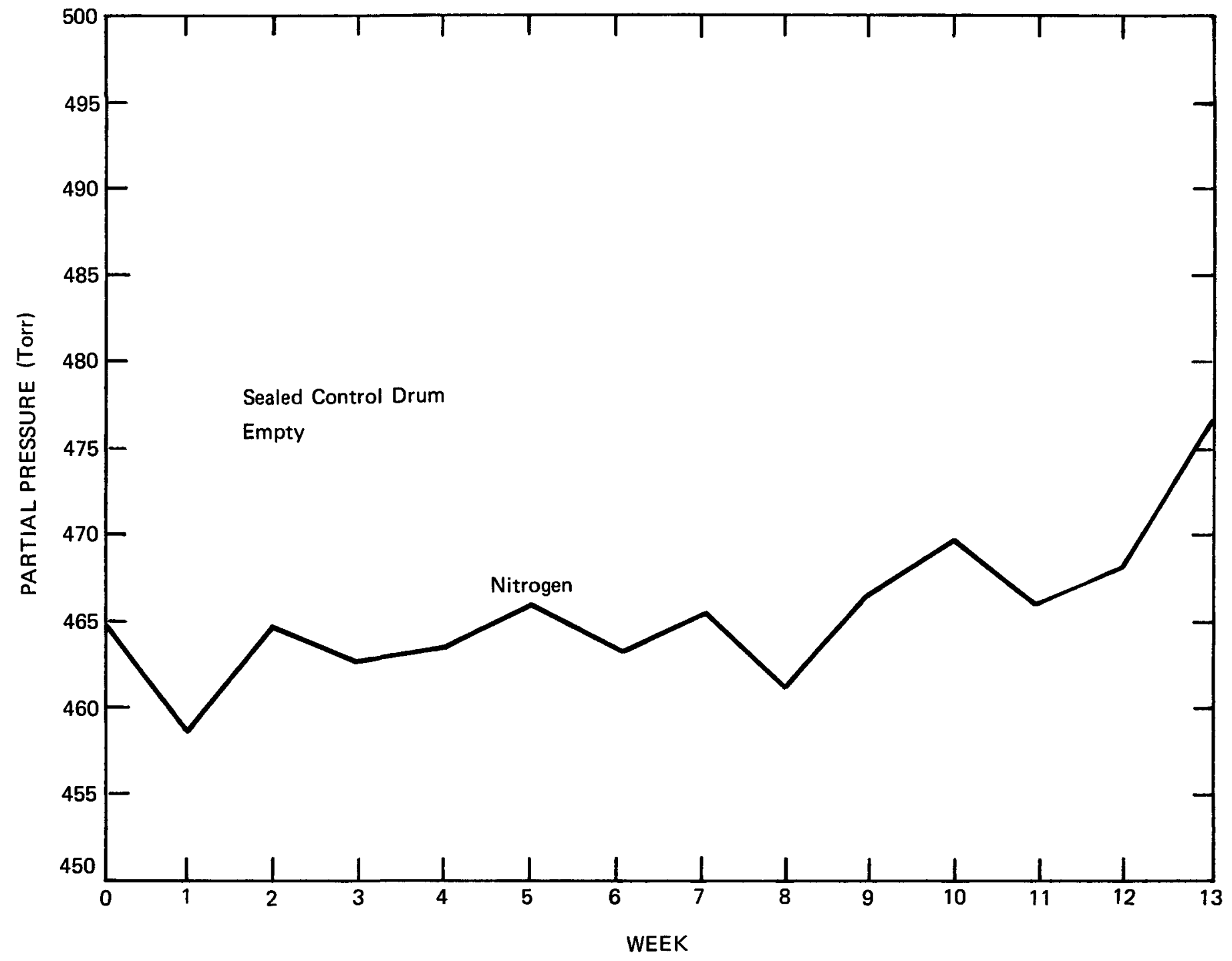

FIGURE B-17b. D32538 Atmosphere: Nitrogen 


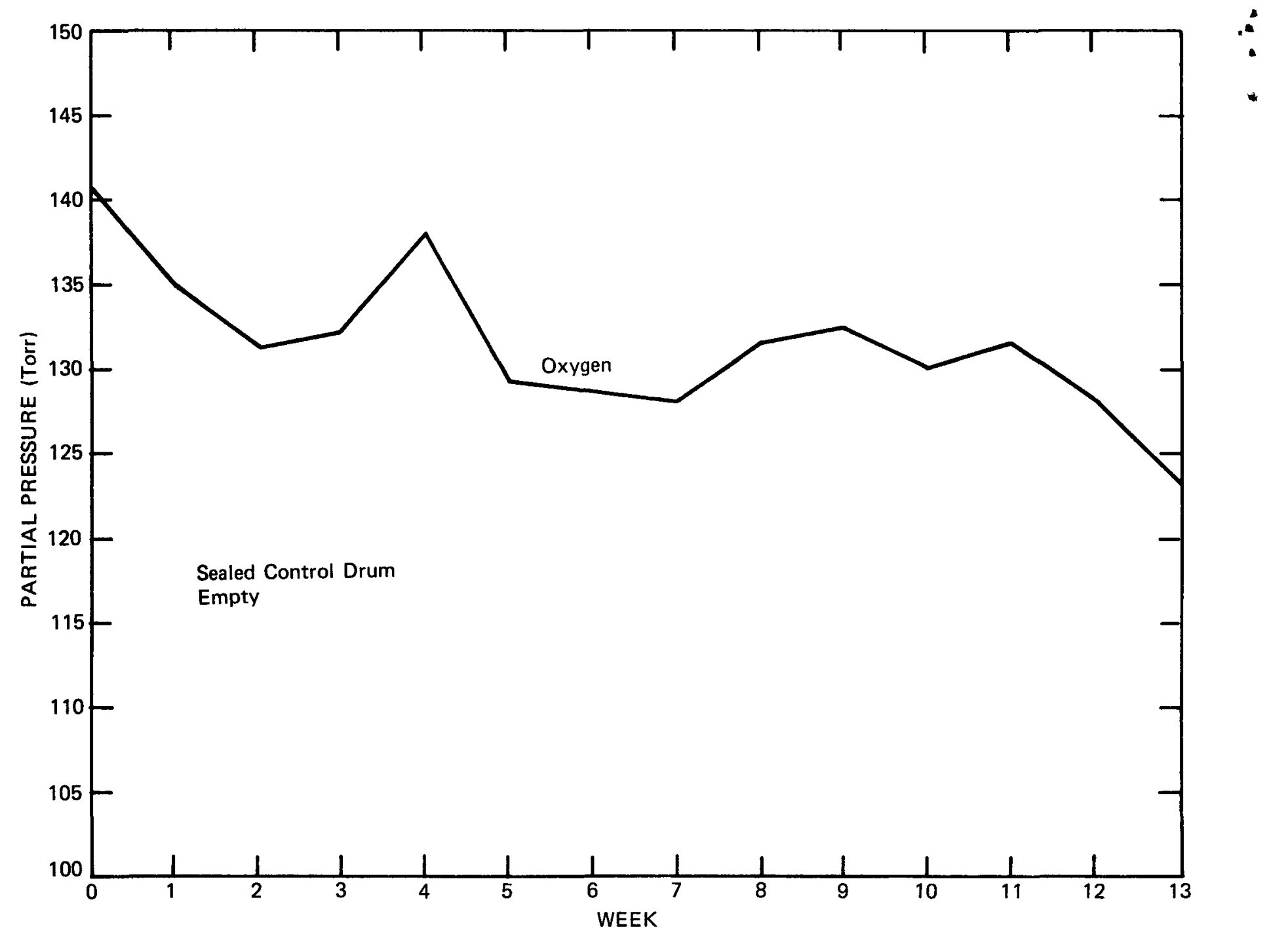

FIGURE B-17c. D32538 Atmosphere: Oxygen 
$\because$

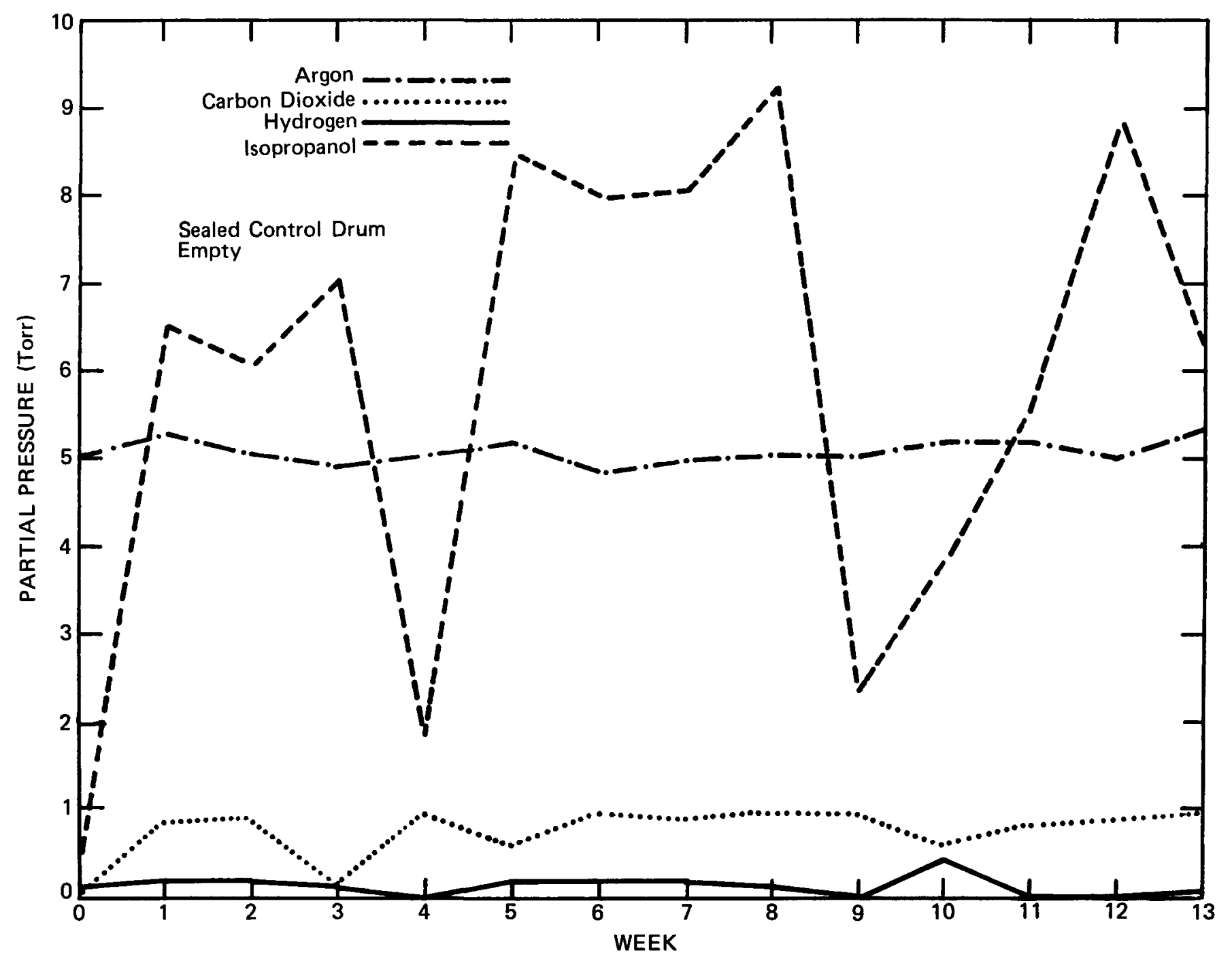

FIGURE B-17d. D32538 Atmosphere: Argon, Carbon Dioxide, Hydrogen, Isopropanol 
RFP-3739

2

, 